Hebert Azevedo Sá

\title{
Desenvolvimento e Simulação de um Controlador Semiautônomo Baseado em Inteligência Artificial para Viaturas Militares - Aplicações da Família de Blindados GUARANI
}

Dissertação apresentada como requisito parcial para obtenção do grau de Mestre pelo Programa de Pós-Graduação em Engenharia Mecânica do Centro Técnico Científico da PUC-Rio.

Orientador: Prof. Marco Antonio Meggiolaro 
Hebert Azevedo Sá

\begin{abstract}
Desenvolvimento e Simulação de um Controlador Semiautônomo Baseado em Inteligência Artificial para Viaturas Militares Aplicações da Família de Blindados GUARANI
\end{abstract}

Dissertação apresentada como requisito parcial para obtenção do grau de Mestre pelo Programa de Pós-Graduação em Engenharia Mecânica do Centro Técnico Científico da PUC-Rio. Aprovada pela Comissão Examinadora abaixo assinada.

Prof. Marco Antonio Meggiolaro

Orientador

Departamento de Engenharia Mecânica - PUC-Rio

Prof. Mauro Speranza Neto

Departamento de Engenharia Mecânica - PUC-Rio

Prof. Armando Morado Ferreira Instituto Militar de Engenharia

Prof. Ricardo Teixeira da Costa Neto Instituto Militar de Engenharia

Prof. Márcio da Silveira Carvalho

Coordenador Setorial do Centro Técnico Científico - PUC-Rio 
Todos os direitos reservados. É proibida a reprodução total ou parcial do trabalho sem autorização da universidade, do autor e do orientador.

\section{Hebert Azevedo Sá}

Graduou-se em Engenharia Eletrônica no Instituto Militar de Engenharia (Rio de Janeiro, RJ). Foi adjunto do Projeto de P\&D da Família de Blindados GUARANI do Exército Brasileiro atuando como oficial de ligação na empresa IVECO Veículos de Defesa (Sete Lagoas, MG).

Ficha Catalográfica

Sá, Hebert Azevedo

Desenvolvimento e Simulação de um Controlador Semiautônomo Baseado em Inteligência Artificial para Viaturas Militares - Aplicações da Família de Blindados GUARANI / Hebert Azevedo Sá; orientador: Marco Antonio Meggiolaro. $-2015$.

132 f.: il. (color.) ; $30 \mathrm{~cm}$

Dissertação (mestrado) - Pontifícia Universidade Católica do Rio de Janeiro, Departamento de Engenharia Mecânica, 2015.

Inclui bibliografia.

1. Engenharia Mecânica - Teses. 2. Robôs Móveis Autônomos. 3. Veículos Militares. 4. Lógica Fuzzy. 5. Controle Preditivo. 6. Sistemas Semiautônomos. I. Meggiolaro, Marco Antonio. II. Pontifícia Universidade Católica do Rio de Janeiro. Departamento de Engenharia Mecânica. III. Título. 


\section{Agradecimentos}

Ao Professor Marco Antonio Meggiolaro, pela oportunidade que nos permitiu desenvolver este trabalho. Sua valiosa orientação e o contato com suas fascinantes habilidades são experiências de extrema relevância para meu desenvolvimento acadêmico e profissional.

Ao Professor Mauro Speranza Neto, por toda colaboração desde os primeiros passos deste projeto. Sua participação, além de ter sido fundamental para a execução do trabalho, conferem-lhe maior credibilidade.

Ao Coronel Armando Morado Ferreira, admirável exemplo de Oficial do Quadro de Engenheiros Militares, por suas contribuições e principalmente pelos esforços que me permitiram ter a chance de encarar este desafio, reflexos da confiança em mim depositada.

Ao Major Ricardo Teixeira da Costa Neto, pelas proveitosas discussões e sugestões em alguns encontros no IME. Sua presença na banca de avaliação deste trabalho é um privilégio, por sua competência técnica reconhecida entre seus colegas e alunos.

Aos amigos do Departamento de Engenharia Mecânica da PUC-Rio, em especial: Dario Prada Parra, Hugo Francisco Lisboa Santos, Samuel Elias Ferreira e Capitão Gustavo Simão Rodrigues, pelos nossos esforços conjuntos nas horas de intenso estudo e na resolução dos mais diversos tipos de problemas.

A todos os integrantes do Projeto de Pesquisa \& Desenvolvimento da Família de Blindados GUARANI, pelo apoio, incentivo e preciosos ensinamentos profissionais e pessoais durante estes anos de convívio. Obrigado por me fazerem acreditar em nossa Força.

À CAPES, pelo suporte financeiro.

Ao Exército Brasileiro, instituição à qual devo todas as minhas oportunidades de adquirir conhecimento técnico-científico. Espero conseguir retribuí-lo conforme as expectativas.

À minha irmã Tamyres, pelo companheirismo, e aos meus pais Lourdes e Hebert, nobres exemplos de esforço e dedicação que me passaram os valores fundamentais para atingir este objetivo.

À minha querida "quase esposa" Eliane, por todo amor, carinho, compreensão e serenidade nos difíceis e sacrificantes momentos em que a distância nos maltrata.

Ao Criador, pela proteção e pela força que me permitiram trabalhar para vencer mais uma etapa. 


\section{Resumo}

Sá, Hebert Azevedo; Meggiolaro, Marco Antonio. Desenvolvimento e Simulação de um Controlador Semiautônomo Baseado em Inteligência Artificial para Viaturas Militares - Aplicações da Família de Blindados GUARANI. Rio de Janeiro, 2015. 132p. Dissertação de Mestrado - Departamento de Engenharia Mecânica, Pontifícia Universidade Católica do Rio de Janeiro.

O objetivo deste trabalho é investigar a utilização de um Sistema de Inferência Fuzzy (Fuzzy Inference System) para projetar um sistema de controle semiautônomo adequado a veículos militares, a partir do qual serão definidos valores para o Nível de Intervenção de um controlador automático. São apresentados conceitos básicos sobre a aplicação de Sistemas de Inferência Fuzzy para a concepção de um ponderador de sinais e sobre a teoria de Controladores Preditivos Baseados em Modelo (Model Predictive Controllers), utilizados na implementação do sistema proposto. A partir da modelagem matemática do sistema dinâmico veicular foram obtidos resultados de simulações do veículo militar enquanto operado em situações perigosas e em que se faça necessária a intervenção do controlador, por exemplo, na presença de ameaças inimigas hostis ou em manobras altamente desestabilizadoras. O comportamento da variável de intervenção do controlador é apresentado por meio de suas curvas de evolução, e indica o seu aumento de acordo com o crescimento do nível de ameaça à qual o veículo está exposto. Os resultados são analisados criticamente, e conclui-se que o uso do sistema proposto resulta em um aumento qualitativo na segurança do veículo, tornando-o um sistema militar mais eficiente, com maior capacidade operacional, além de melhorar as habilidades de seu condutor.

\section{Palavras-chave}

Robôs Móveis Autônomos; Veículos Militares; Lógica Fuzzy; Controle Preditivo; Sistemas Semiautônomos; 


\section{Abstract}

Sá, Hebert Azevedo; Meggiolaro, Marco Antonio (Advisor). Development and Simulation of an Artificial Intelligence based Semiautonomous Controller for Military Vehicles. Rio de Janeiro, 2015. 132p. MSc. Dissertation — Departamento de Engenharia Mecânica, Pontifícia Universidade Católica do Rio de Janeiro.

The purpose of this work is to investigate the use of Fuzzy Inference Systems to design an appropriate semi-autonomous control system for military vehicles, from which the choice of the automatic controller intervention level would be achieved. Basic concepts about the application of Fuzzy Inference Systems for the design of a weighted signal generator and about the Model Predictive Controllers theory are presented. These concepts were used for the implementation of the proposed semiautonomous control system. From the mathematical model of the vehicular dynamic system, results were obtained through simulated tests where the military vehicle was being operated in hazardous situations and in which the intervention of the automatic controller was necessary, e.g., in the presence of hostile enemy threats or in highly destabilizing maneuvers. The behavior of the controller's intervention variable is presented through its evolution curves and indicates its increase accordingly to the growth of the threat level to which the vehicle is exposed. The results are criticyzed, and it is concluded that the use of the proposed system will result in a qualitative increase in vehicle's safety, making it a more efficient military system, with greater operational capacity and enhancing the skills of its driver.

\section{Keywords}

Mobile Autonomous Robots; Military Vehicles; Fuzzy Logic; Predictive Control; Semi-Autonomous Systems; 


\section{Sumário}

1 Introdução $\quad 14$

1.1 Motivação 14

1.2 Antecedentes e Revisão Bibliográfica 16

1.3 Propostas deste Trabalho 22

1.4 Organização da Dissertação 24

2 Visão Geral do Projeto de um Controlador Semiautônomo $\quad 27$

2.1 Sistemas Avançados de Assistência ao Motorista 27

2.2 Níveis Variáveis de Intervenção do Controlador Digital 28

2.3 Estrutura Analítica do Projeto 29

2.4 Arquitetura do Controlador Semiautônomo 30

3 Desenvolvimento do Ponderador Fuzzy 33

3.1 Lógica Fuzzy 33

3.2 Ponderação de Sinais com Técnicas Fuzzy 37

3.3 Caracterização das variáveis de entrada e de saída do Ponderador Fuzzy 38

3.4 Arquitetura Proposta 51

3.5 Detalhamento dos Sistemas de Inferência Fuzzy 55

3.6 Resultados Preliminares $\quad 58$

4 Subcontrolador Preditivo Baseado em Modelo 63

4.1 Controladores Preditivos Baseados em Modelos - MPCs 63

4.2 Modelo dinâmico de Predição para o Subcontrolador 68

$\begin{array}{lll}4.3 & \text { Função Objetivo } & 71\end{array}$

4.4 Estabelecimento das Restrições Matemáticas 74

4.5 Comparação de Resultados para diferentes Funções Objetivo 74

5 Modelagem Dinâmica do Veículo para Simulação $\quad 79$

5.1 Modelos Matemáticos para Sistemas Dinâmicos 79

5.2 Modelagem a partir de Equações de Movimento 82

5.3 Comparação dos Comportamentos 93

6 Simulações e Resultados $\quad 100$

6.1 Configurações dos Testes 100

6.2 Seleção da Função Objetivo do Subcontrolador Preditivo 101

6.3 Resultados Obtidos 101

7 Conclusões e Sugestões para Trabalhos Futuros 123

$\begin{array}{lll}7.1 & \text { Principais Contribuições desta Dissertação } & 123\end{array}$

$\begin{array}{lll}7.2 & \text { Dificuldades Encontradas } & 124\end{array}$

7.3 Sugestões para Trabalhos Futuros 125

$\begin{array}{ll}\text { Referências Bibliográficas } & 127\end{array}$ 


\section{Lista de figuras}

Figura 1.1 Viatura Blindada de Transporte de Pessoal - Média de Rodas (VBTP-MR) GUARANI. Fonte: DefesaNet (www.defesanet.com.br).

Figura 1.2 Militares em operação real no Complexo da Maré, Rio de Janeiro. Em vermelho são representadas as possíveis linhas de tiro que representam ameaças. (Fonte: Acervo da Diretoria de Fabricação do Exército Brasileiro)

Figura 1.3 Viaturas militares empregadas em um terreno com ameaças hostis.

Figura 1.4 Integração de conceitos para o desenvolvimento do sistema de controle semiautônomo aplicado à VBTP-MR GUARANI.

Figura 2.1 Estrutura Analítica do Projeto do sistema de controle semiautônomo proposto.

Figura 2.2 Malha em que se insere o sistema de controle semiautônomo proposto.

Figura 2.3 Arquitetura de alto nível do sistema de controle semiautônomo proposto.

Figura 3.1 Funções de Pertinência para a variável Estatura.

Figura 3.2 Sistema de Inferência Fuzzy. Adaptado de [56].

Figura 3.3 Esterçamentos nulo, positivo e negativo do volante do veículo.

Figura 3.4 Universo de Discurso de $\Delta u$ e seus conjuntos fuzzy. $\quad 40$

Figura 3.5 Modelo de veículo de quatro rodas. Fonte: [51]. 41

Figura 3.6 Esquemático do modelo de veículo com seis rodas numeradas de forma sequencial. Os eixos de giro são determinados pelos pontos de contato de duas rodas consecutivas com o solo.

Figura 3.7 Universo de discurso de $\left|R_{S M}\right|$ e seus conjuntos fuzzy. $\quad 46$

Figura 3.8 Veículo a uma distância de $D_{e, i}$ até o $i$-ésimo explosivo improvisado.

Figura 3.9 Veículo a uma distância de $D_{a, i}$ até a linha de tiro do $i$-ésimo atirador.

Figura 3.10 Universo de discurso das distâncias $D_{x, i}$ e seus conjuntos fuzzy.

Figura 3.11 Universo de discurso das velocidades $V_{x, i}$ e seus conjuntos fuzzy.

Figura 3.12 Arquitetura proposta para o Ponderador Fuzzy.

Figura 3.13 Universo de discurso da variável $A_{x}$ e seus conjuntos fuzzy. 54

Figura 3.14 Universo de discurso do comportamento do motorista $B_{\text {Motr }}$ e seus conjuntos fuzzy.

Figura 3.15 Universo de discurso do Nível de Intervenção $K$ e seus conjuntos fuzzy. 
Figura 3.16 Trajetória (a) e Evolução de $K$ (b) para o cenário de Ambiente Hostil.

Figura 3.17 Trajetória (a) e Evolução de $K$ (b) para o cenário de Manobra Arriscada.

Figura 3.18 Trajetória (a) e Evolução de $K$ (b) para o cenário de Manobra Arriscada em Ambiente Hostil.

Figura 4.1 Arquitetura básica de um Controlador Preditivo baseado em Modelo.

Figura 4.2 Estratégia de Controle Preditivo implementada pelo uso de Model Predictive Controllers (MPC)s.

Figura 4.3 Analogia entre MPCs e a direção de um automóvel. $\quad 66$

Figura 4.4 Modelo cinemático para o movimento lateral do veículo. 69

Figura 4.5 Predição do posicionamento do veículo em um instante $t$. 73

Figura 4.6 Resultado preliminar para o teste \#1. 76

Figura 4.7 Resultado preliminar para o teste \#2.

Figura 4.8 Resultado preliminar para o teste \#3. 78

$\begin{array}{lll}\text { Figura } 4.9 & \text { Resultado preliminar para o teste \#4. }\end{array}$

Figura 5.1 Rede Neural Dinâmica Recorrente. $\quad 81$

Figura 5.2 Modelo multicorpos do veículo completo descarregado. $\quad 82$

$\begin{array}{lll}\text { Figura 5.3 Geometria do powertrain. } & 84\end{array}$

Figura 5.4 Geometria do sistema de direção. $\quad 84$

Figura 5.5 Suspensão Hidropneumatica MacPherson. 85

Figura 5.6 Curva bilinear de amortecimento do amortecedor da suspensão.

86

$\begin{array}{lll}\text { Figura 5.7 } & \text { Modelo mola-amortecedor para as suspensões. } & 87\end{array}$

$\begin{array}{lll}\text { Figura 5.8 Representação geométrica do modelo dos pneus. } & 87\end{array}$

$\begin{array}{lll}\text { Figura 5.9 } & \text { Modelo Massa-Mola para os pneus. } & 88\end{array}$

$\begin{array}{ll}\text { Figura 5.10 Modelo linear para a força lateral dos pneus. } & 88\end{array}$

Figura 5.11 Esquemático simplificado para o veículo 6x6 (perspectiva). 89

Figura 5.12 Esquemático simplificado para o veículo 6x6 (vista de cima).

Figura 5.13 Padrão de Entrada para uma manobra Single Lane Change aplicado ao modelo ADAMS disponibilizado.

Figura 5.14 Padrão de Entrada para uma manobra Single Lane Change aplicado ao modelo desenvolvido.

Figura 5.15 Comportamento do Ângulo de Rolagem $\varphi$ em uma manobra de Single Lane Change, para o modelo implementado no MSC.ADAMS.

Figura 5.16 Comportamento do Ângulo de Deslizamento $\beta$ em uma manobra de Single Lane Change, para o modelo implementado no MSC.ADAMS.

Figura 5.17 Comportamento do Ângulo de Rolagem $\varphi$ em uma manobra de Single Lane Change, para o modelo implementado no Simulink.

Figura 5.18 Comportamento do Ângulo de Deslizamento $\beta$ em uma manobra de Single Lane Change, para o modelo implementado no Simulink. 
Figura 5.19 Padrão de Entrada para uma manobra Double Lane Change aplicado ao modelo ADAMS.

Figura 5.20 Padrão de Entrada para uma manobra Double Lane Change aplicado ao modelo desenvolvido.

Figura 5.21 Comportamento do Ângulo de Rolagem $\varphi$ em uma manobra de Double Lane Change, para o modelo implementado no MSC.ADAMS.

Figura 5.22 Comportamento do Ângulo de Deslizamento $\beta$ em uma manobra de Double Lane Change, para o modelo implementado no MSC.ADAMS.

Figura 5.23 Comportamento do Ângulo de Rolagem $\varphi$ em uma manobra de Double Lane Change, para o modelo implementado no Simulink.

Figura 5.24 Comportamento do Ângulo de Deslizamento $\beta$ em uma manobra de Double Lane Change, para o modelo implementado no Simulink.

Figura 6.1 Resultados obtidos no primeiro teste simulado. Neste caso, a entrada proveniente do motorista é nula e as trajetórias verde e cor-de-rosa se devem à ação do sistema proposto. O Nível de Intervenção é, em média, mais baixo devido a utilização da função objetivo $J_{1}(t)$.

Figura 6.2 Resultados obtidos no segundo teste simulado. Também neste caso as trajetórias verde e cor-de-rosa se devem apenas à ação do sistema proposto, pois a entrada do motorista é nula. O Nível de Intervenção também tem sua média diminuída pela utilização da função objetivo $J_{1}(t)$.

Figura 6.3 Resultados obtidos no terceiro teste simulado. A entrada do motorista permanece nula, da mesma forma que os testes anteriores. Os níveis de médios de intervenção são claramente mais altos, e sua comparaçãonão é evidente, o que reflete o maior desafio para o sistema de controle.

Figura 6.4 Trajetórias e Níveis de Intervenção para o Sistema Proposto e para um Controlador PID. Em todos os casos as estradas provenientes do motorista são nulas.

Figura 6.5 Sinal de entrada aplicado pelo motorista sobre o volante do veículo.

Figura 6.6 Resultados obtidos no quinto teste simulado. A trajetória em azul mostra o comportamento do veículo sob ação apenas do motorista, enquanto as outras são resultado da intervenção do sistema proposto.

Figura 6.7 Resultados obtidos para uma situação de incapacidade do motorista, com velocidade longitudinal de $30 \mathrm{~km} / \mathrm{h}$.

Figura 6.8 Resultados obtidos para uma situação de incapacidade do motorista, com velocidade longitudinal de $60 \mathrm{~km} / \mathrm{h}$.

Figura 6.9 Resultados obtidos para uma situação de incapacidade do motorista, com velocidade longitudinal de $90 \mathrm{~km} / \mathrm{h}$.

Figura 6.10 Resultados obtidos para uma situação de reação tardia do motorista, com velocidade longitudinal de $60 \mathrm{~km} / \mathrm{h}$. 
Figura 6.11 Resultados obtidos para uma situação de reação tardia do motorista, com velocidade longitudinal de $90 \mathrm{~km} / \mathrm{h}$.

Figura 6.12 Deslocamento artificial de explosivos em situações de configuração simétrica.

Figura 6.13 Resultados obtidos para uma situação de configuração simétrica dos explosivos com os algoritmos original e modificado, para a velocidade longitudinal de $60 \mathrm{~km} / \mathrm{h}$.

Figura 6.14 Resultados obtidos para uma situação de configuração simétrica dos explosivos com os algoritmos original e modificado, para a velocidade longitudinal de $90 \mathrm{~km} / \mathrm{h}$.

Figura 6.15 Função Penalidade à Posição Lateral utilizada no teste de navegação em rodovias com faixas estreitas.

Figura 6.16 Resultados obtidos para a navegação do veículo em rodovias com faixas estreitas ameaçado pela presença de um Improvised Explosive Devices (IED). 


\section{Lista de tabelas}

Tabela 2.1 Categorias dos ADAS e suas principais características. 27

Tabela 3.1 Base de Regras Fuzzy dos Sistemas de Inferência 1 e $2 . \quad 56$

Tabela 3.2 Base de Regras Fuzzy dos Sistemas de Inferência 3. $\quad 57$

Tabela 3.3 Base de Regras Fuzzy dos Sistemas de Inferência $4 . \quad 58$

Tabela 4.1 Valores dos parâmetros da função objetivo para cada teste. 75 
"Somente a paixão pelo estudo e uma vasta experiência poderão formar um grande capitão."

Arquiduque Carlos da Áustria, Princípios de Estratégia para Generais. 


\section{Introdução}

\section{1}

\section{Motivação}

No âmbito do Exército Brasileiro (EB), as atividades e eventos que se desenvolvem durante o ciclo de vida de um Material de Emprego Militar (MEM) são regulamentados por instruções específicas que constituem um modelo administrativo [1]. De acordo com este modelo, são conferidas ao Departamento de Ciência e Tecnologia (DCT) do Exército diversas atribuições de natureza técnica, dentre quais se podem destacar a realização de estudos de prospecção tecnológica e de identificação de problemas ou melhorias em materiais de uso corrente na força. Um importante exemplo de MEM em fase de adoção pela força terrestre é a VBTP-MR 6x6 GUARANI (Figura 1.1), cujo desenvolvimento é realizado pelo EB em cooperação com a empresa IVECO Veículos de Defesa, e que representa o principal sistema ao qual se aplica o objeto de estudo desta dissertação.

Em todo o planeta, os acidentes de trânsito com veículos automotores constituem um problema preocupante a ser combatido pela sociedade. De acordo com estudos da Organização Mundial da Saúde (OMS), aproximadamente 1,24 milhões de pessoas morreram em acidentes automobilísticos apenas no ano de 2010 [2]. Outras estatísticas apontam para a grande dificuldade de se solucionar o problema da segurança do tráfego em estradas [3]. Na conferência Rio+20, por exemplo, a década de 2011-2020 foi declarada a "Década da Ação para Segurança nas Estradas" pela Organização das Nações Unidas (ONU), o que evidencia esta preocupação.

Os acidentes envolvendo veículos são em sua maioria provocados por motoristas que, independentemente dos motivos, tenham controlado a direção de forma imprudente ou deficiente [4]. Quando tratando-se de viaturas militares, os riscos se amplificam devido às ameaças a que estas são expostas (explosivos improvisados, armamentos anti-carro, etc.) e também ao ambiente não estruturado em que são possivelmente empregadas. Como exemplo disso, pode-se citar as situações de perigo enfrentadas por tropas do Exército Brasileiro no Com- 


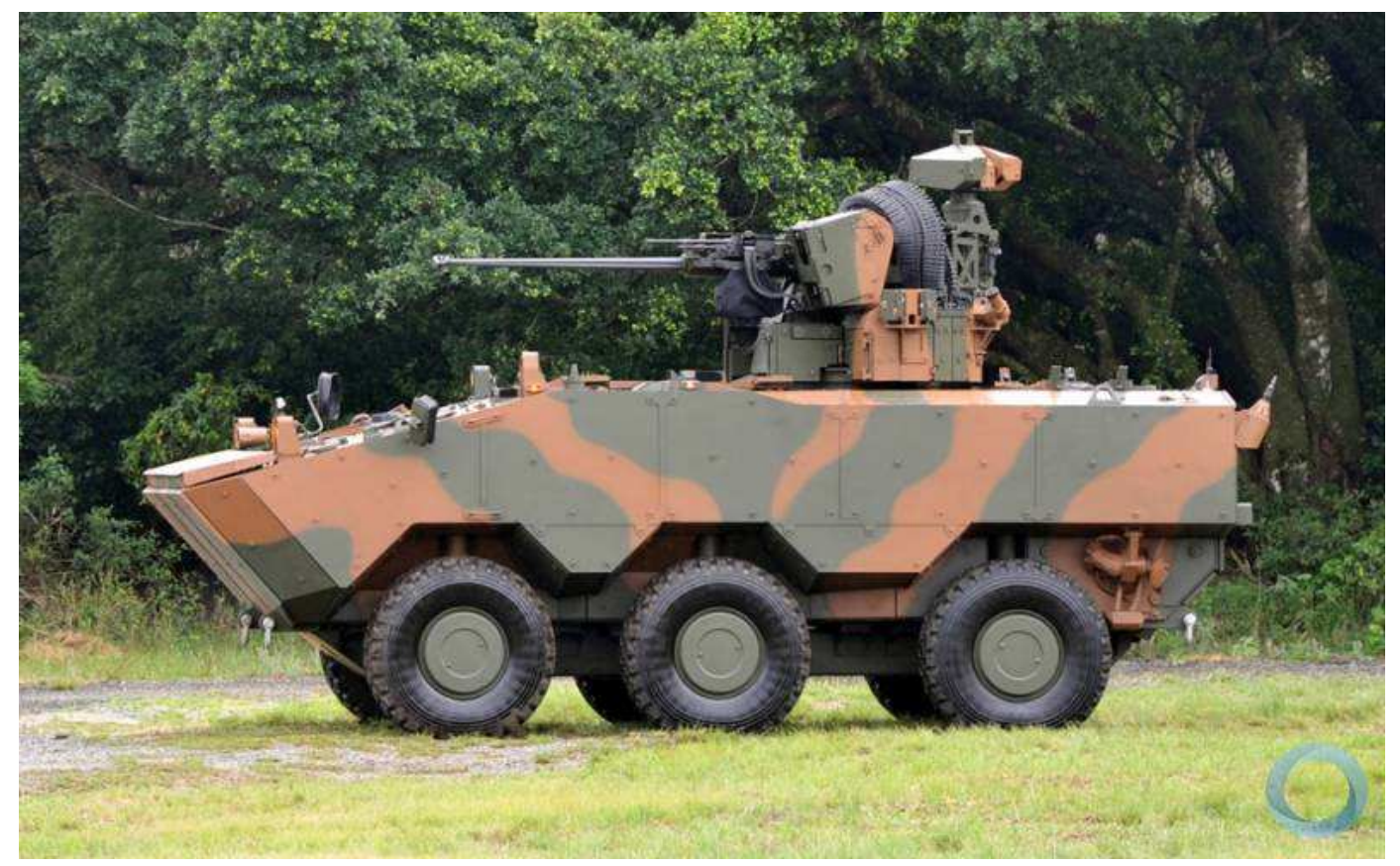

Figura 1.1: VBTP-MR GUARANI. Fonte: DefesaNet

(www.defesanet.com.br).

plexo da Maré, conforme o caso ilustrado na Figura 1.2, em que o motorista e a tripulação do veículo encontram-se em risco. Além deste exemplo, Henry [5] constatou que os acidentes com veículos automotores constituíram a causa para o maior número de baixas não-hostis do Exército Norte-Americano durante a Operação Iraqi Freedom (OIF). Ainda um outro exemplo grave, embora sem a ocorrências de vítimas, aconteceu no dia 8 de junho de 2015, em meio à elaboração desta dissertação: um capotamento envolvendo uma VBTP-MR GUARANI que levava 9 militares, na rodovia BR-467 na cidade de Cascavel PR.

Diante deste cenário, verifica-se que novas tecnologias podem e devem ser utilizadas em favor da redução destes riscos. Por meio do desenvolvimento de aplicações veiculares que permitam que eventuais colisões e ameaças sejam evitadas, pode-se preservar a segurança e a estabilidade dos veículos e, consequentemente, poupar vidas. Estas soluções podem se basear na estratégia de prover assistência ao motorista, corrigindo ou anulando uma eventual performance insatisfatória deste. Surge neste contexto o ensejo ao desenvolvimento de sistemas de controle semiautônomo, em concordância com a proposta deste trabalho.

Além disso, uma análise crítica sobre as tendências das tecnologias de emprego militar revelaria que os veículos terrestres não tripulados, ou " $U n$ manned Ground Vehicles (UGV)", deverão ser a principal arma dos exércitos 


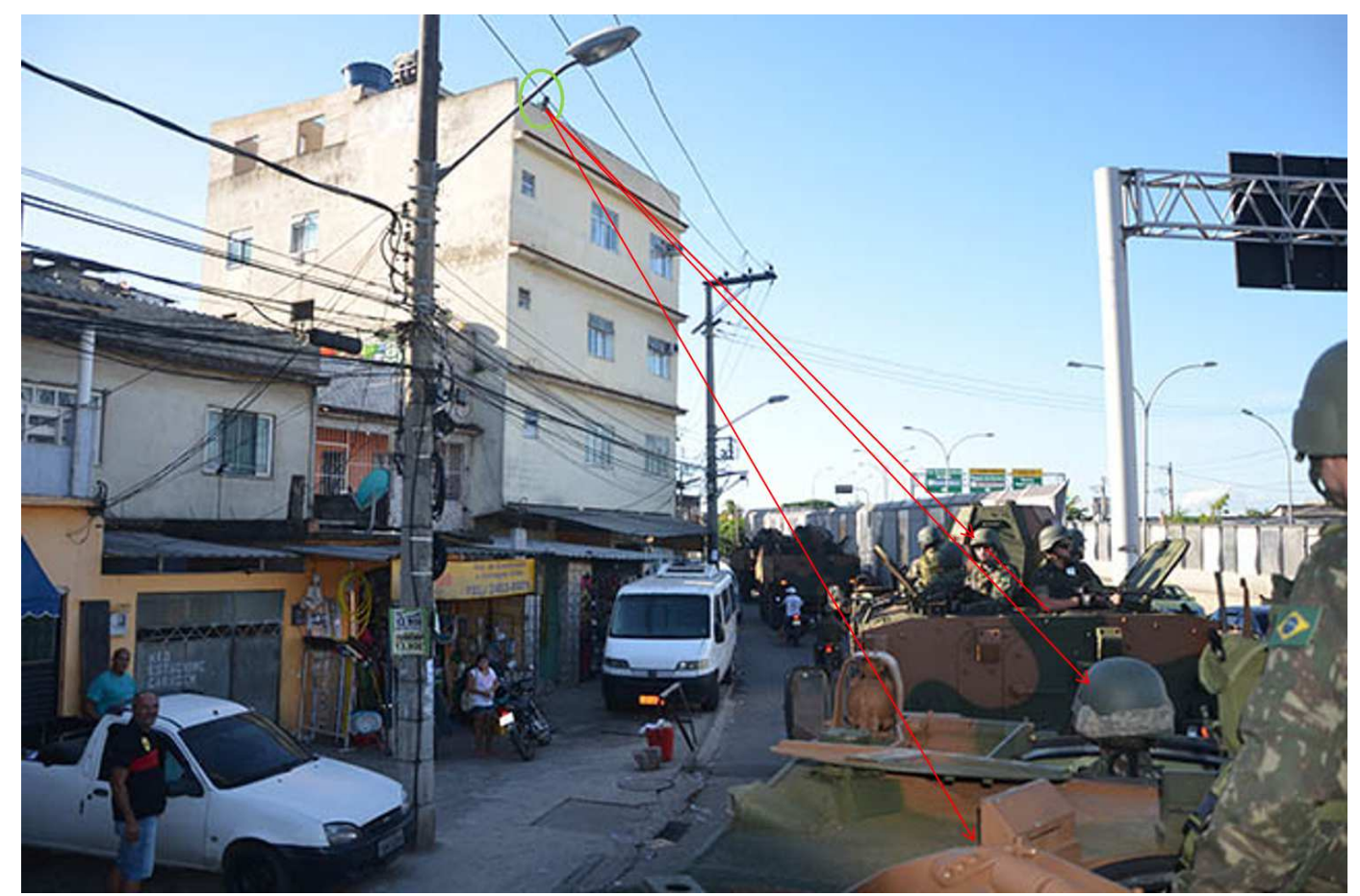

Figura 1.2: Militares em operação real no Complexo da Maré, Rio de Janeiro. Em vermelho são representadas as possíveis linhas de tiro que representam ameaças. (Fonte: Acervo da Diretoria de Fabricação do Exército Brasileiro)

no século XXI [6], [7]. No entanto, é provável que esta evolução doutrinária ocorra gradualmente, de forma que os carros de combate incorporem inovações tecnológicas de assistência ao motorista aos poucos e passando pelo estágio da semiautonomia, conforme vem ocorrendo com os veículos de passeio e comerciais.

Um trabalho investigativo em que se proponha o desenvolvimento de um sistema de controle semiautônomo que possa ser empregado em veículos da família de blindados GUARANI é portanto oportuno, pois encaminha a evolução destes sistemas e permite a formulação de diretrizes estratégicas de inovação tecnológica, buscando torná-los mais eficientes, mais operacionais e acima de tudo mais seguros.

\section{2}

\section{Antecedentes e Revisão Bibliográfica}

Existem diferenças fundamentais entre as capacidades e os formatos de processamento de dados do cérebro humano e de um computador digital convencional, tal como conhecido atualmente. O cérebro é formado por uma estrutura neural altamente complexa que caracteriza um sistema de processamento de informações paralelo e não linear. Por este motivo, o cérebro é adequado à realização de certas tarefas intimamente relacionadas ao desenvolvimento de 
modelos mentais, como por exemplo: reconhecimento de padrões, percepção, etc. Os computadores, por sua vez, são desenvolvidos a partir de arquiteturas bem definidas que se adequam à execução seriada de instruções em algoritmos, priorizando sempre a rapidez de operações matemáticas e a eficiência [8].

O desenvolvimento de algumas áreas da Inteligência Artificial (IA), como o exemplo das Redes Neurais Artificiais (RNA) busca reproduzir as capacidades do cérebro humano. No entanto, o trabalho proposto nesta dissertação busca investigar maneiras de realizar uma integração sinérgica entre homem e máquina, por meio do desenvolvimento de um sistema de controle semiautônomo.

\subsection{1}

\section{Controle Compartilhado}

O estabelecimento de uma relação cooperativa entre homem e máquina por meio do desenvolvimento de sistemas de controle compartilhado não pode ser considerado um assunto recente. Diversos conceitos relativos a isto já haviam sido abordados por pesquisadores ao longo do desenvolvimento de teorias como as de Controle Supervisório e da Telerobótica, em que a execução de tarefas não repetitivas e imprevistas exige a habilidade dos seres humanos para o controle de sistemas físicos com a utilização de computadores [9].

O projeto de sistemas de controle compartilhado ou semiautônomo é uma tarefa desafiadora. Isto se deve ao fato de que o aumento do nível de automação em processos que sejam tradicionalmente controlados apenas por seres humanos nem sempre resulta em uma melhoria de eficiência em seu controle. A característica intrusiva da automação ou a dificuldade de se contornar falhas técnicas sem a ocorrência de acidentes podem ser considerados óbices para a concepção destes sistemas híbridos. Em um trabalho recente, Strand concluiu que os seres humanos são negligentes no monitoramento de sistemas automáticos, em especial em veículos automotivos altamente automatizados [10].

Apesar dessas dificuldades, o desenvolvimento de técnicas de controle compartilhado tem ganhado relevância em pesquisas mais recentes. Esta importância é evidenciada pelo surgimento de sistemas de controle semiautônomo, cuja principal característica é o estabelecimento de um método para realizar a mesclagem de sinais de controle de entrada provenientes dos seres humanos e dos computadores e aplicá-los em uma determinada planta ou processo.

Em um trabalho investigativo, Yu e Dubowsky propuseram o emprego de um sistema de controle compartilhado para solucionar problemas de mobi- 
lidade de pessoas mais idosas utilizando dispositivos robóticos de assistência chamados "Personal Aids for Mobility and Monitoring" [11]. Na abordagem por eles proposta, o nível de autoridade de controle é ajustado entre o ser humano e o controlador automático de acordo com a performance do usuário. Esse sistema tem características essencialmente reativas, o que o tornaria inapropriado para aplicações de velocidade mais alta, como automotivas ou robóticas.

\subsection{2}

\section{Robótica móvel}

Em paralelo à pesquisa das técnicas semiautônomas, o desenvolvimento de técnicas de localização e navegação em robôs móveis tem servido de subsídio para pesquisas semelhantes com aplicações automotivas.

A pesquisa sobre o planejamento de trajetórias com robôs se iniciou no fim dos anos '60, tornando-se mais intensa na década de '80. A referência clássica para este assunto pode ser encontrada em [12]. Este livro foi posteriormente complementado por Laumond [13], que dividiu o problema em três principais tópicos: planejamento de trajetórias de sistemas não holonômicos, abordagens probabilísticas e detecção de colisões. A abordagem comportamental tratada por Arkin [14] foi também aplicada para a concepção de modelos para planejadores de trajetórias. Siegwart e Nourbakhsh formalizaram uma valiosa introdução a todos os assuntos referentes ao campo da robótica móvel [15], enquanto Choset procurou reunir em um único livro o resultado de diversos trabalhos mais complexos de pesquisa no mesmo campo, com destaque para os princípios da robótica probabilísitica [16]. Técnicas de IA foram também utilizadas para a solução dos problemas da robótica móvel, como a utilização de algoritmos genéticos apresentada por Nedjah [17].

Em [18], uma estratégia de planejamento dinâmico de trajetórias para robôs móveis é implementada a partir da utilização de um Sistema de Inferência Fuzzy (SIF) complexo, capaz de calcular forças provenientes de um campo potencial artificial fuzzy. São criadas trajetórias livres de colisões, e a técnica apresenta um melhor desempenho no tratamento de problemas de mínimo local, além de ser implementada por meio de algoritmos de complexidade computacional relativamente baixa.

Fajen e Warren propuseram uma estratégia de navegação baseada num modelo inspirado nas caraterísticas biológicas dos seres humanos. Este modelo foi desenvolvido por meio de experimentos em que foram observadas as atitudes e caminhos escolhidos por pessoas diante de um ambiente com obstáculos devidamente posicionados [19]. Posteriormente este modelo foi aperfeiçoado por Huang, que além de adicionar a dinâmica longitudinal ao modelo passou 
a considerar a largura angular de objetos como parâmetro de referência ao invés da distância direta entre o robô e o objeto. Isto possibilitou a redução do número de sensores a apenas uma câmera [20].

Robôs móveis projetados para aplicações em terrenos acidentados, em especial as sondas (ou "rovers") utilizadas em missões interplanetárias, foram abordados por Iagnemma e Dubowsky em [21], [22], [23] e [24]. Estes pesquisadores buscaram desenvolver modelos para a previsão do comportamento dinâmico do robô com maiores velocidades e, com isso, definir manobras reativas que preservassem sua estabilidade. A realização destas manobras reativas pode ser considerada o nível mais baixo da estratégia de controle utilizada nos rovers, que é implementada também com a utilização de planejadores de trajetória local e macro.

A necessidade de utilização de ferramentas de simulação para o controle e a análise do comportamento de sistemas robóticos estimulou o desenvolvimento de um simulador dinâmico em tempo real de veículos robóticos sobre terrenos acidentados no Departamento de Engenharia Mecânica da PUC-Rio [25]. Este simulador foi utilizado por Blois [26], que propôs um algoritmo de detecção de descolamento das rodas de um veículo robótico do terreno. Esta detecção ativava um controlador capaz de garantir o retorno do veículo para o solo com segurança.

\section{2 .3}

\section{Desenvolvimento de Veículos Autônomos}

O desenvolvimento de veículos inteligentes e totalmente autônomos também continua sendo um assunto extensamente investigado. $\mathrm{O}$ controle da dinâmica veicular é geralmente implementado por meio do emprego de atuadores nos mecanismos de esterçamento das rodas ou dos freios.

As principais vantagens de se utilizar o esterçamento como entrada de controle para a estabilização de veículos foram apresentadas por Ackermann em [27]. No referido trabalho é apresentado um método de estabilização do ângulo de guinada por meio do desacoplamento das dinâmicas longitudinal, lateral e da própria guinada de um veículo, com emprego de integradores. Demonstrase que o amortecimento da guinada pode aumentar significativamente com a implementação do esterçamento das rodas traseiras de um veículo, facilitando as ações de controle do motorista. Em um trabalho posterior, são comparadas as eficiências de se realizar a estabilização do ângulo de guinada (ou yaw) a partir da distribuição do torque e da frenagem nas rodas de um veículo e de fazê-lo por meio da atuação no ângulo de esterçamento. São analisadas, inclusive, maneiras de se evitar o capotamento de veículos com o emprego da 
frenagem e do esterçamento ativos em conjunto [28].

Nesses trabalhos, a geração de sinais de controle se dá pela utilização de controladores do tipo Proporcional-Integral-Derivativo (PID). Com uma abordagem diferente, mas mantendo a prática de planejar e seguir uma trajetória, Guo e Ge apresentam uma metodologia que parte da mínima aceleração lateral solicitada aos pneus e geram, através de uma modelagem matemática adequada, a posição e a orientação de referência para a implementação de um controlador do tipo integral backstepping [29]. Essa metodologia é aplicada de forma específica, em veículos realizando manobras de "troca de pista" (lane changing) em uma trajetória curva.

Com o estímulo de competições acadêmicas de robótica avançada (mais especificamente o "DARPA Grand Challenge"), Hoffmann e Thrun desenvolveram um controlador não linear para veículos de corrida off road completamente autônomos. A lei de controle proposta toma como base um modelo cinemático para o veículo, e a partir destes elementos é realizada uma análise de estabilidade semelhante à de Lyapunov, de onde se conclui que o sistema controlado é estável e, neste caso, capaz de seguir uma trajetória pré-definida [30]. É relatada ainda a validação experimental do controlador, que se complementa com a apresentação dos bons resultados obtidos pelo veículo autônomo utilizado nas competições.

\subsection{4}

\section{Controladores Preditivos Baseados em Modelo}

Em trabalhos mais recentes, a utilização de Controladores Preditivos baseados em Modelos, ou Model Predictive Controllers - MPC, tem se mostrado adequada para o controle de veículos. Os MPC formam uma classe de controladores que inicialmente foram empregados em processos industriais mais lentos, por demandarem grandes esforços computacionais e altos tempos de processamento para gerar os sinais de controle para a planta ou processo que seriam controlados [31]. O avanço das tecnologias de processadores digitais permitiu a aplicação desta classe de controladores à plantas e processos dinâmicos com menores tempos de resposta, como é o caso dos automóveis.

Borrelli, Falcone e Keviczky apresentaram relatos sobre a utilização dos MPCs no controle de um veículo autônomo, tendo sido capazes de estabilizálo ao longo de uma determinada trajetória ao mesmo tempo que mantiveram invioladas as restrições físicas impostas ao problema [32]. Seus trabalhos continuaram a ser desenvolvidos, produzindo os resultados apresentados em [33], em que mostra-se a eficácia do MPC não linear proposto na estabilização de veículos em pistas escorregadias e perturbados pela ação de correntes de 
ar laterais. Ainda no mesmo projeto de pesquisa são propostas e analisadas diferentes abordagens para a redução da complexidade computacional dos algoritmos de controle inerentes aos MPC, por meio da linearização por partes dos modelos utilizados ou ainda pela concepção de um controlador preditivo linear variante no tempo, ou Linear Time Varying MPC - LTV MPC [34], [35].

\subsection{5}

\section{Controle Semiautônomo de Veículos Automotivos}

Para adequar esses sistemas à realidade das aplicações automotivas, Anderson e Iagnemma buscaram integrar os conhecimentos e técnicas aplicadas ao controle de veículos autônomos ao desenvolvimento de um sistema capaz de planejar trajetórias, avaliar níveis de ameaça e realizar o controle semiautônomo de veículos de passeio [36]. Naquele trabalho, um MPC é utilizado como elemento principal do sistema semiautônomo. Conforme será apresentado com maiores detalhes nos Capítulos 2 e 4, os MPCs também são utilizados neste trabalho.

Nos trabalhos posteriores publicados por aqueles autores, a navegação dos veículos semiautônomos é tratada como um problema de otimização com restrições, sendo estas representadas pelos limites das regiões do terreno em que os veículos são empregados. Um MPC é utilizado como um planejador de trajetórias ótimas dentro das regiões especificadas pelas restrições, permitindo o cálculo de parâmetros representativos do nível de ameaças a que o carro estaria sujeito. Com base em avaliações destes parâmetros de ameaças é estabelecido um método para a definição da intervenção do sistema de controle, escalonando as entradas dos operadores humanos e dos controladores digitais [37], [38].

A utilização do framework desenvolvido em veículos militares foi também proposta por Anderson, motivada pela necessidade de se estabelecer um controle de estabilidade eficiente para este tipo de sistema. São apresentados resultados de simulações que demonstram a eficácia da abordagem [39]. Em um trabalho diferente, são conduzidos experimentos que produziram resultados de acordo com as simulações realizadas [40].

A evolução da pesquisa permitiu o desenvolvimento de uma abordagem original para o controle semiautônomo de veículos, em que o planejamento de uma trajetória toma como base as restrições ao movimento da viatura. As restrições passaram a ser definidas por meio das Triangulações de Delaunay estruturas topológicas correspondentes aos Diagramas de Voronoi [41], [42].

Gray e Borrelli utilizaram técnicas de Controle Preditivo Robusto para implementar sistemas semiautônomos com aplicações em veículos, conside- 
rando a existência de um motorista representado por um modelo com incertezas [43]. Nesse trabalho, os autores demonstram uma relevante preocupação com a característica intrusiva do controle semiautônomo. Por este motivo, buscaram desenvolver um algoritmo preditivo cujo principal objetivo é minimizar os níveis de intervenção do controlador, priorizando apenas ações corretivas para manter a estabilidade do veículo.

Dando maior ênfase a aplicações de robótica móvel de alta velocidade, Storms e Tilbury propuseram um sistema de controle robótico semiautônomo também baseado em MPC e projetado para evitar colisões [44]. Para reduzir os níveis de intervenção do controlador, a diferença entre os sinais de entrada provenientes do operador humano e do controlador digital é considerada um parâmetro importante do problema de minimização referente ao MPC. Os resultados de simulações são apresentados, e é possível verificar a queda dos níveis de intervenção, tornando o sistema mais confortável e menos suscetível a falhas ocasionadas pela automação.

\subsection{6}

\section{Semiautonomia e Inteligência Artificial}

Apesar da implementação de sistemas de controle semiautônomo com o uso de controladores preditivos, o emprego de ferramentas de IA para esta tarefa é um assunto que permanece pouco explorado. Sarimveis e Bafas utilizaram técnicas de lógica fuzzy para implementar um modelo dinâmico não linear de uma planta química, e com este modelo desenvolveram um Fuzzy Model Predictive Controller. Empregaram ainda técnicas de Computação Evolucionária (ou Algoritmos Genéticos) para a realização das otimizações referentes ao funcionamento dos MPC [45]. Garus aplicou um controlador Proporcional-Derivativo fuzzy para dar assistência aos operadores de um veículo submarino militar semiautônomo, buscando facilitar o controle de posição nos transientes ou na presença de perturbações externas, como fortes correntes marítimas [46].

\section{3 \\ Propostas deste Trabalho}

Em harmonia com as diretrizes de pesquisa, desenvolvimento e inovação do DCT, o trabalho apresentado nesta dissertação deve estruturar uma alternativa para a evolução tecnológica da Família de Blindados GUARANI. A revisão bibliográfica investigativa permitiu a identificação de tópicos de pesquisa científica pouco investigados na área de controle de sistemas dinâmicos, em especial sobre controle semiautônomo de veículos. 
A principal proposta do trabalho resume-se em realizar a concepção conceitual da aplicação de sistemas de controle semiautônomo em veículos militares, levando-se em consideração os perigos e ameaças hostis a que um veículo com estas características está sujeito. A integração destes parâmetros de risco operacional toma como premissa a existência de mecanismos de monitoramento e identificação destas ameaças, representados por sensores militares considerados perfeitos, capazes de detectar a presença de explosivos improvisados, ou $I E D$, e de atiradores inimigos equipados com armamentos anti-carro de mira e pontaria LASER. A Figura 1.3 ilustra uma situação em que se faz necessária a atuação de um sistema deste tipo.

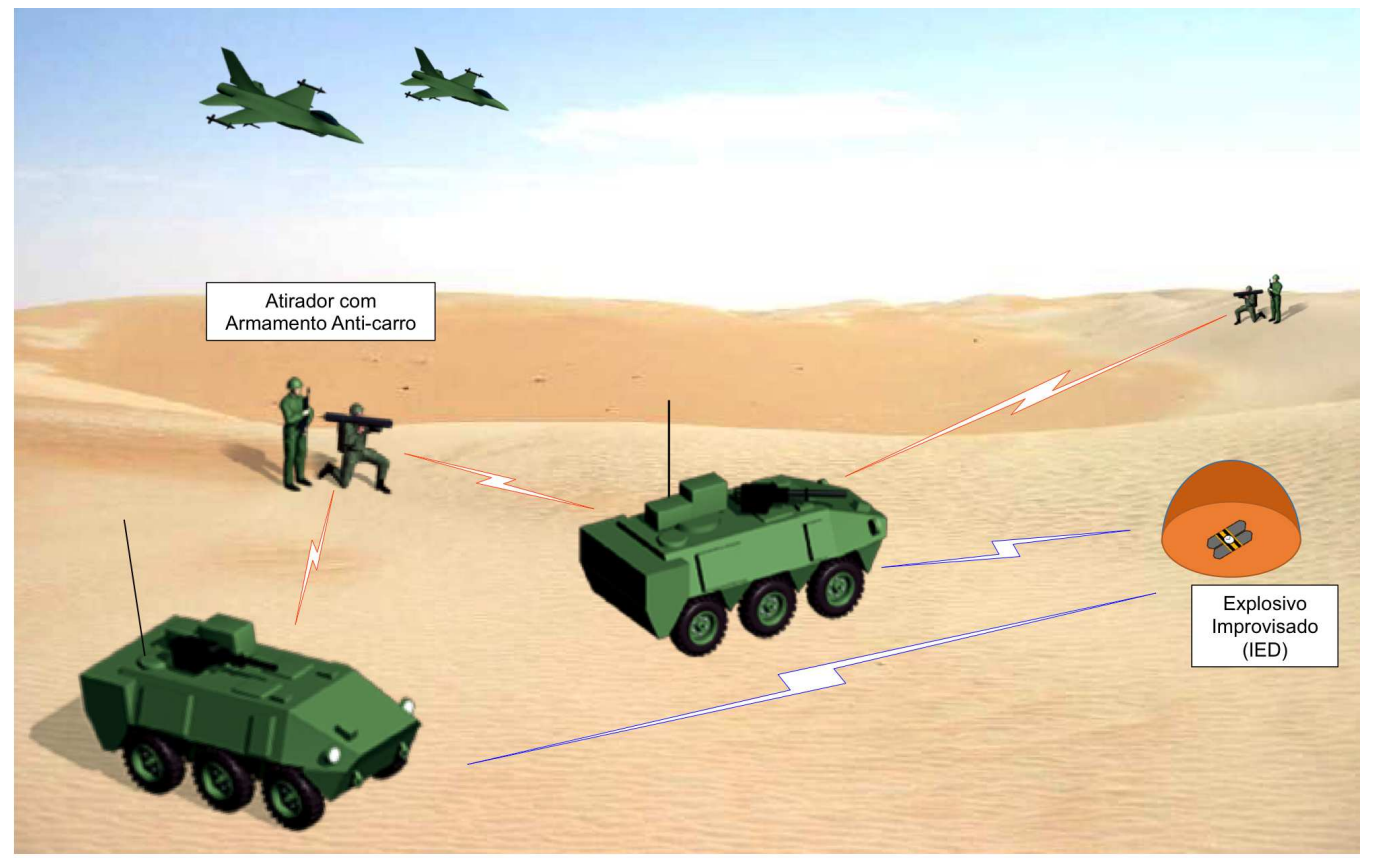

Figura 1.3: Viaturas militares empregadas em um terreno com ameaças hostis.

Além de incluir os parâmetros de natureza militar ao controle semiautônomo de veículos, uma outra proposta consiste na utilização de técnicas de IA para a implementação deste sistema. Conforme mencionado na subseção 1.2.6, a escassez de trabalhos de pesquisa sobre a integração entre os sistemas semiautnônomos e a IA estimula a busca pelo desenvolvimento desta área. Levando-se em consideração que a principal característica dos sistemas de controle semiautônomo identificados na seção 1.2 é a sua capacidade de ponderar sinais de controle de entrada provenientes de operadores humanos e de controladores automáticos, são empregados conceitos de Lógica Fuzzy para a concepção da metodologia para essa ponderação. A escolha da Lógica Fuzzy deve-se à sua adequação ao tratamento de dados ou informações imprecisas, 
conforme a natureza de um fator de ponderação para os sinais de controle. Embora não abordadas neste trabalho, outras técnicas de IA podem ser propostas, como as Redes Neurais e os Algoritmos Genéticos.

O esquema apresentado na Figura 1.4 mostra de forma resumida as propostas deste trabalho.

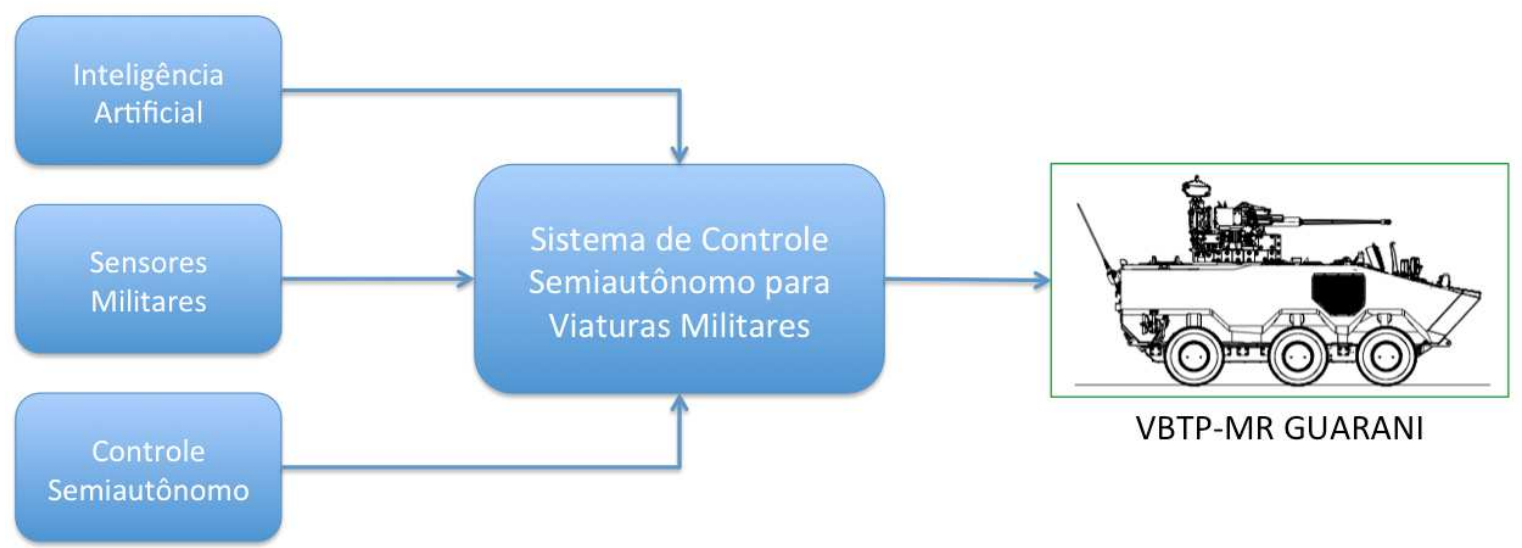

Figura 1.4: Integração de conceitos para o desenvolvimento do sistema de controle semiautônomo aplicado à VBTP-MR GUARANI.

O emprego de um sistema de controle conforme especificado por estas propostas representa uma potencial ampliação das habilidades de direção dos motoristas. Além disso, deverá trazer vantagens, como o aumento dos níveis de segurança e de capacidade operacional da VBTP-MR. Sendo a viatura um sistema militar mais seguro, espera-se como efeito a redução de perdas para a força terrestre nos campos econômico, operacional e de seus recursos humanos.

\section{4}

\section{Organização da Dissertação}

Neste trabalho, pretende-se realizar estudos relevantes tanto para a comunidade acadêmica quanto para a área de Ciência, Tecnologia e Inovação do EB e, por generalização, do Ministério da Defesa e do Governo Federal. O escopo deste trabalho se estende até as seguintes temáticas:

- desenvolvimento de campos de pesquisa relacionados à área de sistemas de controle, destacando-se os assuntos referentes ao campo do controle semiautônomo com aplicações veiculares; 
- propostas de integração entre os tópicos de IA e o controle semiautônomo, com o intuito de aperfeiçoar e otimizar as técnicas e métodos existentes nesta área ainda incipiente;

- estímulo à pesquisa e ao desenvolvimento de sensores de natureza militar, capazes de detectar e identificar ameaças hostis. Estes sensores se fazem necessários para um estudo de caráter experimental sobre o sistema aqui proposto; e,

- fornecimento de um estudo investigativo e especulativo acerca de tecnologias embarcadas em viaturas militares que poderão permitir ganhos operacionais e de segurança, conforme já mencionado.

Para descrever as contribuições deste trabalho e alcançar os demais objetivos aqui propostos, esta dissertação foi dividida em um total de 7 capítulos, organizados da seguinte maneira: este primeiro capítulo introdutório busca detalhar as motivações para o trabalho, o referencial teórico em que se embasa o restante de seu desenvolvimento, as principais propostas da dissertação e uma visão preliminar de suas contribuições para as áreas acadêmica e científica.

O Capítulo 2 apresenta uma visão geral e ampla sobre o projeto do sistema de controle semiautônomo proposto neste trabalho, enquadrandoo como um Sistema Avançado de Assistência ao Motorista e ilustrando a arquitetura simplificada do sistema.

O Capítulo 3 é dedicado ao desenvolvimento do Ponderador Fuzzy, um dos elementos mais importantes do sistema proposto, por meio do qual os conceitos de IA são aplicados neste trabalho. São apresentados conceitos básicos sobre a própria Lógica Fuzzy e o detalhamento do funcionamento do ponderador, além de resultados preliminares deste subsistema.

No Capítulo 4 são tratados os tópicos relativos à implementação do Subcontrolador Preditivo Baseado em Modelo, outro importante elemento da arquitetura do sistema proposto. São apresentadas informações sobre técnicas relacionadas ao projeto de controladores preditivos e suas particularidades para o subsistema implementado, bem como outros resultados preliminares pertinentes a ele.

A modelagem matemática do sistema veicular representado pela VBTP-MR GUARANI é apresentada no Capítulo 5. Apresenta-se de forma detalhada o estabelecimento do modelo a partir de equações de movimento da viatura. Os parâmetros necessários para a utilização dessas equações foram obtidos através da análise de informações técnicas disponibilizadas pelo DCT - EB.

O Capítulo 6 aborda a realização de simulações com a implementação do sistema proposto em ambiente de simulação numérica. O objetivo principal 
dessas simulações é atestar a eficácia da solução desenvolvida, buscando-se simular situações de perigo em que a ação do sistema se faria necessária em casos reais.

Finalmente, o Capítulo 7 traz um sumário geral do trabalho desenvolvido e os principais objetivos alcançados. São apresentadas as contribuições mais importantes desta dissertação e as maiores dificuldades envolvidas em seu desenvolvimento, além de serem sugeridas algumas diretrizes para a continuidade deste trabalho em oportunidades futuras. 


\section{2}

\section{Visão Geral do Projeto de um Controlador Semiautônomo}

O sistema de controle semiautônomo cujo projeto é relatado neste capítulo pode ser considerado um Sistema Avançado de Assistência ao Motorista, ou Advanced Driver Assistance Systems (ADAS), conforme definido pela literatura recente [47], [48]. Suas características, tanto as mais gerais quanto as mais específicas e inerentes à concepção da arquitetura do sistema, são apresentadas nas seções subsequentes.

\section{1}

\section{Sistemas Avançados de Assistência ao Motorista}

Os ADAS são sistemas complexos projetados para aperfeiçoar as habilidades de direção dos motoristas e a segurança em veículos automotivos. Estas características são semelhantes àquelas desejadas para os Sistemas de Aumento de Estabilidade (ou Stability Augmentation Systems - SAS), adequados para veículos aéreos [49]. Conforme exposto no Capítulo 1, muitos desses sistemas têm sido estudados por pesquisadores, estimulados pela comunidade científica/acadêmica e pela indústria. De acordo com Chen [50], estes tipos de sistemas podem ser divididos em três categorias básicas, conforme organizado na Tabela 2.1.

Tabela 2.1: Categorias dos ADAS e suas principais características.

\begin{tabular}{|l|l|}
\hline CATEGORIA & CARACTERÍSTICAS \\
\hline $\begin{array}{l}\text { Alertas ou } \\
\text { Warning }\end{array}$ & $\begin{array}{l}\text { Sistemas que fornecem diversos tipos } \\
\text { de informações, de maneiras diferentes e } \\
\text { para diferentes níveis de emergência e } \\
\text { ameaças potenciais. }\end{array}$ \\
\hline $\begin{array}{l}\text { Assistência Ativa/ } \\
\text { Sistemas Semiautomáticos }\end{array}$ & $\begin{array}{l}\text { Sistemas projetados para dar assistência } \\
\text { aos motoristas em suas tarefas } \\
\text { ligadas à direção (aceleração, frenagem, } \\
\text { esterçamento do volante e etc.) }\end{array}$ \\
\hline $\begin{array}{l}\text { Sistemas Automáticos ou } \\
\text { "Totalmente" Automáticos }\end{array}$ & $\begin{array}{l}\text { Sistemas projetados para tomar o controle } \\
\text { dos veículos e agirem automaticamente } \\
\text { durante a direção. }\end{array}$ \\
\hline
\end{tabular}

O sistema proposto nesta dissertação pode ser classificado como um 
Sistema de Assistência Ativa ou Semiautomático. Em geral, estes sistemas podem ainda ser subdivididos em dois tipos, sendo estes,

Sistemas Reativos: São aqueles que atuam quando os estados do sistema dinâmico (neste caso, o veículo) são desviados de valores de referência ou estão se aproximando de alguma barreira crítica de estabilidade, o que pode levar a uma operação perigosa ou a acidentes; e,

Sistemas Preditivos: São aqueles em que a decisão sobre atuação leva também em consideração algum tipo de previsão da evolução dos estados do sistema dinâmico, além de estimar perturbações indesejadas provenientes do meio ambiente.

A utilização dos MPC na implementação do sistema permite que este seja classificado como um Sistema Preditivo.

\section{2}

\section{Níveis Variáveis de Intervenção do Controlador Digital}

A lacuna de desenvolvimento existente entre as tecnologias de sistemas puramente manuais e sistemas totalmente autônomos pode ser preenchida por sistemas semiautônomos ou de controle compartilhado. Estes sistemas, por sua vez, podem prover uma estratégia de assistência ao operador humano de forma peculiar, em que o seu nível de autonomia sobre o controle do sistema dinâmico pode se adaptar às circunstâncias. A importância de se ajustar o nível de autonomia do operador (ou de intervenção do controlador automático digital) se torna mais evidente se as habilidades dos especialistas humanos forem consideradas essenciais para o controle, exigindo-se sua presença na malha ("human in the loop").

Um relevante desafio para o projeto destes sistemas é justamente a definição de uma metodologia para a alocação da autoridade de controle entre o operador humano e o controlador automático digital. Geralmente, esta ponderação é realizada por meio de minimizações de funções objetivo indesejadas, como por exemplo: nível de ameaças de colisão; diferença entre os sinais de controle de entrada fornecidos pelo operador humano e pelo controlador automático digital; ou, ainda, uma função abstrata que considere estes parâmetros [36].

A partir da avaliação dessas métricas e de algum método de otimização, calcula-se um parâmetro representado por uma variável real $K \in[0,1]$ capaz de representar o nível ótimo de intervenção do controlador. Este parâmetro é portanto utilizado para a ponderação dos sinais de controle de entrada a serem aplicados ao sistema dinâmico, resultando em uma entrada total dada por 


$$
u=K u_{c}+(1-K) u_{h},
$$

onde $u_{c}$ é o sinal de entrada do controlador automático digital e $u_{h}$ é o sinal de entrada do operador humano.

Neste trabalho, propõe-se que as entradas do controlador automático digital sejam fornecidas por um MPC, enquanto que a escolha da variável de intervenção $K$ é realizada por um sistema baseado em lógica fuzzy, projetado para levar em consideração alguns parâmetros de entrada relevantes para o conforto e para a segurança da direção do veículo (que representa controle do sistema dinâmico), além de outros parâmetros relacionados relacionados à presença de ameaças hostis inimigas, como distâncias e velocidades do veículo com relação às ameaças, importantes para o contexto de aplicação em viaturas militares.

\section{3}

\section{Estrutura Analítica do Projeto}

O projeto de um sistema de controle inclui alguns elementos essenciais, como os conjuntos de sensores e de atuadores empregados e uma unidade de controle capaz de processar informações e gerar as leis de controle pré-definidas. No caso do sistema de controle semiautônomo proposto neste trabalho, seus elementos podem ser organizados de acordo com a Estrutura Analítica de Projeto (EAP) ilustrada na Figura 2.1.

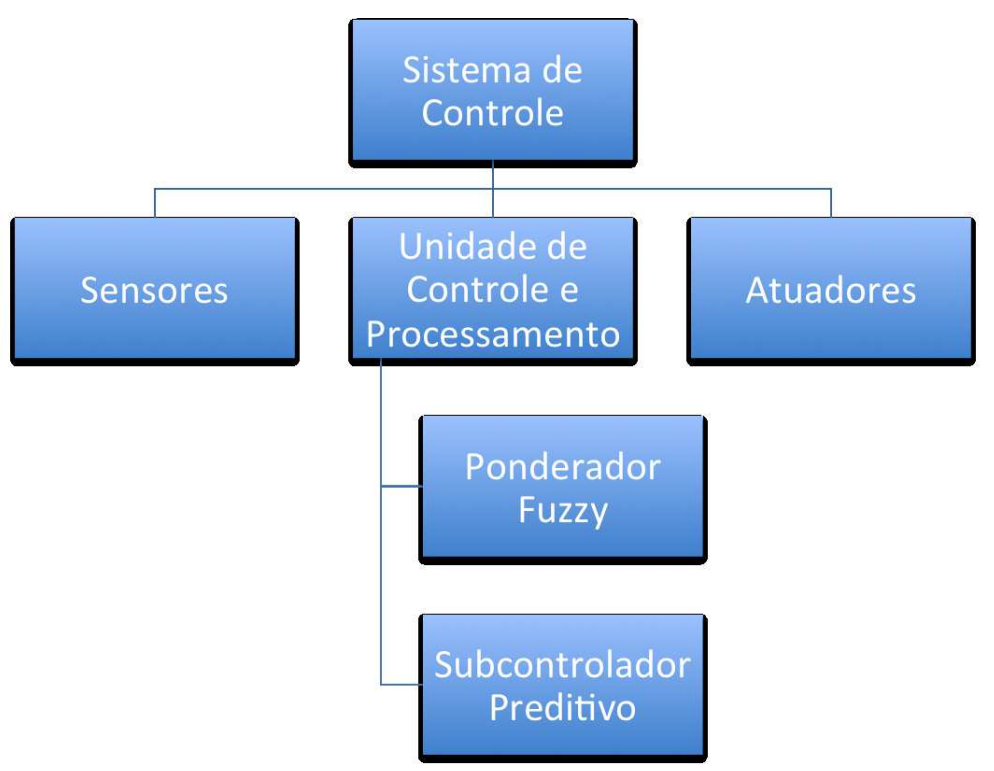

Figura 2.1: Estrutura Analítica do Projeto do sistema de controle semiautônomo proposto.

Uma implementação experimental do sistema proposto neste trabalho 
demandaria a definição de todos os elementos apresentados na EAP mostrada. Entretanto, pelas dificuldades de ordem prática, pela escassez de tempo hábil para o planejamento e execução de atividades experimentais, e também por este se tratar de um estudo teórico focado na concepção, desenvolvimento e simulação do sistema, esta dissertação tem seu escopo limitado ao projeto e simulação da unidade de controle e seus subelementos: o Ponderador Fuzzy e o Subcontrolador Preditivo.

\section{4}

\section{Arquitetura do Controlador Semiautônomo}

Conforme mencionado na Seção 2.2, a abordagem para a ponderação dos sinais de controle de entrada proposta neste trabalho conta com a utilização de um sistema de inferência fuzzy complexo para o processamento de algumas informações relevantes e ainda com a utilização de um controlador baseado na classe dos MPC para a geração dos sinais de controle de entrada.

Uma arquitetura geral e de alto nível para malha de controle é proposta e ilustrada na Figura 2.2. Essa figura mostra uma malha fechada de controle onde o controlador deve ser considerado o elemento principal. O projeto desse controlador representa o objetivo essencial do desenvolvimento deste trabalho. Para alcançá-lo, propõe-se a arquitetura ilustrada na Figura 2.3, formada pelo Ponderador Fuzzy e pelo Subcontrolador Preditivo.

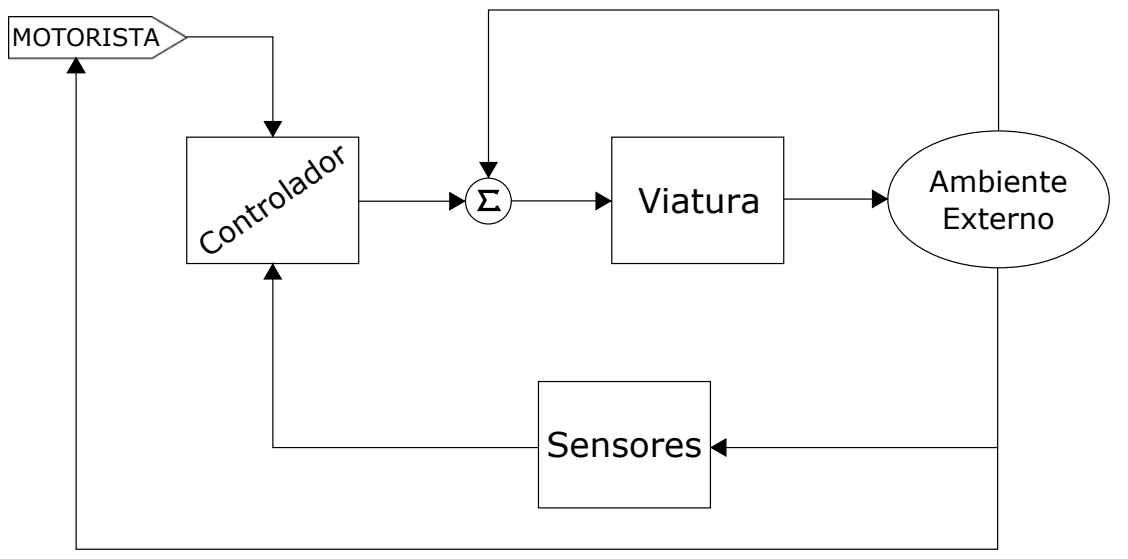

Figura 2.2: Malha em que se insere o sistema de controle semiautônomo proposto.

Pode-se observar que as entradas desse controlador estão estritamente relacionadas aos atributos enumerados na subseção 2.4.1, de forma que estes devem ser quantificados com medidas da entrada fornecida pelo motorista, do parâmetro de estabilidade e do parâmetro de ameaças externas. 


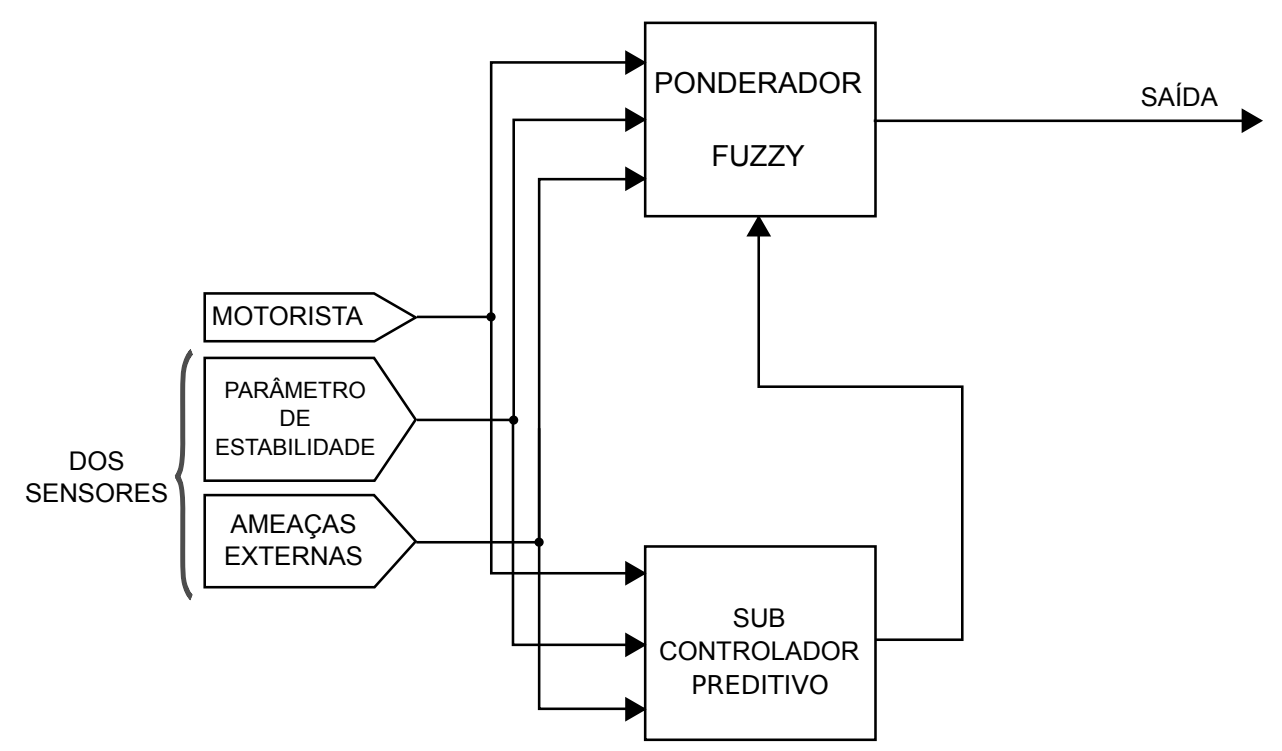

Figura 2.3: Arquitetura de alto nível do sistema de controle semiautônomo proposto.

\subsection{1}

\section{Ponderador Fuzzy}

O sistema fuzzy utilizado para a ponderação dos sinais de controle tem como entradas algumas informações (ou atributos) importantes, como por exemplo: as ameaças externas a que o veículo está exposto, o comportamento do motorista, e a própria estabilidade do veículo. Para quantificar estes atributos, devem ser considerados:

1. O cálculo de parâmetros de estabilidade, sendo aplicado neste caso o Momento de Estabilidade, ou Stability Moment (SM) e, com estes parâmetros, a geração de uma medida representativa da "tendência ao capotamento" de um veículo. O SM foi apresentado por Peters e Iagnemma em [51], e é brevemente discutido no Capítulo 3. Sua obtenção se dá a partir do emprego de sensores inerciais nos veículos, como acelerômetros e giroscópios.

2. A presença de sensores militares ideais no veículo. Estes sensores devem ser capazes de identificar situações em que o veículo é iluminado por um dispositivo de mira ou pontaria $L A S E R$, bem como a existência de explosivos IED no terreno em que o veículo é empregado.

3. A diferença entre os sinais de controle de entrada fornecidos pelo motorista e pelo sistema de controle.

A partir do processamento desses parâmetros, são definidos os valores para a variável de intervenção $K$, mencionada na equação 2-1. 


\section{4 .2}

\section{Subcontrolador Preditivo}

O Subcontrolador Preditivo é o sistema cuja função é gerar os sinais de controle provenientes do controlador digital representados pela variável $u_{c}$, também mostrada na equação 2-1. Por sua demonstrada propensão ao emprego em sistemas de controle veiculares, os MPCs são utilizados em sua implementação.

O projeto de um MPC depende basicamente de um modelo matemático da planta a ser controlada (neste caso, o veículo) e da definição de um problema de otimização, usando uma função objetivo calculada dentro de um horizonte de previsão capaz de representar uma quantidade a ser minimizada, restrições matemáticas e um algoritmo para solução desse problema, a ser periodicamente executado.

O projeto de cada um destes subelementos é abordado com maior detalhamento nos Capítulos 3 e 4. 


\section{Desenvolvimento do Ponderador Fuzzy}

O projeto e a implementação do sistema semiautônomo demandam a existência de um elemento capaz de realizar a ponderação dos sinais de controle de entrada. Conforme exposto anteriormente na Seção 1.3, as técnicas de IA derivadas da Lógica Fuzzy foram escolhidas para a implantação deste elemento. Neste Capítulo são mostrados conceitos básicos sobre a própria lógica fuzzy, os detalhes de projeto do Ponderador, e dos SIF que o compõem. Concluindo o Capítulo, alguns resultados preliminares da simulação do Ponderador Fuzzy são apresentados.

\section{1}

\section{Lógica Fuzzy}

Os conceitos referentes à lógica fuzzy devem ser aplicados ao tratamento de processos complexos tendo como base informações vagas, com pouca precisão. Isso permite que os sistemas fuzzy sejam apropriados para a aplicações em dois contextos gerais [52]:

1. Situações envolvendo sistemas complexos cujos comportamentos, geralmente não lineares, não são bem compreendidos pelos seres humanos; $\mathrm{ou}$,

2. Situações que exijam um processamento rápido de informações vagas que viabilize soluções aproximadas para determinado problema.

A origem desses conceitos, suas principais características e aplicações nos campos da engenharia são descritos a seguir.

\subsection{1}

\section{Origens}

A teoria dos conjuntos fuzzy foi proposta por Zadeh [53], que tinha por objetivo dar um tratamento matemático para classes e conjuntos imprecisos ou ambíguos comuns no mundo físico. A integração de conceitos entre esses conjuntos e a lógica clássica permitiu a definição de mecanismos de inferência 
e de operadores lógicos fuzzy, por meio dos quais tornou-se possível o próprio desenvolvimento da Lógica Fuzzy.

\subsection{2}

\section{Características}

A base teórica da lógica fuzzy é formada pelos seus conjuntos, operações lógicas e sistemas de inferência.

\section{Conjuntos Fuzzy}

Diferentemente do conceito de pertinência a um conjunto (bem definido na teoria da lógica clássica), na teoria de conjuntos fuzzy propõe-se que sejam definidas funções de pertinência de um elemento a um determinado conjunto, onde uma função pode assumir infinitos valores no intervalo $[0,1]$. Portanto, um conjunto fuzzy $A$ em um universo de discurso $X$ é definido por uma função de pertinência $\mu_{A}(x): X \rightarrow[0,1]$, e representado por um conjunto de pares ordenados

$$
A=\mu_{A}(x) / x, x \in X
$$

em que $\mu_{A}(x)$ indica o grau de compatibilidade entre o elemento $x$ e o conjunto A. Desta maneira, um determinado elemento pode pertencer a mais de um conjunto com diferentes graus de compatibilidade (ou pertinência).

Os universos de discursos sobre os quais se definem os conjuntos fuzzy podem ser contínuos ou discretos. É comum que estes conjuntos sejam representados por $\sum_{i=1}^{n} \mu_{A}\left(x_{i}\right) / x_{i}$ quando discretos ou por $\int_{X} \mu_{A}(x) / x$ quando contínuos. Observa-se que estas notações não devem ser confundidas com as operações de somatório ou integração.

As variáveis linguísticas são aquelas cujos valores dão nome aos conjuntos fuzzy. Seja, por exemplo, definida como uma variável linguística a estatura de um determinado grupo de pessoas, podendo assumir os valores: baixo, médio e alto. Estes valores podem ser descritos por conjuntos fuzzy e representados por suas funções de pertinência, conforme mostrado na Figura 3.1.

Estas variáveis linguísticas e seus valores (ou conjuntos fuzzy) permitem a caracterização aproximada de fenômenos. As funções de pertinência, que por sua vez podem assumir diferentes "formatos", indicam o grau de compatibilidade entre o valor que a variável assume e os conjuntos. No caso da Figura 3.1, uma pessoa com estatura de 1,90m seria mais compatível com o conjunto dos altos, embora tivesse ainda algum grau de compatibilidade com o conjunto dos médios. 


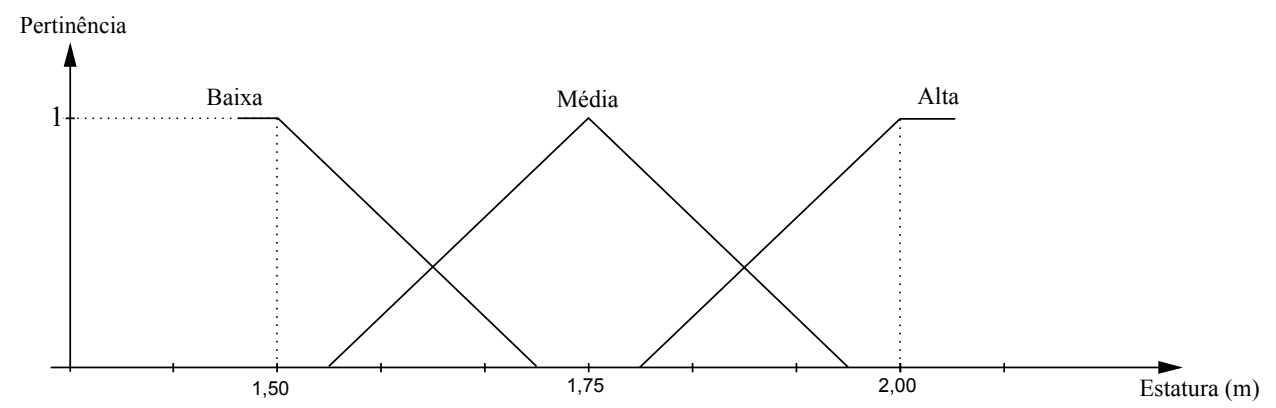

Figura 3.1: Funções de Pertinência para a variável Estatura.

\section{Operações Lógicas Fuzzy}

Diversas operações matemáticas com conjuntos fuzzy podem ser definidas, basicamente representando alterações em suas funções de pertinência. As operações de união e interseção entre conjuntos fuzzy são as operações mais importantes para os sistemas de inferência componentes do Ponderador Fuzzy, e em geral são representadas por operações genéricas de norma- $t$ e co-norma-t [54], [55]. Os operadores de mínimo e máximo são casos particulares dessas normas, e são utilizados neste trabalho.

Esses operadores permitem a definição de relações fuzzy e a combinação de proposições, com a utilização dos conectivos lógicos $e$ e ou, da negação não e da estrutura de implicação se ... então.

Dessa forma, pode-se estender o modus ponens para o modus ponens generalizado, que pode ser descrito da seguinte maneira:

Premissa 1: $x$ é $A^{*}$.

Premissa 2: Se $x$ é $A$ então $y$ é $B$.

Consequência: $y$ é $B^{*}$.

Observa-se que, como $A^{*}$ e $B^{*}$ não são necessariamente iguais a $A$ e $B$, a Premissa 1 não é exatamente o antecedente da regra da Premissa 2. No entanto, pode-se considerar que a regra pode ser "ativada", diferentemente da lógica clássica. Uma operação deste tipo modificará a função de pertinência de $y$ ao conjunto $B$, gerando a função de pertinência ao conjunto $B^{*}$.

Um conjunto de regras fuzzy, integrado a métodos de fuzzificação e defuzzificação permitem o desenvolvimento dos SIF. 


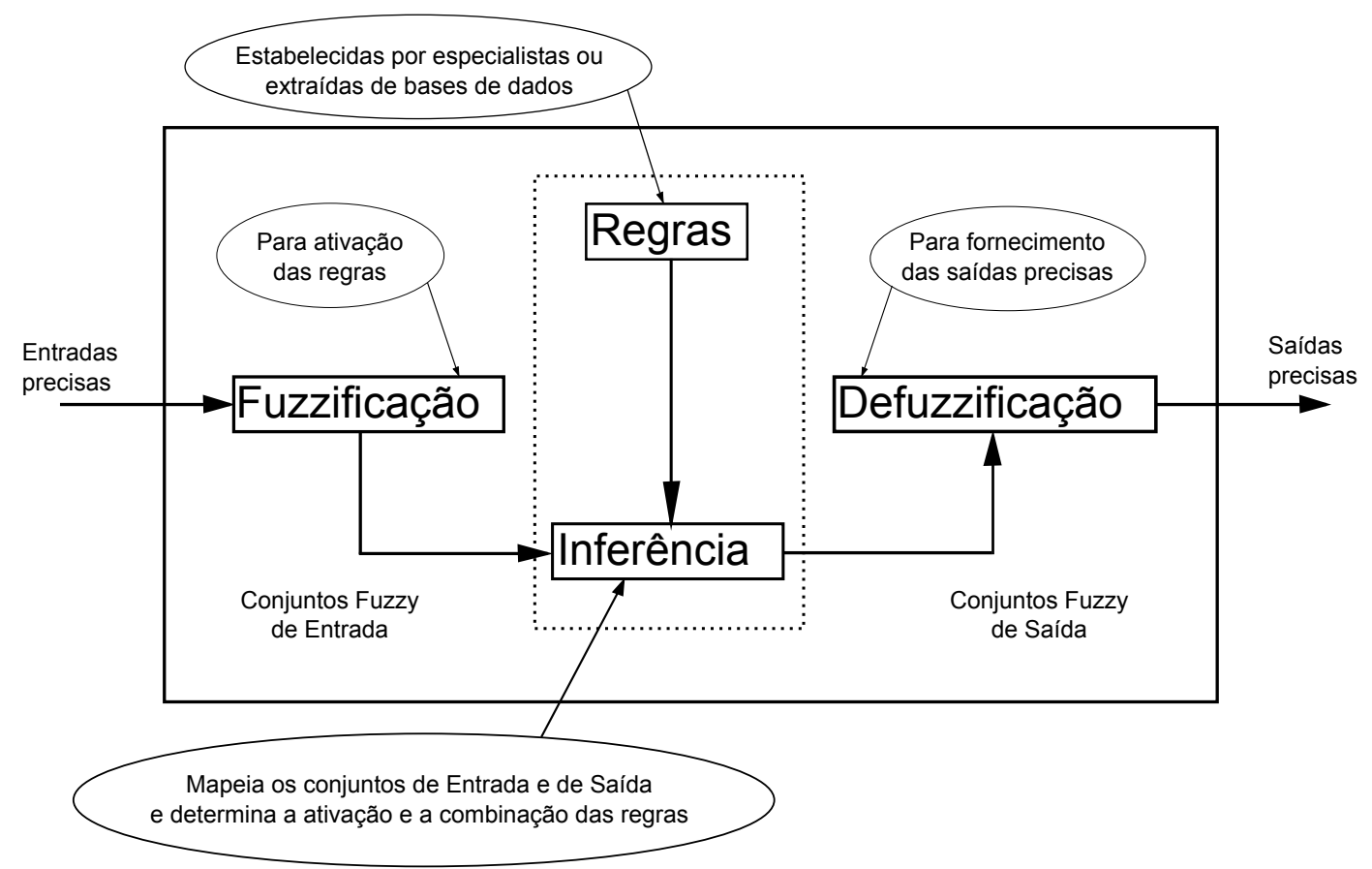

Figura 3.2: Sistema de Inferência Fuzzy. Adaptado de [56].

\section{Sistemas de Inferência Fuzzy}

Um Sistema de Inferência Fuzzy é mostrado na Figura 3.2, com as funções de cada bloco identificadas.

Neste sistema, as entradas precisas resultantes de medições são não-fuzzy, sendo necessário o processo de fuzzificação. Este processo consiste em um mapeamento dos dados de entrada para os conjuntos fuzzy, ativando-se as regras relevantes de acordo com as circunstâncias. Por meio da inferência a partir do modus ponens generalizado, obtém-se um conjunto fuzzy de saída. Em seguida realiza-se um mapeamento inverso para que sejam obtidas saídas precisas. Este mapeamento se concretiza com o processo de defuzzificação. Existem vários métodos de defuzzificação na literatura. Dois dos mais empregados são o centro de gravidade e a média dos máximos.

As regras que compõem o SIF em geral podem ser fornecidas por especialistas em formas de sentenças linguísticas.

\subsection{3}

\section{Aplicações}

A teoria de Conjuntos e da Lógica Fuzzy, bem como os SIF, são aplicados com sucesso em diversas áreas do conhecimento e possuem grande utilidade dentro da engenharia. As primeiras aplicações relatadas deram-se justamente na área de Controle de Sistemas Dinâmicos. Entretanto, desde então, a 
utilização das técnicas e sistemas fuzzy vem crescendo em outros campos, como por exemplo a classificação e mineração de dados, a identificação de sistemas, previsão de séries temporais, planejamento, otimização e etc [56].

\section{2}

\section{Ponderação de Sinais com Técnicas Fuzzy}

A criação de um sistema semiautônomo caracterizado pela equação 2-1 demanda a concepção de uma estratégia para a escolha dos valores instantâneos para a variável de intervenção $K$, tomando como base uma série de fatores (ou atributos de entrada) que dependem essencialmente do sistema a ser controlado e das limitações ou referências que definem os critérios de controle.

Esta escolha poderia ter sido feita diretamente pelo próprio MPC, conforme realizado em [36], [37], [39], [40], [38], [41], [42] ou [44] ou por meio de uma avaliação adaptativa do comportamento do operador humano e suas falhas anteriores, de forma semelhante ao que foi realizado em [11]. No entanto, é estabelecida como premissa deste trabalho a utilização de técnicas de IA para a implementação do ponderador com capacidade para realizar a alocação desta autoridade de controle entre o ser humano e o controlador digital.

Dentre as técnicas mais importantes, verifica-se a possibilidade de serem utilizadas as Redes Neurais Artificiais e os Algoritmos Genéticos. As RNA demandariam a pré-existência ou o desenvolvimento de um conjunto de dados de treinamento com uma quantidade relativamente grande de entradas e saídas correspondentes. Somente este treinamento permitiria o estabelecimento de um modelo neural satisfatório. Os algoritmos genéticos, por suas características evolucionárias, exigiriam a definição de uma função de avaliação para cada uma das soluções e um grande esforço computacional, além de uma quantidade de tempo considerável para a resolução de um problema de otimização que seria definido para a escolha da variável $K$, o que inviabilizaria sua utilização. Este processo deveria ser continuamente executado com curtos períodos de repetição.

Considera-se a Lógica Fuzzy a mais adequada para o projeto do ponderador, devido a sua característica de tratar informações de entrada imprecisas e produzir saídas satisfatórias. A partir das técnicas fuzzy e dos SIF torna-se possível a concepção de modelos matemáticos cujo comportamento se assemelha ao da mente humana. Desta forma, portanto, busca-se projetar um sistema capaz de representar aquele que seria o comportamento de um operador humano especializado com a capacidade de alocar os níveis de autoridade de controle entre o ser humano e o controlador digital (correspondente ao Subcontrolador Preditivo). 


\section{3}

\section{Caracterização das variáveis de entrada e de saída do Ponderador Fuzzy}

Observando-se a Figura 2.3, pode-se verificar que o ponderador fuzzy deve ser projetado de forma a processar informações provenientes de diversas fontes que representem o controle do motorista, a estabilidade do veículo e as ameaças externas a que este estaria submetido. Além destas, considera-se também como entrada o sinal de controle proveniente do subcontrolador preditivo. Conforme mencionado, a partir do processamento destas informações determina-se o valor do nível de intervenção do controlador digital.

As informações relevantes e necessárias para a caracterização dos universos de discurso das variáveis de entrada e para a implementação do ponderador são descritas a seguir. Observa-se que esta caracterização é estabelecida de acordo com as necessidades levantadas pelo próprio projetista do SIF, podendo ser modificada de acordo com a conveniência.

\subsection{1}

\section{Controle do Motorista}

Dada a equação 2-1, o sinais de entrada do controlador e do operador humano representados por $u_{c}$ e $u_{h}$ são os mecanismos de atuação que permitem a evolução dos estados do sistema dinâmico, normalmente aplicados ao esterçamento das rodas, aceleração ou frenagem do veículo. O escopo deste trabalho limita-se à hipótese de atuação exclusivamente realizada no esterçamento das rodas do primeiro e do segundo eixos do veículo, que são geometricamente relacionados. Neste caso o sinal de controle de entrada $u$ é unidimensional, isto é, reduz-se a apenas uma única variável.

Considerando-se a diferença entre as entradas provenientes do controlador digital e do operador humano dada por

$$
\Delta u=\left|u_{h}-u_{c}\right|
$$

pode-se utilizá-la como um parâmetro de entrada importante para o Ponderador Fuzzy. Isto se deve ao fato de que um valor muito alto para $\Delta u$ representa uma grande diferença entre as trajetórias pretendidas pelo operador humano e pelo controlador, o que pode causar instabilidades no sistema e prejudicar a condução da viatura.

Os sinais $u_{c}$ e $u_{h}$ são definidos pelas distâncias angulares que representam o esterçamento do volante a partir de uma posição neutra, em que as rodas anteriores e intermediárias estão paralelamente alinhadas com o eixo longitudinal da viatura. Valores positivos indicam esterçamento à esquerda e valores negativos à direita, conforme ilustrado na Figura 3.3. 

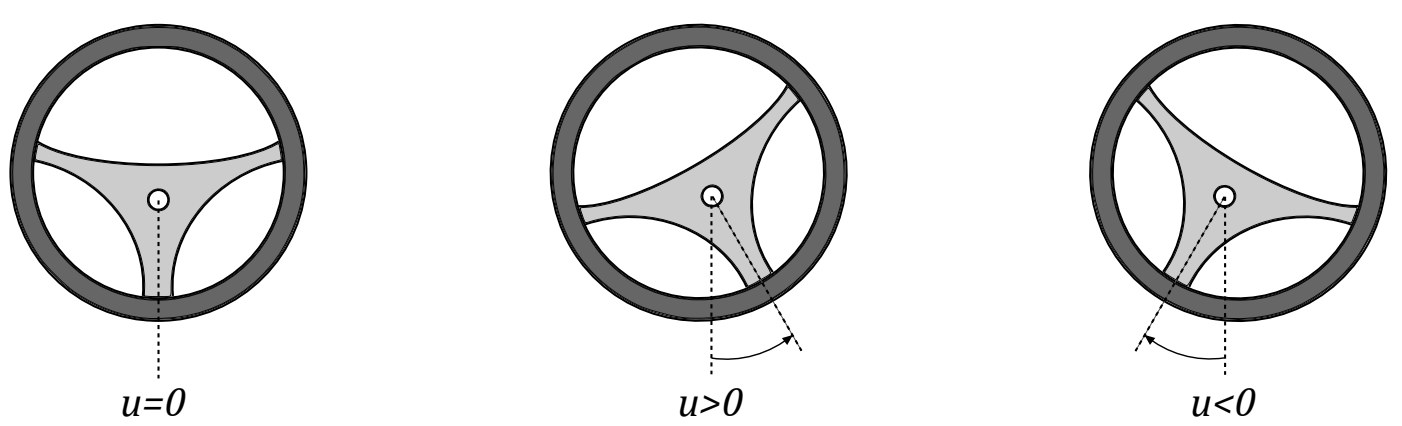

Figura 3.3: Esterçamentos nulo, positivo e negativo do volante do veículo.

Tomando-se as medidas destas distâncias angulares em graus, podese definir um universo de discurso representativo da diferença angular $\Delta u$, dividindo-o em quatro conjuntos fuzzy denominados: diferenças angulares pequenas $(\mathrm{P})$, médias $(\mathrm{M})$, grandes $(\mathrm{G})$ e muito grandes $(\mathrm{MG})$. Estes conjuntos são definidos da seguinte maneira:

\section{Diferenças Angulares Pequenas - P}

Este conjunto fuzzy tem graus de pertinência diferentes de zero no intervalo $0^{\circ} \leq \Delta u<15^{\circ}$. O valor máximo $(\mu=1)$ se dá para $\Delta u=0^{\circ} \mathrm{e}$ decresce proporcionalmente até chegar em $\mu=0$ para $\Delta u=15^{\circ}$.

\section{Diferenças Angulares Médias - M}

Os graus de pertinência deste conjunto fuzzy são diferentes de zero no intervalo $0^{\circ}<\Delta u<60^{\circ}$. A função de pertinência tem um formato "triangular", sendo $\mu=0$ para $\Delta u=0^{\circ}$ e $\Delta u=60^{\circ}$ e o valor máximo $\mu=1$ para $\Delta u=20^{\circ}$.

\section{Diferenças Angulares Grandes - G}

No terceiro conjunto fuzzy os graus de pertinência são diferentes de zero no intervalo $15^{\circ}<\Delta u<180^{\circ}$. A função de pertinência tem também um formato "triangular", sendo $\mu=0$ para $\Delta u=15^{\circ}$ e $\Delta u=180^{\circ}$ e o valor máximo $\mu=1$ para $\Delta u=60^{\circ}$.

\section{Diferenças Angulares Muito Grandes - MG}

O quarto e último conjunto fuzzy de $\Delta u$ tem graus de pertinência diferentes de zero para $\Delta u>60^{\circ}$. A função de pertinência é caracterizada por $\mu=0$ para $\Delta u=60^{\circ}$ e cresce proporcionalmente até que se atinja o valor máximo $\mu=1$ para $\Delta u=180^{\circ}$. Qualquer valor de $\Delta u \geq 180^{\circ}$ tem função de pertinência $\mu=1$. 
Desta maneira, pode-se representar graficamente o universo de discurso de $\Delta u$ e seus conjuntos fuzzy pela Figura 3.4.

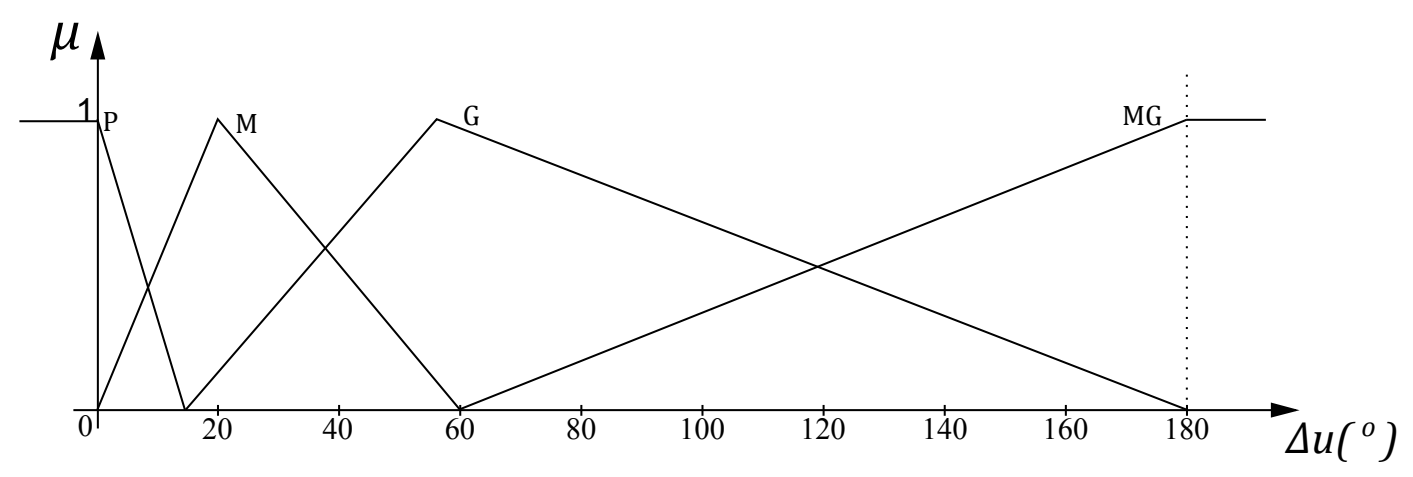

Figura 3.4: Universo de Discurso de $\Delta u$ e seus conjuntos fuzzy.

\subsection{2}

\section{Estabilidade do Veículo}

As metas mais importantes para o sistema proposto neste trabalho incluem a manutenção da estabilidade do veículo militar a ser controlado e a prevenção de acidentes que possam pôr vidas em risco. Por este motivo, há a necessidade de se utilizar uma medida em tempo real do grau de estabilidade do sistema dinâmico (veículo) no projeto do controlador semiautônomo. Esta medida, por sua vez, caracteriza uma das variáveis de entrada do ponderador fuzzy e exerce influência sobre a escolha do nível de intervenção do controlador digital.

Alguns parâmetros de estabilidade previstos na literatura poderiam ter sido utilizados neste projeto. No entanto, devido a sua aplicabilidade em veículos genéricos de $l$ rodas $(l \geq 2)$, em alta velocidade, e navegando em terrenos irregulares, os Momentos de Estabilidade definidos por Peters e Iagnemma [51] são utilizados para o estabelecimento do parâmetro aqui empregado.

Com o intuito de manter-se a autossufiência deste texto, algumas definições e conceitos básicos primeiramente apresentados em [51] são reproduzidos a seguir.

\section{Definição do Momento de Estabilidade}

A definição do Momento de Estabilidade torna-se possível por meio da modelagem de um veículo de $l$ rodas e uma massa suspensa representando o chassis como sendo um sistema multicorpos de $l+1$ corpos rígidos. As propriedades inerciais dos corpos rígidos são dadas pelas massas $m_{i}$, as matrizes 
de inércia $\mathbf{I}_{i}$ e seus centros de gravidade $\mathbf{c}_{O}^{i}$, sendo $i \in\{1,2, \ldots, l+1\}$. Os vetores posição $\mathbf{c}_{O}$ são determinados a partir de um referencial inercial $\{X Y Z\}$ definido no ponto $O$, enquanto que as matrizes $\mathbf{I}_{i}$ são determinadas a partir de referenciais fixados nos corpos rígidos associados a matrizes de rotação $\mathbf{R}_{O}^{i}$, de forma que $\mathbf{I}_{O}^{i}=\mathbf{R}_{O}^{i} \mathbf{I}_{i}\left(\mathbf{R}_{O}^{i}\right)^{T}$. As velocidades angulares são dadas por $\boldsymbol{\omega}_{i}$ no referencial do corpo e $\boldsymbol{\omega}_{O}^{i}$ no referencial $O$. A Figura 3.5 ilustra este modelo.
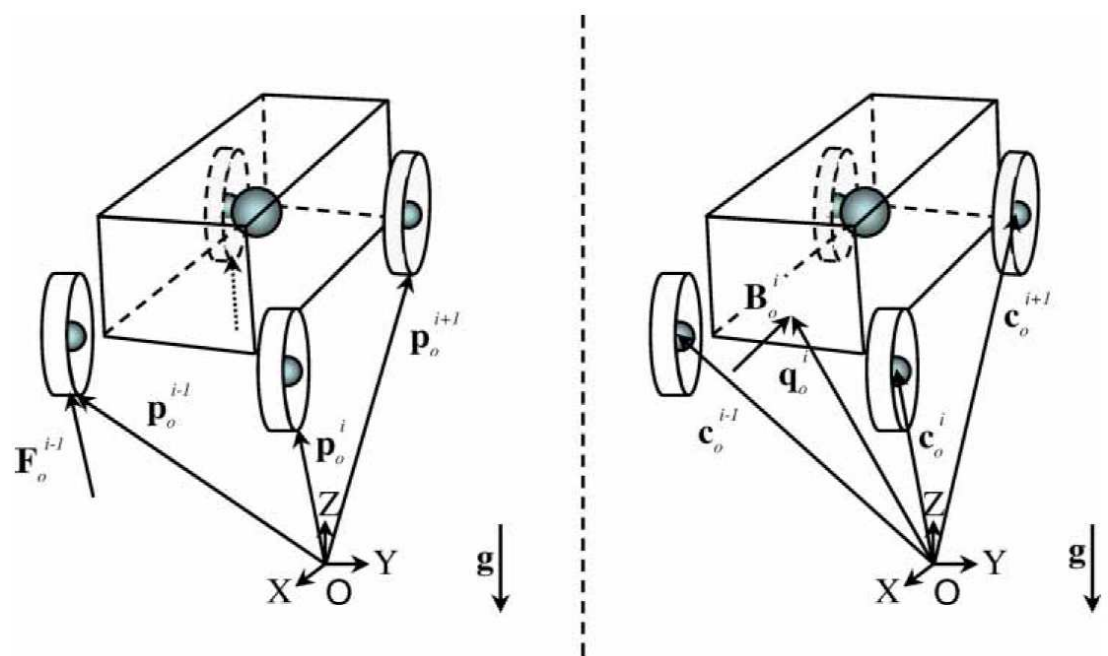

Figura 3.5: Modelo de veículo de quatro rodas. Fonte: [51].

Considera-se que cada uma das rodas do veículo estão em contato com o terreno em um único ponto, sendo este terreno irregular. Estes pontos de contato são definidos pelos vetores posição $\mathbf{p}_{O}^{i}$, e suas forças de contato correspondentes são dadas por $\mathbf{F}_{O}^{i}$, sendo $i \in\{1,2, \ldots, l\}$. As outras forças atuantes no sistema são o peso $m \mathbf{g}$ e quaisquer $k$ forças externas indicadas por $\mathbf{B}_{i}$, aplicadas nos pontos $\mathbf{q}_{i}$, sendo $i \in\{1,2, \ldots, k\}$.

Dois pontos de contato consecutivos caracterizam um eixo sobre qual o veículo pode girar, tendendo à instabilidade. Os eixos laterais, isto é, aqueles definidos por pontos de contato localizados nas laterais do veículo são os mais susceptíveis a este giro. Os vetores $\mathbf{r}_{O}^{i}$ representam estes eixos, e são dados por

$$
\begin{aligned}
& \mathbf{r}_{O}^{i}=\frac{\mathbf{p}_{O}^{i+1}-\mathbf{p}_{O}^{i}}{\left\|\mathbf{p}_{O}^{i+1}-\mathbf{p}_{O}^{i}\right\|}, i \in\{1,2, \ldots, l-1\}, \\
& \text { оu } \\
& \mathbf{r}_{O}^{i}=\frac{\mathbf{p}_{O}^{1}-\mathbf{p}_{O}^{l}}{\left|\mathbf{p}_{O}^{1}-\mathbf{p}_{O}^{l}\right|}, i=l .
\end{aligned}
$$

O momento produzido por uma força de contato entre uma roda e o terreno com relação a um eixo será portanto

$$
\mathbf{M}_{O}^{i}=\left(\mathbf{p}_{O}^{i}-\mathbf{b}_{O}\right) \times \mathbf{F}_{O}^{i}
$$


em que $\mathbf{b}_{O}$ é um ponto qualquer do eixo a ser considerado. O Momento de Estabilidade do $j$-ésimo eixo $S M_{j}$ é dado pela soma das componentes de todos os momentos que estejam alinhadas com este mesmo eixo, de forma que

$$
S M_{j}=\left[\sum_{i=1}^{l} \mathbf{M}_{O}^{i}\right] \cdot \mathbf{r}_{O}^{j}=\left[\sum_{i=1}^{l}\left(\mathbf{p}_{O}^{i}-\mathbf{b}_{O}\right) \times \mathbf{F}_{O}^{i}\right] \cdot \mathbf{r}_{O}^{j} .
$$

Observa-se que os vetores da equação são definidos a partir do referencial inercial $O$. Para computar o Momento de Estabilidade a partir de um referencial arbitrário relacionado a uma matriz de rotação $\mathbf{R}_{b}^{O}$, basta pré-multiplicar os dois lados da equação por esta matriz. Definindo-se $\mathbf{p}_{b}^{i} \equiv \mathbf{R}_{b}^{O}\left(\mathbf{p}_{O}^{i}-\mathbf{b}_{O}\right)$, $\mathbf{F}_{b}^{i} \equiv \mathbf{R}_{b}^{O} \mathbf{F}_{O}^{i}$, e $\mathbf{r}_{b}^{j} \equiv \mathbf{R}_{b}^{O} \mathbf{r}_{O}^{j}$, tem-se

$$
S M_{j}=\left[\sum_{i=1}^{l} \mathbf{p}_{b}^{i} \times \mathbf{F}_{b}^{i}\right] \cdot \mathbf{r}_{b}^{j} .
$$

Observa-se que os Momentos de Estabilidade $S M$ são portanto uma medida da influência desestabilizadora exercida pelas forças de contato e seus momentos em torno de um determinado eixo.

Os valores de $S M$ podem ser computados de forma direta (conforme apresentado) ou de forma indireta, com a utilização de sensores inerciais, de acordo com o detalhamento a seguir.

\section{Cálculo Indireto do Momento de Estabilidade}

Para o cálculo indireto dos $S M$, deve-se partir do princípio de conservação da quantidade de movimento angular do veículo com relação ao ponto $O$. Dessa forma, pode-se afirmar que

$$
\mathbf{M}_{O}=\dot{\mathbf{H}}_{O}
$$

onde $\mathbf{M}_{O}$ e $\dot{\mathbf{H}}_{O}$ são respectivamente o somatório dos momentos das forças atuantes no veículo e a taxa de variação do quantidade de movimento angular do veículo, ambos com relação ao ponto $O$. Portanto,

$$
\mathbf{M}_{O}=\sum_{i=1}^{l} \mathbf{p}_{O}^{i} \times \mathbf{F}_{O}^{i}+\sum_{i=1}^{l+1} \mathbf{c}_{O}^{i} \times m_{i} \mathbf{g}_{O}+\sum_{i=1}^{k} \mathbf{q}_{O}^{i} \times \mathbf{B}_{O}^{i}
$$

e ainda,

$$
\mathbf{H}_{O}=\sum_{i=1}^{l+1}\left(\mathbf{R}_{O}^{i} \mathbf{I}_{i} \boldsymbol{\omega}_{i}+\mathbf{c}_{O}^{i} \times m_{i} \dot{\mathbf{c}}_{O}^{i}\right) .
$$

Sendo a matriz de rotação $\mathbf{R}_{O}^{i}$ composta basicamente por vetores unitários girantes, tem-se que a sua derivada temporal é calculada facilmente por $\dot{\mathbf{R}}_{O}^{i}=\boldsymbol{\omega}_{O}^{i} \times \mathbf{R}_{O}^{i}$. A derivada temporal do momento angular é portanto dada por 


$$
\dot{\mathbf{H}}_{O}=\sum_{i=1}^{l+1}\left(\boldsymbol{\omega}_{O}^{i} \times \mathbf{R}_{O}^{i} \mathbf{I}_{i} \boldsymbol{\omega}_{i}+\mathbf{R}_{O}^{i} \mathbf{I}_{i} \dot{\boldsymbol{\omega}}_{i}+\mathbf{c}_{O}^{i} \times m_{i} \ddot{\mathbf{c}}_{O}^{i}\right) .
$$

Seja a quantidade $\tilde{\mathbf{M}}_{b}$ definida por

$$
\tilde{\mathbf{M}}_{b} \equiv \sum_{i=1}^{l} \mathbf{b}_{O} \times \mathbf{F}_{O}^{i}+\sum_{i=1}^{l+1} \mathbf{b}_{O} \times m_{i} \mathbf{g}_{O}+\sum_{i=1}^{k} \mathbf{b}_{O} \times \mathbf{B}_{O}^{i}
$$

e associada ao ponto $\mathbf{b}_{O}$. A diferença $\mathbf{M}_{O}-\tilde{\mathbf{M}}_{b}$ será dada por

$$
\mathbf{M}_{O}-\tilde{\mathbf{M}}_{b}=\sum_{i=1}^{l}\left(\mathbf{p}_{O}^{i}-\mathbf{b}_{O}\right) \times \mathbf{F}_{O}^{i}+\sum_{i=1}^{l+1}\left(\mathbf{c}_{O}^{i}-\mathbf{b}_{O}\right) \times m_{i} \mathbf{g}_{O}+\sum_{i=1}^{k}\left(\mathbf{q}_{O}^{i}-\mathbf{b}_{O}\right) \times \mathbf{B}_{O}^{i}
$$

que representa a soma dos momentos com relação a $\mathbf{b}_{O}$.

Para expressar estas grandezas em um referencial fixado em $\mathbf{b}_{O}$, aplicamse as seguintes rotações: $\mathbf{p}_{b}^{i} \equiv \mathbf{R}_{b}^{O}\left(\mathbf{p}_{O}^{i}-\mathbf{b}_{O}\right), \mathbf{c}_{b}^{i} \equiv \mathbf{R}_{b}^{O}\left(\mathbf{c}_{O}^{i}-\mathbf{b}_{O}\right), \mathbf{q}_{b}^{i} \equiv$ $\mathbf{R}_{b}^{O}\left(\mathbf{q}_{O}^{i}-\mathbf{b}_{O}\right), \mathbf{F}_{b}^{i} \equiv \mathbf{R}_{b}^{O} \mathbf{F}_{O}^{i}$ e $\mathbf{B}_{b}^{i} \equiv \mathbf{R}_{b}^{O} \mathbf{B}_{O}^{i}$. Pode-se portanto escrever

$$
\mathbf{R}_{O}^{b}\left(\mathbf{M}_{O}-\tilde{\mathbf{M}}_{b}\right)=\sum_{i=1}^{l} \mathbf{p}_{b}^{i} \times \mathbf{F}_{b}^{i}+\sum_{i=1}^{l+1} \mathbf{c}_{b}^{i} \times m_{i} \mathbf{R}_{b}^{O} \mathbf{g}_{O}+\sum_{i=1}^{k} \mathbf{q}_{b}^{i} \times \mathbf{B}_{b}^{i}
$$

Colocando-se $\mathbf{b}_{O}$ em evidência na equação 3 -11, pode-se reescrever $\tilde{\mathbf{M}}_{b}$ como

$$
\tilde{\mathbf{M}}_{b}=\mathbf{b}_{O} \times\left[\sum_{i=1}^{l} \mathbf{F}_{O}^{i}+\sum_{i=1}^{l+1} m_{i} \mathbf{g}_{O}+\sum_{i=1}^{k} \mathbf{B}_{O}^{i}\right],
$$

e pela segunda lei de Newton

$$
\left[\sum_{i=1}^{l} \mathbf{F}_{O}^{i}+\sum_{i=1}^{l+1} m_{i} \mathbf{g}_{O}+\sum_{i=1}^{k} \mathbf{B}_{O}^{i}\right]=\sum_{i=1}^{l+1} m_{i} \ddot{\mathbf{c}}_{O}^{i}
$$

sendo o termo $\mathbf{R}_{O}^{b}\left(\dot{\mathbf{H}}_{O}-\tilde{\mathbf{M}}_{b}\right)$ expressado por

$$
\mathbf{R}_{O}^{b}\left(\dot{\mathbf{H}}_{O}-\tilde{\mathbf{M}}_{b}\right)=\sum_{i=1}^{l+1} \mathbf{R}_{b}^{i}\left(\boldsymbol{\omega}_{i} \times \mathbf{I}_{i} \boldsymbol{\omega}_{i}+\mathbf{I}_{i} \dot{\boldsymbol{\omega}}_{i}\right)+\sum_{i=1}^{l+1} \mathbf{c}_{b}^{i} \times m_{i} \mathbf{R}_{b}^{O} \ddot{\mathbf{c}}_{O}^{i}
$$

Utilizando-se a equação 3-7, pode-se concluir que $\mathbf{R}_{O}^{b}\left(\mathbf{M}_{O}-\tilde{\mathbf{M}}_{b}\right)=$ $\mathbf{R}_{O}^{b}\left(\dot{\mathbf{H}}_{O}-\tilde{\mathbf{M}}_{b}\right)$. Portanto, com as equações 3-13 e 3-16 conclui-se que

$\sum_{i=1}^{l} \mathbf{p}_{b}^{i} \times \mathbf{F}_{b}^{i}+\sum_{i=1}^{l+1} \mathbf{c}_{b}^{i} \times m_{i} \mathbf{R}_{b}^{O} \mathbf{g}_{O}+\sum_{i=1}^{k} \mathbf{q}_{b}^{i} \times \mathbf{B}_{b}^{i}=\sum_{i=1}^{l+1} \mathbf{R}_{b}^{i}\left(\boldsymbol{\omega}_{i} \times \mathbf{I}_{i} \boldsymbol{\omega}_{i}+\mathbf{I}_{i} \dot{\boldsymbol{\omega}}_{i}\right)+\sum_{i=1}^{l+1} \mathbf{c}_{b}^{i} \times m_{i} \mathbf{R}_{b}^{O} \ddot{\mathbf{c}}_{O}^{i}$

de onde se pode finalmente definir uma expressão para o somatório dos momentos causados por forças de contato, dada por 


$$
\sum_{i=1}^{l} \mathbf{p}_{b}^{i} \times \mathbf{F}_{b}^{i}=\sum_{i=1}^{l+1} \mathbf{R}_{b}^{i}\left(\boldsymbol{\omega}_{i} \times \mathbf{I}_{i} \boldsymbol{\omega}_{i}+\mathbf{I}_{i} \dot{\boldsymbol{\omega}}_{i}\right)+\sum_{i=1}^{l+1} \mathbf{c}_{b}^{i} \times m_{i} \mathbf{R}_{b}^{O}\left(\ddot{\mathbf{c}}_{O}^{i}-\mathbf{g}_{O}\right)-\sum_{i=1}^{k} \mathbf{q}_{b}^{i} \times \mathbf{B}_{b}^{i}
$$

Observa-se, neste ponto, que a aceleração dada por $\mathbf{R}_{b}^{O}\left(\ddot{\mathbf{c}}_{O}^{i}-\mathbf{g}_{O}\right)$ pode ser obtida a partir do sinal de saída de um acelerômetro localizado no centro de gravidade do $i$-ésimo corpo do sistema. Definindo-se esta grandeza por $\mathbf{a}_{b}^{i}$ e tomando-se o produto escalar dos termos da equação 3-18 por um vetor unitário contido no $j$-ésimo eixo $\mathbf{r}_{b}^{j}$, tem-se

$$
\left[\sum_{i=1}^{l} \mathbf{p}_{b}^{i} \times \mathbf{F}_{b}^{i}\right] \cdot \mathbf{r}_{b}^{j}=\left[\sum_{i=1}^{l+1} \mathbf{R}_{b}^{i}\left(\boldsymbol{\omega}_{i} \times \mathbf{I}_{i} \boldsymbol{\omega}_{i}+\mathbf{I}_{i} \dot{\boldsymbol{\omega}}_{i}\right)+\sum_{i=1}^{l+1} \mathbf{c}_{b}^{i} \times m_{i} \mathbf{a}_{b}^{i}-\sum_{i=1}^{k} \mathbf{q}_{b}^{i} \times \mathbf{B}_{b}^{i}\right] \cdot \mathbf{r}_{b}^{j} .
$$

Percebe-se portanto que as equações 3-19 e 3-6 são equivalentes. Desta maneira, pode-se concluir ainda que o lado direito da equação 3-19 representa uma maneira indireta de se calcular os Momentos de Estabilidade $S M$, a partir de informações de sensores inerciais (dados por $\boldsymbol{\omega}_{i}, \dot{\boldsymbol{\omega}}_{i}$ e $\mathbf{a}_{b}^{i}$ ) e de forças de perturbação externas, como por exemplo o arrasto aerodinâmico. Estas forças de perturbação são dadas por $\mathbf{B}_{b}^{i}$, e são em geral desprezadas nas simulações realizadas neste trabalho.

Os $S M$ por si próprios já tornariam possível uma análise simplificada do nível de estabilidade do sistema multicorpos, pois permitiriam a constatação da existência de um momento de forças total que pudesse causar o giro sobre um eixo específico, determinado por dois pontos de contato entre o solo e o veículo. No entanto, um veículo tem uma maior tendência a rolar sobre eixos laterais, i.e., àqueles determinados por dois pontos de contato consecutivos dados pelas rodas localizadas em um mesmo lado. Isto permite a definição de uma outra métrica de estabilidade, mais simplificada e adequada ao sistema de inferência fuzzy, conforme apresentado a seguir.

\section{Métrica de Estabilidade $R_{S M}$}

Sejam os Momentos de Estabilidade $S M_{j}$ definidos para cada um dos eixos determinados entre os pontos de contato entre solo e rodas consecutivas, conforme numeradas na Figura 3.6.

Com estes valores, pode-se definir uma métrica adimensional de estabilidade $R_{S M}$, levando-se em consideração algum dos Momentos de Estabilidade dos eixos da esquerda $\left(S M_{1}\right.$ ou $\left.S M_{2}\right)$ e algum dos Momentos de Estabilidade dos eixos da direita $\left(S M_{4}\right.$ ou $\left.S M_{5}\right)$. Sendo esta Métrica de Estabilidade dada por 


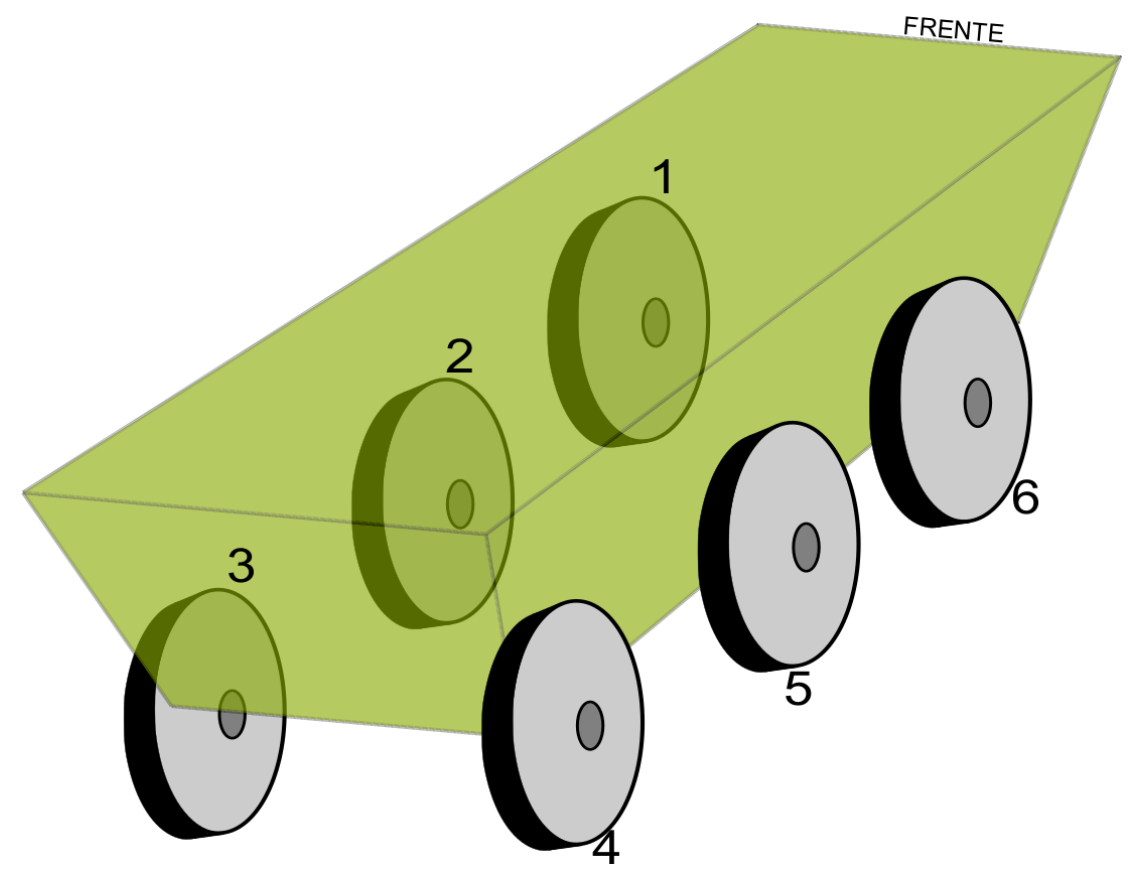

Figura 3.6: Esquemático do modelo de veículo com seis rodas numeradas de forma sequencial. Os eixos de giro são determinados pelos pontos de contato de duas rodas consecutivas com o solo.

$$
R_{S M}=\frac{S M_{\text {esquerda }}-S M_{\text {direita }}}{S M_{\text {esquerda }}+S M_{\text {direita }}}
$$

torna-se fácil perceber que, enquanto todas as rodas do veículo mantém contato com o solo, os valores de $S M$ são necessariamente positivos e

$$
-1<R_{S M}<1
$$

Caso o valor de $R_{S M}$ se aproxime de 1 , o momento de estabilidade indicado por $S M_{\text {esquerda }}$ tem um valor muito maior do que àquele indicado por $S M_{\text {direita. }}$. Portanto, conclui-se que o veículo tende a rolar sobre o eixo da esquerda, estando sob forte influência desestabilizadora. De maneira semelhante, se $R_{S M}$ se aproximar de -1 , a tendência é rolar sobre o eixo da direita. Concluise portanto que, para que se tenha uma situação de maior estabilidade, o valor mais adequado de $R_{S M}$ será o mais próximo de 0 possível.

Desta forma, o valor dado por

$$
0 \leq\left|R_{S M}\right|<1
$$

é escolhido como sendo a variável de entrada adequada para o ponderador fuzzy. O universo de discurso representativo de $\left|R_{S M}\right|$ é então dividido em quatro conjuntos fuzzy, denominados: Métrica de Estabilidade Pequena $(\mathrm{P})$, Média (M), Grande (G) e Muito Grande (MG). Estes conjuntos são definidos 
de acordo com o que se apresenta a seguir.

\section{Métrica de Estabilidade Pequena - P}

É o conjunto fuzzy que tem valores para o grau de pertinência diferente de zero $(\mu \neq 0)$ para $0 \leq\left|R_{S M}\right|<0,075$. Seu valor máximo $(\mu=1)$ ocorre para $\left|R_{S M}\right|=0$ e decresce proporcionalmente até chegar em $\mu=0$ para $\left|R_{S M}\right|=0,075$.

\section{Métrica de Estabilidade Média - M}

Para este conjunto fuzzy, os graus de pertinência são diferentes de zero $(\mu \neq 0)$ no intervalo $0<\left|R_{S M}\right|<0,3$. A função de pertinência tem um formato "triangular", sendo $\mu=0$ para $\left|R_{S M}\right|=0$ e $\left|R_{S M}\right|=0,3$ e o valor máximo $(\mu=1)$ para $\left|R_{S M}\right|=0,1$.

\section{Métrica de Estabilidade Grande - G}

Os graus de pertinência para este conjunto fuzzy são diferentes de zero $(\mu \neq 0)$ no intervalo $0,075<\left|R_{S M}\right|<0,9$. A função de pertinência tem tembém um formato "triangular", sendo $\mu=0$ para $\left|R_{S M}\right|=0,075 \mathrm{e}$ $\left|R_{S M}\right|=0,9$ e o valor máximo $(\mu=1)$ para $\left|R_{S M}\right|=0,3$.

\section{Métrica de Estabilidade Muito Grande - MG}

O último conjunto fuzzy deste universo de discurso tem graus de pertinência diferentes de zero $(\mu \neq 0)$ para $\left|R_{S M}\right|>0,3$. A função de pertinência é caracterizada por $\mu=0$ para $\left|R_{S M}\right|=0,3$ e cresce proporcionalmente até que se atinja o valor máximo $(\mu=1)$ para $\left|R_{S M}\right|=0,9$. Qualquer valor de $\left|R_{S M}\right| \geq 0,9$ tem função de pertinência $\mu=1$.

Pode-se, portanto, representar graficamente o universo de discurso de $\left|R_{S M}\right|$ e seus conjuntos fuzzy pela Figura 3.7.

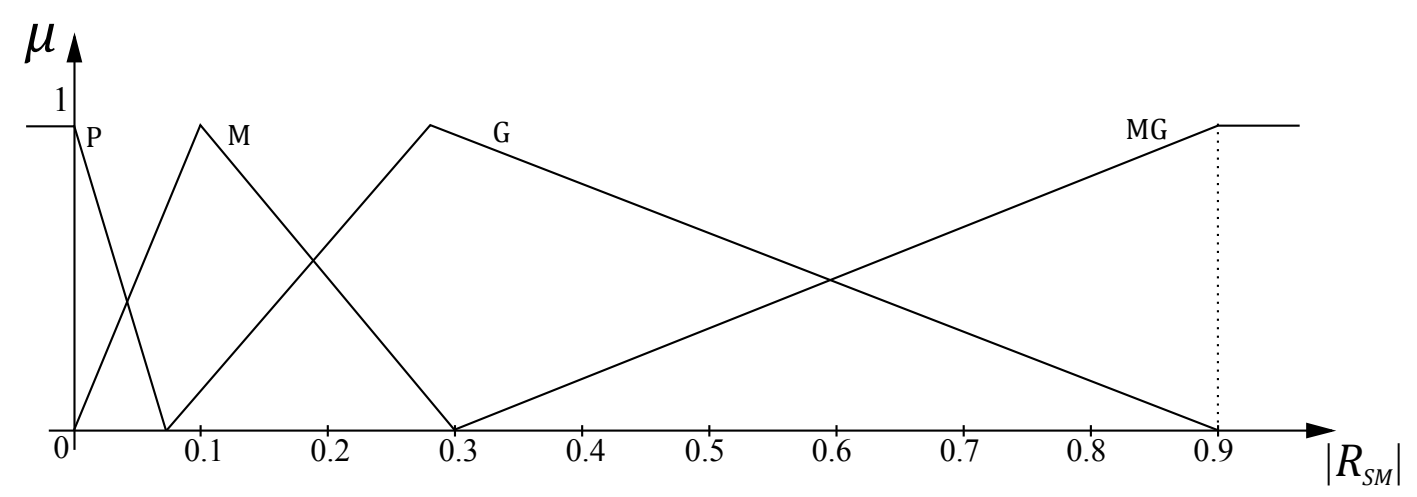

Figura 3.7: Universo de discurso de $\left|R_{S M}\right|$ e seus conjuntos fuzzy. 


\subsection{3}

\section{Ameaças Externas}

Ainda em conformidade com o esquema apresentado na Figura 2.3, é necessário definir variáveis de entrada para o ponderador fuzzy, e estas variáveis devem ser capazes de estabelecer um nível de ameaças externas a que a viatura está sujeita. Para a definição dessas variáveis, limita-se o escopo deste trabalho à ocorrência de dois tipos de ameaças militares apenas: a existência de explosivos improvisados (ou IED) empregados no terreno de operação da viatura e a presença de atiradores inimigos equipados com armamentos anticarro de mira ou pontaria LASER.

Considera-se, adicionalmente, que o veículo conta com a presença de sensores militares ideais capazes de detectar e identificar estes tipos de ameaça externa, além de disponibilizar para o sistema proposto informações importantes para uma estimativa do nível de perigo associado ao seu movimento, como a distância até um elemento que represente uma ameaça qualquer e a velocidade de encontro a este elemento. Sensores com estas características existem, porém representam tecnologias militares de alta complexidade e custo, o que também inviabilizaria sua utilização em experimentos práticos com o sistema proposto neste trabalho.

No caso de detecção e identificação de um IED localizado no terreno de operação do veículo, é importante que se consiga calcular ou medir a distância entre dois pontos, determinados pelo centro de gravidade da própria viatura e o ponto de aplicação do explosivo. Tão importante quanto a distância seria a sua primeira derivada temporal, a partir da qual pode-se determinar a velocidade de encontro entre os dois elementos. Tomando-se como referência os parâmetros ilustrados na Figura 3.8, tem-se

$$
D_{e, i}(t)=\sqrt{\left[x(t)-x_{e, i}\right]^{2}+\left[y(t)-y_{e, i}\right]^{2}}
$$

e além disso,

$$
V_{e, i}(t)=\dot{D}_{e, i}(t)=\frac{\left[x(t)-x_{e, i}\right] \dot{x}(t)+\left[y(t)-y_{e, i}\right] \dot{y}(t)}{\sqrt{\left[x(t)-x_{e, i}\right]^{2}+\left[y(t)-y_{e, i}\right]^{2}}}
$$

De forma ligeiramente diferente, caso haja a detecção e identificação de um atirador inimigo capaz de representar alguma ameaça ao veículo, devese calcular ou medir a distância entre os dois pontos ou ainda entre o ponto determinado pelo centro de gravidade e a reta definida pela linha de tiro do inimigo, a partir do seu ponto de localização. Neste caso, deve-se considerar a distância entre dois pontos quando o atirador não está voltado diretamente para o veículo ou a distância entre ponto e reta se o atirador estiver voltado para o veículo. Estas condições podem ser descritas da seguinte maneira, 


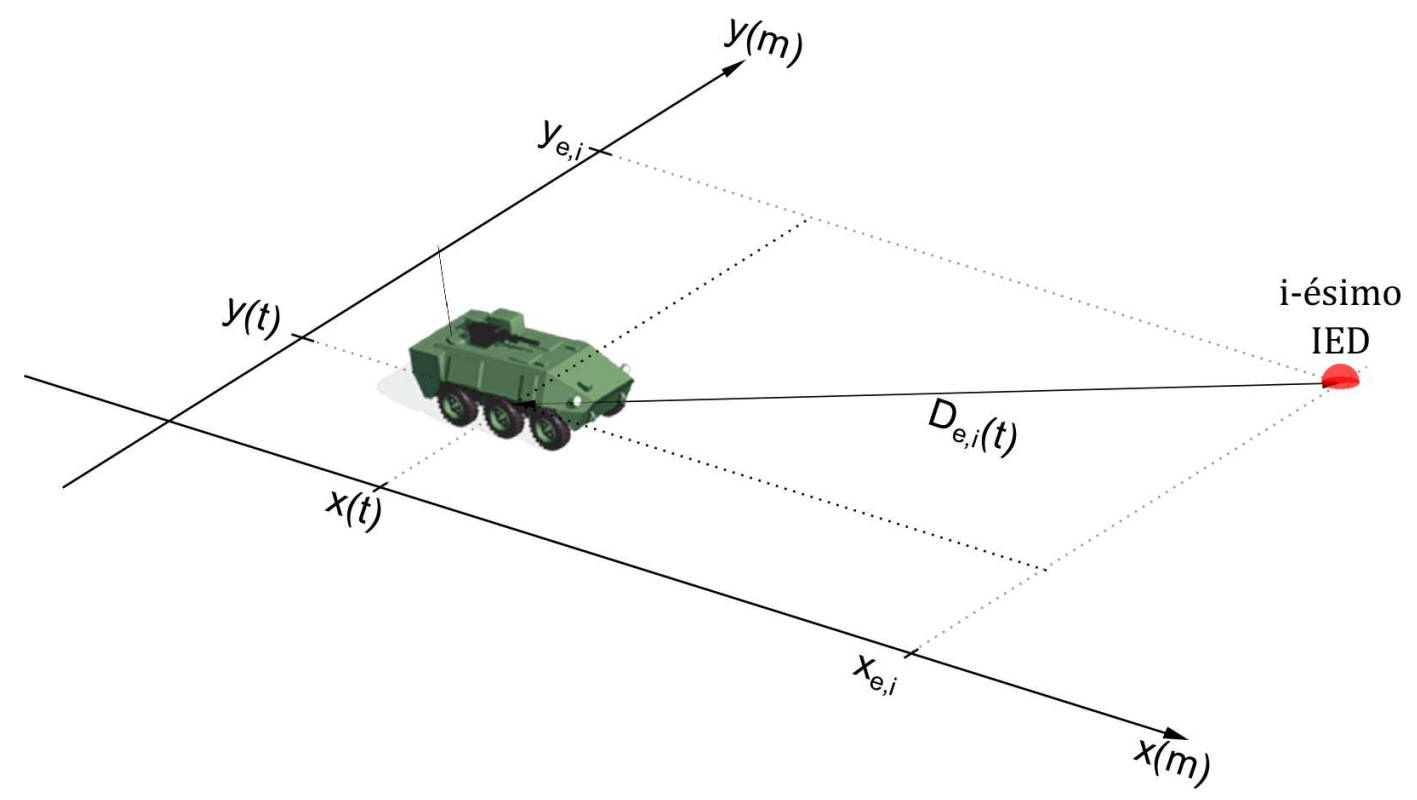

Figura 3.8: Veículo a uma distância de $D_{e, i}$ até o $i$-ésimo explosivo improvisado.

$$
\left\{\begin{aligned}
\cos \theta\left[x(t)-x_{a, i}\right] & +\sin \theta\left[y(t)-y_{a, i}\right] \leq 0 \Longrightarrow \\
D_{a, i}(t) & =\sqrt{\left[x(t)-x_{a, i}\right]^{2}+\left[y(t)-y_{a, i}\right]^{2}}, \text { ou aind } a \\
\cos \theta\left[x(t)-x_{a, i}\right] & +\sin \theta\left[y(t)-y_{a, i}\right]>0 \Longrightarrow \\
D_{a, i}(t) & =\sin \theta\left[x(t)-x_{a, i}\right]-\cos \theta\left[y(t)-y_{a, i}\right]
\end{aligned}\right.
$$

onde a Figura 3.9 ilustra os parâmetros, especialmente o vetor unitário $(\cos \theta, \sin \theta)^{T}$ que representa o azimute de tiro.

A primeira derivada temporal da distância, i.e., $V_{a, i}=\dot{D}_{a, i}$ indica a velocidade de encontro entre o veículo e o atirador (ou a reta determinada pela sua linha de tiro). Tanto as distâncias $D_{e, i}$ e $D_{a, i}$ quanto as velocidades $V_{e, i}$ e $V_{a, i}$ são utilizadas como variáveis de entrada para o Ponderador Fuzzy. A partir destas variáveis determina-se o nível de ameaça contra a viatura, conforme será apresentado posteriormente na Seção 3.5.

O universo de discurso representativo das variáveis de distância (ou alternativamente, proximidade) é dividido em quatro conjuntos fuzzy, denominados por: Veículo Muito Próximo (MP), Próximo (P), Distância Intermediária (I), Distante (D). Os conjuntos são descritos a seguir, onde $D_{x, i}$ pode representar uma distância a um explosivo ou a um atirador.

\section{Veículo Muito Próximo (a uma ameaça) - MP}

Este conjunto fuzzy tem valores de grau de pertinência diferentes de zero $(\mu \neq 0)$ para $0 m \leq D_{x, i}<5 m$. Seu valor máximo $(\mu=1)$ ocorre para 


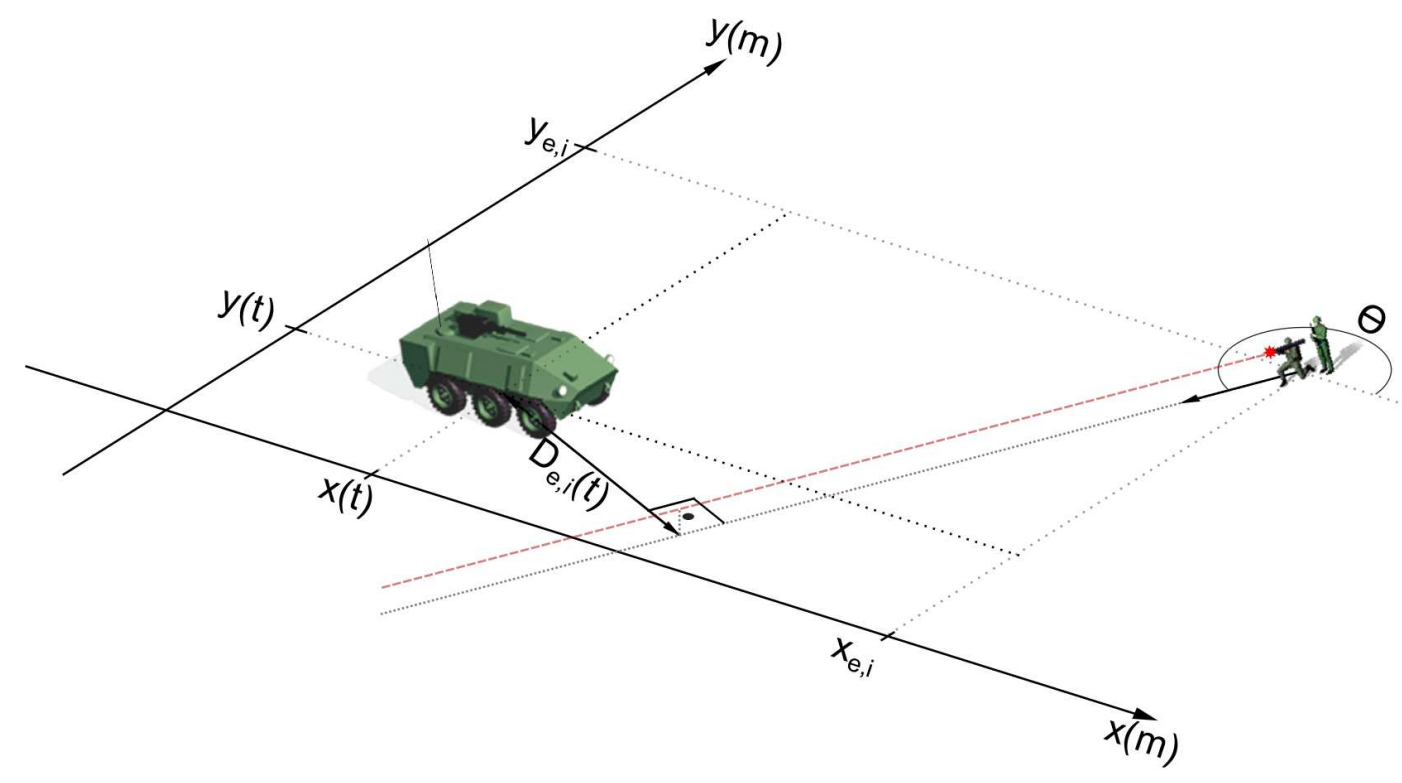

Figura 3.9: Veículo a uma distância de $D_{a, i}$ até a linha de tiro do $i$-ésimo atirador.

$D_{x, i}=0 \mathrm{~m}$ e decresce proporcionalmente até chegar em $\mu=0$ para $D_{x, i}=5 \mathrm{~m}$.

\section{Veículo Próximo (a uma ameaça) - P}

É o conjunto fuzzy em que os graus de pertinência são diferentes de zero $(\mu \neq 0)$ no intervalo $0 m<D_{x, i}<15 \mathrm{~m}$. A função de pertinência tem um formato "triangular", sendo $\mu=0$ para $D_{x, i}=0 \mathrm{~m}$ e $D_{x, i}=15 \mathrm{~m}$ e o valor máximo $\mu=1$ para $D_{x, i}=5 \mathrm{~m}$.

\section{Veículo a Distância Intermediária (de uma ameaça) - I}

Neste conjunto fuzzy, os graus de pertinência são diferentes de zero $(\mu \neq 0)$ no intervalo $5 m<D_{x, i}<45 m$. A função de pertinência tem também um formato "triangular", sendo $\mu=0$ para $D_{x, i}=5 \mathrm{~m}$ e $D_{x, i}=45 \mathrm{~m}$ e o valor máximo $\mu=1$ para $D_{x, i}=15 \mathrm{~m}$.

\section{Veículo Distante (de uma ameaça) - D}

Para este quarto e último conjunto fuzzy do universo de discurso, os graus de pertinência são diferentes de zero $(\mu \neq 0)$ para $D_{x, i}>15 \mathrm{~m}$. A função de pertinência é caracterizada por $\mu=0$ para $D_{x, i}=15 \mathrm{~m}$ e cresce proporcionalmente até que se atinja o valor máximo $(\mu=1)$ para $D_{x, i}=45 \mathrm{~m}$. Qualquer valor de $D_{x, i} \geq 45 m$ tem função de pertinência $\mu=1$.

Representa-se o universo de discurso da variável $D_{x, i}$ pela forma gráfica ilustrada na Figura 3.10. 


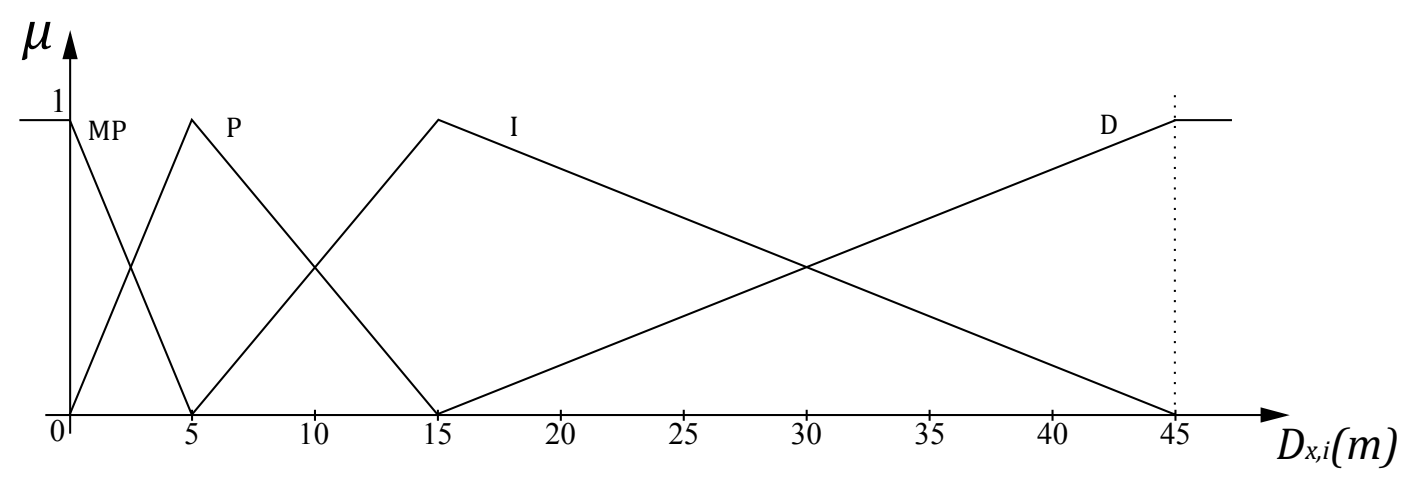

Figura 3.10: Universo de discurso das distâncias $D_{x, i}$ e seus conjuntos fuzzy.

O universo de discurso representativo das variáveis de velocidade, por sua vez, é dividido em cinco conjuntos fuzzy, sendo estes denominados: Velocidade do veículo Negativa Alta (NA), Negativa Baixa (NB), Zerada (ZE), Positiva Baixa (PB) e Positiva Alta (PA). Estes conjuntos são descritos abaixo, onde $V_{x, i}$ pode representar a velocidade do veículo com relação a um explosivo ou a um atirador.

\section{Velocidade do veículo (com relação a uma ameaça) Negativa Alta - NA}

O primeiro conjunto fuzzy deste universo de discurso tem valores de grau de pertinência diferentes de zero $(\mu \neq 0)$ para o intervalo $-25 m / s \leq V_{x, i}<$ $-10 \mathrm{~m} / \mathrm{s}$. O maior grau de pertinência $(\mu=1)$ ocorre para $V_{x, i}=-25 \mathrm{~m} / \mathrm{s}$ e decresce proporcionalmente até chegar em $\mu=0$ para $V_{x, i}=-10 \mathrm{~m} / \mathrm{s}$. Nestas velocidades, o veículo estaria se aproximando da ameaça rapidamente.

\section{Velocidade do veículo (com relação a uma ameaça) Negativa Baixa - NB}

Este conjunto fuzzy tem graus de pertinência diferentes de zero $(\mu \neq 0)$ para $-15 \mathrm{~m} / \mathrm{s}<V_{x, i}<0 \mathrm{~m} / \mathrm{s}$. É um conjunto de formato "triangular", em que $\mu=0$ para $V_{x, i}=-15 \mathrm{~m} / \mathrm{s}$ e $V_{x, i}=0 \mathrm{~m} / \mathrm{s}$, e o maior grau de pertinência $(\mu=1)$ ocorre para $V_{x, i}=-10 \mathrm{~m} / \mathrm{s}$. Nas velocidades deste conjunto, o veículo estaria se aproximando da ameaça lentamente.

\section{Velocidade do veículo (com relação a uma ameaça) Zerada - ZE}

O conjunto fuzzy central deste universo de discurso tem graus de pertinência diferentes de zero $(\mu \neq 0)$ para $-5 \mathrm{~m} / \mathrm{s}<V_{x, i}<5 \mathrm{~m} / \mathrm{s}$. É também um conjunto de formato "triangular", em que $\mu=0$ para $V_{x, i}=-5 \mathrm{~m} / \mathrm{s}$ e $V_{x, i}=5 \mathrm{~m} / \mathrm{s}$, e onde o grau de pertinência máximo $(\mu=1)$ ocorre para $V_{x, i}=0 \mathrm{~m} / \mathrm{s}$. Nestas velocidades, o veículo estaria se aproximando ou se afastando da ameaça de forma extremamente lenta, estando quase parado. 


\section{Velocidade do veículo (com relação a uma ameaça) Positiva Baixa - PB}

Os graus de pertinência deste conjunto fuzzy são diferentes de zero $(\mu \neq 0)$ para $0 m / s<V_{x, i}<15 m / s$. Simétrico ao conjunto NB, tem também formato "triangular", em que $\mu=0$ para $V_{x, i}=0 \mathrm{~m} / \mathrm{s}$ e $V_{x, i}=15 \mathrm{~m} / \mathrm{s}$, e onde o grau de pertinência máximo $(\mu=1)$ ocorre para $V_{x, i}=10 \mathrm{~m} / \mathrm{s}$. Nas velocidades deste conjunto, o veículo estaria se afastando da ameaça lentamente.

\section{Velocidade do veículo (com relação a uma ameaça) Positiva Alta - PA}

O último conjunto fuzzy deste universo de discurso é simétrico ao conjunto NA, e tem valores de grau de pertinência diferentes de zero $(\mu \neq 0)$ para o intervalo $10 \mathrm{~m} / \mathrm{s}<V_{x, i} \leq 25 \mathrm{~m} / \mathrm{s}$. O menor grau de pertinência $(\mu=0)$ ocorre para $V_{x, i}=10 \mathrm{~m} / \mathrm{s}$ e cresce proporcionalmente até chegar em $\mu=1$ para $V_{x, i}=25 \mathrm{~m} / \mathrm{s}$. Nestas velocidades, o veículo estaria se afastando da ameaça de forma rápida.

Finalmente pode-se representar graficamente o universo de discurso da variável $V_{x, i}$ pela Figura 3.11.

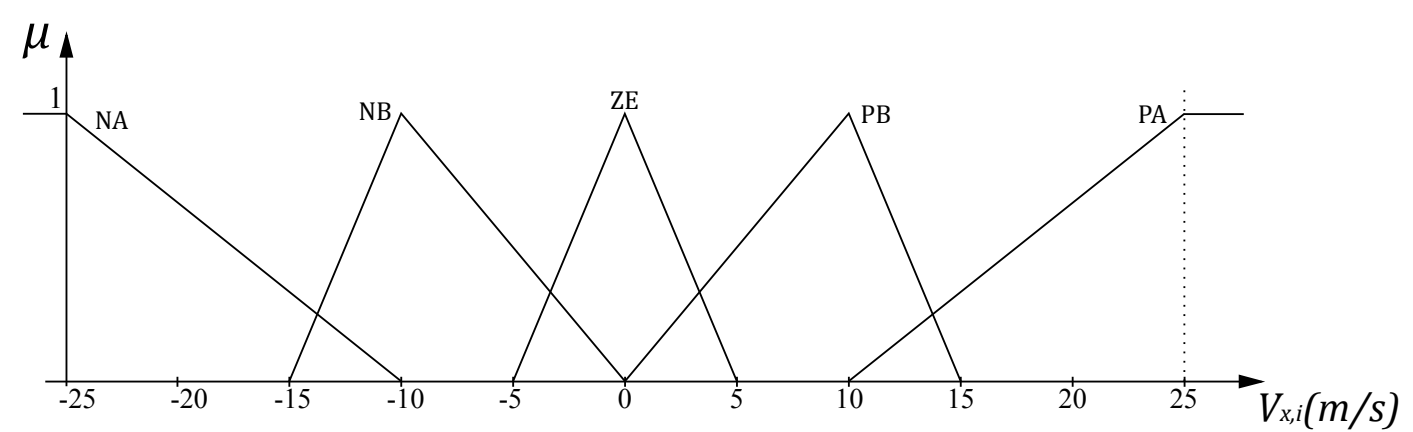

Figura 3.11: Universo de discurso das velocidades $V_{x, i}$ e seus conjuntos fuzzy.

\section{4}

\section{Arquitetura Proposta}

A partir das variáveis de entrada que foram discutidas na Seção 3.3, desenvolve-se a arquitetura sistêmica para o Ponderador Fuzzy. O ponderador é composto por quatro tipos de SIF diferentes, devendo-se aumentar esta quantidade de acordo com o número de elementos que representem algum tipo de ameaça ao veículo em seu Teatro de Operações (TO).

A arquitetura básica proposta para o sistema é ilustrada na Figura 3.12. Nesta ilustração, pode-se observar os quatro SIF básicos, denominados SIF1, SIF2, SIF3 e SIF4. Observa-se também algumas variáveis intermediárias definidas durante o desenvolvimento do ponderador. 


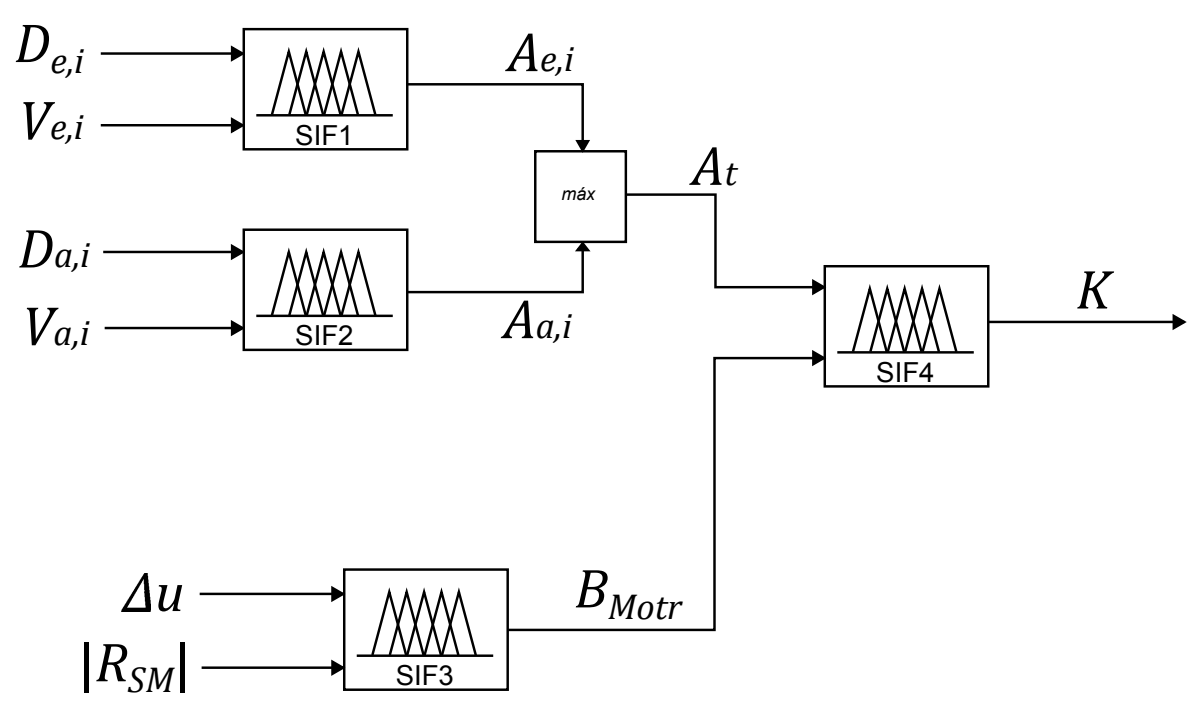

Figura 3.12: Arquitetura proposta para o Ponderador Fuzzy.

As regras fuzzy que definem o funcionamento destes SIF são detalhadas na seção 3.5. As variáveis intermediárias são importantes em SIFs mais complexos, pois permitem sua divisão em diversos sistemas mais simples e tornam o estabelecimento de regras fuzzy menos complicado ao possibilitar a redução do número de antecedentes. Neste caso, mais especificamente, as variáveis intermediárias representam parâmetros subjetivos, sendo estes:

- $A_{e, i}$ - Nível de ameaça externa imposta ao veículo pelo $i$-ésimo explosivo IED;

- $A_{a, i}$ - Nível de ameaça externa imposta ao veículo pelo $i$-ésimo atirador inimigo;

- $A_{t}$ - Nível de ameaça externa total imposta ao veículo; e,

- $B_{\text {Motr }}$ - Nível do Comportamento (ou Desempenho) do Motorista.

Além das variáveis intermediárias, a Figura 3.12 mostra a variável de saída do ponderador definida por $K$. Esta é, portanto, a variável que determina o nível de intervenção do controlador digital sobre o sistema dinâmico representado pela viatura.

Estas variáveis intermediárias e de saída são descritas em seguida. 


\subsection{1}

Níveis de Ameaças Externas - $A_{e, i}, A_{a, i}$ ou $A_{t}$

Os Níveis de Ameaças Externas - sendo estas impostas por explosivos IED, impostas por atiradores ou totais - são representados por grandezas adimensionais cujos valores restringem-se ao intervalo [0,1]. Desta maneira definem-se universos de discurso, que são divididos em cinco conjuntos fuzzy, denominados: Não Ameaçado (NAm), Pouco Ameaçado (PAm), Ameaçado (Am), Muito Ameaçado (MAm) e Extremamente Ameaçado (EAm). As características destes conjuntos são detalhadas abaixo, onde $A_{x}$ pode representar $A_{e, i}, A_{a, i}$ ou $A_{t}$.

\section{Veículo Não Ameaçado - NAm}

Este conjunto fuzzy tem valores de grau de pertinência diferentes de zero $(\mu \neq 0)$ para o intervalo $0 \leq A_{x}<0,25$. O maior grau de pertinência $(\mu=1)$ ocorre para $A_{x}=0$ e decresce proporcionalmente até chegar em $\mu=0$ para $A_{x}=0,25$.

\section{Veículo Pouco Ameaçado - PAm}

Os graus de pertinência deste conjunto fuzzy são diferentes de zero $(\mu \neq 0)$ para $0<A_{x}<0,5$. É um conjunto de formato "triangular", em que $\mu=0$ para $A_{x}=0$ e $A_{x}=0,5$, e o maior grau de pertinência $(\mu=1)$ ocorre para $A_{x}=0,25$.

\section{Veículo Ameaçado - Am}

Este é o conjunto fuzzy central, onde os graus de pertinência são diferentes de zero $(\mu \neq 0)$ para $0,25<A_{x}<0,75$. É também um conjunto de formato "triangular", em que $\mu=0$ para $A_{x}=0,25$ e $A_{x}=0,75$, e o maior grau de pertinência $(\mu=1)$ ocorre para $A_{x}=0,5$.

\section{Veículo Muito Ameaçado - MAm}

Representando níveis mais altos de ameaças, este conjunto fuzzy tem graus de pertinência diferentes de zero $(\mu \neq 0)$ para $0,5<A_{x}<1$. É também um conjunto de formato "triangular", em que $\mu=0$ para $A_{x}=0,5$ e $A_{x}=1$, e o maior grau de pertinência $(\mu=1)$ ocorre para $A_{x}=0,75$.

\section{Veículo Extremamente Ameaçado - EAm}

O último conjunto fuzzy deste universo de discurso tem valores de grau de pertinência diferentes de zero $(\mu \neq 0)$ para o intervalo $0,75 \leq A_{x} \geq 1$. O menor 
grau de pertinência $(\mu=0)$ ocorre para $A_{x}=0,75$ e cresce proporcionalmente até chegar em $\mu=1$ para $A_{x}=1$.

Resumindo as informações acima, pode-se representar graficamente o universo de discurso da variável $A_{x}$ pela Figura 3.13.

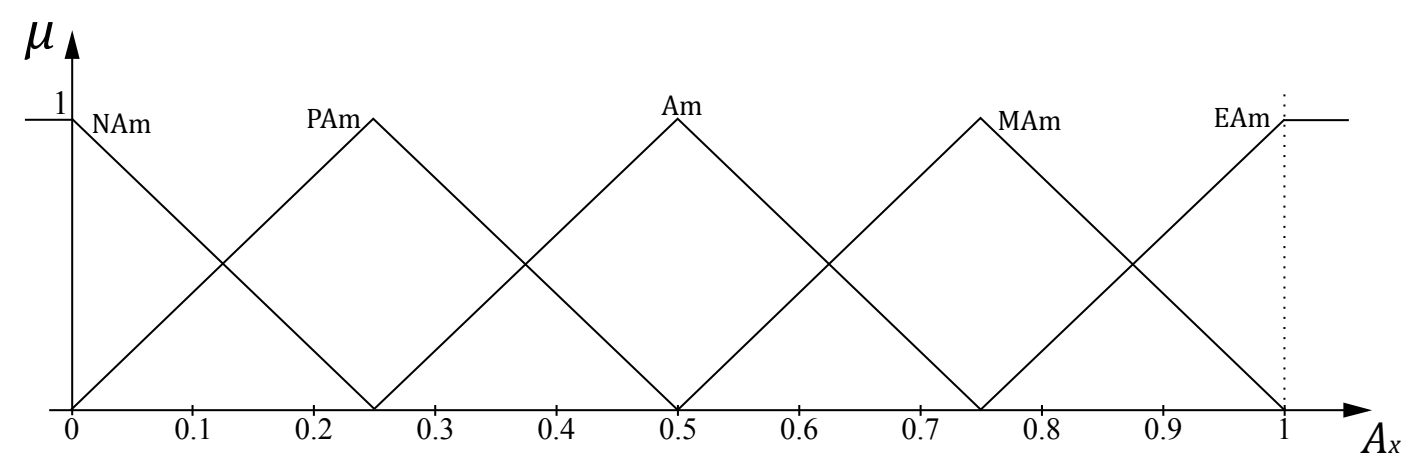

Figura 3.13: Universo de discurso da variável $A_{x}$ e seus conjuntos fuzzy.

\section{4 .2}

Comportamento do Motorista - $B_{M o t r}$

O Comportamento do Motorista, por sua vez, é também representado por uma grandeza adimensional com valores restritos ao intervalo $[0,1]$. Seu universo de discurso é também dividido em cinco conjuntos fuzzy, denominados por: Comportamento Péssimo (Pés), Ruim (R), Mediano (M), Bom (B) e Ótimo $(\mathrm{O})$. Estes conjuntos fuzzy têm características semelhantes aos conjuntos do universo de discurso das Ameaças Externas, sendo seus "formatos" idênticos e seus detalhamentos desnecessários. A Figura 3.14 ilustra este universo de discurso e é suficiente para sua descrição.

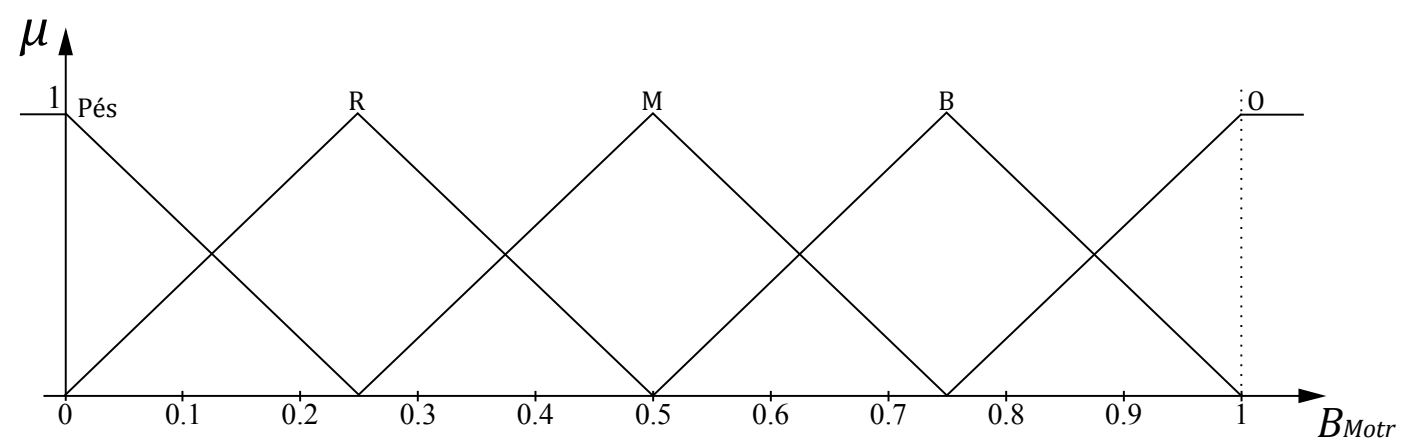

Figura 3.14: Universo de discurso do comportamento do motorista $B_{M o t r}$ e seus conjuntos fuzzy. 


\subsection{3}

\section{Variável de Intervenção - $K$}

Conforme mencionado anteriormente, a variável $K$ que representa o nível de intervenção do controlador digital também se restringe ao intervalo $[0,1]$, sendo seu universo de discurso dividido em cinco conjuntos fuzzy dados por: Intervenção Nula (Nu), Pequena (Peq), Média (Méd), Grande (Grd) e Total (Tot). Estes conjuntos também têm características semelhantes aos conjuntos das duas variáveis anteriores, tendo também os mesmos "formatos" e sendo desnecessário seu detalhamento. A Figura 3.15 ilustra este universo de discurso e contém informações suficientes para sua descrição.

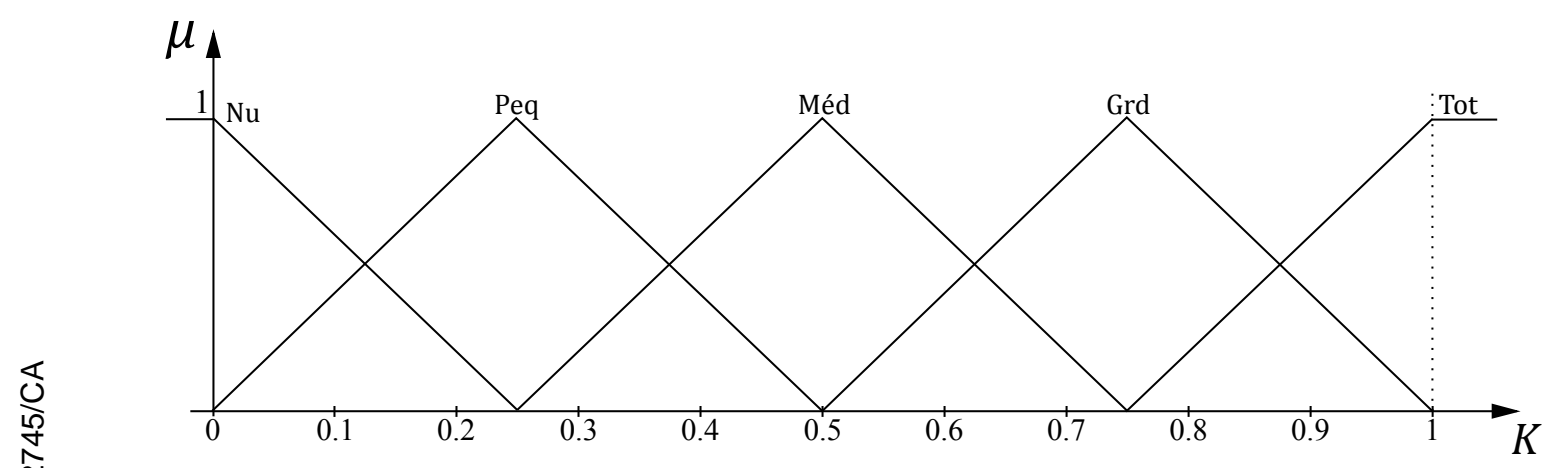

Figura 3.15: Universo de discurso do Nível de Intervenção $K$ e seus conjuntos fuzzy.

O estabelecimento das regras fuzzy e das outras características que determinam o funcionamento dos SIF apresentados na Figura 3.12 deu-se logo em seguida à definição de todas as variáveis do sistema.

\section{5}

\section{Detalhamento dos Sistemas de Inferência Fuzzy}

De acordo com a Figura 3.12, os SIF que compõem a arquitetura do ponderador fuzzy são projetados para terem duas variáveis de entrada e uma variável de saída. Estas variáveis estão descritas com maiores detalhes na seção anterior. Entretanto, para especificar o funcionamento de cada um destes sistemas, é necessário que sejam definidas outras de suas características, como seu método de defuzzificação e principalmente sua base de regras. Nestes casos, todos os SIF têm a técnica do Centro de Gravidade (Center of Gravity - CoG) como método de defuzzificação, e as bases de regras definidas pelo próprio autor. A seguir são listadas as demais especificações dos SIF utilizados. 


\subsection{1}

\section{Sistemas de Inferência Fuzzy 1 e 2}

Os sistemas fuzzy indicados por SIF1 e SIF2 têm a função de quantificar o nível de ameaça à que a viatura está exposta, seja esta representada por um explosivo IED ou um atirador.

\section{Variáveis de Entrada}

As variáveis de entrada consideradas para a determinação destes níveis de ameaça são: a Distância a uma ameaça (representada por $D_{e, i}$ ou $D_{a, i}$ ) e a Velocidade do veículo com relação a uma ameaça (representada por $V_{e, i}$ ou $\left.V_{a, i}\right)$.

\section{Variável de Saída}

A quantidade que indica o nível de ameaça é a variável de saída destes SIF, conforme pode-se observar na Figura 3.12.

\section{Base de Regras Fuzzy}

A base de regras definida para este SIF é apresentada de maneira resumida na Tabela 3.1 abaixo.

Tabela 3.1: Base de Regras Fuzzy dos Sistemas de Inferência 1 e 2.

\begin{tabular}{|c|c|c|c|c|c|}
\hline & \multicolumn{4}{|c|}{$\overline{D_{e, i}}$} \\
\hline & & MP & $\mathrm{P}$ & I & $\mathrm{D}$ \\
\hline \multirow{5}{*}{$V_{e, i}$} & $\overline{\mathrm{NA}}$ & EAm & $\overline{\mathrm{Am}}$ & MAm & $\mathrm{Am}$ \\
\hline & $\mathrm{NB}$ & EAm & MAm & $\mathrm{Am}$ & PAm \\
\hline & $\mathrm{ZE}$ & $\overline{\mathrm{EAm}}$ & & & \\
\hline & $\mathrm{PB}$ & EAm & & PAm & $\mathrm{NAm}$ \\
\hline & $\overline{\mathrm{PA}}$ & $\overline{\mathrm{EAm}}$ & & & NAm \\
\hline
\end{tabular}

\subsection{2}

\section{Sistema de Inferência Fuzzy 3}

O sistemas fuzzy indicado por SIF3 tem a função de quantificar um grau de avaliação para o desempenho ou o comportamento do motorista do veículo durante uma operação qualquer. 


\section{Variáveis de Entrada}

As variáveis de entrada deste SIF são: a diferença entre entradas do controlador digital e do operador humano $\Delta u$ e o módulo da Métrica de Estabilidade $\left|R_{S M}\right|$.

\section{Variável de Saída}

Como variável de saída, este SIF tem o comportamento do motorista $B_{\text {Motr }}$.

\section{Base de Regras Fuzzy}

A sua base de regras fuzzy é resumidamente apresentada na Tabela 3.2 abaixo.

Tabela 3.2: Base de Regras Fuzzy dos Sistemas de Inferência 3.

\begin{tabular}{|c|c|c|c|c|c|}
\cline { 3 - 6 } \multicolumn{2}{c|}{} & \multicolumn{5}{|c|}{$\Delta u$} \\
\cline { 3 - 6 } \multicolumn{2}{c|}{} & $\mathrm{P}$ & $\mathrm{M}$ & $\mathrm{G}$ & $\mathrm{MG}$ \\
\hline \multirow{3}{*}{$R_{S M} \mid$} & $\mathrm{P}$ & $\mathrm{O}$ & $\mathrm{O}$ & $\mathrm{B}$ & $\mathrm{B}$ \\
\cline { 2 - 6 } & $\mathrm{M}$ & $\mathrm{B}$ & $\mathrm{M}$ & $\mathrm{M}$ & $\mathrm{R}$ \\
\cline { 2 - 6 } & $\mathrm{G}$ & $\mathrm{M}$ & $\mathrm{R}$ & $\mathrm{R}$ & Pés \\
\cline { 2 - 6 } & $\mathrm{MG}$ & $\mathrm{R}$ & $\mathrm{R}$ & Pés & Pés \\
\hline
\end{tabular}

\subsection{3}

\section{Sistema de Inferência Fuzzy 4}

O SIF4 é o último estágio do ponderador fuzzy, sendo o sistema cuja função é a de calcular o parâmetro $K$ que representa o nível do intervenção do controlador digital sobre o sistema dinâmico veícular.

\section{Variáveis de Entrada}

As variáveis de entrada deste SIF são: o valor máximo dos níveis de ameaças externas, indicado por $A_{t}$ e o comportamento do motorista indicado por $B_{\text {Motr }}$.

\section{Variável de Saída}

A variável de saída é justamente o nível de intervenção do controlador, indicado por $K$. 


\section{Base de Regras Fuzzy}

A base de regras fuzzy é apresentada de maneira resumida na Tabela 3.3 abaixo.

Tabela 3.3: Base de Regras Fuzzy dos Sistemas de Inferência 4.

\begin{tabular}{|c|c|c|c|c|c|c|}
\cline { 3 - 7 } \multicolumn{2}{c|}{} & \multicolumn{5}{|c|}{$B_{\text {Motr }}$} \\
\cline { 3 - 7 } \multicolumn{2}{c|}{} & Pés & R & M & B & O \\
\hline \multirow{3}{*}{$A_{t}$} & NAm & Tot & Grd & Méd & Nu & Nu \\
\cline { 2 - 7 } & PAm & Grd & Méd & Peq & Peq & Peq \\
\cline { 2 - 7 } & Am & Méd & Peq & Méd & Méd & Méd \\
\cline { 2 - 4 } & MAm & Peq & Nu & Grd & Grd & Grd \\
\cline { 2 - 7 } & EAm & Nu & Nu & Tot & Tot & Tot \\
\hline
\end{tabular}

Com as definições de todos os parâmetros dos SIF tornou-se possível a sua implementação e a obtenção de resultados preliminares que demonstraram as características do funcionamento do ponderador fuzzy, em conformidade com a seção 3.6.

\section{6}

\section{Resultados Preliminares}

Os resultados preliminares apresentados a seguir, publicados pelo autor e seus orientadores em [57], são aqui reproduzidos para manter a autossuficiência deste texto. Estes resultados demonstram apenas as características do funcionamento do ponderador fuzzy em simulações detalhadas adiante. Não há, neste ponto, nenhuma ação do controlador digital (que é proposto somente no Capítulo 4) sobre o sistema dinâmico, e o comportamento de algumas curvas de evolução da variável $K$ em situações diferentes é verificado. Estas situações de testes simulados são descritas a seguir.

\subsection{1}

\section{Situações de Teste do Ponderador Fuzzy}

Os testes simulados são executados para três cenários diferentes, em que é necessária a atuação do controlador semiautônomo para que situações de perigo sejam evitadas. Estas situações são:

1. Ambiente Hostil - Neste caso, a viatura encontra-se em um ambiente hostil simulado, onde encontram-se um explosivo improvisado e um atirador inimigo equipado com armamento anti-carro. Com esta simulação, procura-se verificar o comportamento do Ponderador Fuzzy diante da avaliação das ameaças externas. 
2. Manobra Arriscada - Nesta situação, simula-se o comportamento da viatura e do Ponderador Fuzzy diante de ações imprudentes do motorista, em que uma entrada (esterçamento do volante da viatura) é fornecida ao sistema resultando numa manobra arriscada e aumentando os valores dos parâmetros de estabilidade apresentados. Com esta simulação, procurase verificar o comportamento do Ponderador Fuzzy diante da avaliação do comportamento do motorista.

3. Manobra Arriscada em Ambiente Hostil - Nesta situação procurou-se misturar as duas situações anteriores. No entanto buscase verificar o funcionamento do ponderador em uma situação em que o motorista apresenta um comportamento considerado ruim em uma situação de extremo perigo. De acordo com o projeto apresentado, nestas situações espera-se que o ponderador diminua o nível de intervenção, dando liberdade ao motorista para tomar a decisão de realizar uma manobra mais difícil e de maior risco para resguardar-se de uma ameaça inimiga qualquer.

As figuras apresentadas na Subseção 3.6.2 ilustram estas situações de emprego propostas nas simulações teste.

\subsection{2}

\section{Trajetórias e Curvas de Evolução de $K$}

As simulações realizadas permitem a obtenção das curvas de evolução da variável $K$ diante das situações de perigo especificadas. As Figuras 3.16(b), 3.17(b) e 3.18(b) ilustram estes resultados.

Pode-se observar que o comportamento da variável $K$ se dá conforme esperado, devido ao fato de que a viatura é empregada em ambiente de alto risco, e ao mesmo tempo o motorista fornece entradas que fazem com que o sistema realize uma manobra perigosa, em que um golpe repentino é aplicado ao volante mesmo com a viatura trefegando a $60 \mathrm{~km} / \mathrm{h}$. No entanto, observa-se também a queda de $\mathrm{K}$ por volta do tempo de $6 s$, o que pode ser explicado pelo seguinte fato: de acordo com as bases de regras definidas, em uma situação de extremo perigo em que o motorista apresente um comportamento inesperado, o nível de intervenção deve diminuir. 


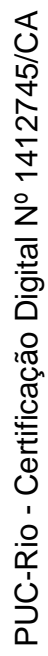

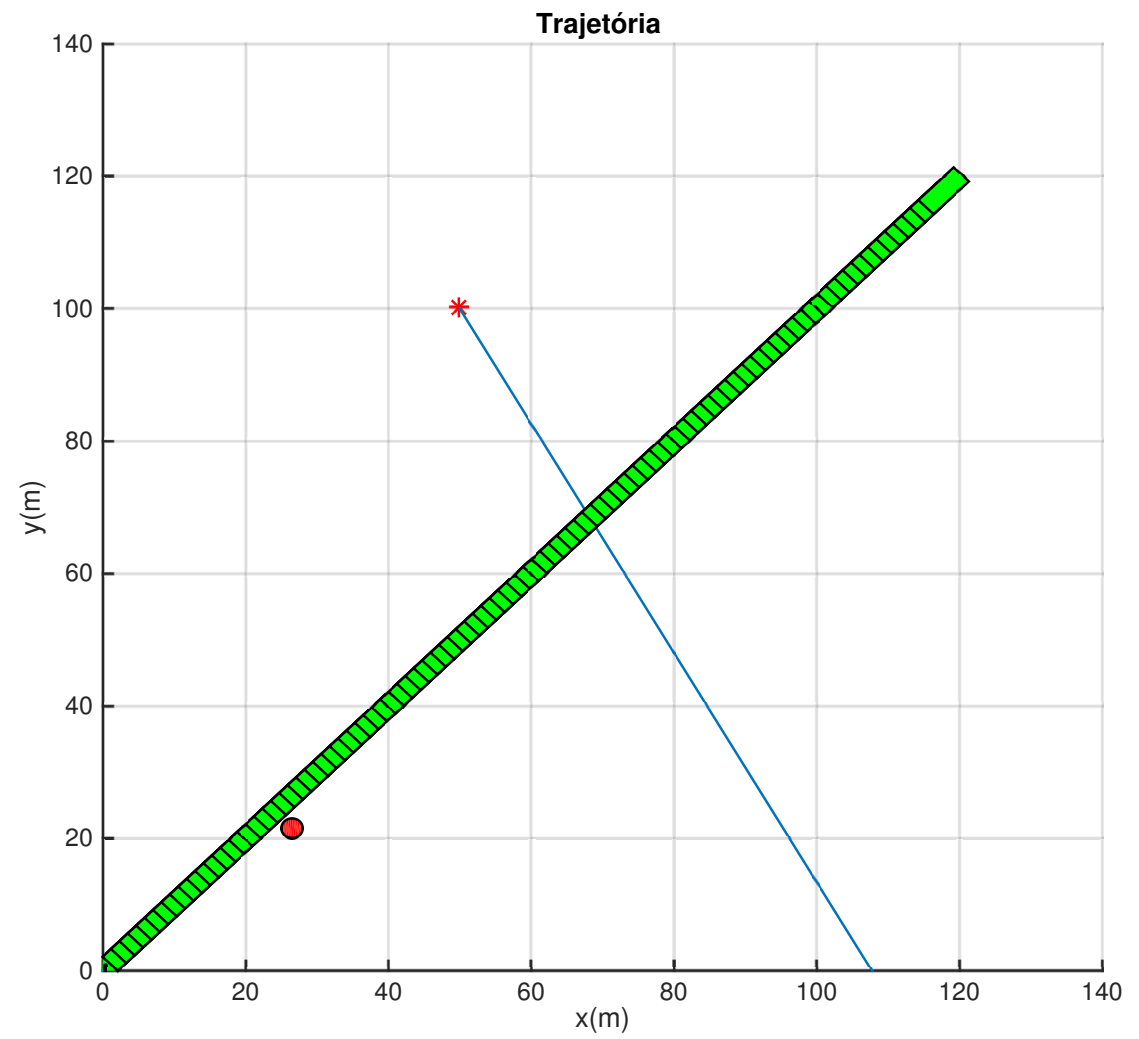

(a)

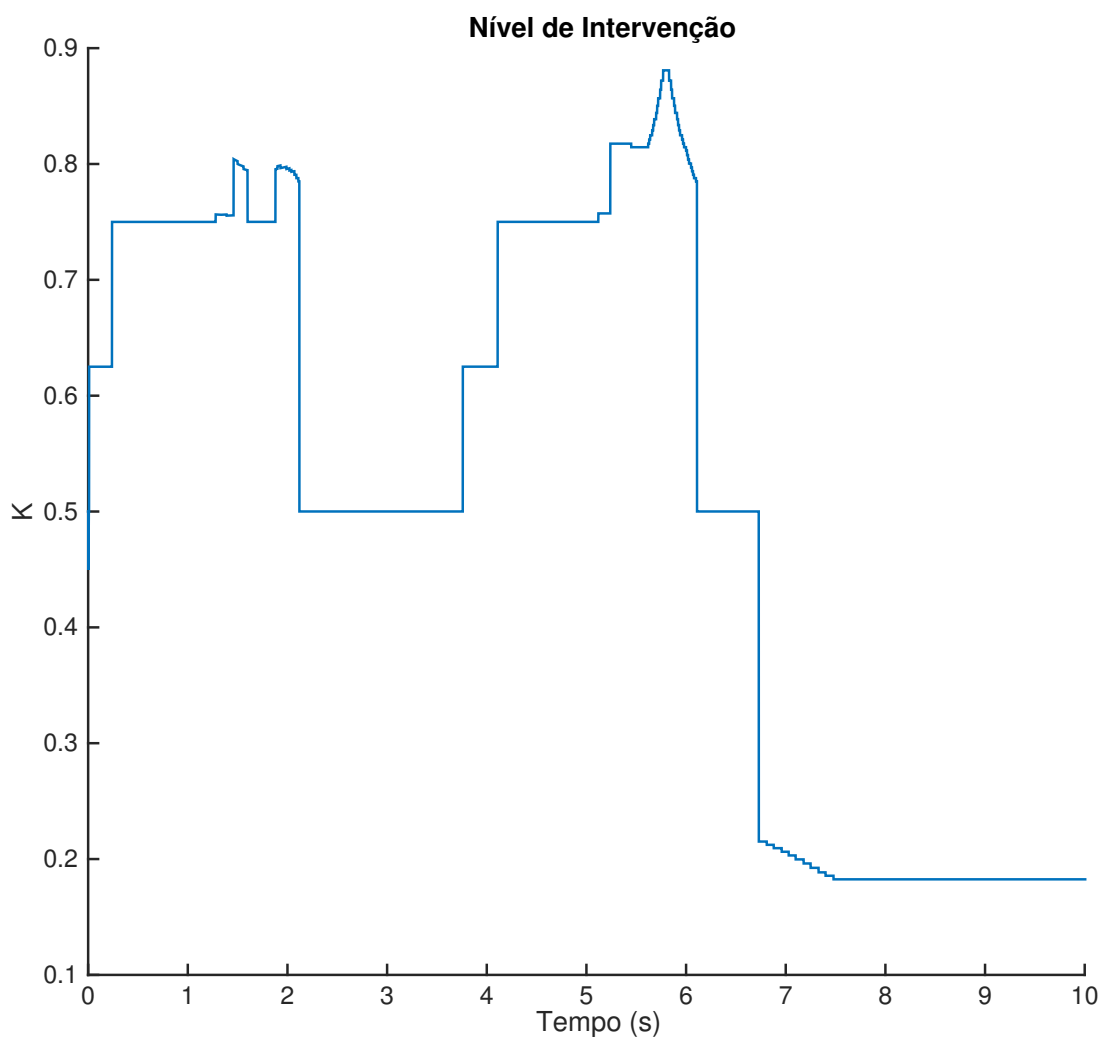

(b)

Figura 3.16: Trajetória (a) e Evolução de $K$ (b) para o cenário de Ambiente Hostil. 


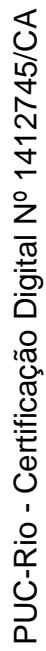

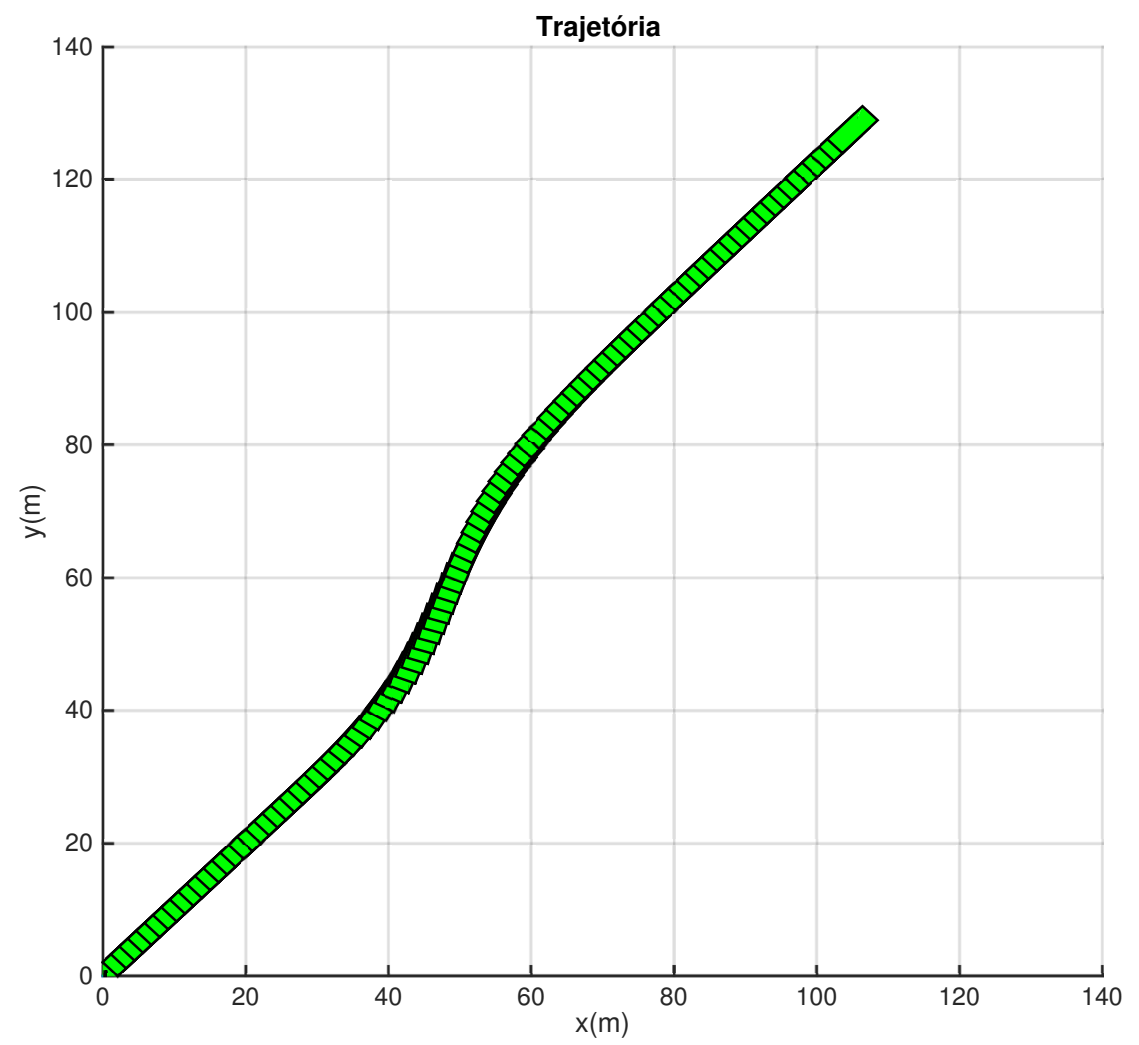

(a)

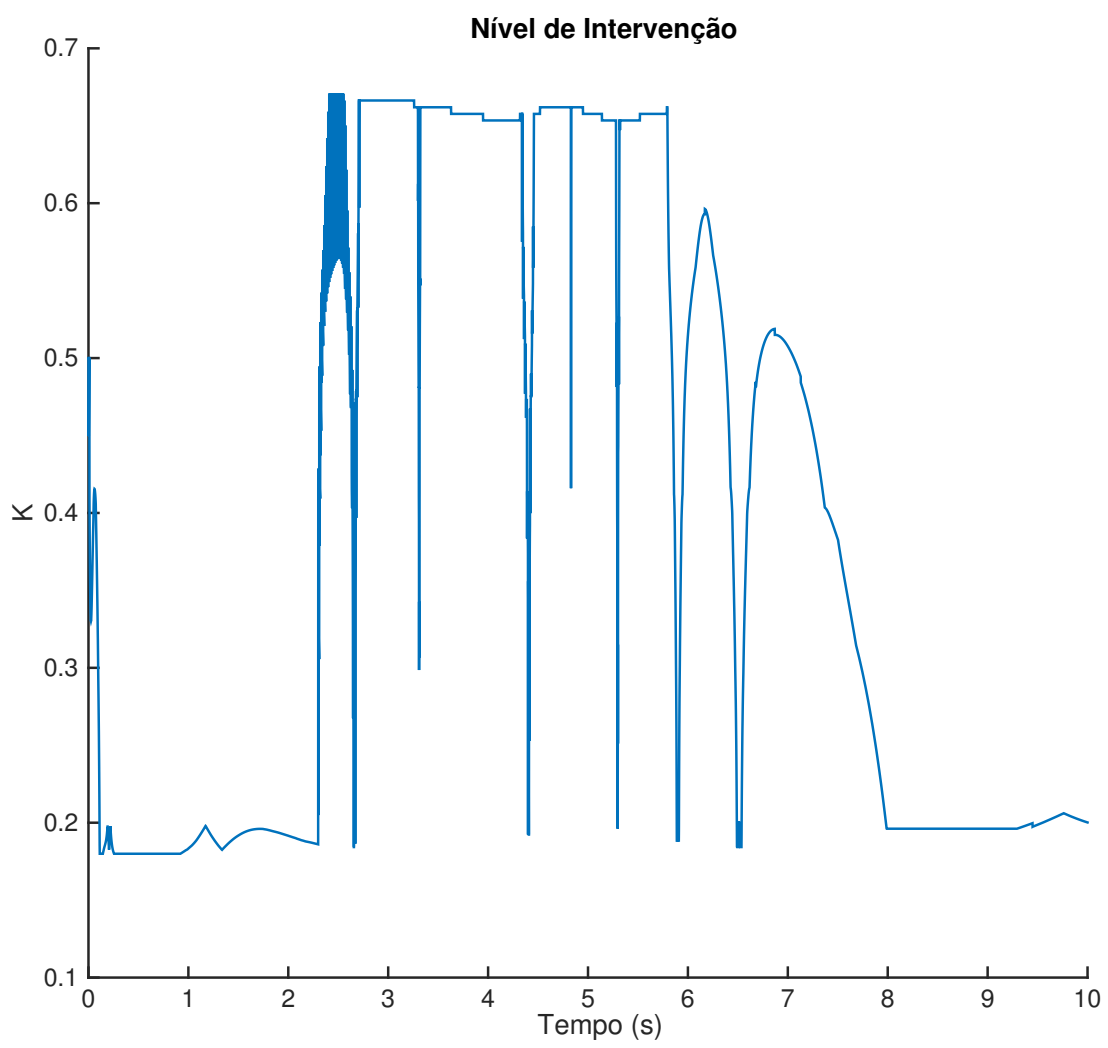

(b)

Figura 3.17: Trajetória (a) e Evolução de $K$ (b) para o cenário de Manobra Arriscada. 


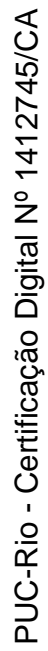

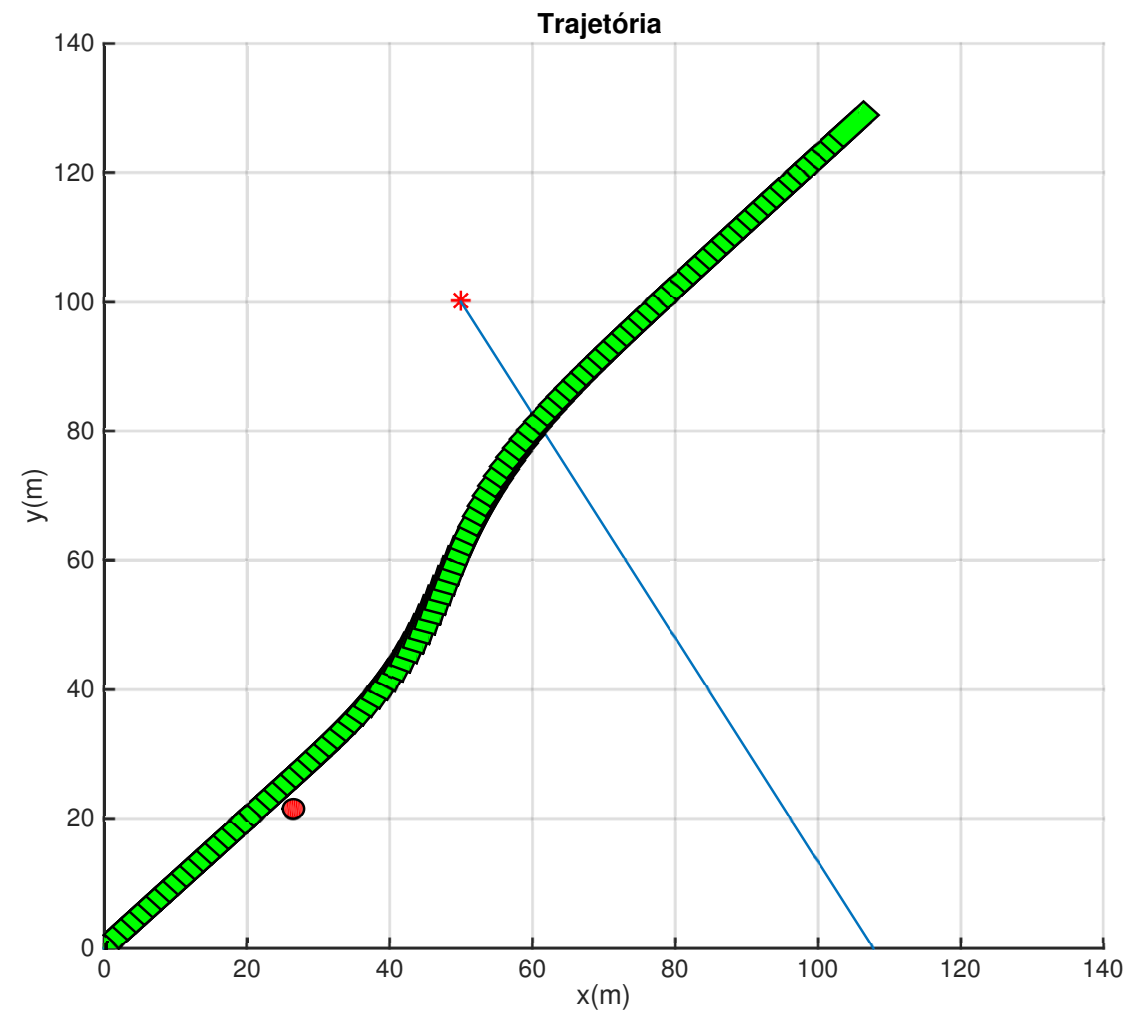

(a)

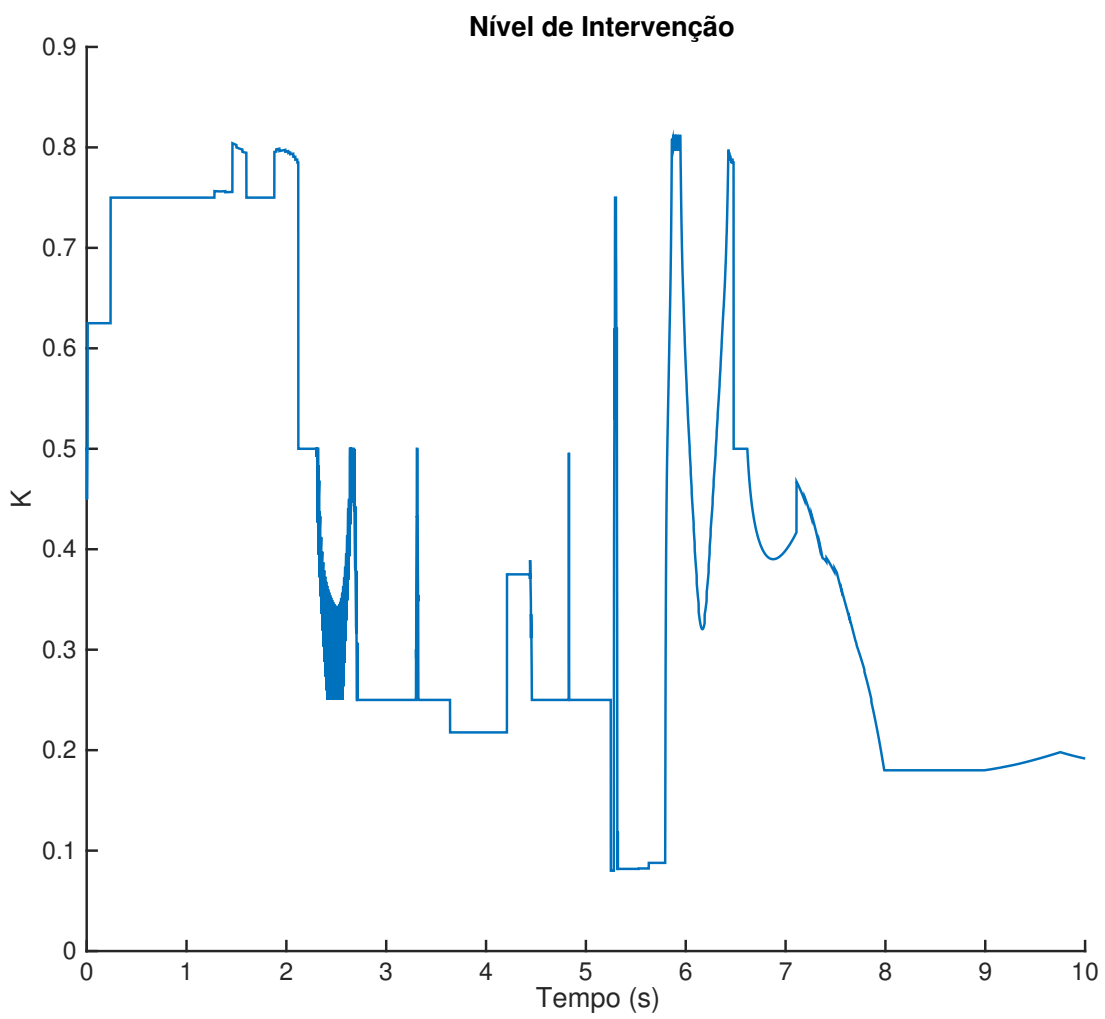

(b)

Figura 3.18: Trajetória (a) e Evolução de $K$ (b) para o cenário de Manobra Arriscada em Ambiente Hostil. 


\section{4}

\section{Subcontrolador Preditivo Baseado em Modelo}

A arquitetura do sistema de controle semiautônomo apresentado nesta dissertação é composta por dois elementos principais: o ponderador fuzzy, apresentado com detalhes no Capítulo 3, e o subcontrolador preditivo. Este capítulo aborda os tópicos importantes sobre a implementação deste elemento do sistema, trazendo informações sobre as técnicas relacionadas ao projeto de Controladores Preditivos Baseados em Modelos (Model Predictive Controllers - MPC), sobre as particularidades que tornam esta categoria de controladores apropriada para aplicações em sistemas dinâmicos veiculares e, em seguida, as especificações técnicas do subcontrolador preditivo proposto.

\section{1}

\section{Controladores Preditivos Baseados em Modelos - MPCs}

Os MPC designam uma variedade de métodos ou estratégias de controle com uma característica em comum: a utilização de um modelo matemático explícito do processo ou sistema dinâmico a ser controlado para a solução de um problema de otimização em que se busquem os valores de variáveis de entrada que, por sua vez, permitam a minimização de uma determinada função objetivo. Estes controladores surgiram ao final na década de 1970 e foram originalmente aplicados a processos químicos em plantas industriais com diversas entradas e saídas e restrições matemáticas [58].

As ideias básicas por trás da estratégia dos MPC são apresentadas a seguir.

\subsection{1}

\section{Estratégia de Controle Preditivo}

De maneira geral, os algoritmos de controle preditivo consistem na execução de etapas que envolvem:

- utilização do modelo matemático para realizar a predição das variáveis de saída do sistema dinâmico em instantes futuros específicos, dentro de um horizonte de tempo pré-definido; 
- cálculo de uma sequência de valores de entradas capazes de minimizar uma determinada função objetivo que represente uma grandeza ou situação indesejada; e,

- repetição periódica das etapas anteriores, permitindo atualização dos estados do sistema e de suas predições, em função da aplicação das entradas calculadas.

Estes algoritmos costumam diferenciar-se apenas pelos modelos matemáticos dos vários sistemas dinâmicos que podem ser controlados e pelas funções objetivo que definem o problema de otimização a ser repetidamente resolvido. Por sua natureza generalista, estes algoritmos têm sido desenvolvidos e amplamente utilizados no controle de diversas plantas, processos ou sistemas, tanto no âmbito acadêmico quanto industrial. Algumas das vantagens de se utilizar controladores preditivos dão-se pela facilidade de ajuste (relacionada apenas com a função objetivo), a eficiência de se controlar processos dinâmicos complexos e com múltiplas variáveis de entrada ou saída, e a capacidade de controle de sistemas cujas variáveis de referência têm valores futuros conhecidos (como é o caso do controle de sistemas veiculares ou mesmo da robótica).

No entanto, os maiores problemas da utilização desta classe de controladores estão relacionados à grande capacidade computacional necessária para a resolução dos problemas de otimização inerentes a estes algoritmos, principalmente por sua natureza periódica. Por este motivo, os MPC passaram a maior parte do seu tempo de existência sendo utilizados basicamente em processos ou plantas industriais mais lentas, que possibilitavam que os processadores mais antigos (de menor capacidade computacional) fossem utilizados nos cálculos de predição de saídas e nas otimizações. O fato de os processadores atuais terem uma maior velocidade e capacidade computacional permite que estes algoritmos sejam utilizados em uma grande variedade de processos ou plantas cada vez mais rápidos. Outras desvantagens não menos importantes estão relacionadas às possíveis discrepâncias entre os processos ou sistemas dinâmicos e seu modelo, e também à dificuldade de se obter resultados teóricos com o devido rigor matemático, quando se trata da análise de estabilidade ou robustez dos sistemas controlados.

A Figura 4.1 representa a estrutura básica de um MPC. Esta estrutura é utilizada para a implementação da estratégia de controle preditivo caracterizada pelo diagrama representado na Figura 4.2.

Em maiores detalhes, o primeiro passo da estratégia consiste em determinar as saídas futuras do sistema para o horizonte de tempo definido por $N_{p} T$. Este intervalo de tempo é chamado Horizonte de Previsão, e as saídas 


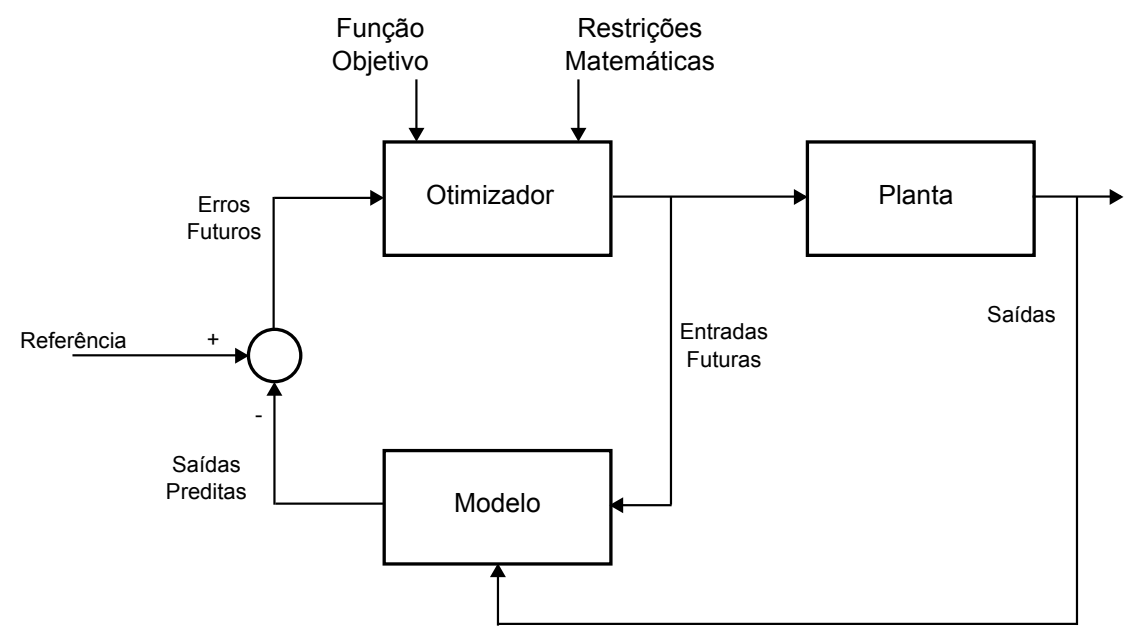

Figura 4.1: Arquitetura básica de um Controlador Preditivo baseado em Modelo.

são determinadas a partir do modelo do sistema ou processo a ser controlado. Esta previsão é realizada no instante $t$ (indicado pela reta tracejada), e as saídas preditas são indicadas por $\hat{y}(t+m T \mid t)$, para $m \in\left\{1,2,3, \ldots, N_{p}\right\}$. Obviamente, para a realização destes cálculos é necessário que se conheça o estado do sistema no instante $t$ e os valores das entradas futuras representadas por $u(t+m T \mid t)$, para $m \in\left\{0,1,2, \ldots, N_{p}-1\right\}$, que deveriam ser aplicadas.

A segunda etapa se dá pelo cálculo da sequência de futuras entradas, resolvendo-se de um problema de otimização com restrições matemáticas de um determinado critério representado por uma função objetivo, mantendo-se as saídas do sistema ou processo o mais próximo possível de uma variável de referência pré-definida indicada por $w(t+m T)$. A função objetivo geralmente tem o formato de uma expressão quadrática dos erros entre as saídas preditas e as referências dados por $e(t+m T \mid t)=\hat{y}(t+m T \mid t)-w(t+m T)$, além dos esforços envolvidos na atuação do controlador dados por $u(t+m T \mid t)$ e $\Delta u=u(t+m T \mid t)-u(t+(m-1) T \mid t)$. A utilização de funções quadráticas facilita a solução das otimizações, principalmente quando o modelo do processo ou do sistema dinâmico é linear, porque pode-se encontrar soluções explícitas por meio de métodos analíticos para os problemas.

Finalmente, o sinal de controle calculado $u(t \mid t)$ é aplicado ao sistema, enquanto os valores seguintes $u(t+m T \mid t)$ são rejeitados. Isso ocorre porque no próximo instante a saída $y(t+T)$, bem como as outras variáveis de estado do sistema, são conhecidas, permitindo-se a repetição do primeiro passo da estratégia com esses novos valores. As sequências são portanto atualizadas, e o valor $u(t+1 \mid t+1)$ é calculado e aplicado ao sistema. Nota-se que $u(t+1 \mid t) \neq u(t+1 \mid t+1)$, pela disponibilidade das informações representadas 


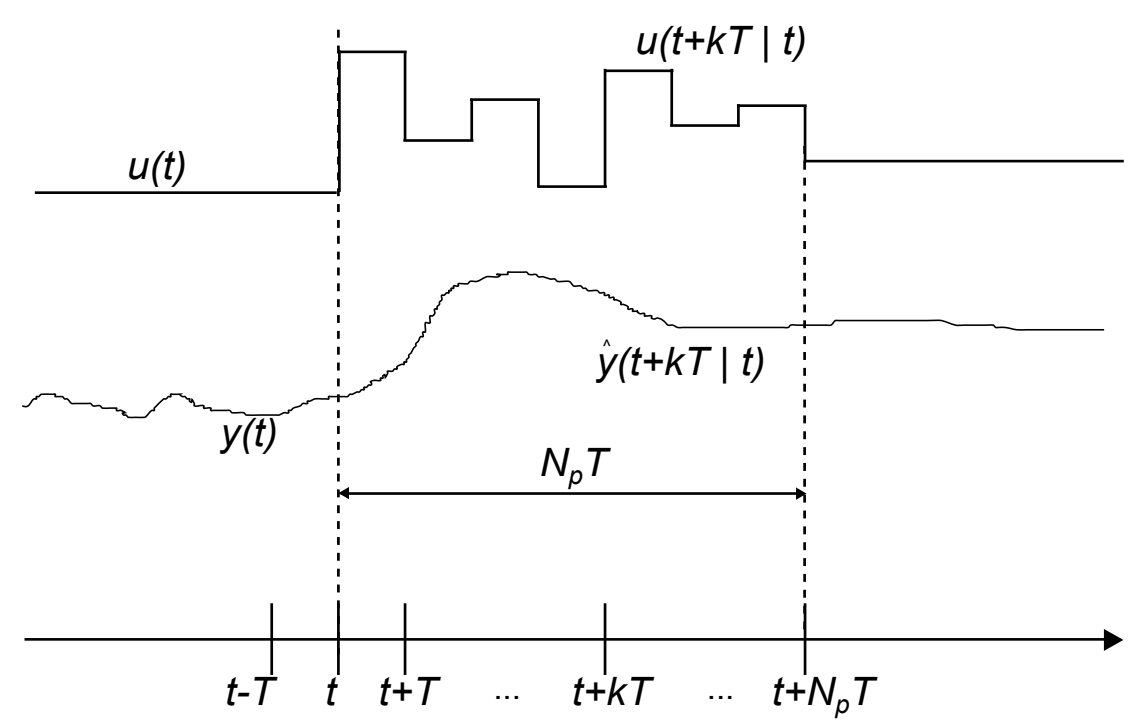

Figura 4.2: Estratégia de Controle Preditivo implementada pelo uso de MPCs.

pelos novos valores.

A estratégia de controle preditivo pode ser comparada à estratégia utilizada por um motorista dirigindo um automóvel, sendo, por este motivo, adequada para a implementação de controladores para sistemas veiculares. Ao executar a tarefa de guiar um automóvel, o motorista conhece a trajetória de referência desejada dentro de um horizonte de tempo finito. Por conhecer as características da dinâmica do automóvel, isto é, por ter concebido previamente um modelo mental do veículo, o motorista decide as ações de controle (esterçamento, aceleração e frenagem) a serem aplicadas no veículo para atingir a trajetória de referência. No entanto, apenas as primeiras ações planejadas são aplicadas, e após um curto período de tempo o processo de decisão é repetido. Esta estratégia se diferencia, por exemplo, de controladores do tipo PID, porque nestes controladores as ações são tomadas de acordo com erros passados, medidos anteriormente através da comparação entre saídas e referências. Esta analogia é representada na Figura 4.3.

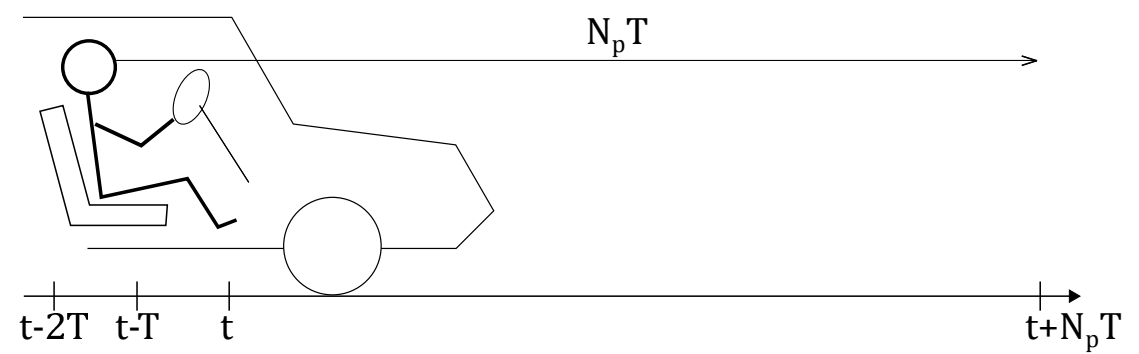

Figura 4.3: Analogia entre MPCs e a direção de um automóvel. 


\subsection{2}

\section{Elementos de um controlador MPC}

\section{Modelo Dinâmico}

Um elemento decisivo para a eficácia da implementação destes controladores é o modelo dinâmico do sistema ou processo a ser controlado. A modelagem deve ser refinada o suficiente para capturar a dinâmica do processo com boa precisão, sendo capaz de prever as saídas futuras e, quando possível, apresentar uma estrutura simples e de fácil compreensão. Diversas técnicas de identificação de sistemas costumam ser utilizadas nestas modelagens, como a identificação por resposta ao impulso ou mesmo por resposta ao degrau. Estas técnicas são extremamente úteis quando se trata de sistemas lineares. Ainda neste tipo de sistemas, é usual que estes sejam representados por modelos lineares em Espaços de Estados ou em Funções de Transferência. Nos MPCs é comum que sejam utilizados modelos de tempo discretizado para os sistemas dinâmicos. Portanto, em geral, tem-se um modelo representado por

$$
\left\{\begin{array}{rl}
x(k T+T) & =A x(k T)+B u(k T) \\
y(k T) & =C x(k T)
\end{array},\right.
$$

com $x$ representando o vetor de estados, $u$ representando as entradas e $y$ representando as saídas do sistema.

No entanto, apesar de tornar o problema mais complexo, neste trabalho é utilizada uma abordagem em que o modelo matemático escolhido é não-linear, conforme observado na seção 4.2.

\section{Otimizador}

O outro componente importante e fundamental para os controladores preditivos é o otimizador, pois a partir dele são geradas as ações de controle. A eficiência deste bloco costuma depender fortemente da função objetivo utilizada, que representa algum custo ou situação indesejada para o sistema dinâmico.

\section{Função Objetivo e Restrições Matemáticas}

Conforme mencionado na Subseção 4.1.1, se esta função objetivo apresenta forma quadrática, seus valores mínimos são obtidos analiticamente e de forma explícita, levando-se em consideração as entradas, saídas e valores futuros para as variáveis de referência. A quantidade de variáveis envolvidas e o tamanho do horizonte de previsão determinam a complexidade do problema de otimização. Além disso, a existência de restrições matemáticas que repre- 
sentem limites operacionais às variáveis de estados ou mesmo outras variáveis relevantes do sistema aumenta o custo computacional e o tempo de execução dos algoritmos.

Em geral, a função objetivo é dada por uma expressão da forma

$$
\begin{aligned}
J(k)=\sum_{i=k+1}^{k+N_{p}} \delta_{i}[\hat{y}(i T \mid t=k T)-w(i T)]^{2} & \\
& +\sum_{i=k}^{k+N_{p}-1} \lambda_{i}[u(i T \mid t=k T)]^{2}+\sum_{i=k}^{k+N_{p}-1} \gamma_{i}[\Delta u(i T \mid t=k T)]^{2},
\end{aligned}
$$

sendo as restrições matemáticas estabelecidas por,

$$
\left\{\begin{array}{c}
u_{\min } \leq u(k T) \leq u_{\max } \quad \forall k \\
\Delta u_{\min } \leq \Delta u(k T) \leq \Delta u_{\max } \quad \forall k . \\
y_{\min } \leq y(k T) \leq y_{\max } \quad \forall k
\end{array}\right.
$$

$\mathrm{Na}$ equação 4-2, as variáveis $\delta_{i}, \lambda_{i}$ e $\gamma_{i}$ indicam os pesos de cada uma das componentes da função objetivo que representa o custo indesejado para o controlador [31]. A função objetivo utilizada na implementação do Subcontrolador Preditivo é discutida com maiores detalhes na seção 4.3.

\section{2}

\section{Modelo dinâmico de Predição para o Subcontrolador}

Conforme mencionado na Subseção 4.1.2, um modelo matemático nãolinear e discretizado no tempo é utilizado para a implementação do MPC. Este modelo é obtido por meio de um equacionamento da cinemática da viatura, sendo portanto um modelo simplificado, onde não são considerados os efeitos dinâmicos e nem as forças que os causam. No entanto, este modelo se mostra eficaz para a realização de previsões sobre o posicionamento do centro de gravidade da viatura, o que para uma primeira abordagem se mostrou satisfatório. Observa-se que a utilização de um modelo cinemático é mais apropriada para situações onde a velocidade longitudinal do veículo é mais baixa, tornando-se mais difícil representar com maior precisão seu comportamento dinâmico. Acrescenta-se, ainda, que com este modelo é possível calcular as entradas a serem aplicadas ao sistema, usando algoritmos de otimização.

O desenvolvimento do modelo se deu de forma semelhante àquela encontrada em [59], onde um modelo cinemático para o movimento lateral de um veículo é apresentado. Considerando-se a Figura 4.4 pode-se observar a existência de duas possibilidades diferentes para o desenvolvimento do mo- 
delo: tomando-se como base o esterçamento das rodas do primeiro eixo (frontal) e seu centro de curvatura instantâneo $O_{f}$, ou tomando-se como base o esterçamento das rodas do segundo eixo (intermediário) e seu centro de curvatura instantâneo $O_{m}$. Na realidade, o centro de curvatura instantâneo é determinado em um ponto no interior do triângulo $O_{i} O_{m} O_{f}$. Considerando-se como o pior caso aquele em que a curva descrita pelo centro de gravidade é a mais aberta, escolhe-se o centro de curvatura mais distante - neste caso, o ponto $O_{m}$ - e portanto toma-se o esterçamento das rodas do eixo intermediário como base.

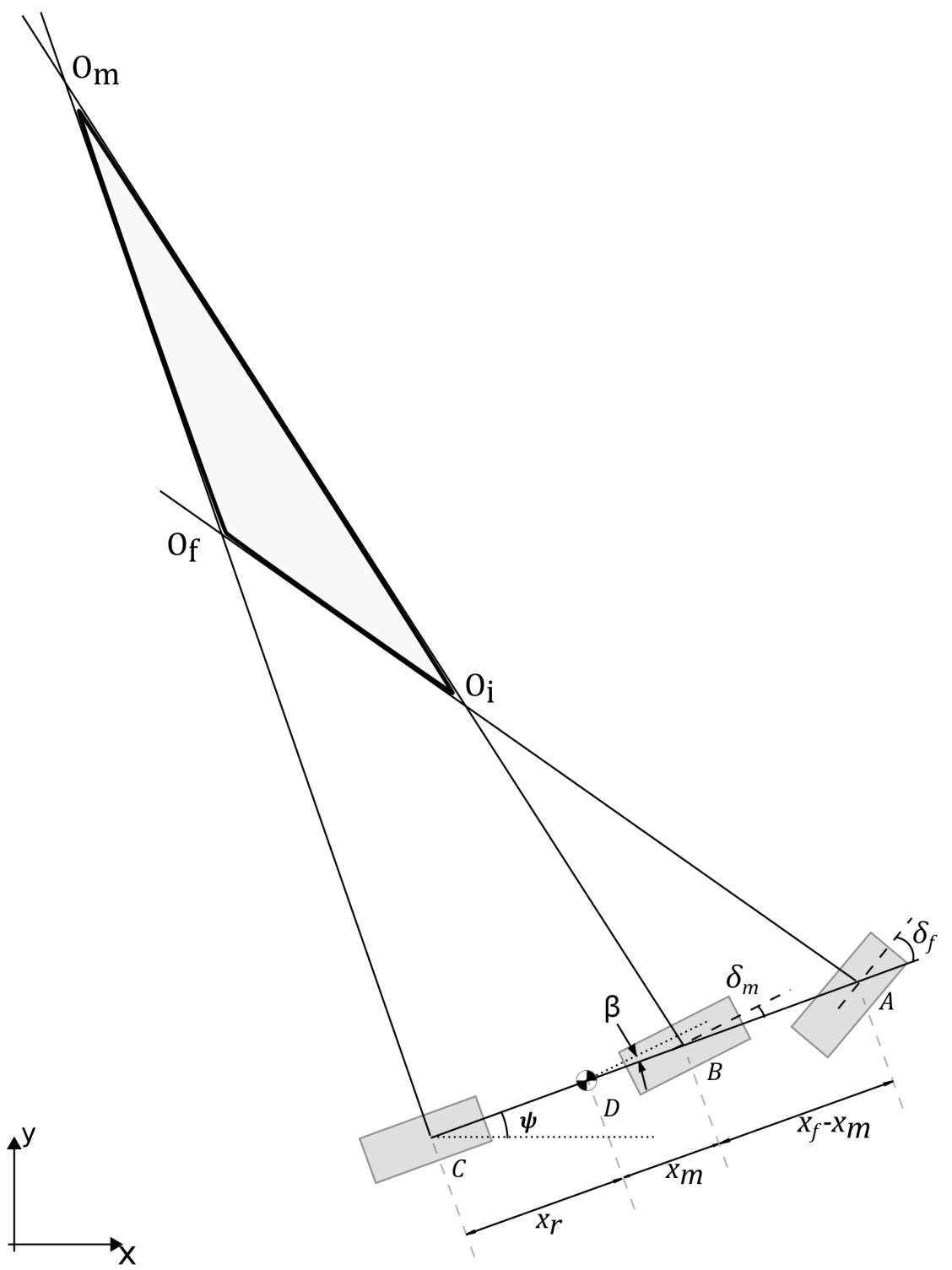

Figura 4.4: Modelo cinemático para o movimento lateral do veículo.

A partir da Figura 4.4, é possível perceber que 


$$
\left\{\begin{array}{l}
\dot{x}=V \cos (\psi+\beta) \\
\dot{y}=V \sin (\psi+\beta) \\
\dot{\psi}=\frac{V \cos \beta}{x_{m}+x_{r}} \tan \delta_{m}
\end{array}\right.
$$

onde,

$$
\beta=\arctan \left(\frac{x_{r} \tan \delta_{m}}{x_{m}+x_{r}}\right)
$$

As entradas deste modelo não-linear são a velocidade longitudinal $V$ e o esterçamento das rodas no eixo intermediário $\delta_{m}=\delta_{f} / k_{\delta}$. No entanto, por simplicidade, os efeitos da dinâmica longitudinal não são considerados, sendo a velocidade $V$ considerada constante. O ângulo de esterçamento $\delta_{f}\left(\right.$ ou $\delta_{m}$ ), por sua vez, é discretizado com o período $T$, assumindo um formato semelhante àquele apresentado na Figura 4.2.

Para discretizar o modelo, deve-se observar que $\dot{\psi}$ é constante ao longo dos intervalos de tempo de tamanho $T$. Se $\dot{\psi} \neq 0$, tem-se

$$
\psi(k T+T)-\psi(k T)=\dot{\psi}_{k} T .
$$

Para a posição longitudinal, pode-se concluir que

$$
\begin{aligned}
x(k T+T)-x(k T) & =\int_{k T}^{k T+T} V \cos (\psi+\beta)= \\
& \frac{V}{\dot{\psi}_{k}}\left[\sin \left(\dot{\psi}_{k} T+\psi_{k}+\beta_{k}\right)-\sin \left(\psi_{k}+\beta_{k}\right)\right],
\end{aligned}
$$

e, adicionalmente, para a posição lateral, tem-se

$$
\begin{aligned}
y(k T+T)-y(k T) & =\int_{k T}^{k T+T} V \sin (\psi+\beta)= \\
& -\frac{V}{\dot{\psi}_{k}}\left[\cos \left(\dot{\psi}_{k} T+\psi_{k}+\beta_{k}\right)-\cos \left(\psi_{k}+\beta_{k}\right)\right] .
\end{aligned}
$$

Obviamente, se $\dot{\psi}=0$ (), o veículo estaria trafegando em linha reta, e o modelo torna-se ainda mais simples, de forma que

$$
\left\{\begin{array}{l}
x(k T+T)=V \cos (\psi+\beta) T+x(k T) \\
y(k T+T)=V \sin (\psi+\beta) T+y(k T) \\
\psi(k T+T)=\psi(k T)
\end{array} .\right.
$$

Esta modelagem matemática não-linear e de tempo discreto para os movimentos do veículo (e mais especificamente de seu centro de massa) permite que as equações sejam utilizadas nos cálculos de previsão de suas 
posições com relação a um referencial fixo, dados os valores para a entrada representada pelo esterçamento das rodas do eixo intermediário $\delta_{m}$. A partir destas previsões são obtidas as soluções para os problemas de otimização com restrições que buscam minimizar uma função objetivo, que por sua vez depende justamente do posicionamento do veículo e de seu movimento, considerando-se suas velocidades longitudinal, lateral e angular (isto é, considerando-se apenas uma movimentação em um plano, a taxa de variação temporal do ângulo de guinada, ou yaw). A formulação matemática da função objetivo é detalhada na seção 4.3 .

\section{3}

\section{Função Objetivo}

O estabelecimento de uma função objetivo a partir de critérios rigorosos possibilita que os comportamentos dinâmicos indesejados (do sistema a ser controlado) sejam identificados e previstos, permitindo-se ainda que sejam escolhidos sinais de entrada adequados, capazes de corrigir ou evitar essas situações. Por este motivo, a função objetivo é um elemento essencial para o projeto dos MPCs. Conforme mencionado, as funções objetivo costumam ser formuladas incorporando-se sinais de referência para as saídas e penalidades para os esforços de controle, ou mesmo para valores de variáveis de estados ou medidas inconvenientes.

Assumindo-se como premissa a existência de sensores militares ideais equipando o veículo, e tendo estes sensores a capacidade de identificar e de avaliar as posições dos elementos que representem ameaças dentro de sua zona de operações, a distância entre o veículo e estas ameaças é facilmente calculada, conforme apresentado no Capítulo 3. Portanto, a partir destas distâncias define-se uma variável de potencial de ameaças instantâneo, tal que

$$
\phi=\sum_{i=1}^{N_{A}} \frac{\tau_{i}}{d_{i}^{2}},
$$

onde $N_{A}$ é o número de ameaças identificadas, $\tau_{i}$ é uma constante que quantifica o nível de perigo associado à $i$-ésima ameaça e $d_{i}$ é a sua distância até o centro de massa do veículo. Este potencial de ameaças é uma variável que serve como uma saída para o sistema, sendo o sinal de referência a ser seguido dado por $\phi_{R}=0$.

Em adição ao potencial de ameaças, são consideradas penalidades para os esforços de controle e também para o posicionamento do veículo, definindo-se limites laterais para os movimentos. Desta maneira, define-se a função objetivo instantânea $J(t)$ como sendo 


$$
\begin{aligned}
J(t)=R_{\phi} \sum_{k=1}^{N_{p}} \hat{\phi}^{2}(t+k T \mid t) & +R_{\delta} \sum_{k=1}^{N_{c}} \delta_{f}^{2}(t+k T) \\
& +R_{y} \sum_{k=1}^{N_{p}}\left[\hat{y}^{2}(t+k T \mid t)-\Lambda^{2}\right] .
\end{aligned}
$$

Os parâmetros acima são definidos como:

- $N_{p}$ - horizonte de previsão do MPC;

- $N_{c}$ - horizonte de controle;

- $R_{\phi}$ - peso de penalidade do potencial de ameaças dentro da função objetivo;

- $R_{\delta}$ - peso de penalidade dos esforços caracterizados pela própria entrada dentro da função objetivo;

- $R_{y}$ - peso de penalidade das distâncias entre o centro de massa do veículo e o limite lateral dentro da função objetivo; e,

- $\pm \Lambda$ - comprimento dos limites laterais impostos ao movimento do veículo.

A função objetivo pode ser modificada para adequação do controlador à algumas situações específicas. Apesar de aumentar ainda mais o custo computacional do algoritmo de otimização, os resultados apresentados no Capítulo 6 demonstram que, em algumas vezes, é conveniente adicionar uma componente de penalidade ligada à velocidade lateral do centro de massa, contribuindo para a estabilização do movimento na direção do eixo $y$. Nestes casos, a função objetivo torna-se

$$
\begin{aligned}
J_{1}(t)=R_{\phi} & \sum_{k=1}^{N_{p}} \hat{\phi}^{2}(t+k T \mid t)+R_{\delta} \sum_{k=1}^{N_{c}} \delta_{f}^{2}(t+k T) \\
& +R_{y} \sum_{k=1}^{N_{p}}\left[\hat{y}^{2}(t+k T \mid t)-\Lambda^{2}\right]+R_{\dot{y}} \sum_{k=1}^{N_{p}}\left[\hat{\dot{y}}^{2}(t+k T \mid t)-v_{y, L I M}^{2}\right],
\end{aligned}
$$

ou ainda,

$$
\begin{aligned}
J_{2}(t)=R_{\phi} & \sum_{k=1}^{N_{p}} \hat{\phi}^{2}(t+k T \mid t)+R_{\delta} \sum_{k=1}^{N_{c}} \delta_{f}^{2}(t+k T) \\
& +R_{y} \sum_{k=1}^{N_{p}}\left[\hat{y}^{2}(t+k T \mid t)-\Lambda^{2}\right]+R_{\dot{y}} \sum_{k=1}^{N_{p}}\left[\frac{\hat{\dot{y}}^{2}(t+k T \mid t)}{v_{y, L I M}^{2}}\right] .
\end{aligned}
$$


Nestas equações, o parâmetro $v_{y, L I M}$ representa a velocidade lateral definida como limitante para que o aumento mais expressivo da penalidade. A Figura 4.5 apresenta uma situação geral para um dado instante de tempo $t$ qualquer.

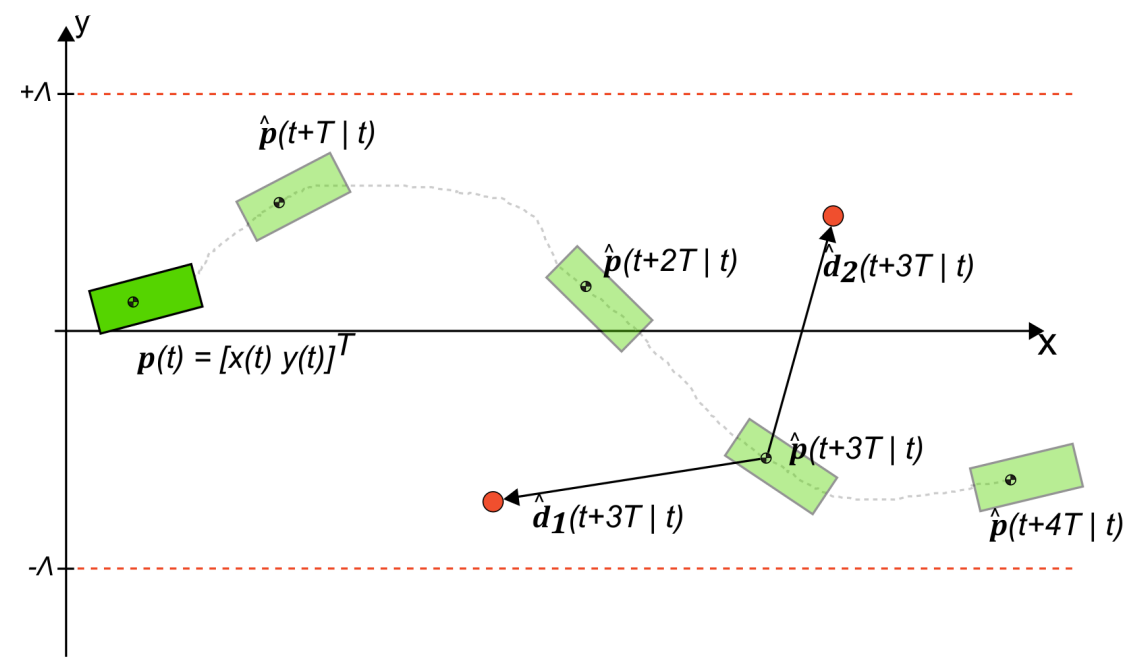

Figura 4.5: Predição do posicionamento do veículo em um instante $t$.

Pode-se realizar alguns ajustes na função objetivo $J$ a partir da modificação dos pesos $R_{\phi}, R_{\delta}, R_{y}$ e $R_{\dot{y}}$ (quando aplicável). Obviamente, aumentar ou diminuir os valores destes parâmetros implica no aumento ou diminuição da relevância de cada um dos fatores que são considerados em $J$.

A minimização do funcional $J$ é o procedimento que permite o cálculo das entradas $\delta_{f}(t+k T)$, apresentadas na equação 4-11. A fim de executar qualquer algoritmo de otimização para esta minimização, é necessário calcular as saídas preditas $\hat{y}(t+k T \mid t)$, o que deve ser feito com base no modelo matemático que compõe o MPC. Neste caso específico, o modelo matemático não-linear utilizado impossibilita que sejam obtidas soluções analíticas para este problema de otimização, o que poderia reduzir o custo computacional das operações. Por este motivo, faz-se necessário o uso de métodos iterativos para a solução dos problemas de otimização, o que representa um alto custo computacional e exige a utilização de processadores de maior velocidade para que as operações sejam realizadas em tempo hábil.

Outro aspecto interessante pode ser analisado quando as variáveis $N_{p}$ e $N_{c}$ são observadas. Quanto maiores forem os horizontes de previsão e de controle, mais complexa se torna a função objetivo $J$, aumentando-se o número de variáveis independentes do problema de otimização. 


\section{4}

\section{Estabelecimento das Restrições Matemáticas}

O problema de otimização proposto para o cálculo dos sinais de controle a serem aplicados no sistema dinâmico deve estar sujeito a algumas restrições operacionais. Isto se aplica a qualquer problema de controle, porque na prática qualquer processo ou sistema dinâmico está sujeito a restrições de ordem operacional ou física. Estas restrições costumam estar relacionadas com razões de segurança ou mesmo limitações de ordem prática. Adicionalmente, em geral, atuadores são elementos que têm saídas limitadas a um determinado intervalo de valores ou ainda suas taxas de variação de saídas (ou slew rate) limitada.

Especificamente neste trabalho, as restrições estão resumidas às limitações físicas das variáveis de entrada de acordo com as possibilidades dos veículos. Estas restrições, baseadas em igualdade e desigualdade são dadas por

$$
V(t+k T)=V_{0},
$$

em que a velocidade longitudinal do veículo mantém-se constante e

$$
\delta_{f}^{2}(t+k T) \leq \delta_{\max }^{2},
$$

em que limita-se o módulo do ângulo de esterçamento a um valor máximo estipulado pela própria geometria do sistema de direção do veículo.

\section{5}

\section{Comparação de Resultados para diferentes Funções Objetivo}

A partir da implementação do Subcontrolador Preditivo e de sua integração com o Ponderador Fuzzy apresentado no Capítulo 3, é possível realizar alguns testes preliminares com o Sistema de Controle Semiautônomo proposto nesta dissertação, com o objetivo de comparar as diferentes configurações possíveis para a função objetivo utilizada no Subcontrolador Preditivo. Foram, portanto, obtidos alguns resultados iniciais em que os parâmetros $R_{\phi}, R_{\delta}$ e $R_{y}$ foram sistematicamente modificados, produzindo-se assim diferentes resultados para o comportamento da viatura sob ação do sistema de controle. Estes primeiros resultados foram apresentados pelo autor e seus orientadores em [60], e são aqui reproduzidos.

\subsection{1}

\section{Configurações dos Parâmetros}

Diversas configurações diferentes para os parâmetros foram testadas inicialmente, sendo então os resultados das quatro configurações mais promissoras apresentadas. Estes resultados demonstram o veículo sob ação do controla- 
dor semiautônomo, em uma área ameaçada pelo emprego apenas de IEDs. Observa-se que, por tratar-se de testes preliminares, as entradas provenientes do motorista foram zeradas, i.e., simulando uma situação em que o ser humano não exerce nenhuma atuação sobre o volante do veículo. A Tabela 4.1 mostra os diferentes valores para os parâmetros utilizados.

Tabela 4.1: Valores dos parâmetros da função objetivo para cada teste.

\begin{tabular}{|l|l|l|l|}
\hline Teste $\#$ & $R_{\phi}$ & $R_{\delta}$ & $R_{y}$ \\
\hline 1 & 1 & 10 & 0,00001 \\
\hline 2 & 10 & 100 & 0,00001 \\
\hline 3 & 1 & 1000 & 0,00001 \\
\hline 4 & 1 & 1000 & 0,00002 \\
\hline
\end{tabular}

Todos os testes foram realizados com a simulação de dois IEDs posicionados em

$$
\mathbf{p}_{I E D 1}=\left[\begin{array}{c}
50 \\
0
\end{array}\right] \quad \text { e } \quad \mathbf{p}_{I E D 2}=\left[\begin{array}{c}
100 \\
0
\end{array}\right]
$$

e os limites laterais para o movimento da viatura foram especificados como $\pm \Lambda= \pm 30 m$.

\subsection{2}

\section{Resultados Preliminares}

As simulações realizadas permitem a obtenção das trajetórias descritas pelos movimentos do veículo, além das curvas de evolução da variável de intervenção $K$. As Figuras 4.6, 4.7, 4.8 e 4.9 mostram os resultados obtidos para os testes $\# 1$, \#2 \#3 e \#4, respectivamente.

Conforme se pode observar nestes resultados, o comportamento do sistema proposto é extremamente sensível às variações dos parâmetros de configuração da função objetivo. Isto se torna evidente pelas diferenças entre as trajetórias apresentadas nas Figuras 4.6, 4.7, 4.8 e 4.9, e portanto tornase necessário estabelecer alguma metodologia consistente para a escolha dos valores destes parâmetros de acordo com as características do veículo a ser controlado e com as necessidades operacionais do usuário. Apesar de não abordada de forma direta neste trabalho, esta metodologia poderia tomar também como base conceitos relacionados à utilização de IA, empregando-se técnicas de treinamento ou de otimização.

Ainda em acordo com as expectativas, a ação do sistema de controle proposto sobre o veículo é suficiente para a realização de manobras necessárias 

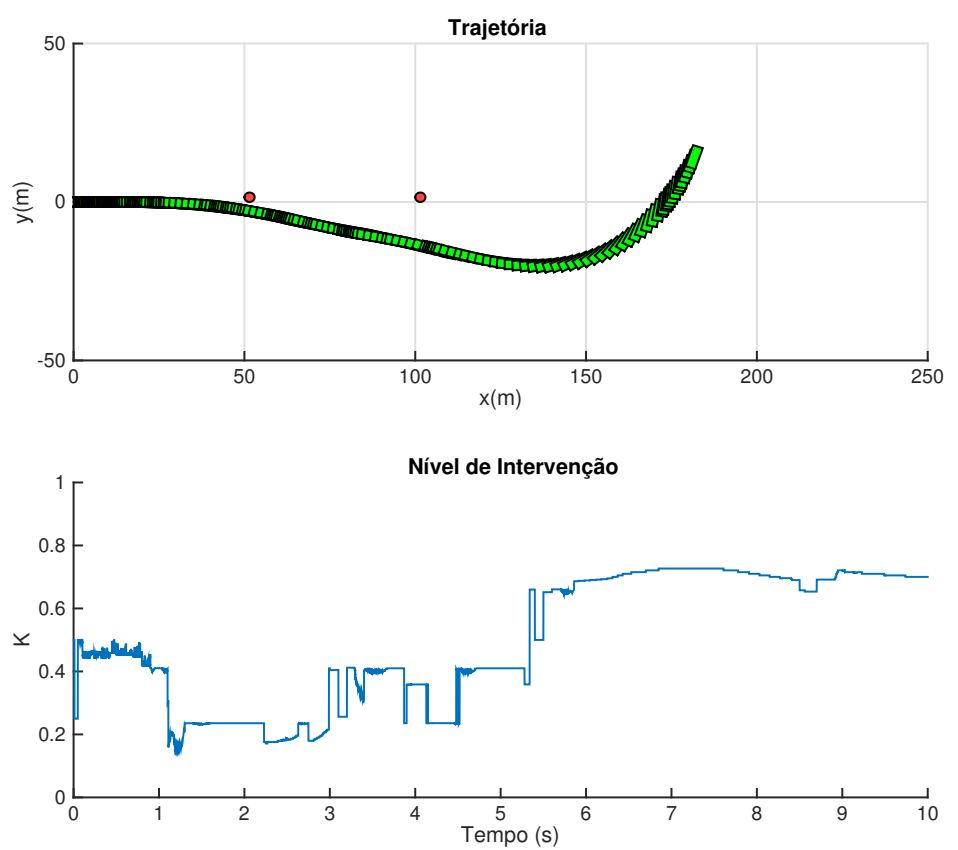

Figura 4.6: Resultado preliminar para o teste \#1.

para mantê-lo dentro de uma zona de segurança, afastado dos elementos que representavam ameaças inimigas hostis. Observa-se ainda o comportamento da variável $K$, que se manteve nos padrões apresentados no Capítulo 3, elevandose principalmente nos intervalos finais de tempo de cada teste, ao mesmo tempo em que a estabilidade lateral da viatura demonstra-se prejudicada por conta das manobras realizadas anteriormente. 


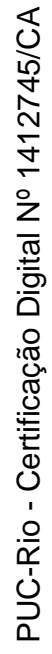
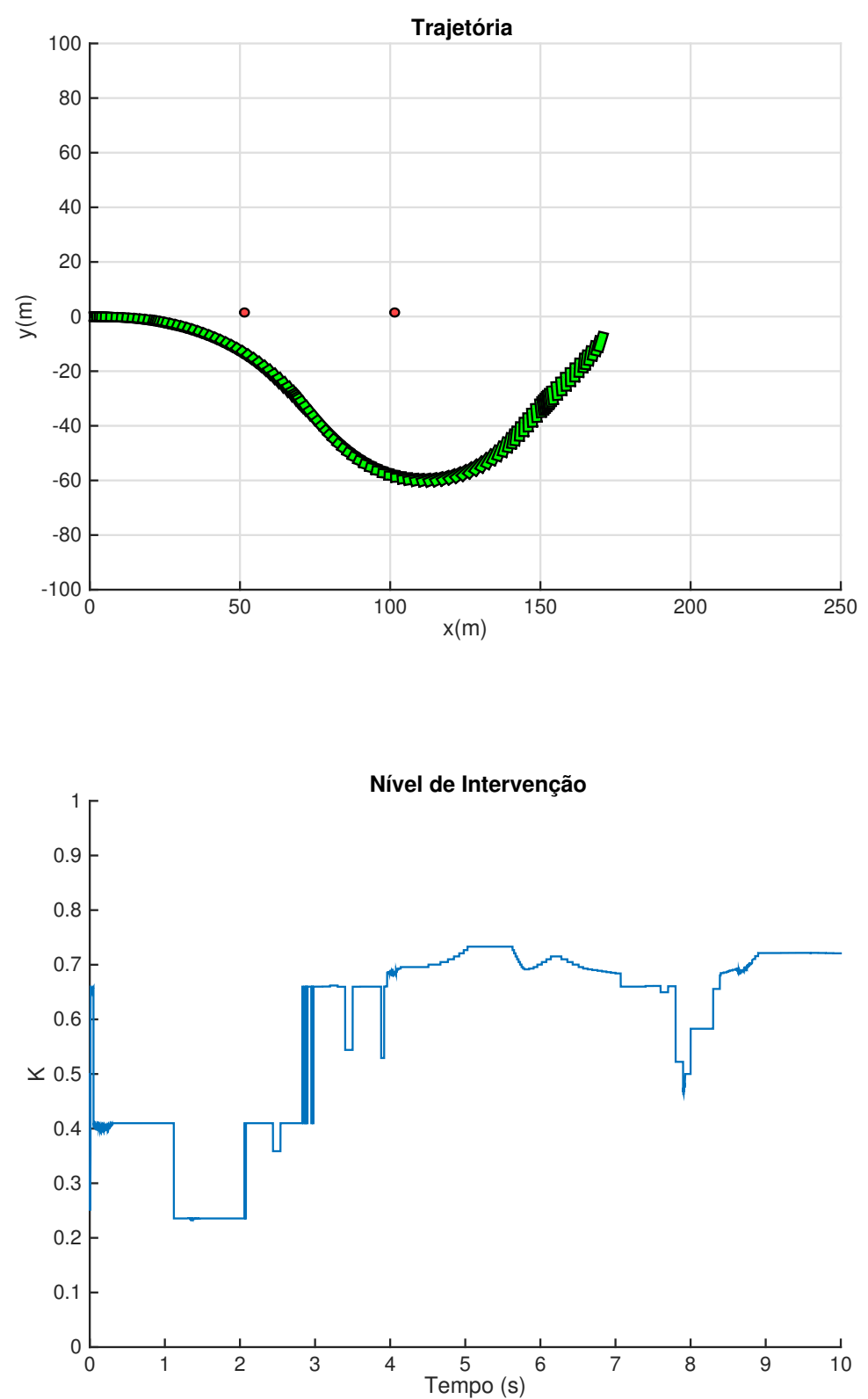

Figura 4.7: Resultado preliminar para o teste \#2. 

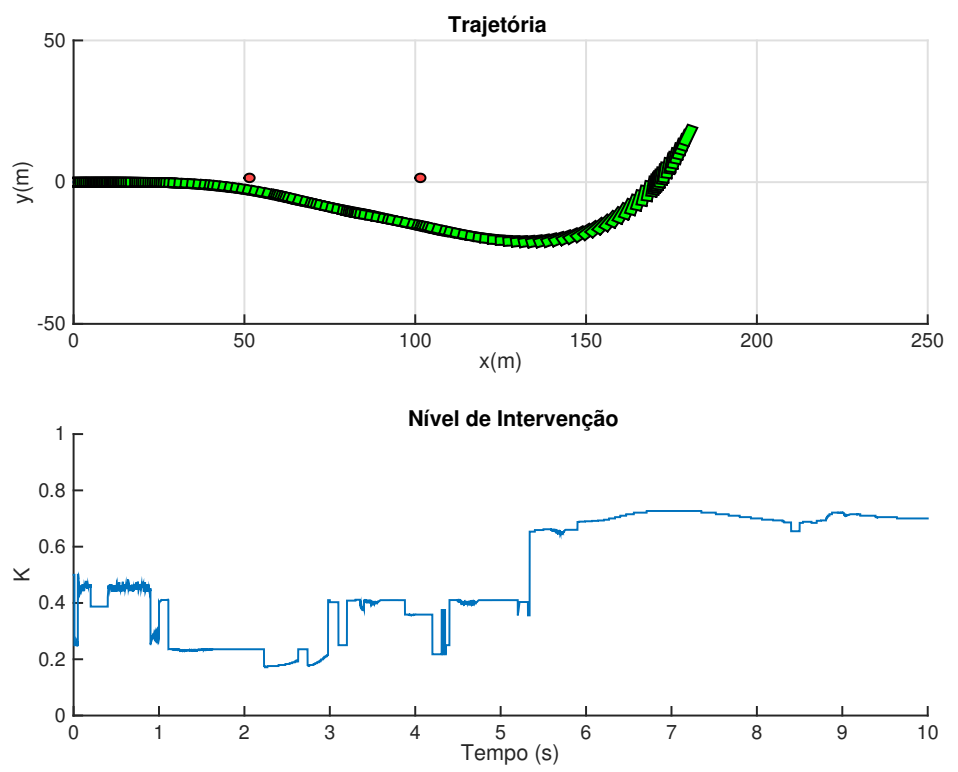

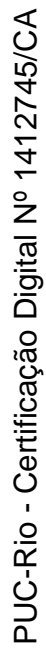

Figura 4.8: Resultado preliminar para o teste \#3.
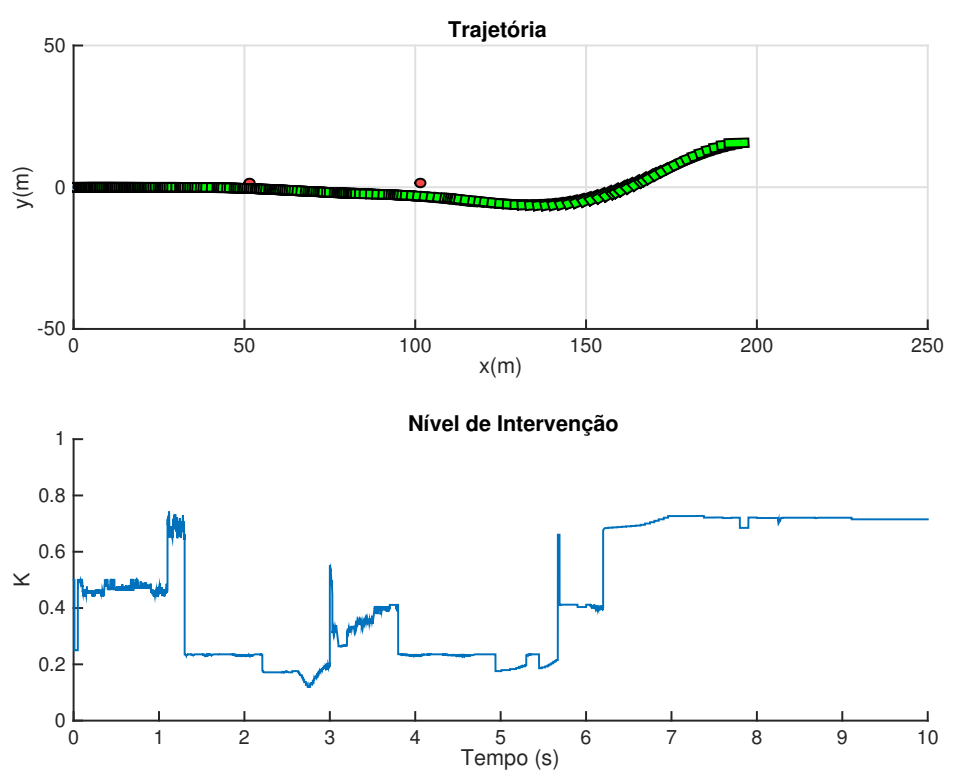

Figura 4.9: Resultado preliminar para o teste \#4. 


\section{5 Modelagem Dinâmica do Veículo para Simulação}

A modelagem matemática de um sistema dinâmico é uma etapa fundamental para a análise de seu comportamento e é, portanto, de grande importância para o projeto de sistemas de controle. Dadas as limitações de tempo e o alto custo que a execução de testes experimentais com o sistema de controle semiautônomo proposto nesta dissertação em um veículo real representaria, optou-se por uma abordagem inicial baseada em simulações, que demandaram a implementação de um modelo dinâmico mais preciso do veículo a ser controlado. O modelo implementado difere daquele apresentado no capítulo anterior, pelo seu maior nível de complexidade e capacidade de descrever a dinâmica veicular de forma satisfatória para os objetivos deste trabalho. O modelo é estabelecido a partir da análise do veículo como um sistema dinâmico, obtendo-se então suas equações de movimento. Os parâmetros do modelo são retirados de informações técnicas da VBTP-MR GUARANI, cedidas pelo Departamento de Ciência e Tecnologia do Exército Brasileiro [61]. O modelo é implementado em ambiente de simulação numérica, e os resultados de suas simulações são comparados com o comportamento já conhecido para a viatura.

Os modelos matemáticos para os sistemas podem ser descritos de diversas formas diferentes, em geral padronizadas para a representação de sistemas dinâmicos lineares, como as funções de transferência ou os modelos de estados. O modelo matemático desenvolvido para a VBTP-MR GUARANI a ser apresentado neste capítulo, no entanto, é caracterizado por suas não linearidades características da dinâmica lateral, sendo representado por equações diferenciais em sua forma original.

\section{1}

\section{Modelos Matemáticos para Sistemas Dinâmicos}

De maneira geral, a caracterização matemática de um sistema dinâmico se dá pela obtenção de equações capazes de descrever seu comportamento, em função das variáveis (de entrada, de estados ou de saída) relacionadas a ele e do tempo. Modelos de tempo contínuo costumam ser representados por equações diferenciais, enquanto as equações de diferenças são utilizadas em modelos 
de tempo discreto. Existem sistemas dinâmicos de naturezas diferentes, como mecânicos, elétricos, térmicos, hidráulicos, econômicos, biológicos, etc., e as equações que os representam são obtidas a partir de suas leis fundamentais.

A teoria dos sistemas de controle engloba uma série de técnicas diferentes utilizadas para o controle de sistemas dinâmicos. Para a maior parte dos sistemas a serem controlados, as técnicas utilizadas se tornam verdadeiramente efetivas quando se tem conhecimento prévio dos seus modelos matemáticos. Em função das dificuldades inerentes à análise e à modelagem de alguns sistemas físicos, principalmente pela possibilidade destes poderem ser tanto não-lineares quanto variantes no tempo, alguns procedimentos de identificação de sistemas podem ser realizados para permitir a síntese dos modelos capazes de representar seus comportamentos dinâmicos.

Uma abordagem possível para a obtenção de um modelo consiste em utilizar técnicas de identificação de sistemas com a utilização de Redes Neurais Artificiais. Essa era uma proposta inicial para a obtenção do modelo dinâmico veicular a ser utilizado neste trabalho. No entanto, devido à alta complexidade do modelo neural e à dificuldade de se obter uma base de dados com uma quantidade de amostras suficientemente grande para permitir o treinamento das redes, esta alternativa foi descartada. Por tratar-se de um assunto relevante para o estudo de sistemas dinâmicos e seus modelos, alguns aspectos sobre a identificação de sistemas com a utilização de RNA são comentados a seguir.

\subsection{1}

\section{Identificação de Sistemas Dinâmicos com Redes Neurais Artificiais}

A utilização de uma RNA para a identificação de um modelo não linear é considerada apropriada, principalmente porque estas são ferramentas com a capacidade de aproximação ou interpolação universal. Em [62], demonstra-se matematicamente que as Redes Neurais Dinâmicas Recorrentes, ou Dynamic Recurrent Neural Networks (DRNN), são capazes de representar aproximações tão precisas quanto se queira dos comportamentos de sistemas dinâmicos. Esta capacidade de representação é ilustrada pela identificação do modelo de um sistema não-linear representativo de um evaporador de múltiplas entradas e múltiplas saídas (MIMO). Ainda em [62], o treinamento da RNA é realizado por meio da execução de um algoritmo híbrido, envolvendo um estágio evolucionário, principalmente porque a execução do algoritmo de backpropagation (que é o principal algoritmo utilizado para o treinamento de redes neurais) neste caso seria de altíssimo custo operacional e impraticável. A Figura 5.1 ilustra este tipo particular de RNA.

As DRNN são capazes de aproximar modelos de sistemas dinâmicos não- 


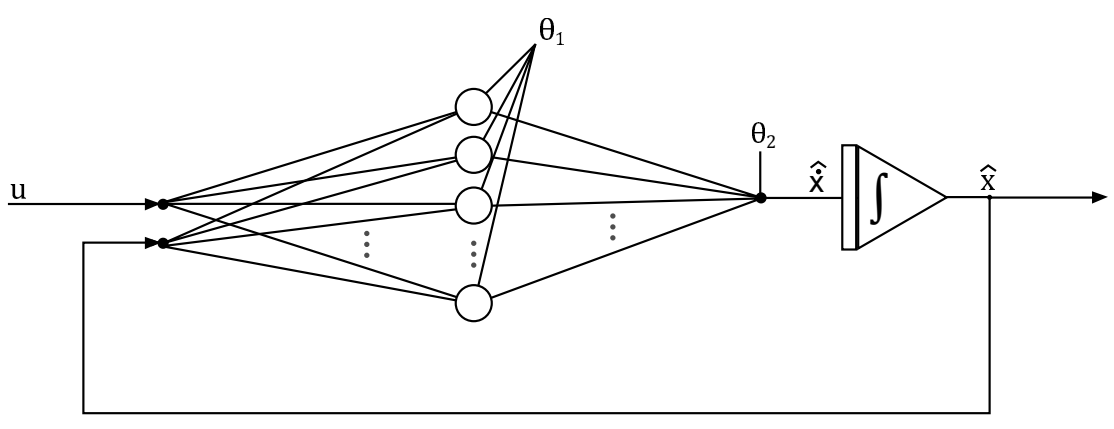

Figura 5.1: Rede Neural Dinâmica Recorrente.

lineares representados por

$$
\left\{\begin{array}{rl}
\dot{x}(t) & =f(x(t), u(t)) \\
y & =g(x)
\end{array},\right.
$$

implementando sistemas dados por

$$
\left\{\begin{array}{l}
\hat{\dot{x}}(t)=\hat{f}(\hat{x}(t), u(t), \Theta) \\
\hat{y}(t)=\hat{g}(\hat{x}(t))
\end{array},\right.
$$

onde, em ambos sistemas de equações tem-se $u(t)$ como um vetor de entradas externas de $n_{u}$ variáveis, $x(t)$ é o vetor de estados composto por $n_{x}$ variáveis de estado e $y(t)$ é o vetor de saída composto por $n_{y}$ variáveis. As variáveis marcadas com acento circunflexo (ou "chapéu" - ^) indicam as aproximações. $\mathrm{O}$ vetor $\Theta$ é composto pelos parâmetros da rede neural, e em muitas vezes a saída é simplesmente dada por algumas variáveis de estado, de forma que

$$
\hat{y}(t)=\hat{g}(\hat{x}(t))=C \hat{x}(t)
$$

em que $C$ é uma matriz dada por

$$
C=\left[\begin{array}{ll}
I_{n_{y} \times n_{y}} & \emptyset_{n_{y} \times n_{x}-n_{y}}
\end{array}\right] .
$$

Observa-se que, neste caso, as saídas são as primeiras $n_{y}$ variáveis do vetor.

\section{1 .2}

\section{Sistemas Veiculares}

A modelagem matemática de um sistema dinâmico veicular é complexa, principalmente porque demanda a descrição precisa de diversos subsistemas que compõem o veículo, como por exemplo: a modelagem dos pneus, das suspensões, do motor, do sistema de transmissão, do sistema de direção, dentre outros. Por serem elementos imprescindíveis para o projeto e para a análise da 
dinâmica de veículos automotivos, diversos modelos matemáticos de caráter generalista podem ser encontrados na literatura especializada.

Neste trabalho optou-se pelo desenvolvimento de um modelo particular, adequado às necessidades do projeto do sistema de controle semiautônomo proposto e ao nível de informação técnica disponível acerca da VBTP-MR GUARANI. O equacionamento deu-se de forma semelhante ao encontrado em [36], exceto pelo fato de que as equações não estão totalmente linearizadas em torno de um ponto de operação. Essa modelagem é apresentada na seção 5.2.

\section{2}

\section{Modelagem a partir de Equações de Movimento}

As equações de movimento de um sistema multicorpos simplificado permite a obtenção de um modelo matemático útil para a execução das simulações necessárias à validação do sistema de controle semiautônomo proposto nesta dissertação. O modelo utilizado neste trabalho é concebido a partir das informações técnicas básicas sobre a VBTP-MR GUARANI encontradas em relatório técnico [61], onde descreve-se a modelagem do veículo no ambiente MSC.ADAMS/Car, em diferentes condições de carregamento e tipos de armamentos equipando a viatura. A Figura 5.2 ilustra esse modelo completo para o veículo descarregado.

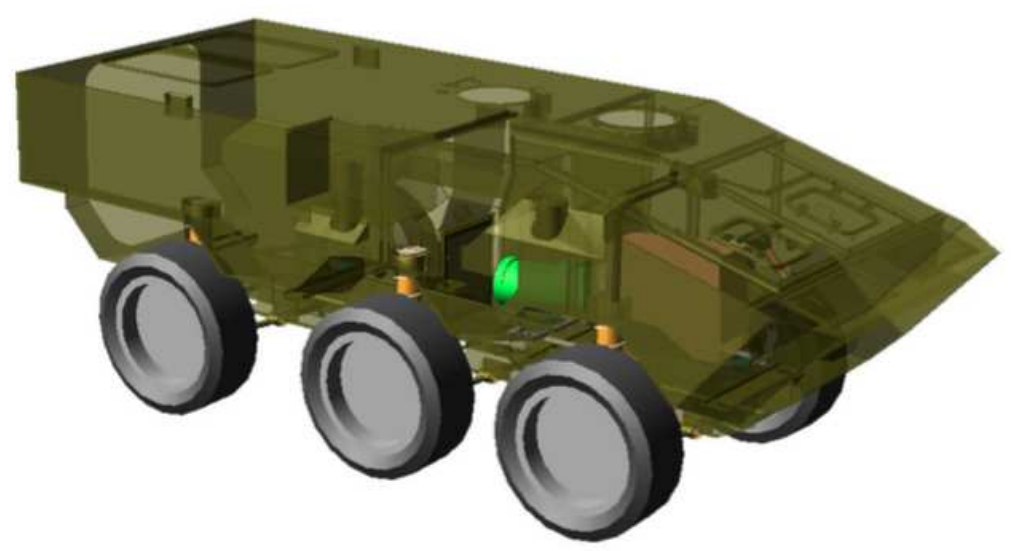

Figura 5.2: Modelo multicorpos do veículo completo descarregado.

As informações disponibilizadas permitiram a modelagem dos seguintes subsistemas do veículo: Massa Suspensa (conjunto Chassis e Carroceria), Trem 
de Força (Powertrain), Sistema de Direção, Suspensões e Pneus. A descrição dos modelos é apresentada nas Subseções 5.2.1 a 5.2.5.

\subsection{1}

\section{Massa Suspensa (com canhão $30 \mathrm{~mm}$ )}

A Massa Suspensa representa o conjunto formado pelo chassis e pela carroceria do veículo, representando um sistema rígido único. A sua modelagem inicial leva em consideração apenas a condição do veículo descarregado e sem armamento. Suas principais propriedades são:

- Massa Suspensa Total (descarregado);

- Localização do Centro de Gravidade em relação ao sistema de coordenadas global do veículo; e,

- Matriz de Inércia.

Os valores destes parâmetros não são apresentados devido à confidencialidade dos dados referentes ao veículo militar.

\section{2 .2}

\section{Trem de Força}

Conforme mencionado anteriormente, todas as análises dinâmicas realizadas no escopo deste trabalho estão limitadas à condição de velocidade longitudinal constante para o veículo. Mesmo nas informações técnicas disponibilizadas, esta condição foi imposta. Por este motivo, o trem de força (ou powertrain) foi inserido no modelo ADAMS apenas para efeitos de visualização, e as forças longitudinais são modeladas como entradas de controle utilizadas para manter constante a velocidade longitudinal do veículo. A Figura 5.3 ilustra a geometria do powertrain utilizado no modelo ADAMS.

Devido à sua menor complexidade, o modelo desenvolvido para a simulação não leva estas forças longitudinais em consideração.

\section{2 .3}

\section{Sistema de Direção}

O modelo utilizado para o sistema de direção tem como principal característica produzir esterçamentos tanto no eixo frontal quanto no intermediário. A geometria do sistema de direção é ilustrada na Figura 5.4.

Nesta modelagem são desconsiderados os efeitos de amortecedores de direção e também os efeitos da influência exercida pela direção hidráulica sobre o sistema, o que não afeta significativamente sua descrição, porque neste caso a modelagem dos esforços exercidos pelo motorista não tem finalidade, isto é, 


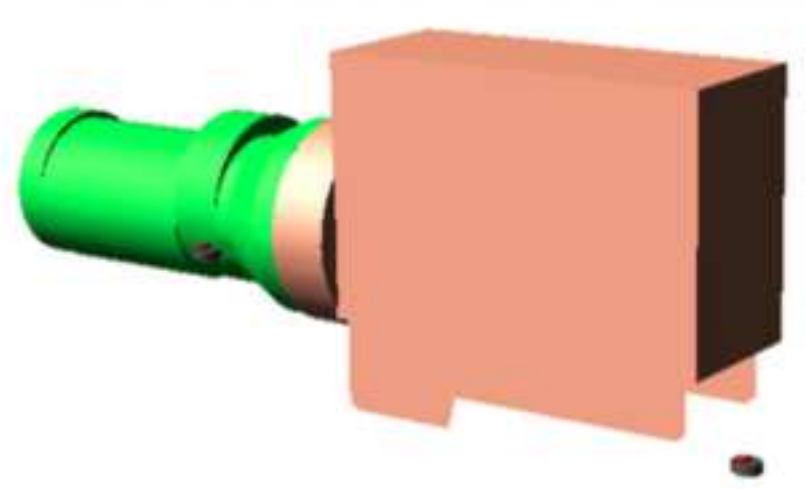

Figura 5.3: Geometria do powertrain.

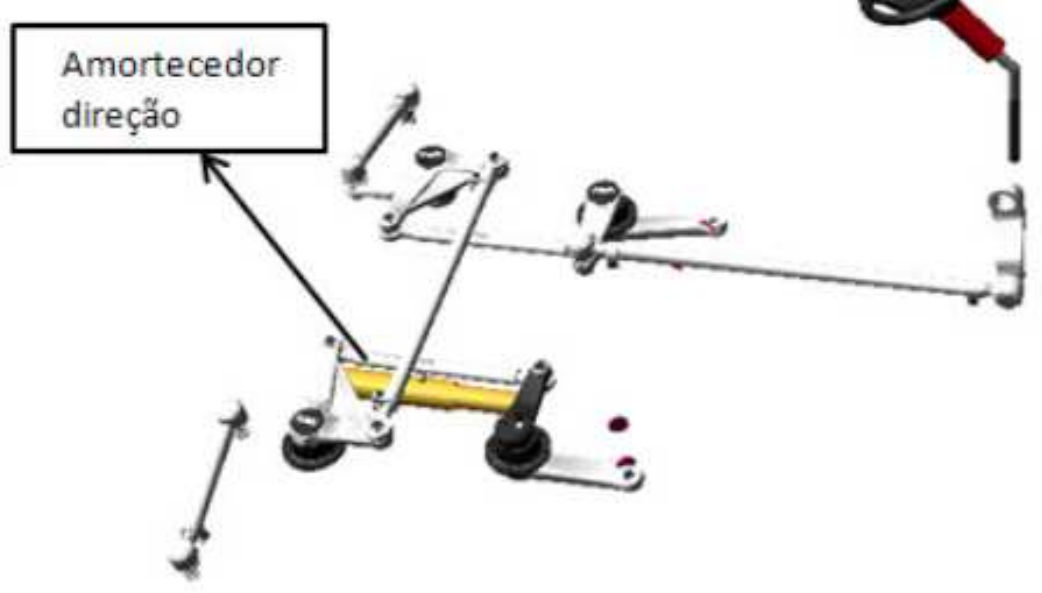

Figura 5.4: Geometria do sistema de direção.

apenas os deslocamentos angulares aplicados ao volante são considerados como sinais de entrada.

Para as simulações do sistema de controle considera-se satisfatórias as relações de proporcionalidade entre os deslocamentos angulares do volante, do esterçamento frontal e intermediário, de forma que

$$
\frac{\delta_{\text {volante }}}{\delta_{f}}=k_{\delta, 1} \quad e \frac{\delta_{f}}{\delta_{m}}=k_{\delta, 2} .
$$

Os valores das constantes de proporcionalidade $k_{\delta, 1}$ e $k_{\delta, 2}$ não são apresentados, também devido à confidencialidade dos dados técnicos sobre o veículo. 


\subsection{4}

\section{Suspensões}

As suspensões da VBTP-MR GUARANI são independentes e do tipo MacPherson, com atuadores hidropneumáticos. Estes atuadores definem tanto a rigidez equivalente quanto o amortecimento, de acordo com as condições de abastecimento de gás nitrogênio e a carga sustentada por cada uma, sendo esta carga distribuída nos três eixos. A Figura 5.5 ilustra um sistema de suspensão hidropneumática do tipo MacPherson.

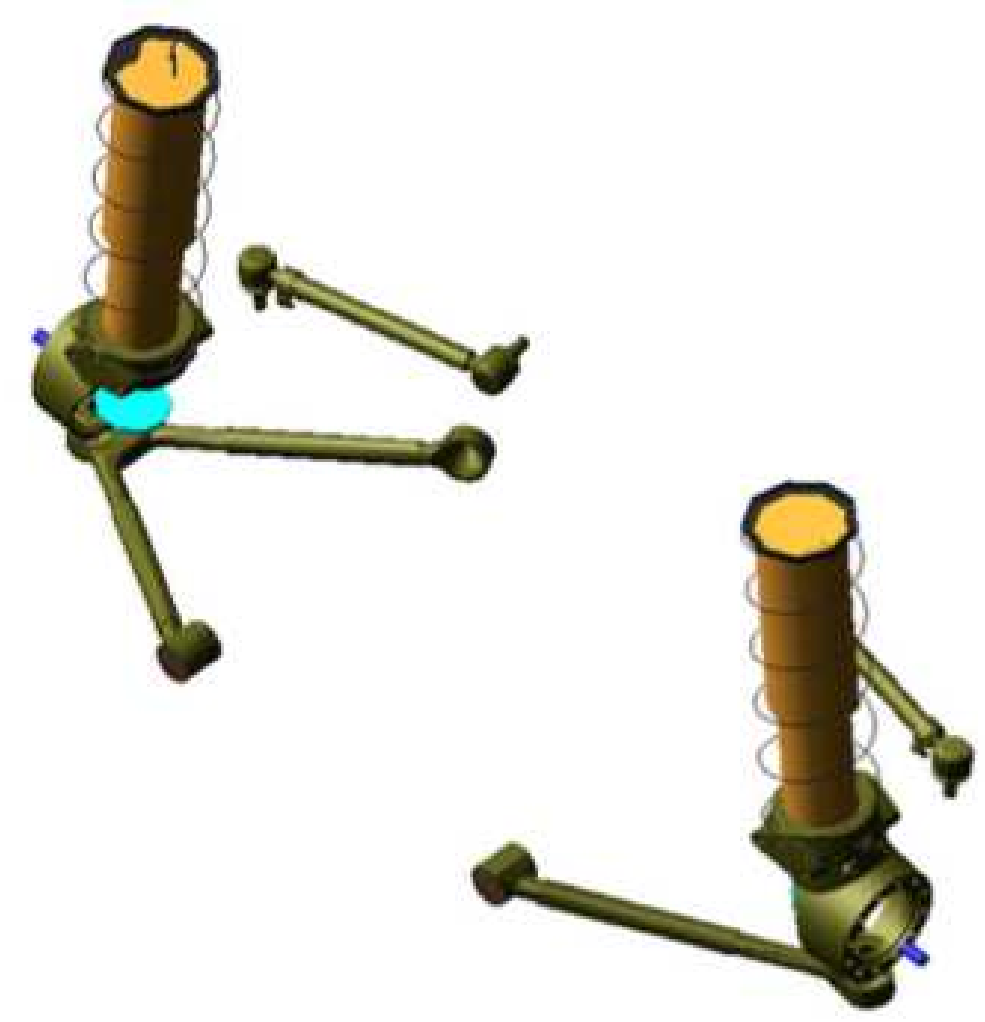

Figura 5.5: Suspensão Hidropneumatica MacPherson.

A modelagem mais precisa da rigidez de cada uma das suspensões envolveria a obtenção e a análise das suas curvas Carga $\times$ Deslocamento. Em geral, essas curvas não apresentam comportamento linear, devendo-se escolher um ponto de equilíbrio (ou operação) e a partir daí realizar-se uma linearização, encontrando-se uma relação de proporcionalidade entre as variações de deslocamento e de carga. A partir daí essa rigidez é representada por uma simples mola de constante $k_{i}$.

Elementos amortecedores também devem ser inseridos em paralelo com as molas, a partir da obtenção e da análise das curvas Força de Amortecimento $\times$ Velocidade de deslocamento. De acordo com as informações disponibilizadas, o modelo da suspensão pode ser representado por uma curva bilinear, em que a 
constante de amortecimento depende exclusivamente do sentido da velocidade de deslocamento da suspensão, isto é, se a suspensão está em compressão ou em extensão. Um exemplo de curva bilinear é apresentado na Figura 5.6.

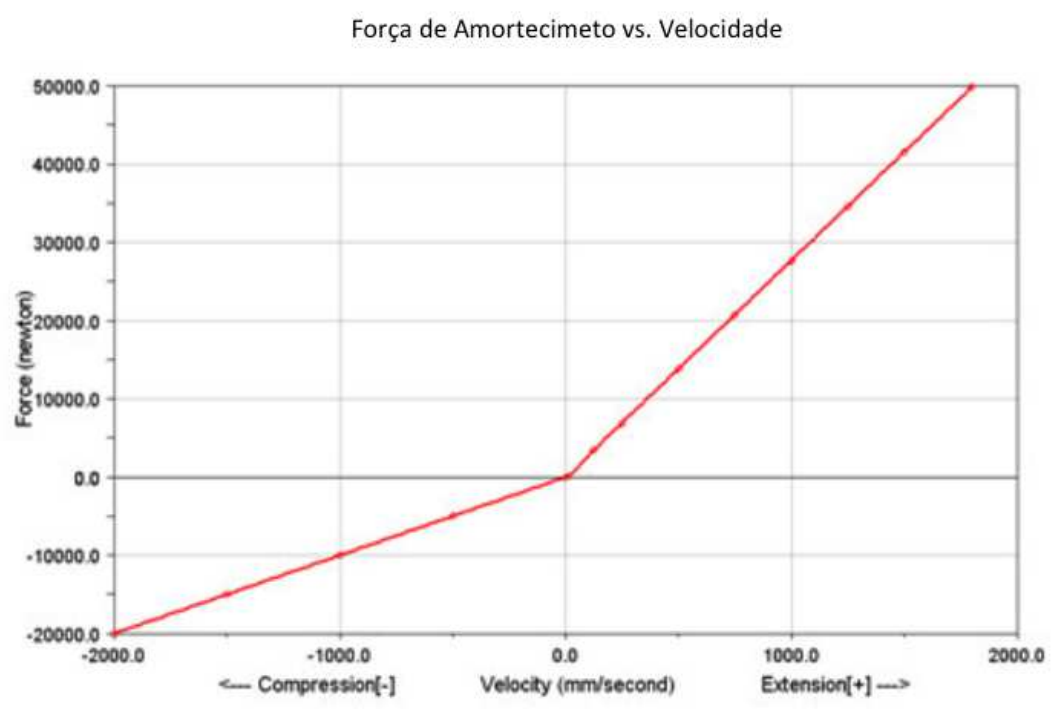

Figura 5.6: Curva bilinear de amortecimento do amortecedor da suspensão.

Assim, considerando-se a característica da curva bilinear, as constantes de amortecimento $b_{i}$ (para cada uma das suspensões) são calculadas da seguinte maneira:

$$
b_{i}=\frac{b_{e x t}+b_{\text {comp }}}{2}+\frac{v_{\text {susp }, i}}{\left|v_{\text {susp }, i}\right|}\left(\frac{b_{\text {ext }}-b_{\text {comp }}}{2}\right)
$$

em que $b_{\text {ext }}$ é a constante de amortecimento quando $v_{\text {susp }}>0$, isto é, na extensão da suspensão, e $b_{\text {comp }}$ é a constante de amortecimento quando $v_{\text {susp }}<0$, na compressão.

Portanto, para o modelo de simulações desenvolvido, cada uma das suspensões é modelada como uma mola de constante $k_{i}$ em paralelo com um amortecedor de constante $b_{i}$, de acordo com a Figura 5.7.

\section{2 .5}

\section{Pneus}

Devido à disponibilidade de dados relativos aos pneus da VBTP-MR GUARANI, é possível obter-se um modelo com grande precisão para estes elementos. Essa modelagem mais complexa implicaria em alto custo computacional para a execução das simulações desejadas, o que seria desnecessário para os testes com o sistema de controle proposto. Portanto, para a modelagem dos 


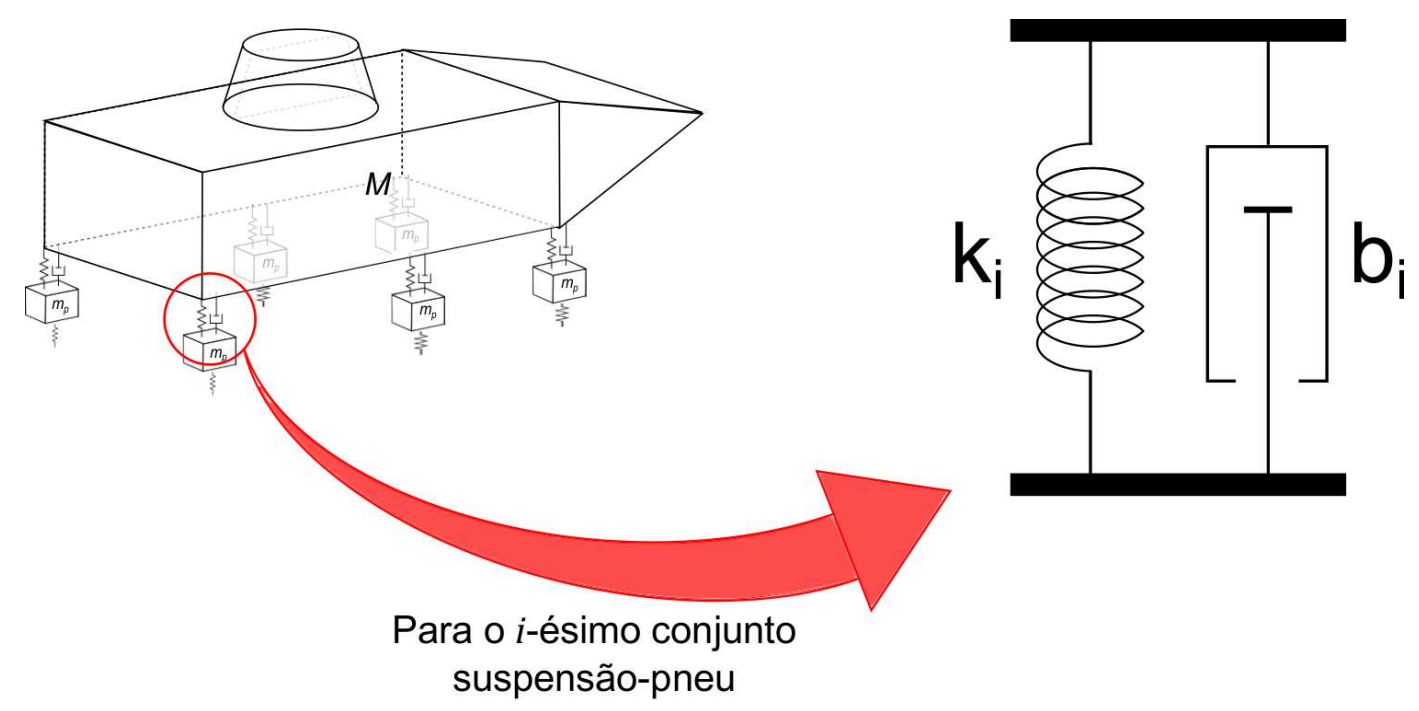

Figura 5.7: Modelo mola-amortecedor para as suspensões.

pneus é adotada uma abordagem simplificada, dividindo-se o problema nas direções vertical e transversal. A Figura 5.8 ilustra a representação geométrica dos pneus do veículo.
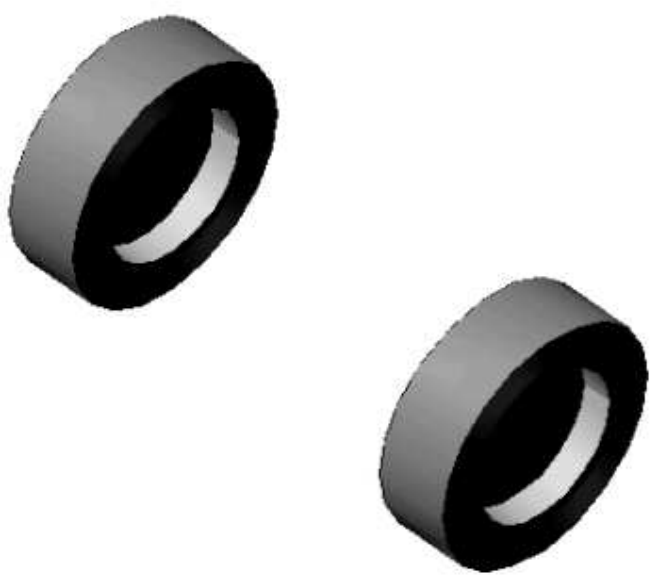

Figura 5.8: Representação geométrica do modelo dos pneus.

\section{Direção Vertical}

Admitindo-se a pressão de operação padrão recomendada pelo fabricante, as propriedades de massa, de inércia e de rigidez vertical dos pneus são disponibilizadas, o que permitiu a concepção de um modelo massa-mola simplificado para as forças verticais fornecidas pelo mesmo. Admite-se ainda que o contato entre o pneu e o solo se dá apenas em um único ponto, o que simplifica as análises. A Figura 5.9 ilustra este modelo, em que $k_{p}$ representa 
a rigidez do pneu e $m_{p}$ a porção da massa não suspensa sobre a mola que representa esta rigidez.
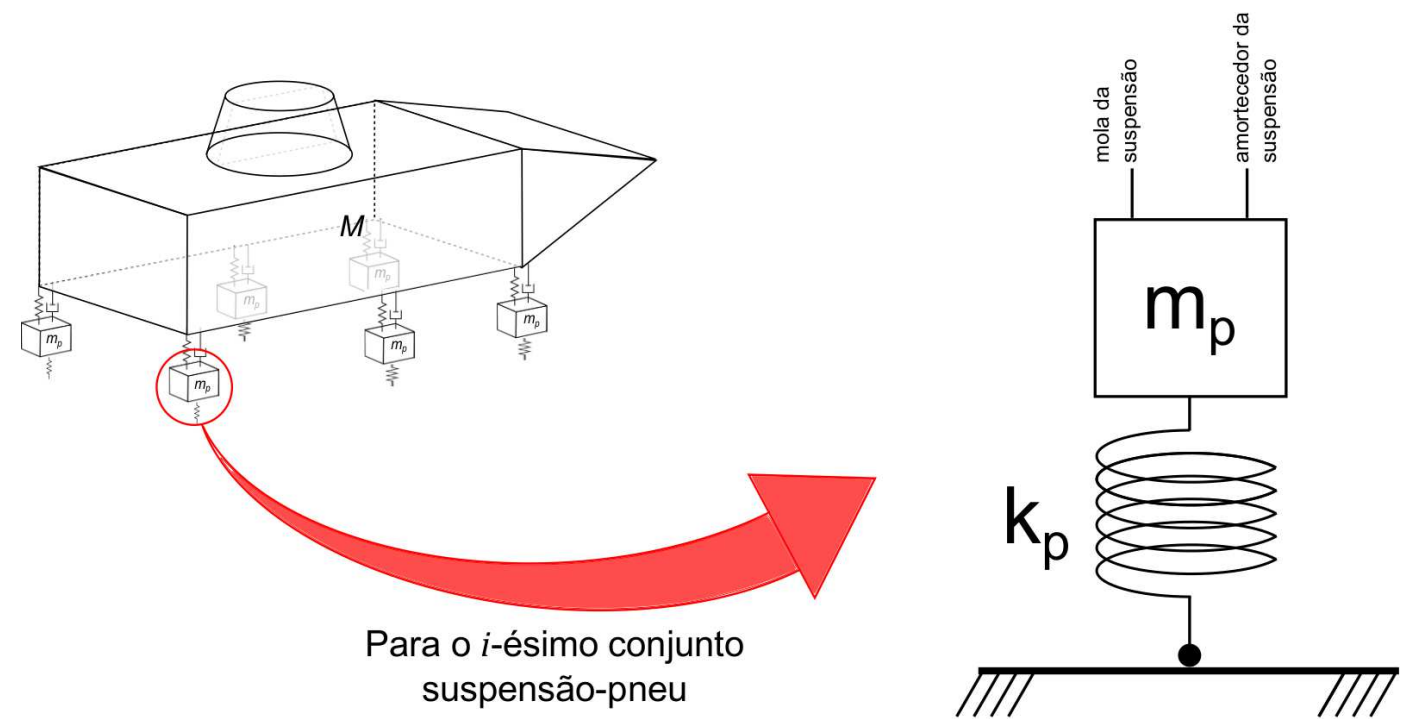

Figura 5.9: Modelo Massa-Mola para os pneus.

\section{Direção Transversal}

As forças laterais devido ao deslizamento (ou deriva) dos pneus são incluídas admitindo-se uma linearização que permite a aproximação dada por

$$
F_{y}=C \alpha
$$

onde $C$ é a rigidez de deriva e $\alpha$ o ângulo de deriva do pneu. A Figura 5.10 ilustra este modelo e a curva $F_{y} \times \alpha$, destacando sua região de linearidade.
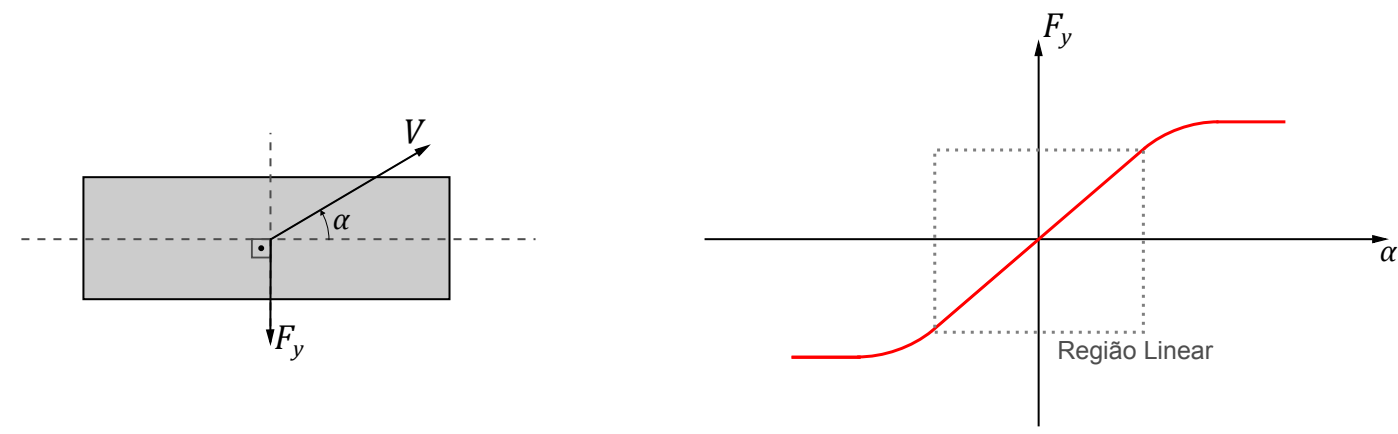

Figura 5.10: Modelo linear para a força lateral dos pneus.

Os valores para estes parâmetros não são apresentados devido à confidencialidade dos dados.

Conforme visto na Subseção 5.2.6, a integração dos modelos desses subsistemas possibilitou o desenvolvimento de um modelo do sistema multicorpos 
utilizado nas simulações de teste do sistema de controle semiautônomo proposto.

\subsection{6}

\section{Sistema Multicorpos}

O modelo mecânico multicorpos para o veículo, desenvolvido a partir da adoção do padrão ISO 4130, tem um total de 12 (doze) graus de liberdade, representados por:

- os ângulos de Euler da massa suspensa (corpo rígido principal do veículo), representando 3 (três) graus de liberdade;

- a posição de um ponto de referência, sendo neste caso considerado o ponto a partir do qual se pode medir o ângulo de rolagem da massa suspensa, também representando 3 (três) graus de liberdade (neste trabalho, chamado de "centro de rolagem"); e,

- A posição vertical dos blocos de massa que representam cada um dos conjuntos pneu-suspensão do veículo, representando 6 (seis) graus de liberdade adicionais.

Além disso, considera-se que o ângulo de deslizamento do veículo (que será identificado por $\beta$ ) não pode ser negligenciado, e que a velocidade longitudinal, também neste modelo, é constante (implicando em uma aceleração longitudinal nula). As Figuras 5.11 e 5.12 ilustram as simplificações consideradas.

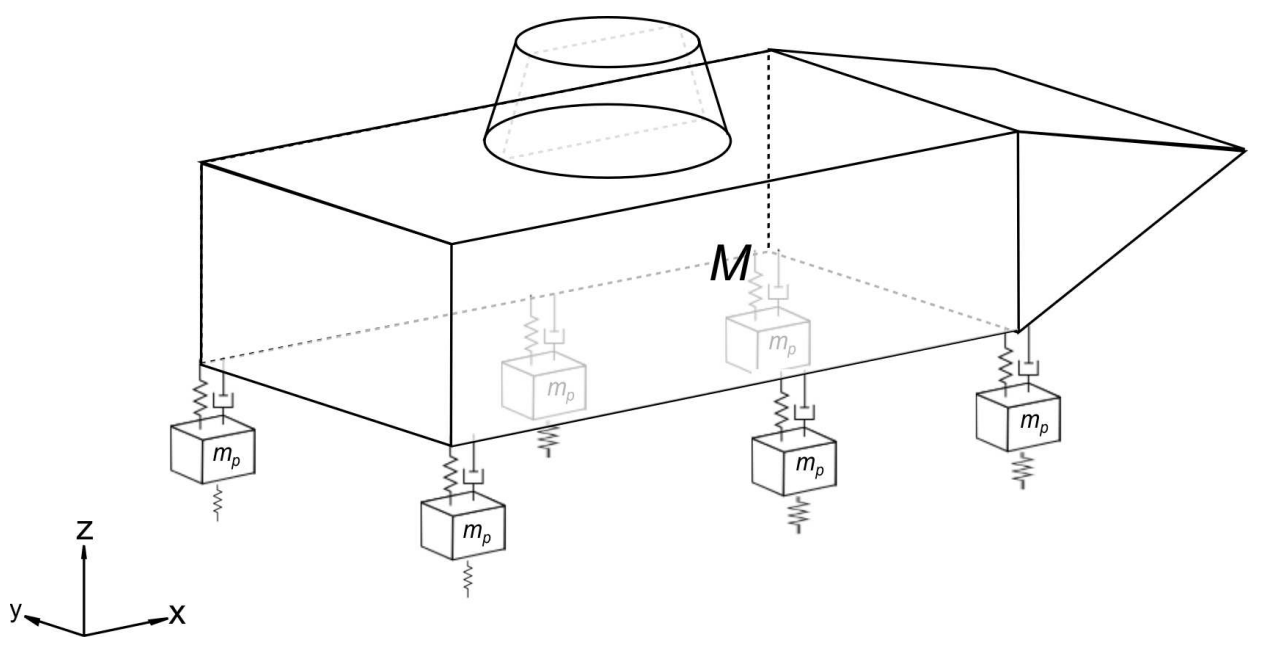

Figura 5.11: Esquemático simplificado para o veículo 6x6 (perspectiva). 


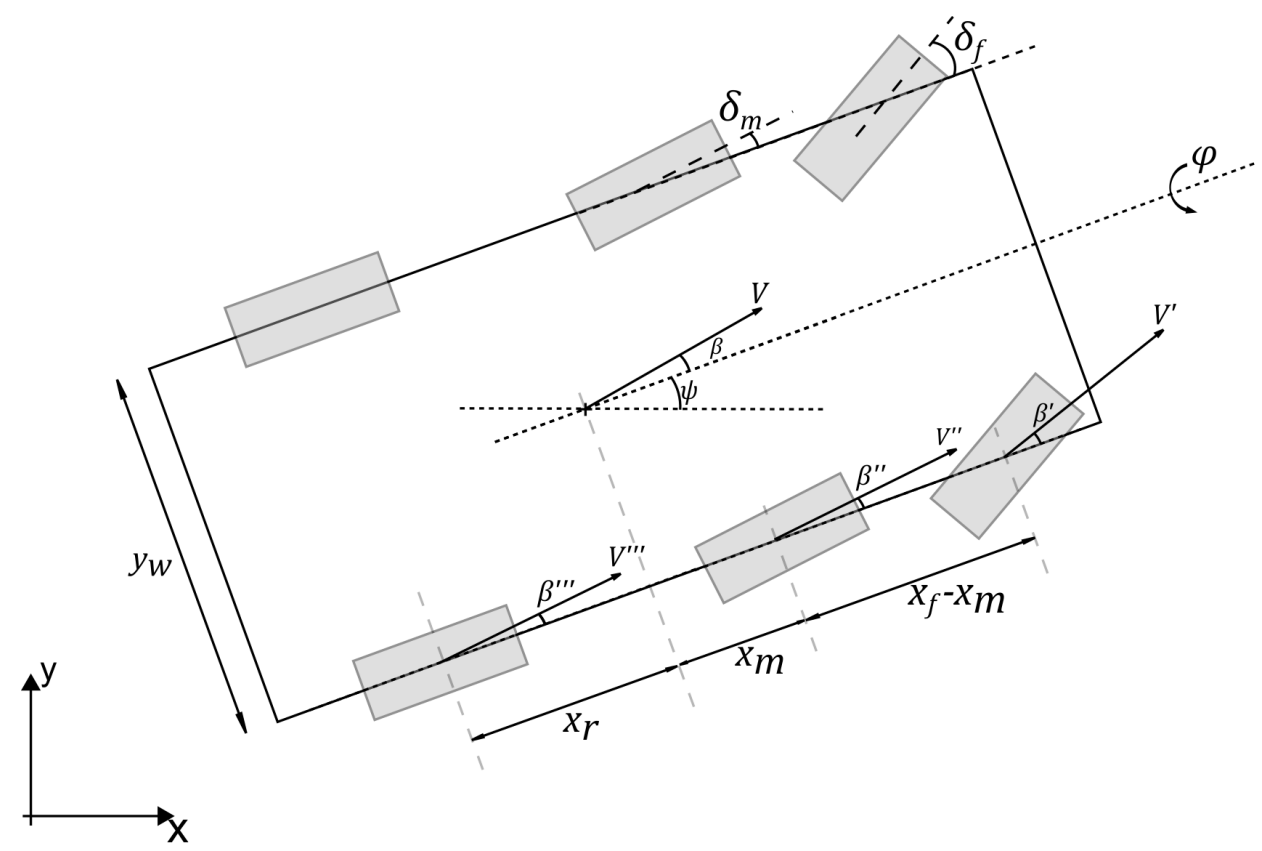

Figura 5.12: Esquemático simplificado para o veículo 6x6 (vista de cima).

Observando-se a Figura 5.11, pode-se chegar às equações de movimento do eixo vertical tanto para a massa suspensa $M$ quanto para os blocos de massa $m_{p}$ (relativamente aos seus centros de gravidade). Estas equações são, com relação e um referencial inercial, dadas por

$$
\begin{gathered}
\sum_{m_{p, i}} \mathbf{F}=m_{p, i} \ddot{z}_{i} \Longrightarrow \\
m_{p, i} \ddot{z}_{i}=k_{p}\left[h_{0}-\left(z_{i}-r_{i}\right)\right]-k_{i}\left[l-\left(z \pm \frac{y_{w}}{2} \varphi \pm x_{r} \theta-z_{i}\right)\right] \\
-b_{i}\left[-\left(\dot{z} \pm \frac{y_{w}}{2} \dot{\varphi} \pm x_{r} \dot{\theta}\right)+\dot{z}_{i}\right]-m_{p, i} g, \quad i=1,2, \ldots, 6,
\end{gathered}
$$

onde os parâmetros representam o seguinte:

- $m_{p, i}$ é o bloco de massa representando o $i$-ésimo conjunto pneususpensão do veículo;

- $z_{i}$ é a altura (variável no tempo) do bloco de massa $m_{p, i}$;

- $k_{p}$ é a constante de rigidez de uma mola representando a cada um dos pneus do veículo;

- $h_{0}$ é a altura em que deveriam se posicionar as massas $m_{p, i}$ em um ambiente de gravidade nula (isto é, quando a suspensão não está em compressão ou em extensão);

- $r_{i}$ é a altura do ponto de contato entre o $i$-ésimo pneu e o solo; 
- $k_{i}$ é constante de rigidez da mola representando o elemento da $i$-ésima suspensão;

- $z_{i}$ é a altura (variável no tempo) do bloco de massa $m_{p, i}$;

- $l$ é a distância entre o centro de gravidade da massa suspensa e a altura dos blocos de massa $m_{p, i}$ em uma ambiente de gravidade nula;

- $z$ é a altura (variável no tempo) da massa suspensa $M$;

- $b_{i}$ é a constante de amortecimento representando o elemento da $i$-ésima suspensão;

- $y_{w}$ e $x_{r}$ são as distâncias indicadas na Figura 5.12

- $\varphi$ é o ângulo de rolagem (variável no tempo) da massa suspensa $M$;

- $\theta$ é o ângulo de arfagem (variável no tempo) da massa suspensa $M$; e,

- $g$ é a aceleração da gravidade.

Na equação 5-6, os termos proporcionais aos ângulos $\varphi$ e $\theta$ foram assinalados com \pm porque seus sinais variam de acordo com o posicionamento de cada um dos seis conjuntos pneu-suspensão. O mesmo vale para os termos proporcionais às velocidades angulares $\dot{\varphi}$ e $\dot{\theta}$.

Para a massa suspensa $M$, com relação a um referencial inercial, pode-se ainda escrever

$$
\begin{gathered}
\sum_{M} \mathbf{F}=M \ddot{z} \Longrightarrow \\
M \ddot{z}=\sum_{i=1}^{6} F_{i}-M g,
\end{gathered}
$$

onde

$$
\begin{aligned}
F_{i}= & k_{i}\left[l-\left(z \pm \frac{y_{w}}{2} \varphi \pm x_{r} \theta-z_{i}\right)\right] \\
& +b_{i}\left[-\left(\dot{z} \pm \frac{y_{w}}{2} \dot{\varphi} \pm x_{r} \dot{\theta}\right)+\dot{z}_{i}\right] .
\end{aligned}
$$

Ainda considerando-se a Figura 5.12 ilustrando a vista de cima do veículo, é possível obter um equacionamento para o movimento lateral equivalente a alguns modelos tipo bicicleta para o sistema, que por sua vez será dado por

$$
\sum \mathbf{F}_{y}=M_{t} \ddot{y}-M h\left[\ddot{\varphi} \cos \varphi-\dot{\varphi}^{2} \sin \varphi\right] \cos \psi,
$$

em que $M_{t}=M+6 m_{p}$ e $h$ é a distância entre o centro de gravidade da massa suspensa e o centro de rolagem.

Levando-se em conta que neste trabalho são consideradas apenas as situações onde não há uma aceleração longitudinal no veículo, pode-se observar que 


$$
\left\{\begin{array}{l}
\dot{x}=V \cos (\psi+\beta) \\
\dot{y}=V \sin (\psi+\beta)
\end{array}\right.
$$

e portanto

$$
\left\{\begin{array}{l}
\ddot{x}=-V \sin (\psi+\beta)(\dot{\psi}+\dot{\beta}) \\
\ddot{y}=V \cos (\psi+\beta)(\dot{\psi}+\dot{\beta})
\end{array},\right.
$$

de onde pode-se concluir que

$$
\begin{aligned}
& M_{t} V \cos (\psi+\beta)(\dot{\psi}+\dot{\beta})= \\
& \quad M h\left[\ddot{\varphi}-\dot{\varphi}^{2} \sin \varphi\right] \cos \varphi+2 F_{f} \cos \left(\delta_{f}+\psi\right) \\
& \quad+2 F_{m} \cos \left(\delta_{m}+\psi\right)-2 F_{r} \cos \psi .
\end{aligned}
$$

As forças $F_{f}, F_{m}$ e $F_{r}$ são calculadas a partir dos parâmetros de rigidez de curva $C_{f}, C_{m}$ e $C_{r}$ dos pneus, pela expressão

$$
\left[\begin{array}{c}
F_{f} \\
F_{m} \\
F_{r}
\end{array}\right]=\left[\begin{array}{ccc}
C_{f} & 0 & 0 \\
0 & C_{m} & 0 \\
0 & 0 & C_{r}
\end{array}\right]\left[\begin{array}{c}
\alpha_{f} \\
\alpha_{m} \\
\alpha_{r}
\end{array}\right]
$$

onde $\alpha_{f}, \alpha_{m}$ e $\alpha_{r}$ são os ângulos entre o eixo longitudinal dos pneus frontais, intermediários e traseiros e seus vetores velocidade. Portanto, pode-se dizer que

$$
\left\{\begin{array}{r}
F_{f}=C_{f}\left(\delta_{f}-\beta^{\prime}\right) \\
F_{m}=C_{m}\left(\delta_{m}-\beta^{\prime \prime}\right) \\
F_{r}=C_{r} \beta^{\prime \prime \prime}
\end{array}\right.
$$

e os ângulos $\beta^{\prime}, \beta^{\prime \prime}$ e $\beta^{\prime \prime \prime}$ são aproximados por

$$
\left\{\begin{array}{l}
\beta^{\prime}=\beta+\frac{x_{f}}{V} \dot{\psi} \\
\beta^{\prime \prime}=\beta+\frac{x_{m}}{V} \dot{\psi} \\
\beta^{\prime \prime \prime}=\beta-\frac{x_{r}}{V} \dot{\psi}
\end{array}\right.
$$

Fixando um referencial não inercial no centro de gravidade da massa suspensa e adotando o padrão ISO 4130 para o sistema de coordenadas, podese escrever a equação de Euler [63], de forma que

$$
\mathbf{M}=\frac{d}{d t} \mathbf{L}=\dot{\mathbf{L}}+\boldsymbol{\omega} \times(\mathbf{I} \boldsymbol{\omega})
$$

Os momentos das forças devem, portanto, ser dados por

$$
\left[\begin{array}{l}
\sum M_{x} \\
\sum M_{y} \\
\sum M_{z}
\end{array}\right]=\left[\begin{array}{lll}
I_{x x} & I_{x y} & I_{x z} \\
I_{x y} & I_{y y} & I_{y z} \\
I_{x z} & I_{y z} & I_{z z}
\end{array}\right]\left[\begin{array}{c}
\ddot{\varphi} \\
\ddot{\theta} \\
\ddot{\psi}
\end{array}\right]+\left[\begin{array}{c}
\dot{\varphi} \\
\dot{\theta} \\
\dot{\psi}
\end{array}\right] \times\left[\begin{array}{lll}
I_{x x} & I_{x y} & I_{x z} \\
I_{x y} & I_{y y} & I_{y z} \\
I_{x z} & I_{y z} & I_{z z}
\end{array}\right]\left[\begin{array}{c}
\dot{\varphi} \\
\dot{\theta} \\
\dot{\psi}
\end{array}\right],
$$

em que tem-se 


$$
\begin{aligned}
& \sum M_{x}=2 F_{f} h \cos \delta_{f}+2 F_{m} h \cos \delta_{m}-2 F_{r} h \\
&+M g h \sin \varphi-\frac{y_{w}^{2}}{4} \varphi \sum_{i=1}^{6} k_{i}-\frac{y_{w}^{2}}{4} \dot{\varphi} \sum_{i=1}^{6} b_{i}, \\
& \sum M_{y}=\left(F_{3}+F_{4}\right) x_{r}-\left(F_{2}+F_{5}\right) x_{m}-\left(F_{1}+F_{6}\right) x_{f},
\end{aligned}
$$

e ainda,

$$
\sum M_{z}=2 F_{f} x_{f} \cos \delta_{f}+2 F_{m} x_{m} \cos \delta_{m}+2 F_{r} x_{r}
$$

O modelo resultante destas equações foi implementado no ambiente de simulação numérica MATLAB/Simulink(C), e gerou resultados satisfatórios, pois seu comportamento foi similar ao comportamento do modelo ADAMS, descrito em [61]. Por esse motivo, o modelo pode ser considerado uma ferramenta que teve grande importância para o desenvolvimento do sistema de controle semiautônomo.

\section{3}

\section{Comparação dos Comportamentos}

Para que fossem comparados os comportamentos dos modelos dinâmicos, o modelo desenvolvido e implementado no ambiente Simulink é submetido a simulações de manobras padronizadas, em que o comportamento do modelo implementado no MSC.ADAMS/Car já era de prévio conhecimento. As manobras realizadas são de Troca de Pistas Simples (ou Single Lane Change) e Troca de Pistas Dupla (ou Double Lane Change). As variáveis que têm seus comportamentos comparados são os ângulos de rolagem da massa suspensa $\varphi$ e o ângulo de deslizamento (ou deriva) $\beta$. As figuras que ilustram os resultados obtidos pela simulação do modelo implementado no MSC.ADAMS para o veículo equipado com torre para metralhadora $7,62 \mathrm{~mm}$ e com canhão $30 \mathrm{~mm}$ são disponibilizadas como informações técnicas e constam no relatório técnico [61].

\subsection{1}

\section{Single Lane Change}

A manobra de Troca de Pistas Simples é realizada a partir de um padrão de entradas representado por um ciclo de senóide, de amplitude e período pré-definidos. Neste caso, a entrada aplicada ao volante no modelo ADAMS é representada pela Figura 5.13.

A entrada aplicada ao volante no modelo desenvolvido é representada na Figura 5.14. Observa-se que o ciclo de senóide aplicado ao deslocamento angular do volante tem uma amplitude de $24^{\circ}$ e um período de $3,2 s$ de duração. 


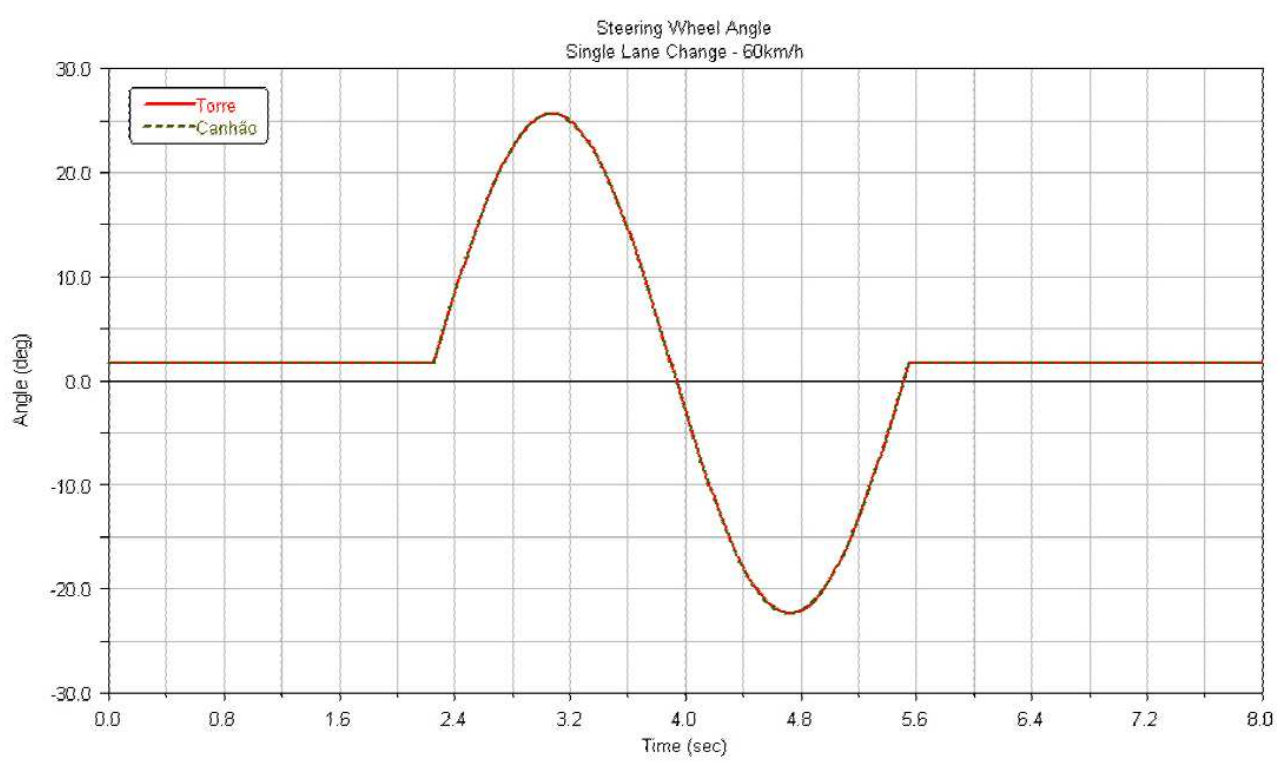

Figura 5.13: Padrão de Entrada para uma manobra Single Lane Change aplicado ao modelo ADAMS disponibilizado.

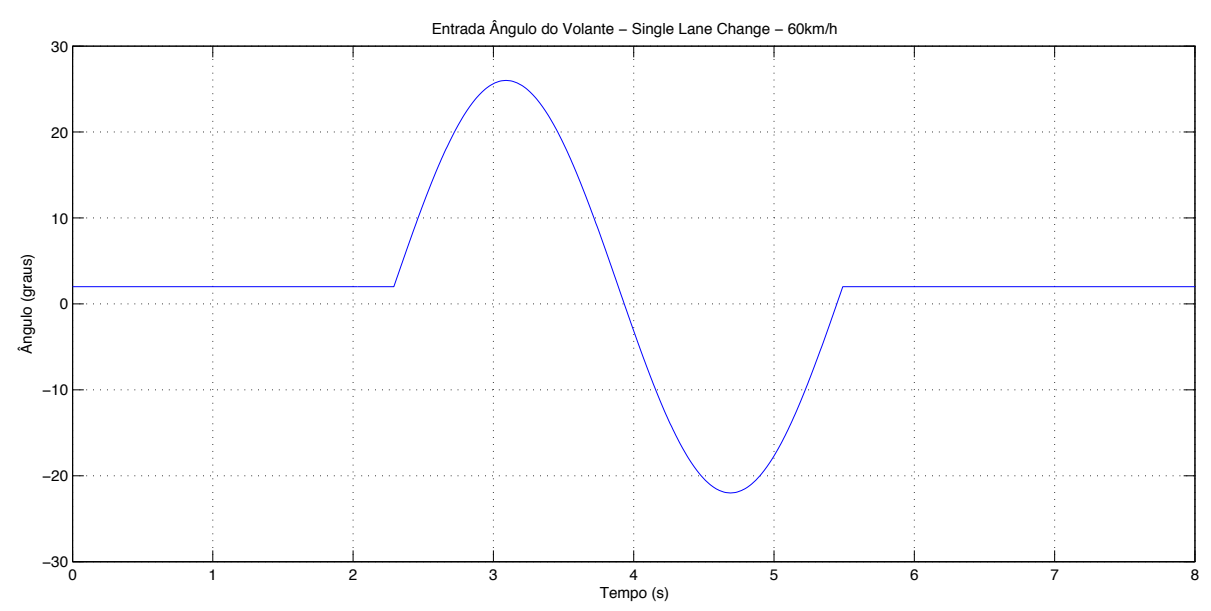

Figura 5.14: Padrão de Entrada para uma manobra Single Lane Change aplicado ao modelo desenvolvido.

As Figuras 5.15 e 5.16 ilustram as curvas de $\varphi$ e $\beta$ para a manobra Single Lane Change, obtidas pela simulação do modelo ADAMS, disponibilizadas como informação técnica.

As Figuras 5.17 e 5.18 ilustram as curvas de $\varphi$ e $\beta$ para a manobra Single Lane Change, obtidas a partir da simulação do modelo implementado. 


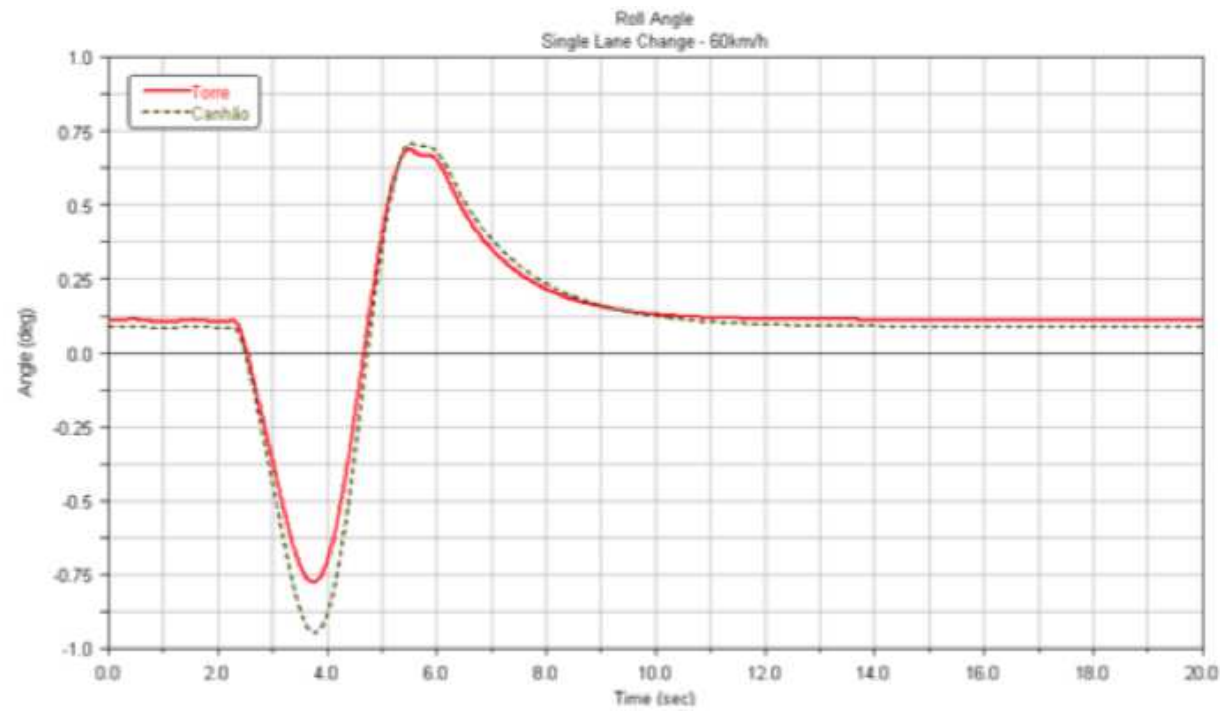

Figura 5.15: Comportamento do Ângulo de Rolagem $\varphi$ em uma manobra de Single Lane Change, para o modelo implementado no MSC.ADAMS.

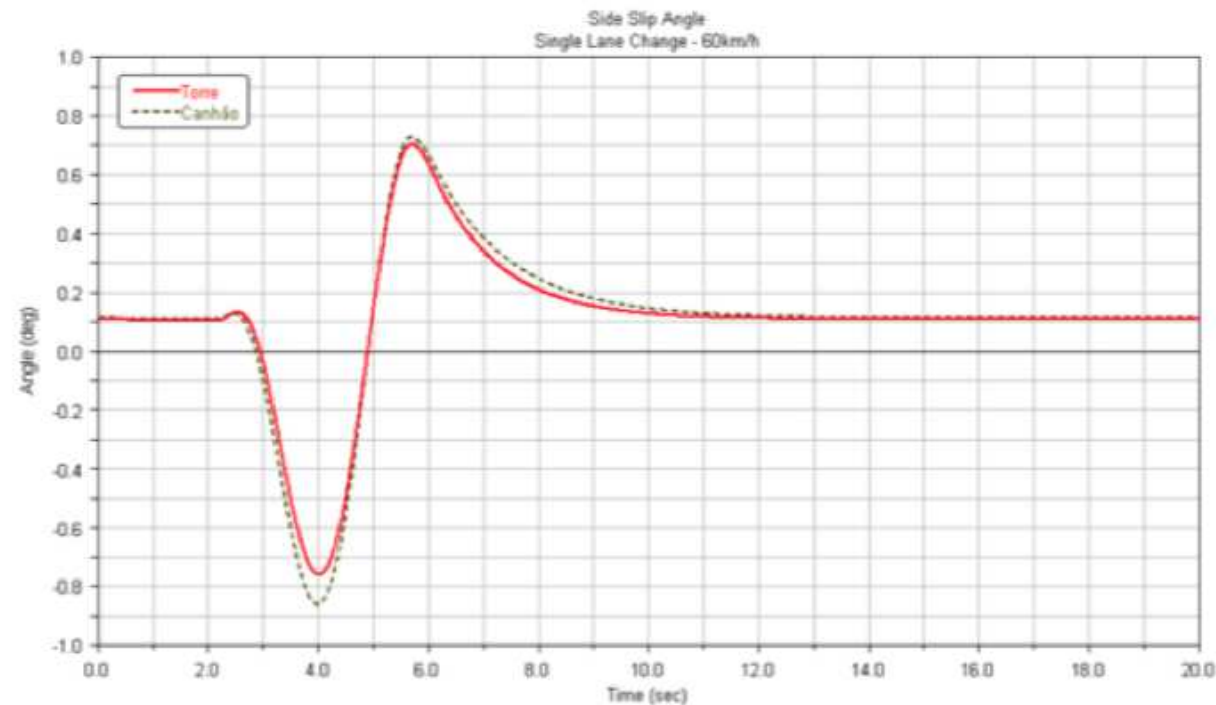

Figura 5.16: Comportamento do Ângulo de Deslizamento $\beta$ em uma manobra de Single Lane Change, para o modelo implementado no MSC.ADAMS.

\subsection{2}

\section{Double Lane Change}

A manobra de Troca de Pistas Dupla é realizada a partir de um padrão de entradas mais complexo, pré-definido em normas específicas. Neste caso, a entrada aplicada ao volante no modelo ADAMS pode ser representada pela Figura 5.19.

Observa-se que, em função da complexidade e da dificuldade de se obter uma representação matemática analítica para a curva apresentada na Figura 


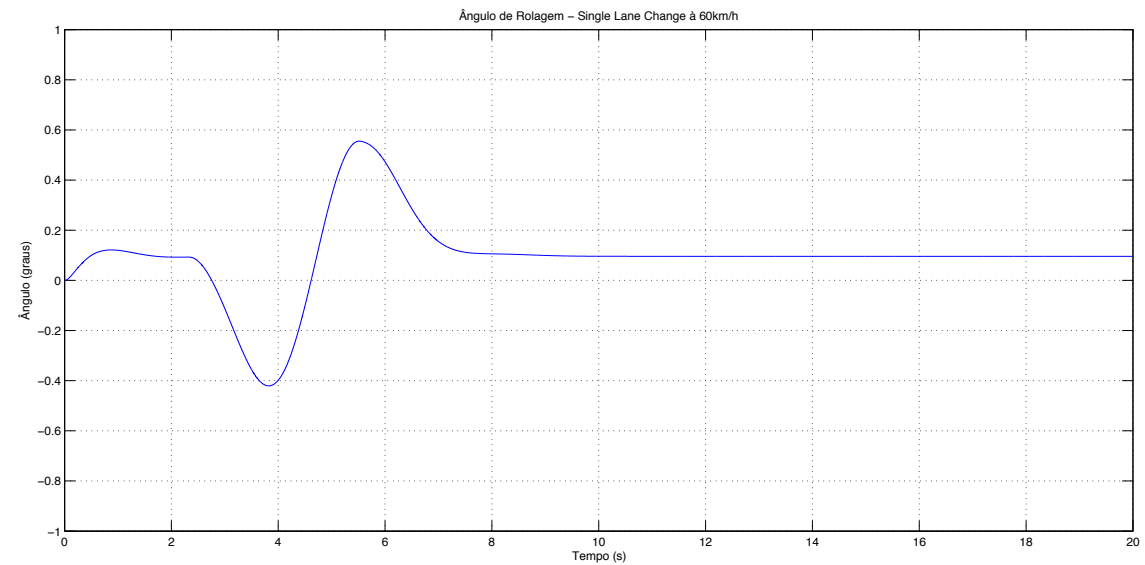

Figura 5.17: Comportamento do Ângulo de Rolagem $\varphi$ em uma manobra de Single Lane Change, para o modelo implementado no Simulink.

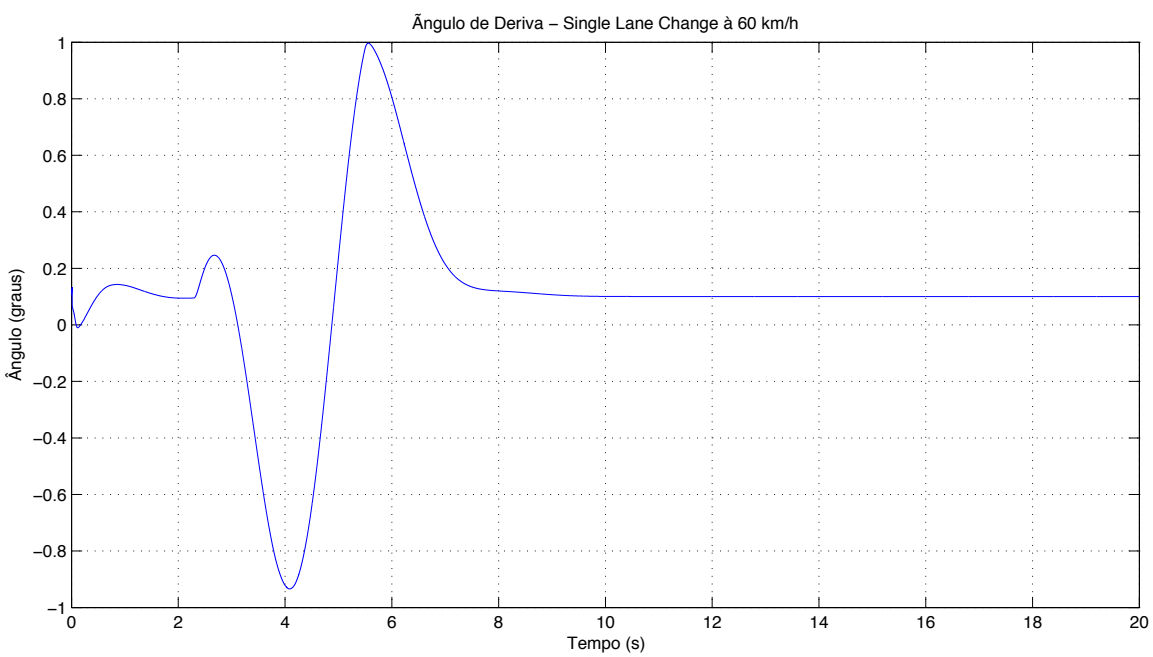

Figura 5.18: Comportamento do Ângulo de Deslizamento $\beta$ em uma manobra de Single Lane Change, para o modelo implementado no Simulink.

5.19, buscou-se reproduzir uma aproximação através da curva ilustrada na Figura 5.20. Este padrão de entradas foi então aplicado ao modelo implementado.

As Figuras 5.21 e 5.22 ilustram as curvas de $\varphi$ e $\beta$ para a manobra Double Lane Change, obtidas pela simulação do modelo ADAMS, disponibilizadas como informação técnica.

As Figuras 5.23 e 5.24 ilustram as curvas de $\varphi$ e $\beta$ para a manobra Double Lane Change, obtidas a partir da simulação do modelo implementado.

As curvas permitem observar que as variáveis têm comportamentos similares quando os modelos do veículo são submetidos às manobras especificadas. Além das óbvias diferenças existentes entre os padrões de entrada (visuali- 


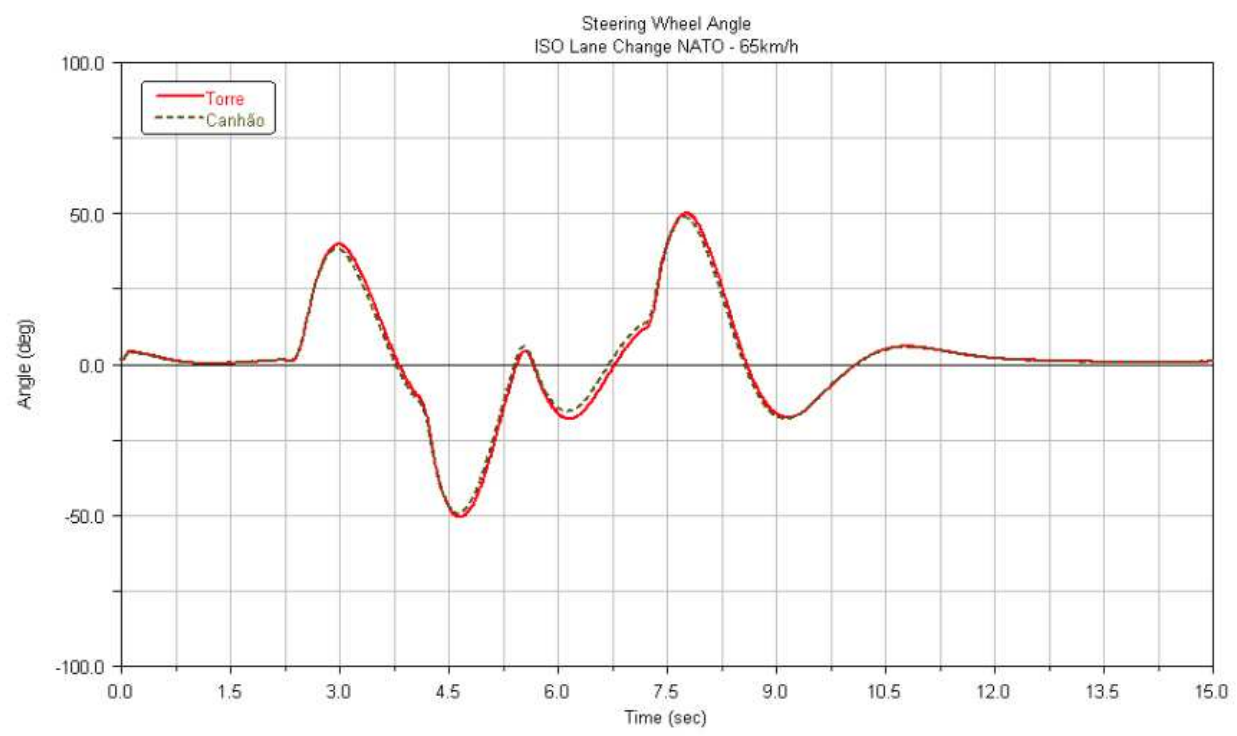

Figura 5.19: Padrão de Entrada para uma manobra Double Lane Change aplicado ao modelo ADAMS.

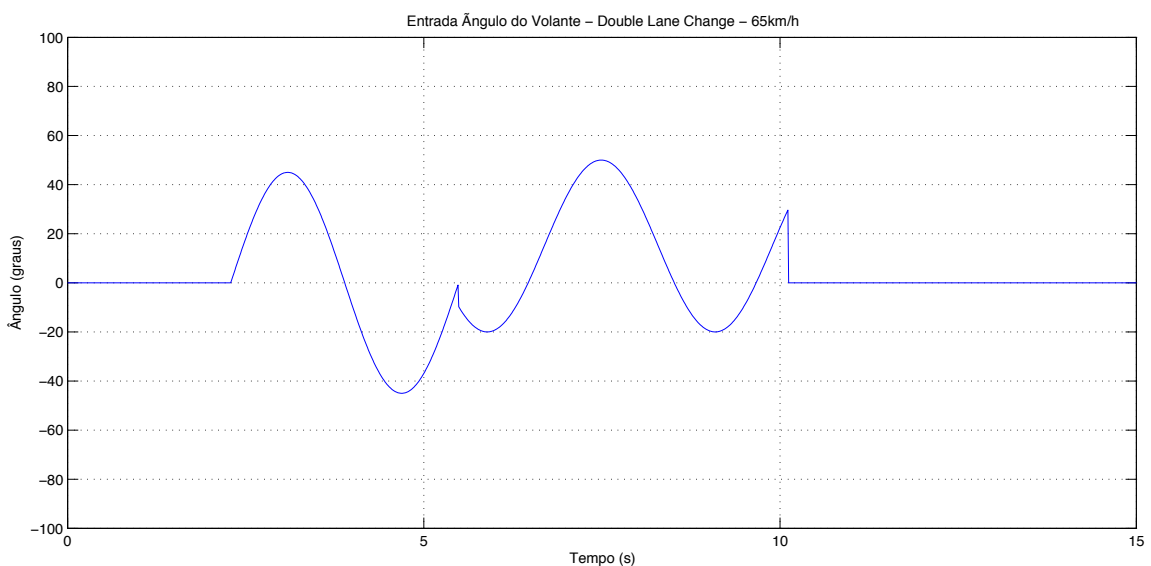

Figura 5.20: Padrão de Entrada para uma manobra Double Lane Change aplicado ao modelo desenvolvido.

zados principalmente para a manobra Double Lane Change) as discrepâncias devem-se ao fato de que o modelo implementado no ambiente Simulink é de menor complexidade, principalmente pelas simplificações que foram assumidas e relatadas na seção 5.2. No entanto, considerou-se que o comportamento deste modelo dinâmico foi satisfatório para que este pudesse ser utilizado nas simulações do sistema de controle semiautônomo proposto nesta dissertação, conforme será visto no próximo capítulo. 


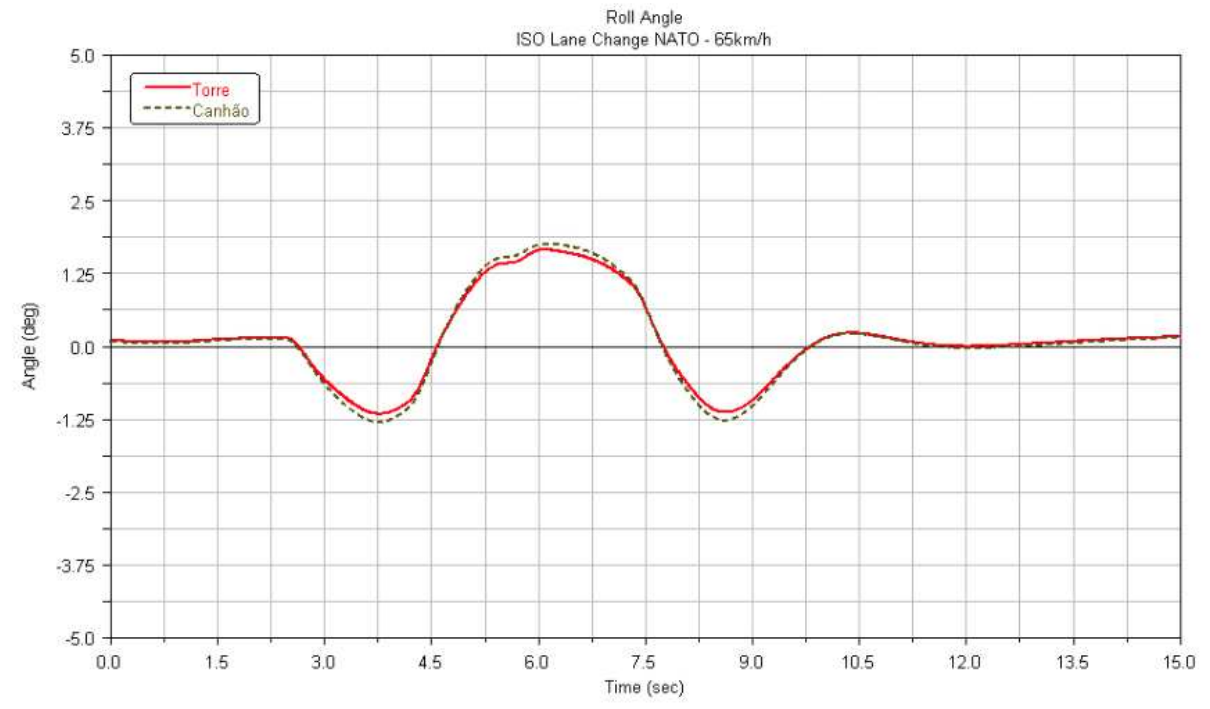

Figura 5.21: Comportamento do Ângulo de Rolagem $\varphi$ em uma manobra de

Double Lane Change, para o modelo implementado no MSC.ADAMS.

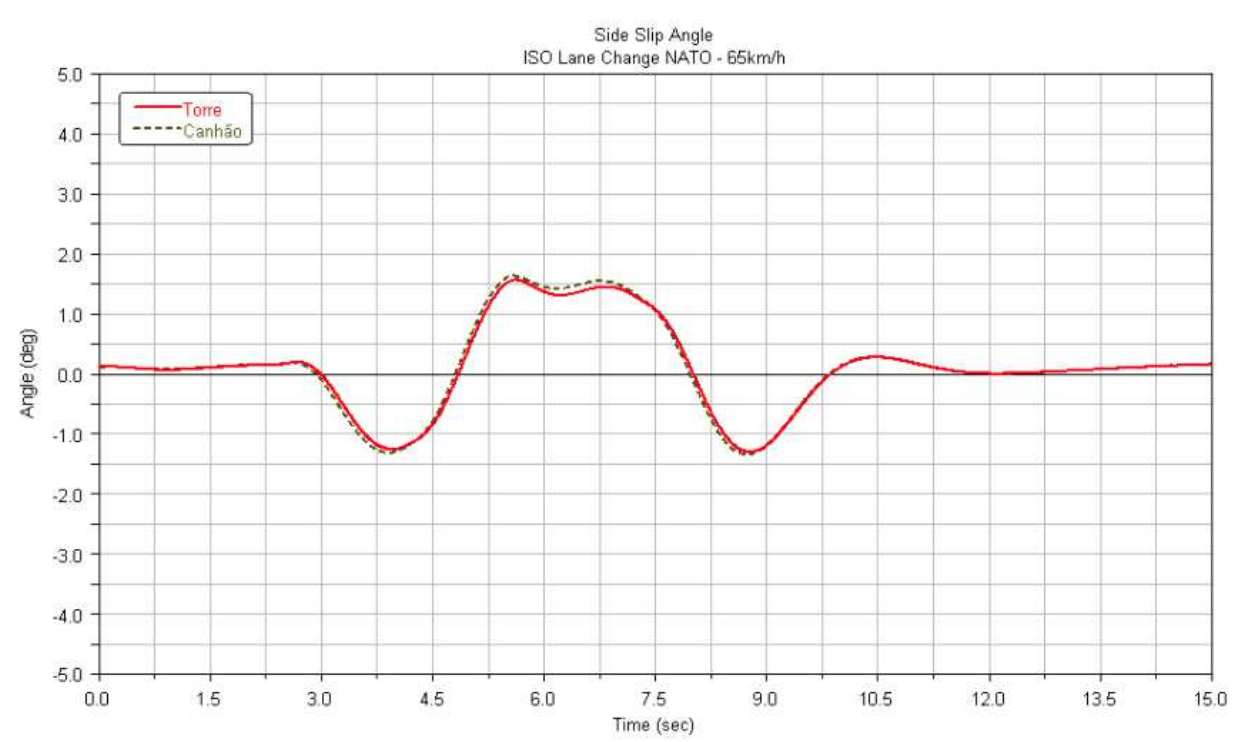

Figura 5.22: Comportamento do Ângulo de Deslizamento $\beta$ em uma manobra de Double Lane Change, para o modelo implementado no MSC.ADAMS. 


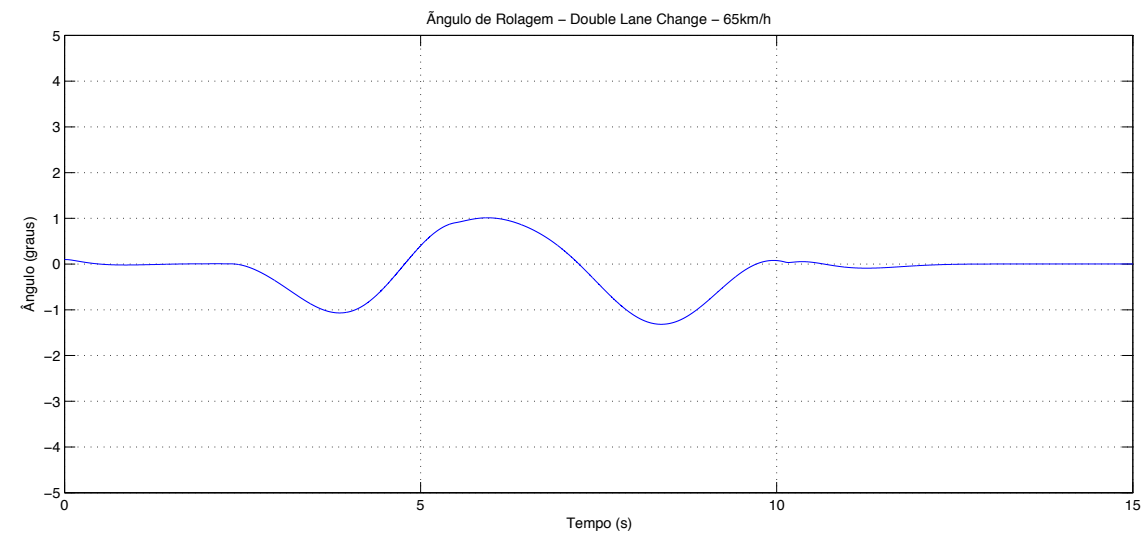

Figura 5.23: Comportamento do Ângulo de Rolagem $\varphi$ em uma manobra de Double Lane Change, para o modelo implementado no Simulink.

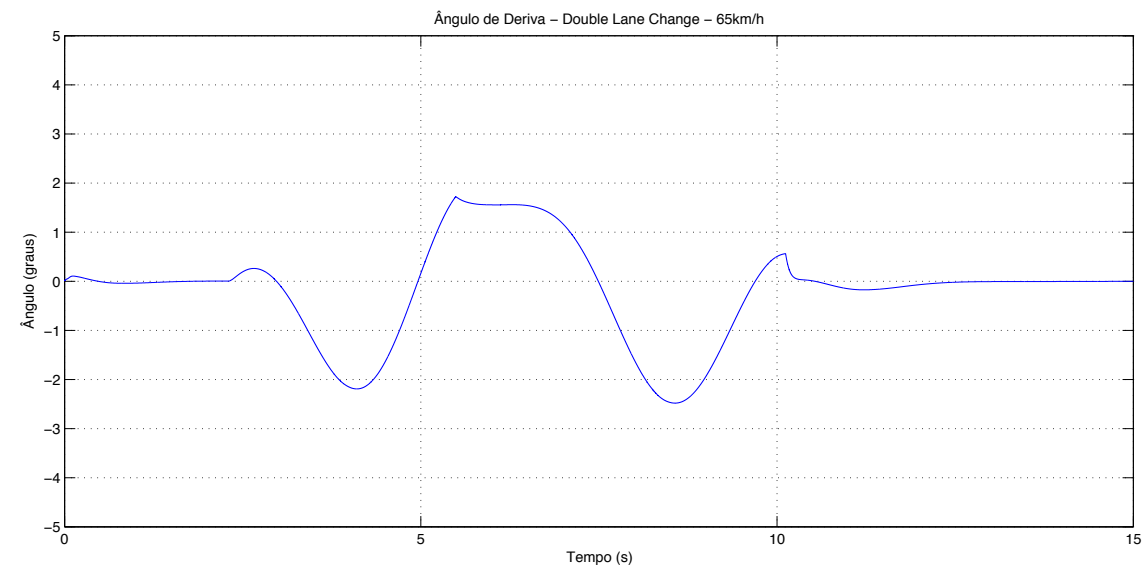

Figura 5.24: Comportamento do Ângulo de Deslizamento $\beta$ em uma manobra de Double Lane Change, para o modelo implementado no Simulink. 


\section{6}

\section{Simulações e Resultados}

Em sequência ao desenvolvimento do Sistema de Controle Semiautônomo proposto e à implementação do modelo dinâmico para simulações descrito no Capítulo 5, são realizadas diversas simulações com a utilização de todos os componentes do sistema, com o objetivo de verificar a eficácia da solução proposta. Os testes consistem na simulação do uso de um veículo em situações de perigo, onde a atuação do sistema de controle se faz necessária para que esse se mantivesse seguro em uma eventual operação real similar. O sistema é também comparado a outro controlador (do tipo PID), conforme visto adiante.

\section{1}

\section{Configurações dos Testes}

Os testes são configurados para apresentarem riscos de ataques inimigos ao veículo, em que IEDs e atiradores com armamentos anti-carro são posicionados dentro do teatro de operações simulado.

As configurações dos testes estão organizadas em níveis crescentes de dificuldade para o controlador. Desta forma torna-se possível a realização de uma análise crítica sequencial, que por sua vez favorece a identificação de erros e causas de resultados inesperados para o funcionamento do controlador semiautônomo e o comportamento do veículo.

De forma geral, as configurações dos testes apresentam as seguintes características:

- utilização de uma ou mais funções objetivo, selecionadas a partir do estabelecimento de valores fixos para os parâmetros $R_{\phi}, R_{\delta}, R_{y}$ e $R_{\dot{y}}$ (quando foi utilizada a função objetivo modificada);

- primeiro teste - simulação de uma situação de perigo em que apenas um explosivo IED é empregado no Teatro de Operações e o motorista não exerce nenhuma ação de controle sobre o veículo;

- segundo teste - simulação semelhante à anterior, porém com o emprego de dois explosivos posicionados de forma a aumentar o grau de periculosidade da situação; 
- terceiro teste - simulação de emprego do veículo sob uma ameaça representada por um atirador, em que o motorista também não exerce ação de controle sobre o veículo;

- quarto teste - simulação de utilização do veículo sob ameaça de dois explosivos IED empregados no terreno, também sem ações de controle do motorista sobre a viatura, porém comparando-se os resultados obtidos pela aplicação de um controlador PID e do sistema de controle proposto;

- quinto teste - simulação de emprego do veículo em uma situação de periculosidade mais alta, advinda do emprego de explosivos improvisados e de um atirador inimigo no Teatro de Operações, além da aplicação de ações de controle exercidas pelo motorista sobre o volante do veículo; e,

- testes adicionais - simulações de utilização do veículo em cenários pouco comuns, que representam principalmente algum tipo de incapacidade do motorista de manter o controle diante de uma ameaça qualquer ou ainda alguma limitação do controlador proposto em situações específicas.

\section{2}

\section{Seleção da Função Objetivo do Subcontrolador Preditivo}

Diversos testes preliminares (semelhantes aos testes relatados na seção 5.3) foram executados com diferentes funções objetivo, o que permitiu que os resultados relacionados a utilização de cada uma delas fossem comparados entre si. Os primeiros resultados foram obtidos para a função $J(t)$ mostrada no Capítulo 4 , com os parâmetros $R_{\phi}=1, R_{\delta}=1000$ e $R_{y}=5 \times 10^{-5}$, foram apresentados pelo autor e seus orientadores em [64]. No entanto, a execução de testes posteriores indicaram que outras configurações se mostravam mais eficientes, de acordo com a situação representada no teste, por dar maior peso a alguma componente com relação às outras.

As configurações foram modificadas de acordo com cada um dos testes, cujos resultados são relatados neste capítulo, não fixando-se, portanto, uma única função objetivo para o Subcontrolador Preditivo.

\section{3}

\section{Resultados Obtidos}

A maneira mais adequada de apresentar os resultados obtidos nos testes simulados é a apresentação da trajetória descrita pelo veículo sob ação de controle do sistema proposto e do operador humano, bem como a apresentação da curva de evolução da variável que representa o Nível de Intervenção do controlador digital $K$, definida no Capítulo 3. As subseções a seguir apresentam 
os resultados obtidos pela simulação do sistema de controle semiautônomo proposto, de acordo com as configurações dos testes pré-estabelecidas.

\subsection{1}

\section{Primeiro Teste Simulado (Um IED)}

Conforme mencionado, para favorecer o aumento gradativo da dificuldade imposta ao sistema proposto, o primeiro teste consistiu na simulação do emprego do veículo em um terreno onde apenas um explosivo é empregado. O posicionamento deste IED é dado por

$$
p_{I E D 1}=\left[\begin{array}{c}
150 \\
-5 \\
0
\end{array}\right],
$$

e o comportamento simulado do motorista se deu de forma que a entrada representada por um deslocamento angular do volante teve valor nulo durante toda a simulação $\left(\delta_{\text {volante }}(t)=0\right)$. O tempo total de simulação foi de $10 \mathrm{~s}$ e definiu-se uma alta velocidade longitudinal para a viatura, sendo $V=$ $90 \mathrm{~km} / \mathrm{h}=25 \mathrm{~m} / \mathrm{s}$. Essa alta velocidade também representa uma dificuldade a mais para o sistema de controle proposto, porque dificulta e prejudica a manutenção da estabilidade do veículo em manobras necessárias para o desvio das ameaças. Para este teste foram inicialmente utilizados os pesos $R_{\phi}=5$, $R_{\delta}=1000, R_{y}=5 \times 10^{-5}$ e $R_{\dot{y}}=0$ (caracterizando a utilização da primeira função objetivo $J(t)$ apresentada na seção 4.3). A análise dos resultados mostrou que a trajetória realizada pelo veículo não se estabilizou na direção do eixo $y$, o que demandou a utilização da função objetivo modificada $J_{1}(t)$, com adição da penalidade à velocidade lateral, implementada pela utilização de $R_{\dot{y}}=1$.

A Figura 6.1 apresenta os resultados obtidos para o primeiro teste simulado. Observam-se três trajetórias diferentes na ilustração, onde a trajetória representada na cor azul mostra o comportamento da viatura apenas sob controle do motorista (em que, neste caso, não são aplicados esforços de controle), a trajetória representada na cor verde mostra o comportamento da viatura sob o controle mesclado entre o motorista e o sistema de controle proposto com utilização da primeira função objetivo, e a trajetória cor-de-rosa apresenta o comportamento dado por aplicação do sistema com a função objetivo modificada.

Ainda na Figura 6.1, pode observam-se as curvas de evolução da variável $K$ que representam o Nível de Intervenção do controlador, que nestes casos mantém-se em um intervalo de valores relativamente baixos (em torno de $25 \%$ 

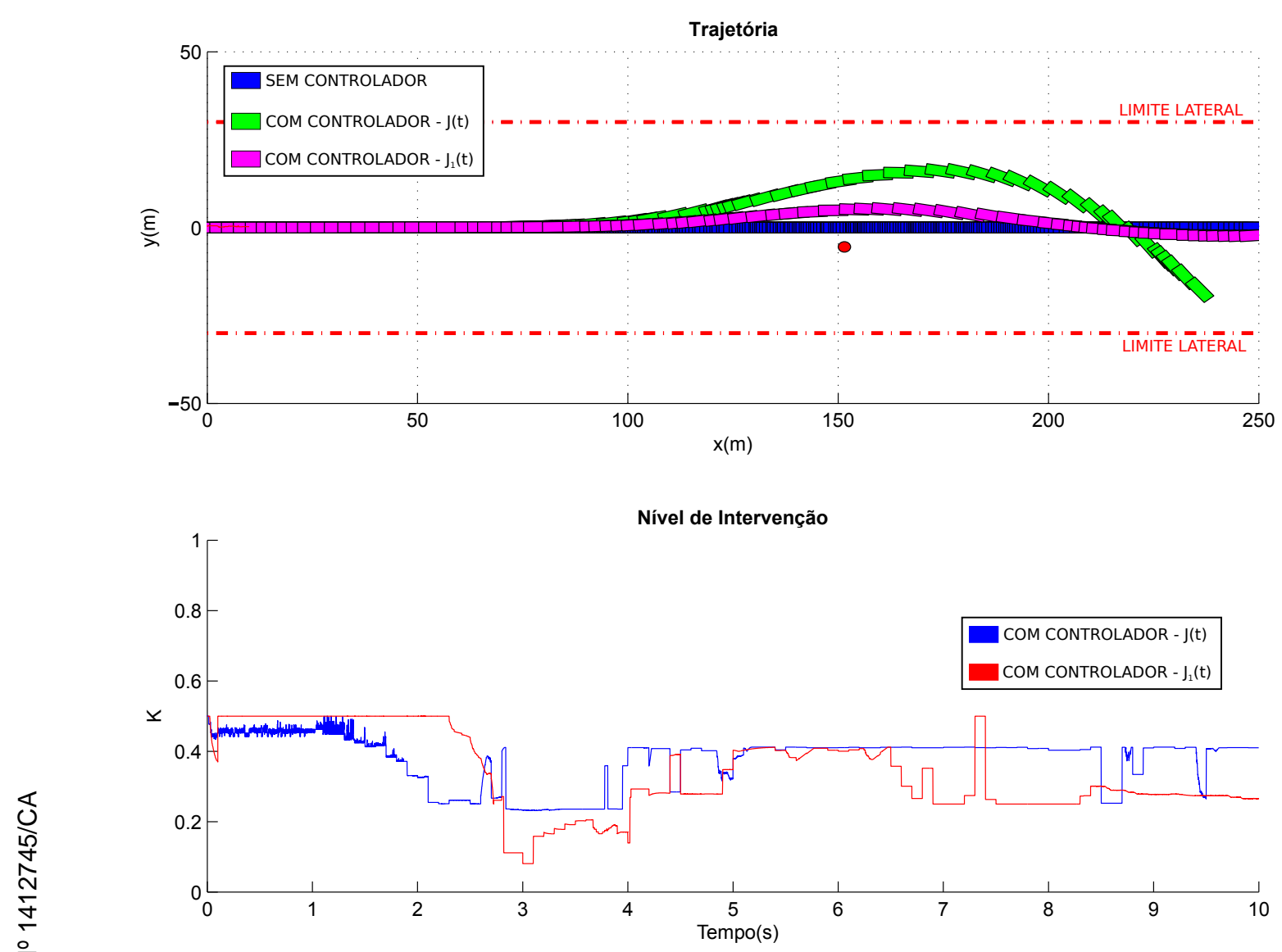

Figura 6.1: Resultados obtidos no primeiro teste simulado. Neste caso, a entrada proveniente do motorista é nula e as trajetórias verde e cor-de-rosa se devem à ação do sistema proposto. O Nível de Intervenção é, em média, mais baixo devido a utilização da função objetivo $J_{1}(t)$.

e $50 \%$ para a primeira função objetivo, e ainda menor em alguns instantes para a função objetivo modificada). Cabe aqui mencionar que esta é uma característica desejada, pois níveis de intervenção mais altos podem trazer desconforto para um motorista com baixo nível de treinamento na utilização de um sistema deste tipo, por tornarem o sistema mais intrusivo.

Realizando-se a comparação entre as trajetórias representadas nas cores azul e verde, pode-se notar que: ao contrário de uma situação de alto risco em que um motorista poderia posicionar o veículo em lugares muito próximos do explosivo, a utilização do sistema proposto foi conveniente para manter-se uma distância de segurança em relação à ameaça, garantindo-se, portanto, a segurança e a integridade do veículo e de seus tripulantes embarcados. A trajetória representada em cor-de-rosa indica que a penalidade à velocidade lateral introduzida com a função $J_{1}(t)$ aumenta a eficácia da solução, favorecendo a 
estabilização do movimento lateral do veículo, diferentemente da trajetória verde, em que a porção final indica uma tendência do veículo a violar o limite lateral inferior.

\subsection{2}

\section{Segundo Teste Simulado (Dois IEDs)}

Com o objetivo de aumentar a complexidade da configuração de teste, e por consequência, a dificuldade imposta ao sistema de controle semiautônomo para a manutenção da estabilidade e da segurança em relação à proximidade de uma ameaça do veículo por ele controlado, foi adicionado mais um explosivo improvisado IED na simulação, posi-cionado em um ponto situado na trajetória resultante do teste anterior.

Desta maneira, o tempo de simulação foi de $10 \mathrm{~s}$, a velocidade longitudinal foi de $90 \mathrm{~km} / \mathrm{h}=25 \mathrm{~m} / \mathrm{s}$, o sinal de entrada proveniente do motorista foi nulo e o posicionamento dos IEDs empregados foi dado por

$$
p_{I E D 1}=\left[\begin{array}{c}
150 \\
-5 \\
0
\end{array}\right] \text { e } p_{I E D 2}=\left[\begin{array}{c}
200 \\
10 \\
0
\end{array}\right]
$$

A Figura 6.2 apresenta as trajetórias e as curvas de evolução do Nível de Intervenção para o segundo teste realizado. De maneira semelhante ao primeiro teste, a trajetória representada na cor azul indica o comportamento do veículo sob ações de controle nulas, provenientes apenas do motorista, enquanto que as trajetórias representadas na cor verde e em cor-de-rosa indicam o comportamento do veículo sob ações de controle mescladas entre os esforços do motorista e do sistema de controle semiautônomo proposto com as funções objetivo original $J(t)$ e modificada $J_{1}(t)$, respectivamente. Nestes casos, para a função $J(t)$ foram utilizados os pesos $R_{\phi}=5, R_{\delta}=1000$ e $R_{y}=5 \times 10^{-5}$, enquanto que para $J_{1}(t)$ foi adicionado o peso e $R_{\dot{y}}=1$.

Observa-se, portanto, que o desempenho do sistema proposto pode ser considerado satisfatório, por conservar o veículo em condições seguras, garantindo sua estabilidade e também um baixo nível de periculosidade (por manter o veículo a uma distância conveniente das ameaças representadas pelos explosivos). Além disso, a trajetória representada em cor-de-rosa mostra que a inclusão da penalidade à velocidade lateral impediu que a trajetória do veículo violasse a restrição dos limites laterais e também a perda da estabilidade em função do movimento lateral. É também relevante comparar os níveis de intervenção, que em média foram mais baixos para a situação de utilização da função objetivo $J_{1}(t)$. 

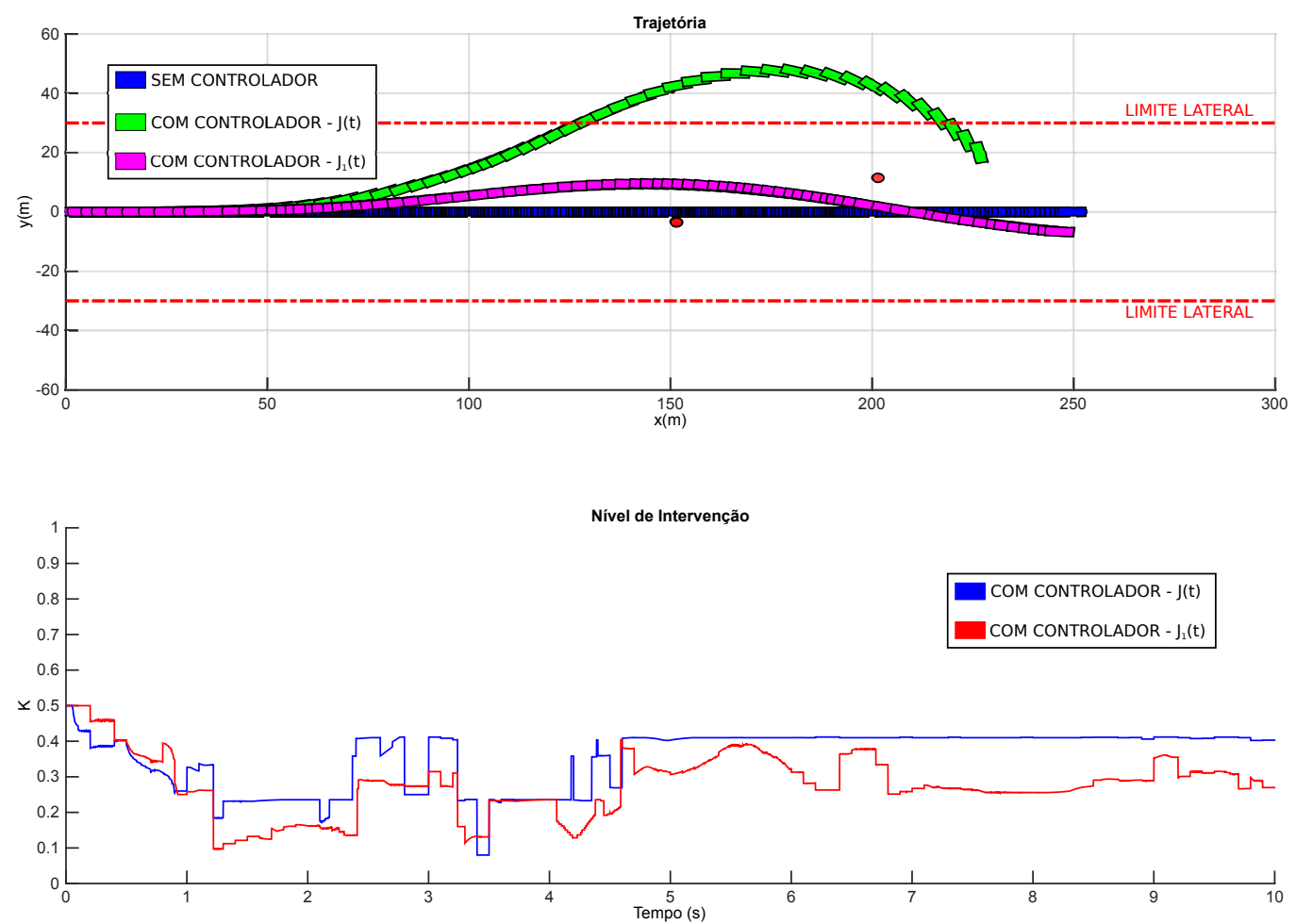

Figura 6.2: Resultados obtidos no segundo teste simulado. Também neste caso as trajetórias verde e cor-de-rosa se devem apenas à ação do sistema proposto, pois a entrada do motorista é nula. O Nível de Intervenção também tem sua média diminuída pela utilização da função objetivo $J_{1}(t)$.

\subsection{3}

\section{Terceiro Teste Simulado (Atirador com Armamento Anti-Carro)}

O terceiro teste foi idealizado para que fosse possível a verificação dos comportamentos do sistema de controle e da viatura controlada quando empregados em uma situação em que um atirador equipado com armamento anti-carro representa uma ameaça inimiga. Neste teste os IEDs foram retirados para não exercerem influência sobre o comportamento do sistema, permitindo a análise dos resultados para esta configuração específica.

Foram mantidos os parâmetros de simulação, como os pesos $R_{\phi}=5$, $R_{\delta}=1000 R_{y}=5 \times 10^{-5}$ e $R_{\dot{y}}=1$ para $J_{1}(t)$, o tempo de simulação de $10 \mathrm{~s}$, a velocidade longitudinal de $90 \mathrm{~km} / \mathrm{h}=25 \mathrm{~m} / \mathrm{s}$, e o sinal de entrada do motorista constante e igual a zero. O atirador permaneceu posicionado no ponto

$$
p_{a t r}=\left[\begin{array}{c}
200 \\
10 \\
0
\end{array}\right] \text {, }
$$


e seu azimute de tiro foi fixado no ângulo de $225^{\circ}$, com relação ao eixo $x$ indicado na Figura 6.3.

De forma semelhante aos resultados apresentados nos primeiros testes, as curvas de evolução do Nível de Intervenção do controlador automático também são apresentadas na Figura 6.3. A trajetória em azul mostra o comportamento do veículo quando submetido apenas à ação de controle nula de um motorista, enquanto que as trajetórias representadas nas cores verde e cor-de-rosa mostram o comportamento do veículo submetido às ações do sistema de controle e do próprio motorista mescladas. A principal diferença entre as trajetórias é a parte final, em que a trajetória cor-de-rosa mostra ângulos de guinada mais próximos de zero, mostrando-se ser um movimento próximo da estabilização.
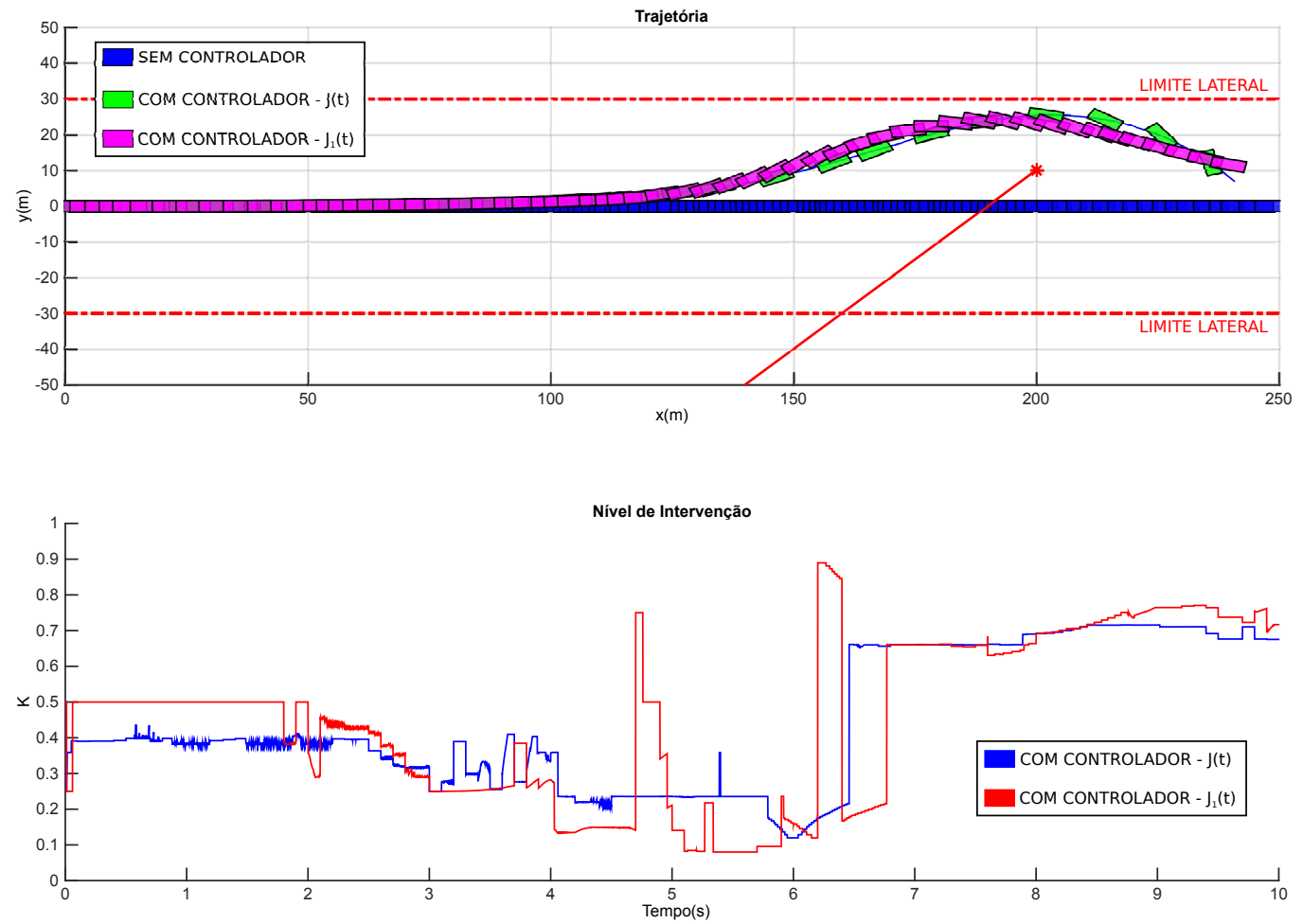

Figura 6.3: Resultados obtidos no terceiro teste simulado. A entrada do motorista permanece nula, da mesma forma que os testes anteriores. Os níveis de médios de intervenção são claramente mais altos, e sua comparaçãonão é evidente, o que reflete o maior desafio para o sistema de controle.

Os resultados do terceiro teste indicam que a ação do sistema de controle semiautônomo proposto garantiu uma distância mínima de segurança entre o veículo e o atirador, ou mesmo sua linha de tiro. Por este motivo, a estabilidade 
e a segurança do veículo controlado foram mantidas, sendo, portanto, o comportamento do sistema proposto considerado satisfatório também para este tipo de ameaça. Os Níveis de Intervenção, por sua vez, mostraram-se mais altos do que as situações anteriores, demonstrando uma maior dificuldade para os controladores.

\subsection{4}

\section{Quarto Teste Simulado (Comparação com PID)}

Uma comparação entre a utilização do sistema de controle semiautônomo proposto e de um sistema diferente, implementado a partir de um controlador PID (ao invés do subcontrolador preditivo) foi realizada no quarto teste. Foram empregados explosivos IEDs para representar ameaças ao veículo, posicionados em

$$
p_{I E D 1}=\left[\begin{array}{c}
125 \\
0 \\
0
\end{array}\right], \quad e, \quad p_{I E D 2}=\left[\begin{array}{c}
200 \\
10 \\
0
\end{array}\right] .
$$

O controlador PID foi projetado para produzir deslocamentos angulares no volante do veículo (como entradas para o sistema veicular), tomando como sinais de erro as diferenças angulares entre a direção de guinada (ou orientação) do veículo e a direção da reta definida pelo seu centro de gravidade e o ponto médio entre as posições dos explosivos.

A Figura 6.4 apresenta a trajetória do veículo quando controlado pelo sistema proposto na cor verde (com utilização da função objetivo $J(t)$ ) e em cor-de-rosa (com a função $J_{1}(t)$ ), enquanto a trajetória do veículo controlado pelo sistema implementado a partir do controlador PID é apresentada na cor marrom. Além das trajetórias, são apresentadas as curvas de evolução dos Níveis de Intervenção $K$ para cada um dos sistemas, onde as curvas em azul e em vermelho indicam o comportamento obtido pelo emprego do sistema de controle proposto (para $J(t)$ e $J_{1}(t)$, respectivamente), e a curva em amarelo indica o comportamento obtido através do emprego do sistema implementado a partir do controlador PID.

Os resultados mostram que o sistema proposto apresentou uma melhor performance do que o controlador do tipo PID, forçando a realização de manobras que permitiram que altos riscos de explosão dos IED e mesmo de acidentes com o veículo fossem evitados. Adicionalmente, ao observar-se os Níveis de Intervenção $K$ de ambos os sistemas, pode-se considerar que o sistema com controlador PID é, em média, mais intrusivo, pelo fato de que este manteve o nível mais alto em maiores partes do tempo. 

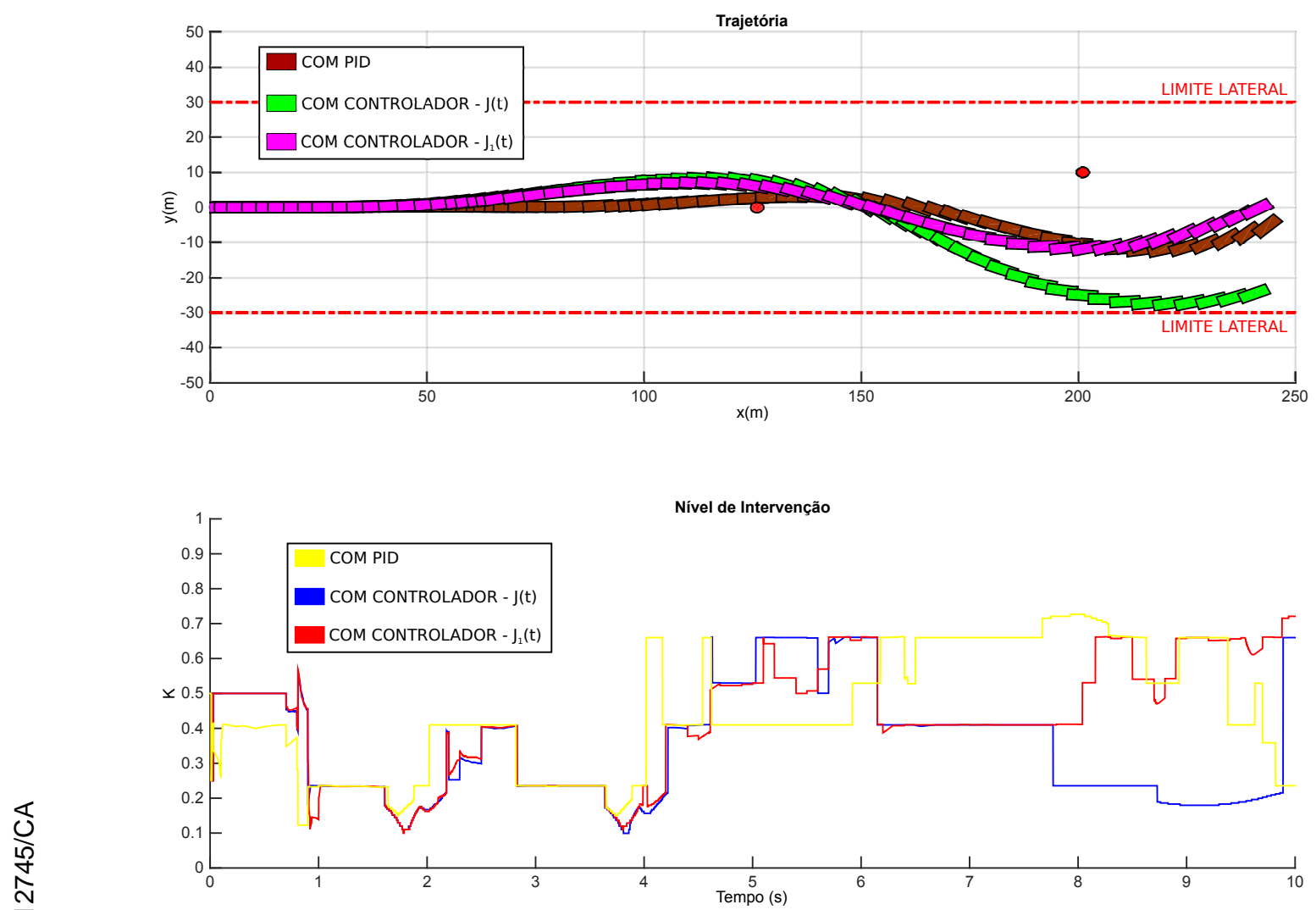

Figura 6.4: Trajetórias e Níveis de Intervenção para o Sistema Proposto e para um Controlador PID. Em todos os casos as estradas provenientes do motorista são nulas.

\subsection{5}

\section{Quinto Teste Simulado (Motorista Imprudente)}

O quinto teste simulado apresentado neste trabalho foi concebido de forma a reproduzir o emprego de um veículo em uma situação mais elaborada, com o envolvimento de ameaças inimigas representadas tanto por explosivos improvisados quanto por um atirador, além de se considerar ações de controle não nulas por parte do motorista. O sistema foi também aplicado a partir da utilização das funções objetivo $J(t)$ e $J_{1}(t)$.

Mantendo-se ainda o tempo de simulação em $10 \mathrm{~s}$ e a velocidade longitudinal em $90 \mathrm{~km} / \mathrm{h}=25 \mathrm{~m} / \mathrm{s}$, o posicionamento dos explosivos IEDs foram dados por

$$
p_{I E D 1}=\left[\begin{array}{c}
50 \\
-5 \\
0
\end{array}\right], \quad e, \quad p_{I E D 2}=\left[\begin{array}{c}
150 \\
-25 \\
0
\end{array}\right] \text {. }
$$


O posicionamento do atirador foi dado por

$$
p_{a t r}=\left[\begin{array}{c}
200 \\
-30 \\
0
\end{array}\right] \text {, }
$$

e seu azimute de tiro dado pelo ângulo de $180^{\circ}$, com relação ao eixo $x$ indicado nas figuras.

A entrada aplicada pelo motorista sobre o volante do veículo, representada por seu deslocamento angular $\delta_{\text {volante }}$ é mostrada na Figura 6.5.

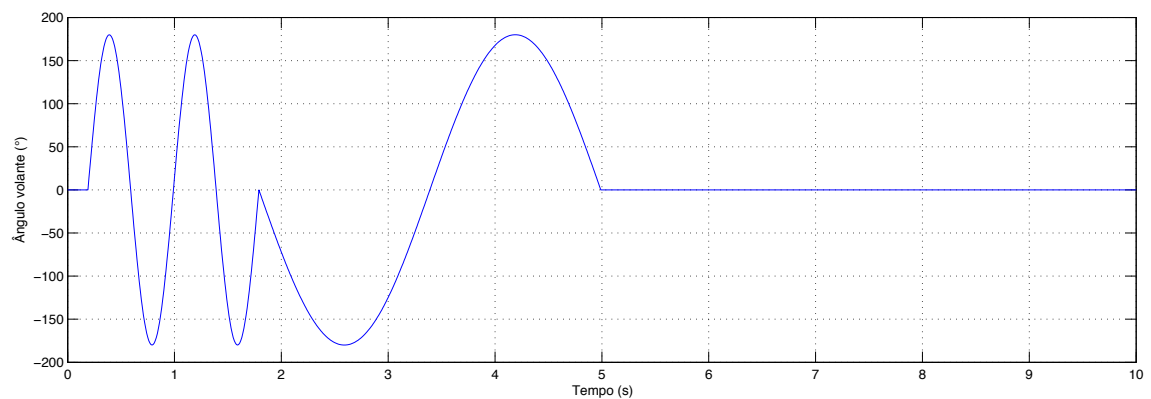

Figura 6.5: Sinal de entrada aplicado pelo motorista sobre o volante do veículo.

As trajetórias realizadas pelo veículo estando sob as ações de controle apenas do motorista e também do sistema de controle semiautônomo (mesclando-se as ações do motorista e do controlador digital) são ilustradas na Figura 6.6. De forma semelhante aos resultados dos testes anteriores, a trajetória em azul reproduz o comportamento do veículo somente sob ação do motorista (sendo agora não-nula durante o teste), a trajetória representada em verde mostra o movimento do veículo sob ação do sistema de controle proposto com a função objetivo $J(t)$ e a trajetória cor-de-rosa mostra o movimento do veículo sob ação do sistema com a função objetivo $J_{1}(t)$. Além das trajetórias, as curvas de evolução do nível de intervenção também são ilustradas na Figura 6.6, demonstrando que os maiores valores são atingidos nos intervalos de tempo finais, coincidido com a menor estabilidade relativa do veículo.

Conforme se pode observar na figura, a trajetória do veículo resultante da ação apenas do motorista foi idealizada de forma a expor o veículo a altos níveis de periculosidade, tornando necessária a ação do sistema de controle para garantir sua estabilidade e segurança. Comparando as trajetórias, conclui-se que a ação do sistema foi suficiente para garantir a segurança do veículo, mantendo-o a uma distância conveniente dos explosivos improvisados, do atirador e de sua linha de tiro. Estes resultados indicam que o desempenho do sistema de controle semiautônomo proposto pode ser considerado satisfatório também para esta situação. 

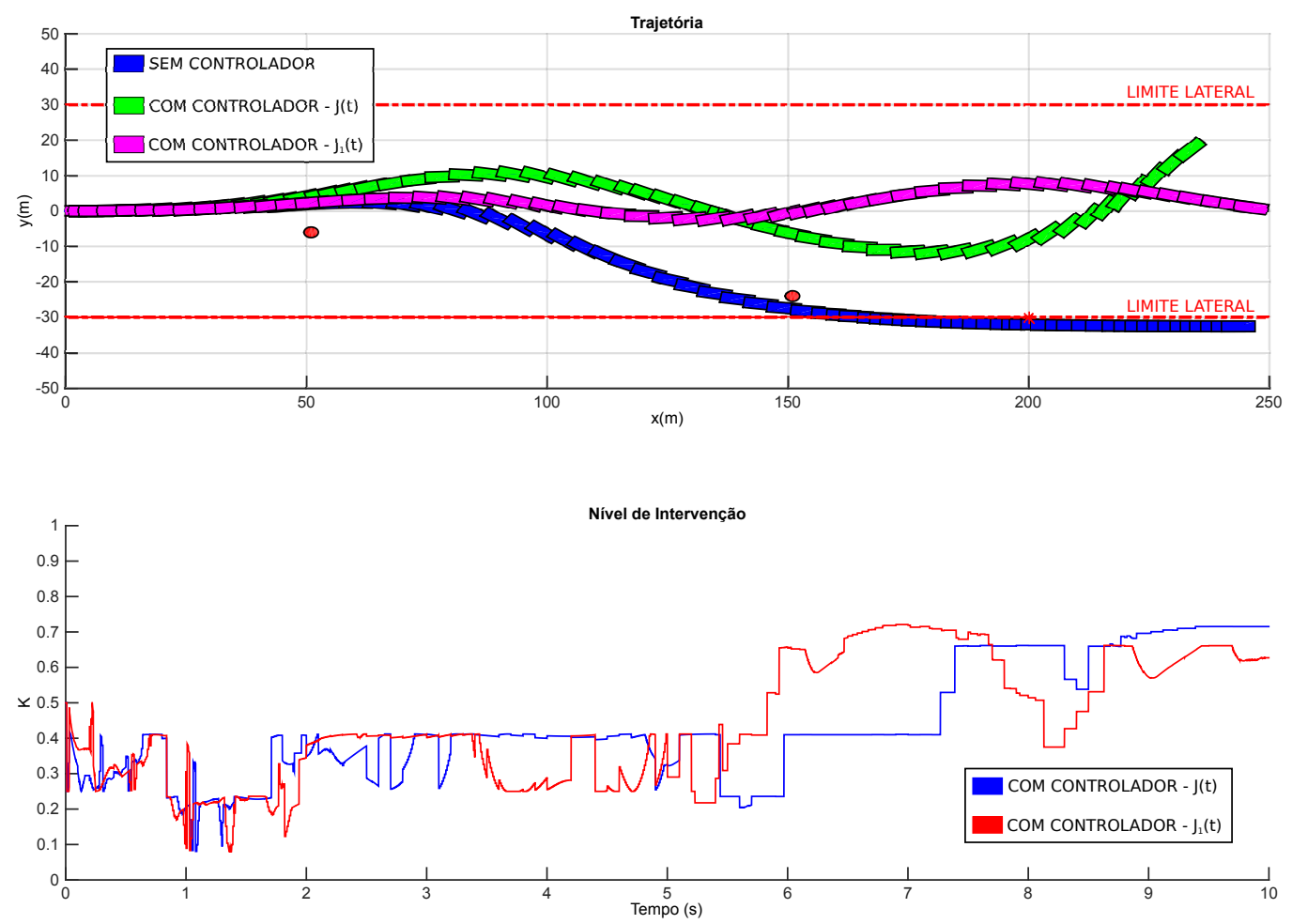

Figura 6.6: Resultados obtidos no quinto teste simulado. A trajetória em azul mostra o comportamento do veículo sob ação apenas do motorista, enquanto as outras são resultado da intervenção do sistema proposto.

\subsection{6}

\section{Testes Adicionais}

Após a realização dos testes necessários para a comprovação da eficácia da solução proposta em situações mais comuns e de menor complexidade, foram executados testes adicionais em que buscou-se simular cenários de emprego de maior perigo, porém com menor probabilidade de ocorrência. Estas novas situações foram concebidas para representar incapacidades do motorista de controlar a viatura ou limitações do controlador semiautônomo.

Os testes adicionais executados cujos resultados são apresentados a seguir consistiram na representação de quatro cenários distintos: situação de incapacidade do motorista, reação tardia do motorista frente a uma ameaça qualquer, limitação das ações do controlador semiautônomo baseado em potenciais de ameaças diante de uma configuração simétrica de obstáculos e, finalmente, navegação do veículo em rodovias com faixas estreitas com a modificação da função penalidade ao seu movimento lateral. 


\section{Incapacidade do Motorista}

A intenção desse cenário é a de representar uma possível situação em que o motorista, por qualquer motivo, aplica uma entrada do tipo degrau durante um longo intervalo de tempo ao volante do veículo, independentemente de sua velocidade longitudinal. Isto ocorreria, por exemplo, em um conflito onde o motorista fosse atingido por um projétil e por conta disso forçasse o volante mantendo-o em uma posição fixa. A Figura 1.2 ilustra uma operação real em que o risco de ocorrência de um evento como este é alto.

Considera-se que um sinal de entrada aplicado ao veículo por um motorista inconsciente pode variar bruscamente entre diversos valores, tendo um tipo de comportamento imprevisível. Apesar da imprevisibilidade dos sinais que poderiam ser aplicados ao volante do veículo em casos deste tipo, foi selecionado um formato de entrada simples, como um degrau atrasado em $2 s$ e de amplitude de $45^{\circ}$. Este formato já é suficiente para prejudicar a estabilidade do veículo, fazendo-se portanto necessária a atuação do sistema de controle semiautônomo proposto.

Sem a atuação do sistema de controle proposto, a aplicação desta entrada implicaria no movimento do veículo em uma trajetória praticamente circular. O sistema, por sua vez, passa a atuar, pelo fato de que o comportamento do motorista passa a ser mal classificado. Estes testes foram executados a partir da aplicação do sistema proposto com a função objetivo $J_{1}(t)$, mas também com a variação do parâmetro de configuração $R_{y}$, sendo os outros parâmetros dados por $R_{\phi}=5, R_{\delta}=1000$ e $R_{\dot{y}}=1$. A Figura 6.7 ilustra os comportamentos do veículo em três situações: sem a atuação do sistema de controle semiautônomo (na cor azul) e com a atuação do sistema (nas cores laranja e rosa) para diferentes configurações do parâmetro peso de penalidade lateral $\left(R_{y}=10^{-10}\right.$ e $2,5 \times 10^{-7}$ ), a uma velocidade longitudinal de $30 \mathrm{~km} / \mathrm{h}$. A Figura 6.8 ilustra os comportamentos para as mesmas condições, exceto a velocidade longitudinal, que passa a ser de $60 \mathrm{~km} / \mathrm{h}$, e a Figura 6.9 apresenta os comportamentos para a velocidade longitudinal de $90 \mathrm{~km} / \mathrm{h}$.

Os resultados mostrados nas figuras demonstram a capacidade do sistema de manter a trajetória do veículo dentro dos limites estabelecidos, dependendo do valor do parâmetro $R_{y}$, mesmo após a aplicação do degrau de entrada ao volante. A ação do sistema contribui, portanto, para a estabilidade e segurança do veículo mesmo que o comportamento do motorista seja prejudicado por qualquer motivo.

Neste ponto torna-se importante o levantamento de questões adicionais relativas à dificuldade de se projetar um sistema de controle semiautônomo que não prejudique a capacidade do motorista de intencionalmente tomar 

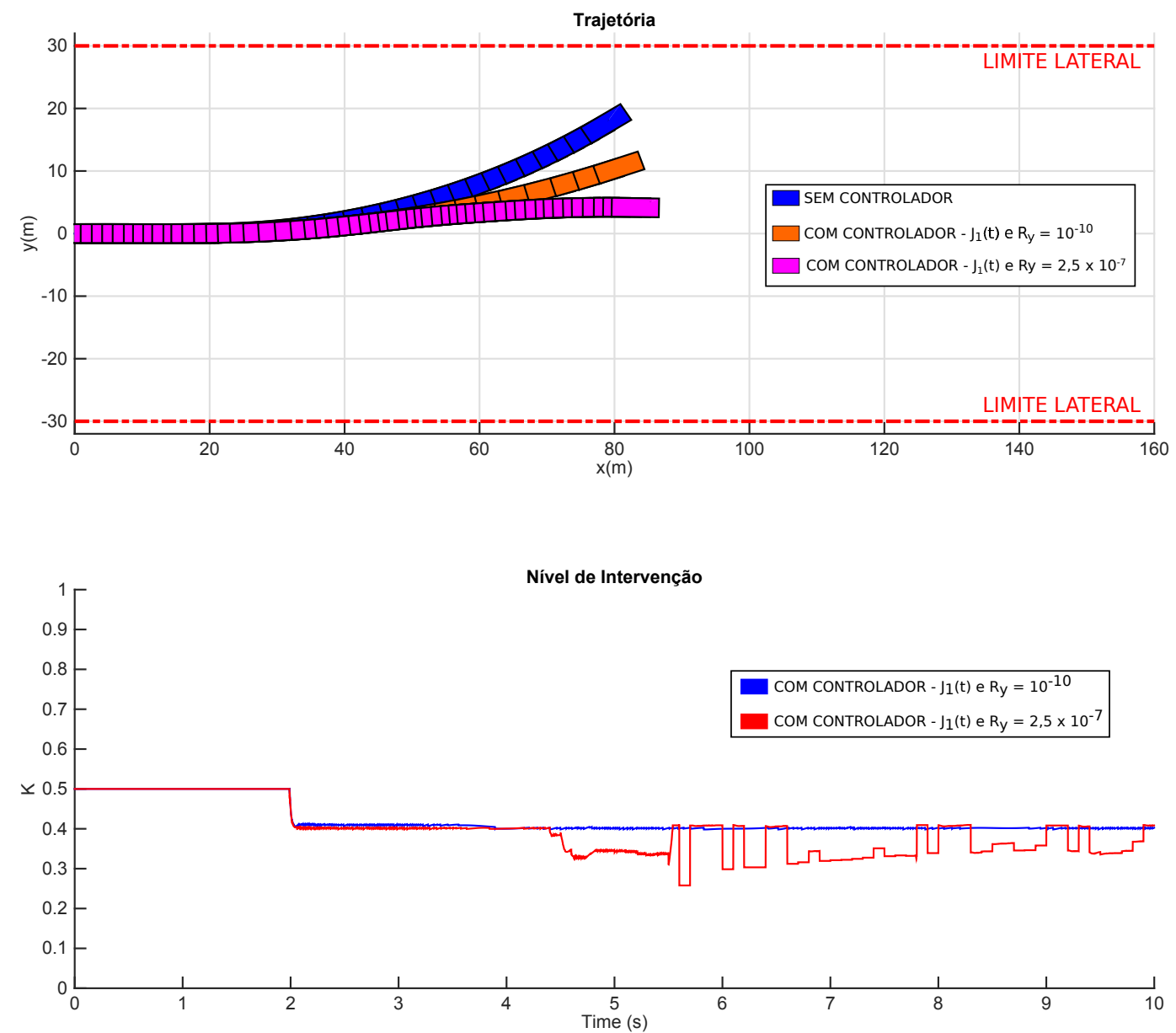

Figura 6.7: Resultados obtidos para uma situação de incapacidade do motorista, com velocidade longitudinal de $30 \mathrm{~km} / \mathrm{h}$.

uma iniciativa de controlar o veículo de forma pouco prudente, do ponto de vista da estabilidade do veículo. Apesar desta situação tentar representar uma incapacidade do motorista, em determinados casos é possível que seja de sua espontânea vontade aplicar uma entrada do tipo degrau ao volante do veículo. Sendo este o caso, numa situação de implementação prática do sistema, seria necessário haver a possibilidade de desligá-lo quando o motorista do veículo assim o desejasse.

\section{Reação Tardia do Motorista}

Esta configuração de teste foi concebida para tentar representar uma situação em que um motorista percebe a presença de uma ameaça referente a um explosivo improvisado IED a uma distância muito pequena, tendo, portanto, 

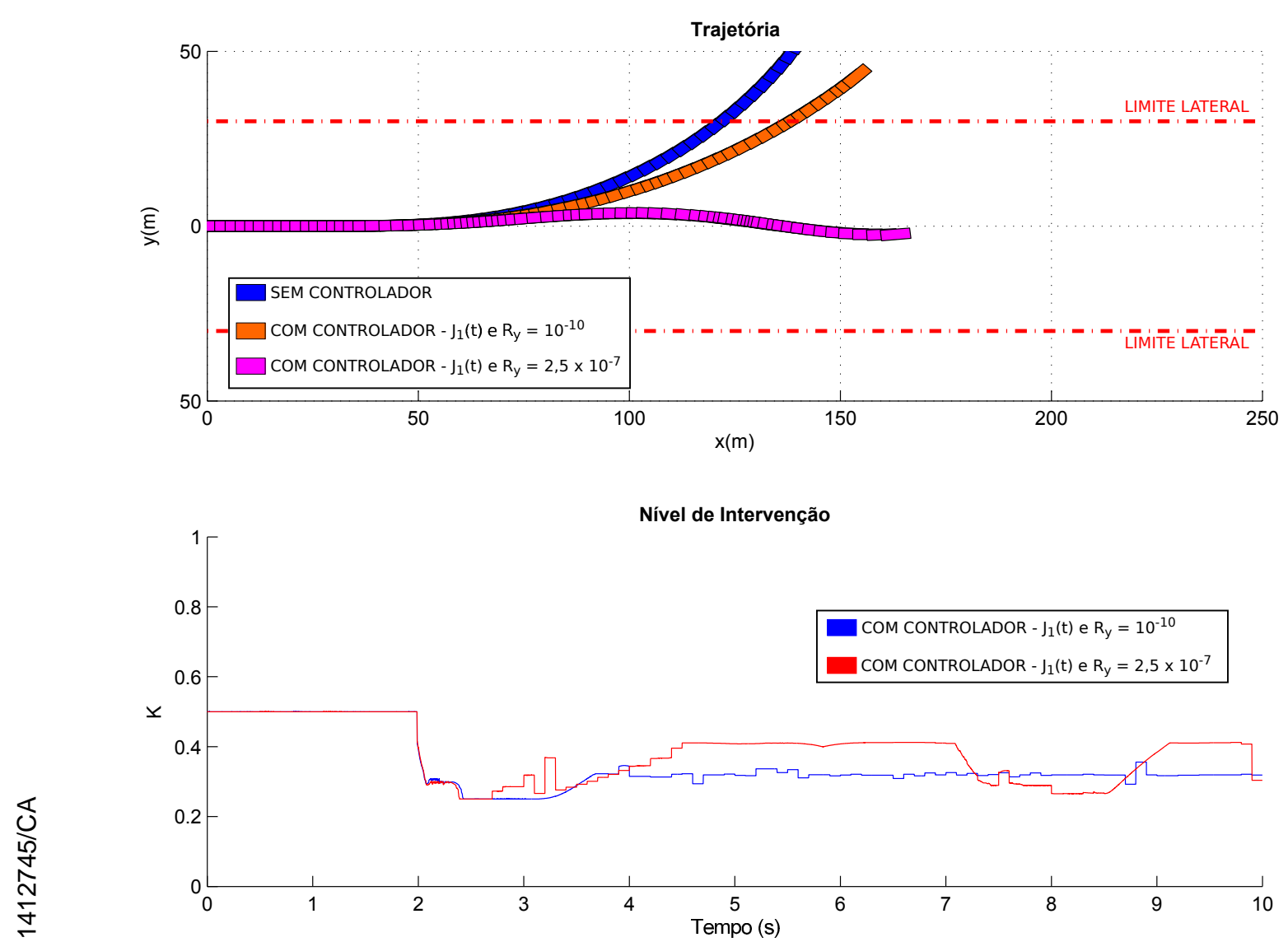

Figura 6.8: Resultados obtidos para uma situação de incapacidade do motorista, com velocidade longitudinal de $60 \mathrm{~km} / \mathrm{h}$.

um curto intervalo de tempo para reagir. Tomando-se como parâmetro o tempo mínimo de reação de um ser humano a um estímulo visual como sendo de $0,1 s$, foi possível realizar simulações em que o sinal de posição angular de entrada padrão da manobra de Troca de Pistas Simples (ciclo de senóide) é aplicado ao volante do veículo, a exatamente um intervalo de $0,1 s$ para a ativação do explosivo.

Foram realizados testes com velocidades longitudinais de $60 \mathrm{~km} / \mathrm{h}$ e $90 \mathrm{~km} / \mathrm{h}$. As trajetórias descritas foram semelhantes nos dois casos, em que a ação do sistema de controle semiautônomo proposto permitiu que o veículo ficasse a uma distância mínima de segurança em relação à localização dos explosivos. A diferença fundamental está nas curvaturas das trajetórias que, conforme era de se esperar, foi maior para a velocidade de $90 \mathrm{~km} / \mathrm{h}$. A aplicação das diferentes funções objetivo $J(t)$ e $J_{1}(t)$ permite a comparação entre as trajetórias representadas em verde e em cor-de-rosa, e indicam que a introdução da penalidade à velocidade lateral não permite que os limites 

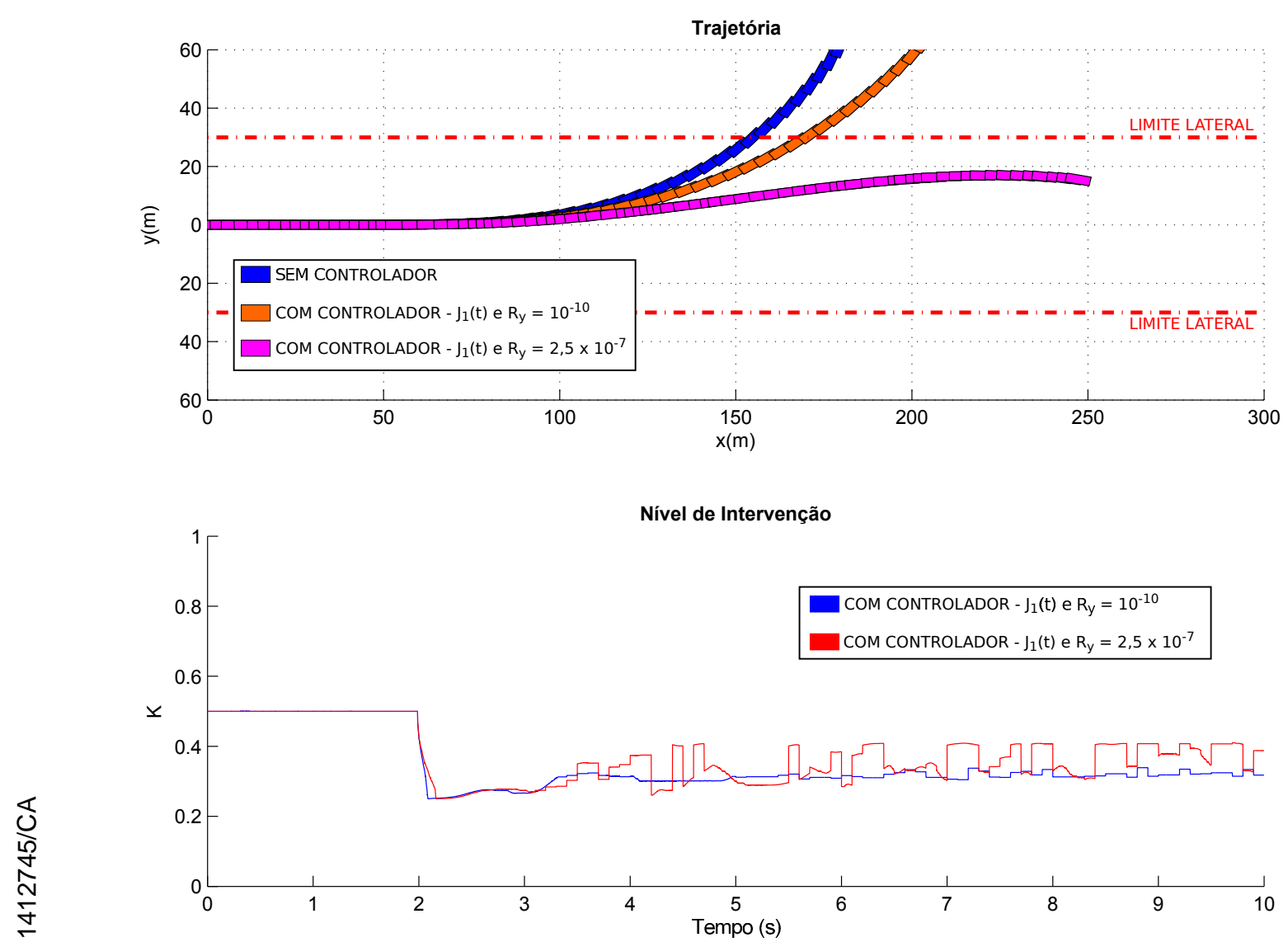

Figura 6.9: Resultados obtidos para uma situação de incapacidade do motorista, com velocidade longitudinal de $90 \mathrm{~km} / \mathrm{h}$.

laterais estabelecidos para o movimento do veículo sejam violados, além de favorecer à estabilização da trajetória sem diminuir consideravelmente a distância de segurança até a posição do IED.

As Figuras 6.10 e 6.11 apresentam os resultados obtidos para estes testes.

Pode-se verificar também que as curvas do Nível de Intervenção têm formas diferentes para a aplicação das funções $J(t)$ e $J_{1}(t)$. A função $J_{1}(t)$ favorece a diminuição da média da variável $K$ ao longo do intervalo, o que é uma característica positiva por tornar o sistema menos intrusivo. Ao serem comparadas as curvas de mesma função objetivo para as diferentes velocidades longitudinais, pode-se observar que seus comportamentos são semelhantes, exceto nos períodos finais dos testes. O Nível de Intervenção $K$ é maior para a velocidade longitudinal de $90 \mathrm{~km} / \mathrm{h}$ do que para $60 \mathrm{~km} / \mathrm{h}$, o que é causado pelo menor grau de estabilidade para manobras realizadas em velocidades mais altas. 

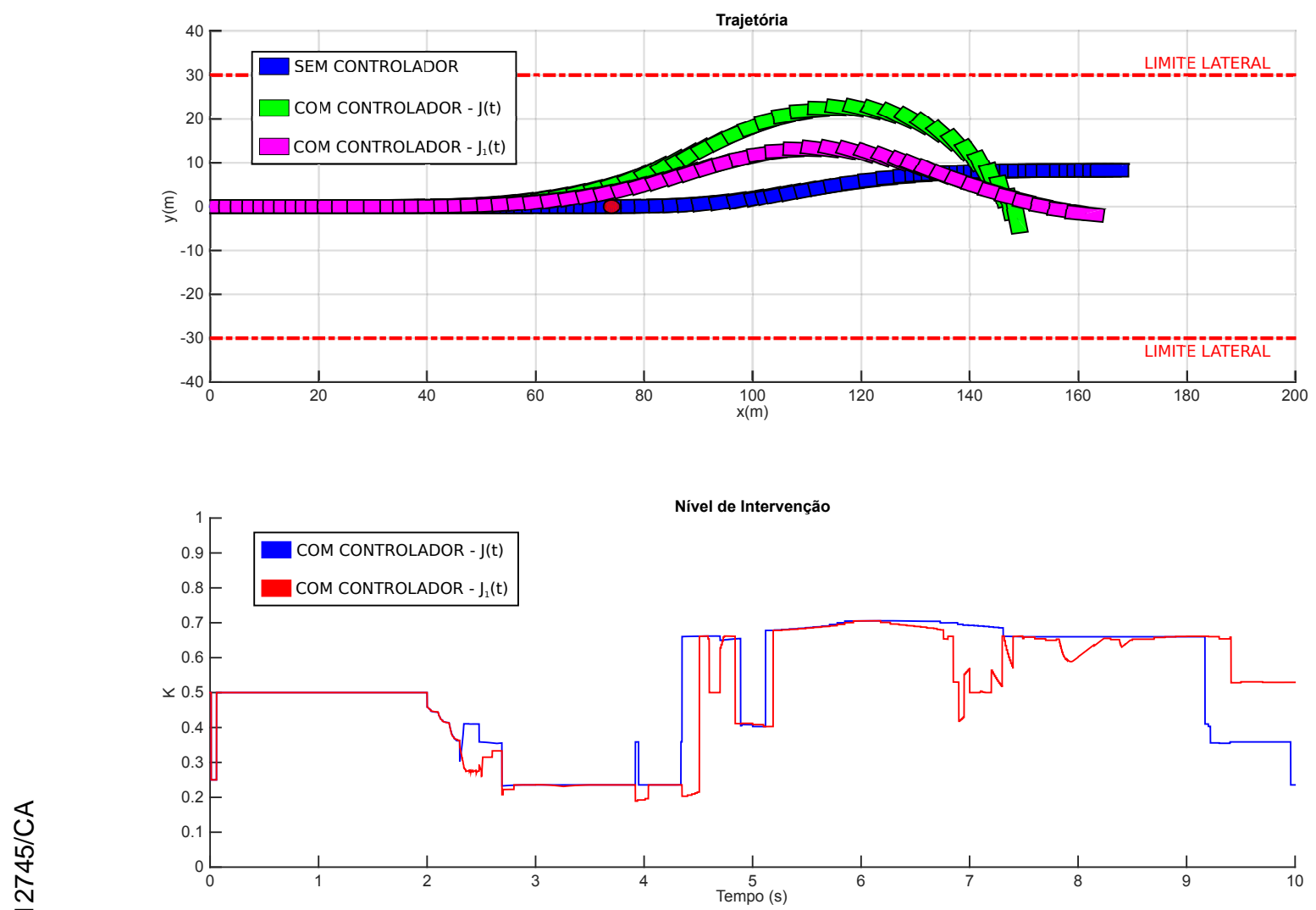

Figura 6.10: Resultados obtidos para uma situação de reação tardia do motorista, com velocidade longitudinal de $60 \mathrm{~km} / \mathrm{h}$.

\section{Configuração Simétrica de Obstáculos}

Conforme visto anteriormente, a função objetivo $J(t)$ do subcontrolador preditivo é formada por parcelas referentes às penalidades do posicionamento lateral do veículo e do esforço total do motorista para realizar as ações de controle. A função $J_{1}(t)$ incorpora ainda uma parcela referente à penalidade da velocidade lateral do veículo. Além destas parcelas, existe a componente referente a um potencial artificial de ameaças gerado a partir das distâncias até os explosivos improvisados ou atiradores inimigos. Por estes motivo, pode-se considerar que este método de controle tem características semelhantes às dos algoritmos de planejamento e controle de trajetórias de robôs móveis baseados em campos potenciais. De acordo com Latombe [12], apesar de serem eficientes, estes métodos têm uma inconveniente desvantagem relacionada à otimização de funções potenciais por técnicas de máximo declive. Caso as funções tenham mínimos locais, o algoritmo pode ser incapaz de encontrar mínimos globais e o ponto ótimo resultante pode acabar preso. Diversos mecanismos podem ser 

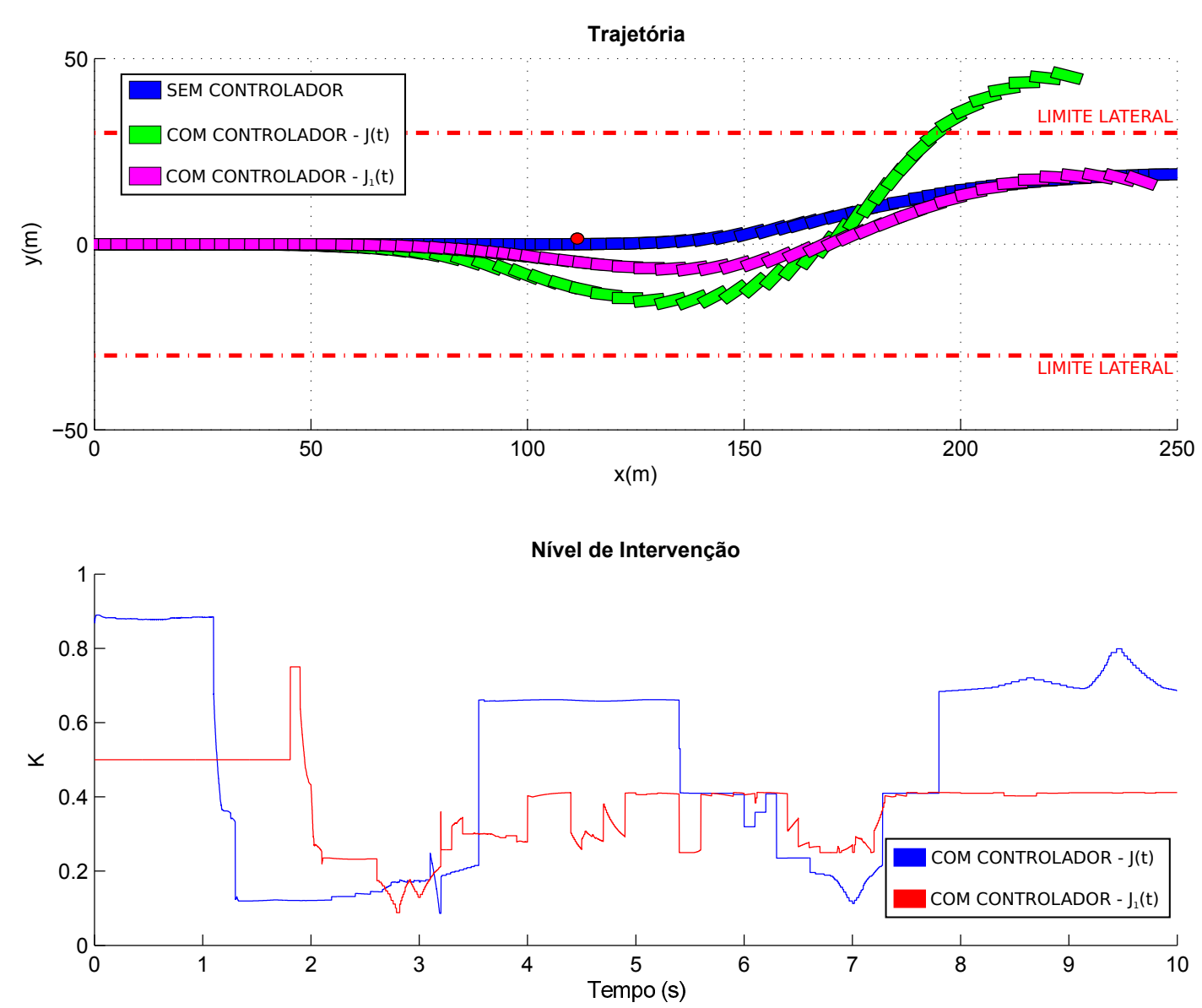

Figura 6.11: Resultados obtidos para uma situação de reação tardia do motorista, com velocidade longitudinal de $90 \mathrm{~km} / \mathrm{h}$.

implementados para evitar que isto aconteça.

O teste adicional com uma configuração simétrica de obstáculos foi realizado para representar uma situação problemática comum em planejamento e controle de trajetórias por métodos de campos potenciais. Neste caso, um obstáculo se situa no eixo de simetria entre dois outros e o veículo acaba por chocar-se com ele. Os resultados do teste, mesmo com a ação do controlador proposto, demonstraram que este era um aspecto inconveniente a ser tratado no algoritmo de controle preditivo implementado.

Desta forma buscou-se adicionar uma estrutura condicional ao código do algoritmo, em que o cálculo do potencial de ameaças é executado. A modificação introduzida consistiu em deslocar artificialmente os elementos que pudessem constituir ameaças para localizações mais próximas das laterais do veículo caso seu centro de gravidade e seu ângulo de orientação (ou guinada) estivessem alinhados com o eixo ligando os centros de gravidade do veículo e de 
um explosivo qualquer (dentro de limites de tolerância específicos). A Figura 6.12 ilustra este tipo de situação.

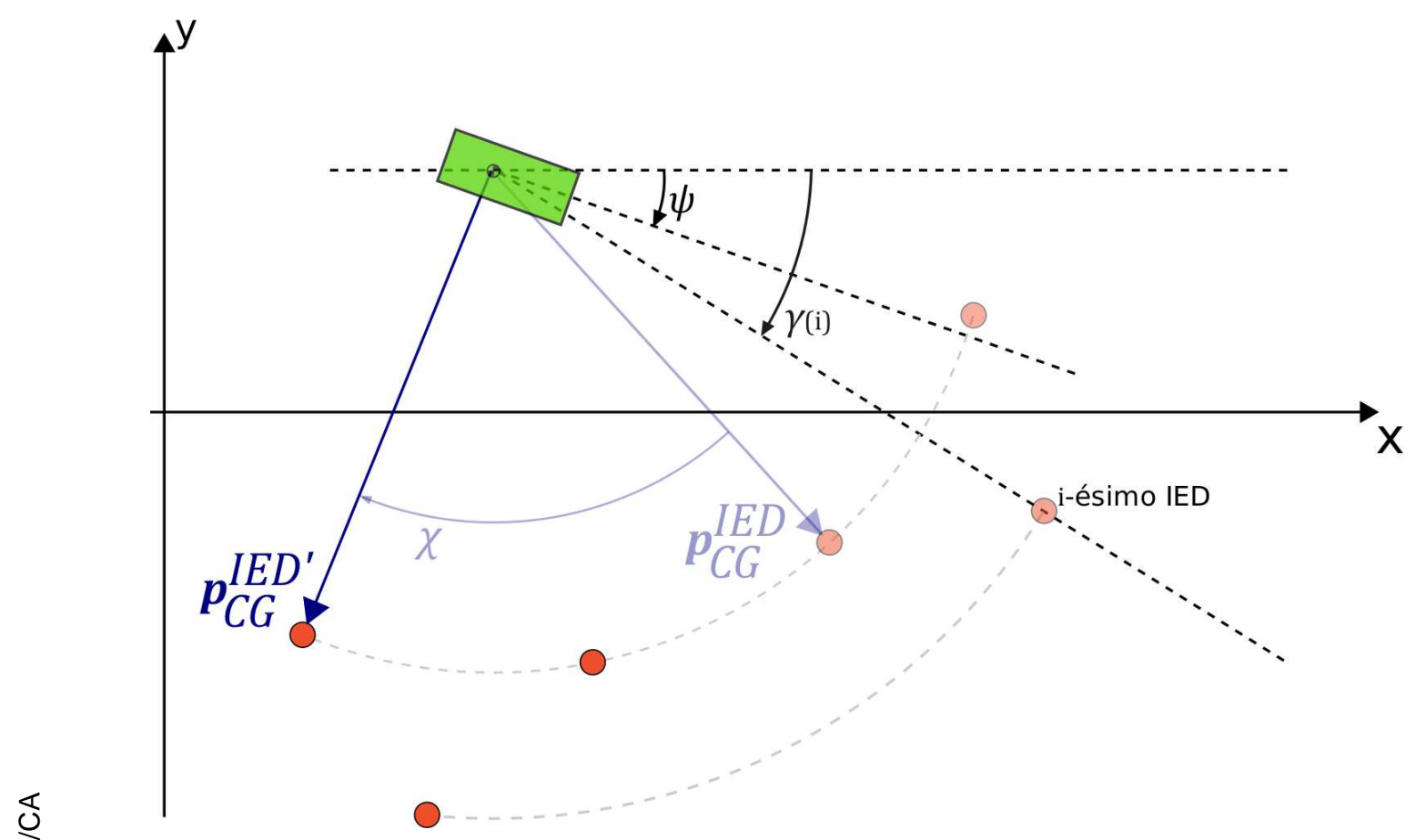

Figura 6.12: Deslocamento artificial de explosivos em situações de configuração simétrica.

O pseudo-código do Algoritmo 1 apresentado abaixo ilustra a estrutura condicional implementada, onde as variáveis $\psi, \gamma$ e $\chi$ representam, respectivamente, o ângulo de guinada do veículo, o ângulo formado entre o eixo $x \mathrm{e}$ os eixos direcionados aos obstáculos e o ângulo de rotação negativo a ser imposto aos vetores posição relativa entre os explosivos improvisados e o veículo através da multiplicação à esquerda por uma matriz $\operatorname{Rot}_{C G}(\chi)$. Além disso, os valores limites da tolerância são representados por $\theta_{L I M-}$ e $\theta_{L I M+}$, e o vetor $\mathbf{p}_{C G}^{I E D}(i), i \in\left\{1,2, \ldots, N_{I E D}\right\}$ representa a posição do $i$-ésimo IED com relação ao Centro de Gravidade do veículo. 


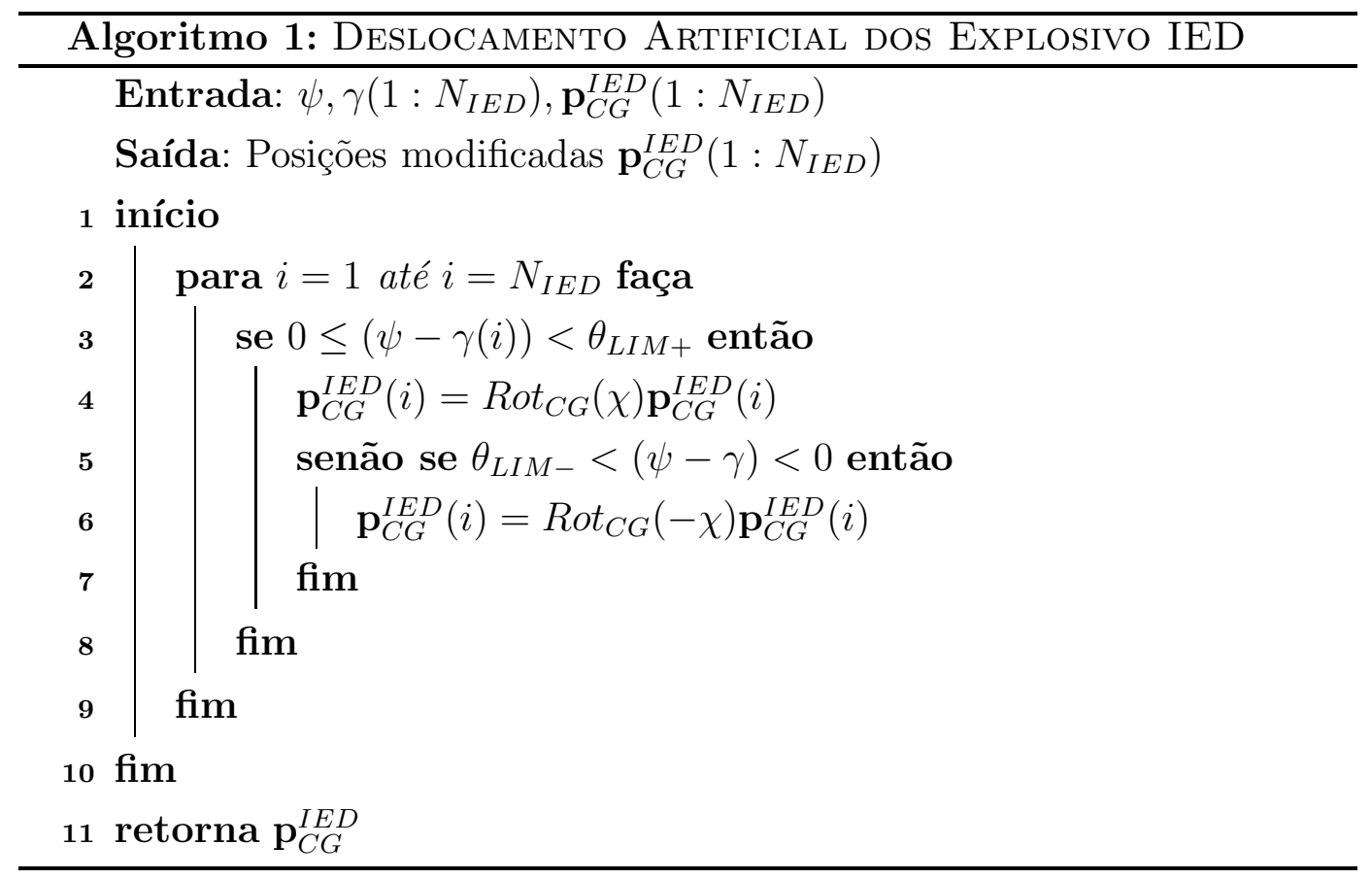

A partir da implementação desta estrutura condicional, verificou-se que o sistema de controle passou a ser capaz de contornar o problema da simetria, conforme ilustram os resultados mostrados nas Figuras 6.13 e 6.14. Primeiramente são apresentados os resultados para a velocidade longitudinal de $60 \mathrm{~km} / \mathrm{h}$ e posteriormente para a velocidade de $90 \mathrm{~km} / \mathrm{h}$.

É possível observar que o sistema proposto, com seu algoritmo de controle preditivo original (trajetória representada na cor azul) não era eficaz na detecção de explosivos posicionados em configuração simétrica. Após a introdução da estrutura condicional proposta, o algoritmo modificado foi capaz de corrigir a trajetória do veículo, mantendo-o a uma distância mínima dos explosivos capaz de garantir sua segurança. Além disso, é importante observar a diferença entre as trajetórias resultantes da aplicação do sistema configurado com as funções $J(t)$ e $J_{1}(t)$. A utilização de $J(t)$, apesar de manter a segurança do veículo com relação aos IEDs, permite que os limites laterais estabelecidos sejam violados, e não favorece a estabilização do movimento lateral do veículo. A utilização de $J_{1}(t)$ se mostrou mais apropriada, apesar de demandar um maior esforço computacional para ser implementada.

\section{Veículo Navegando em Rodovias com Faixas Estreitas}

Este último teste adicional foi concebido para representar uma conjuntura em que a viatura se encontra sendo operada em uma rodovia ou estrada mais estreita, dividida em faixas nas quais os veículos devem trafegar em um único sentido. O caso mais geral, em que as faixas deveriam estabelecer sentidos de 

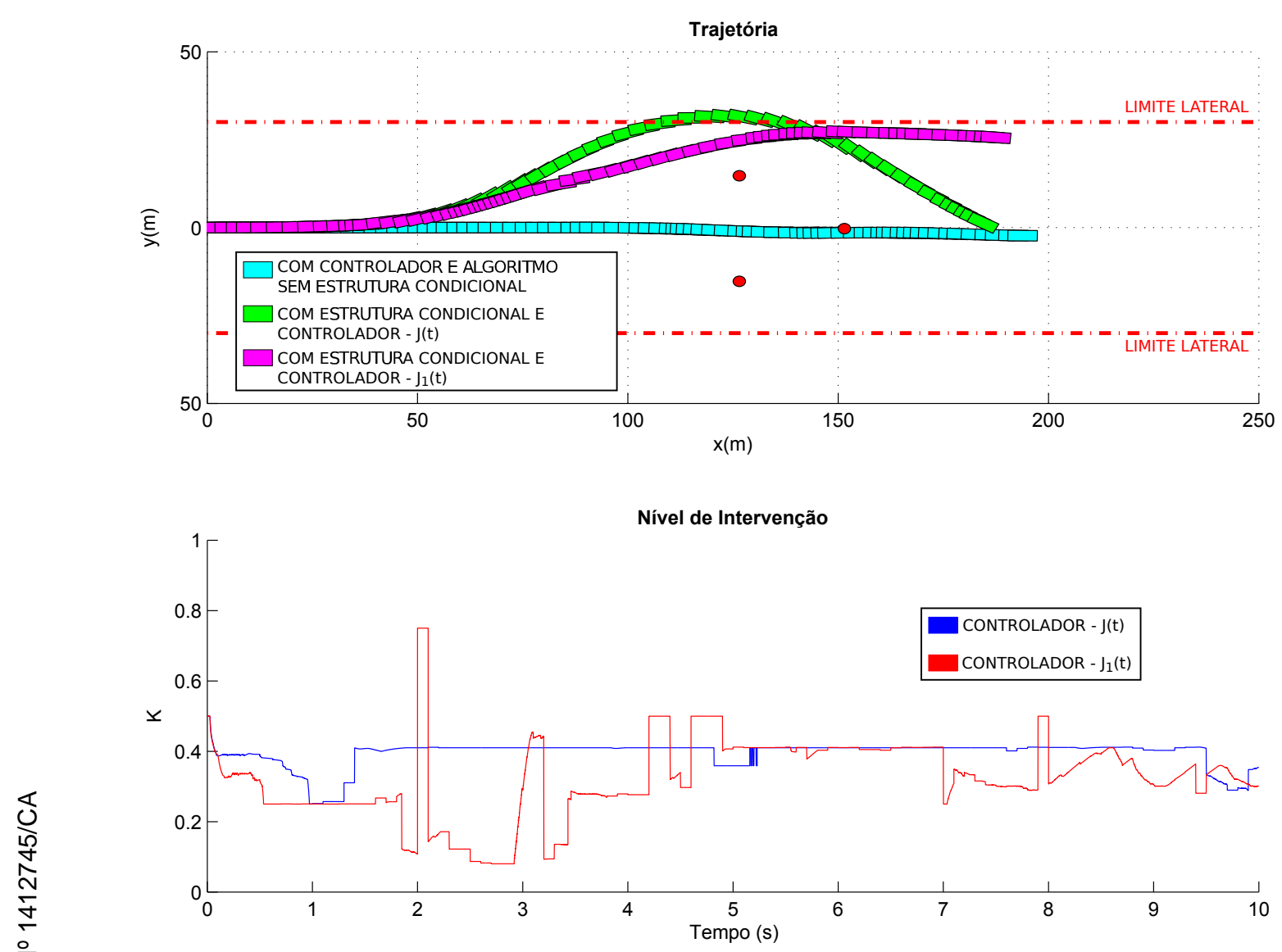

Figura 6.13: Resultados obtidos para uma situação de configuração simétrica dos explosivos com os algoritmos original e modificado, para a velocidade longitudinal de $60 \mathrm{~km} / \mathrm{h}$.

tráfego de mão e contra-mão não foi tratado dentro do escopo desta dissertação. O objetivo principal deste cenário de teste foi o de verificar a possibilidade de o Sistema de Controle Semiautônomo ser empregado em ambientes com maior limitação de espaço e com ameaças hostis, sem que se prejudique a estabilidade do veículo.

Para execução desta experiência simulada foi idealizada uma situação em que o veículo estaria navegando em uma rodovia dividida em três faixas de largura $\lambda$. Neste caso, a função que estabelece a Penalidade à Posição Lateral do centro de gravidade do veículo foi modificada para tornar viável a troca de pistas e a estabilização do movimento lateral do veículo dentro dos limites de uma faixa. Esta nova função substitui a parábola quadrática deslocada que compunha as parcelas referentes aos somatórios de penalidade lateral das funções objetivo expressas nas equações 4-11, 4-12 e 4-13. A nova função é dada por 

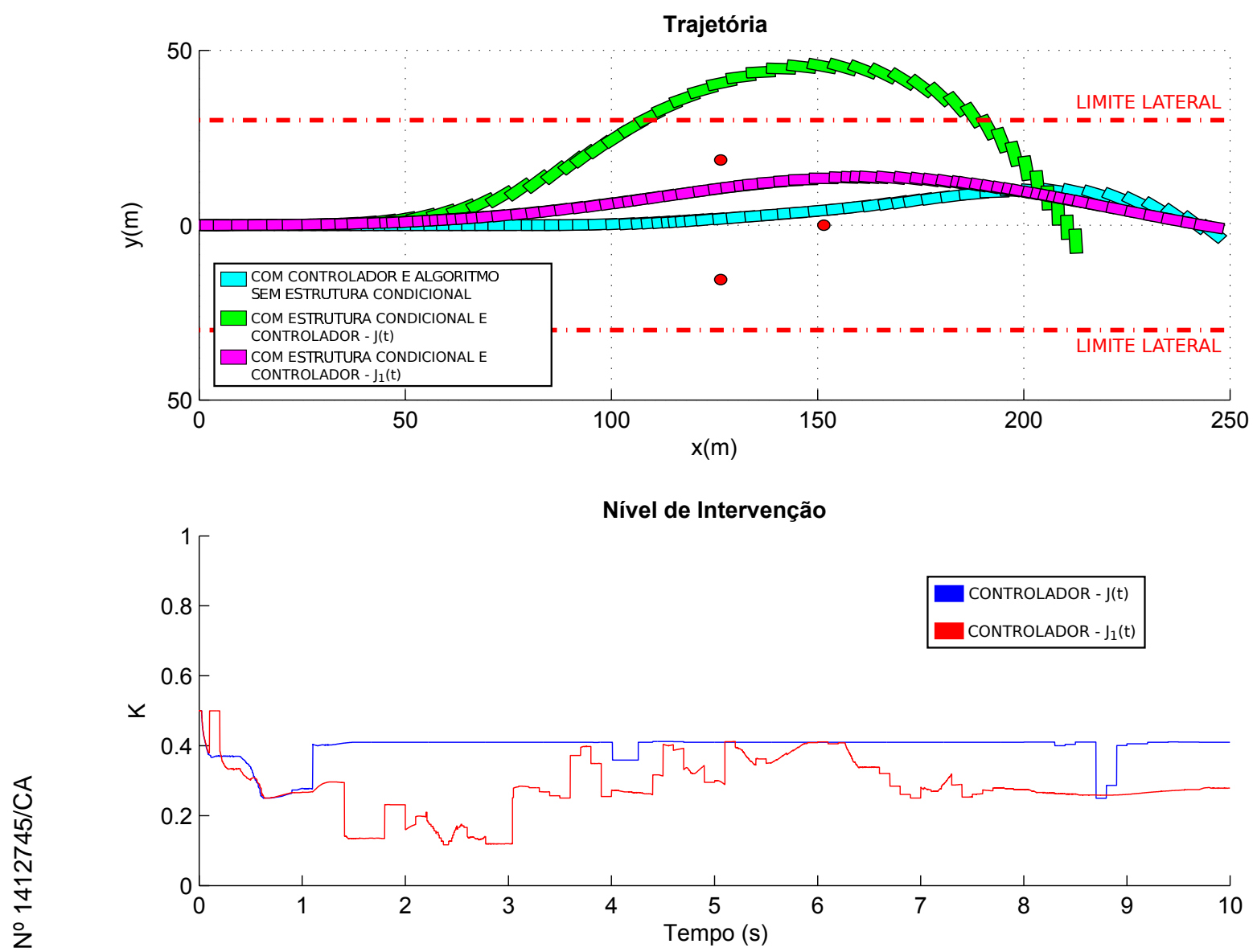

Figura 6.14: Resultados obtidos para uma situação de configuração simétrica dos explosivos com os algoritmos original e modificado, para a velocidade longitudinal de $90 \mathrm{~km} / \mathrm{h}$.

$$
P_{\text {lateral }}(y)=\left\{\begin{array}{lll}
10\left(y-\frac{\lambda}{2}\right)^{2}, & \text { para } & y<\frac{\lambda}{2} \\
2\left(y-\frac{\lambda}{2}\right)^{2}, & \text { para } & \frac{\lambda}{2} \leq y<\lambda \\
2\left(y-3 \frac{\lambda}{2}\right)^{2}, & \text { para } & \lambda \leq y<2 \lambda \\
2\left(y-5 \frac{\lambda}{2}\right)^{2}, & \text { para } & 2 \lambda \leq y<5 \frac{\lambda}{2} \\
10\left(y-5 \frac{\lambda}{2}\right)^{2}, & \text { para } & y \geq 5 \frac{\lambda}{2}
\end{array} .\right.
$$

O diagrama da Figura 6.15 ilustra a função $P_{\text {lateral }}(y)$ para $\lambda=10 \mathrm{~m}$.

Com a substituição da função, foi possível observar que o Sistema de 


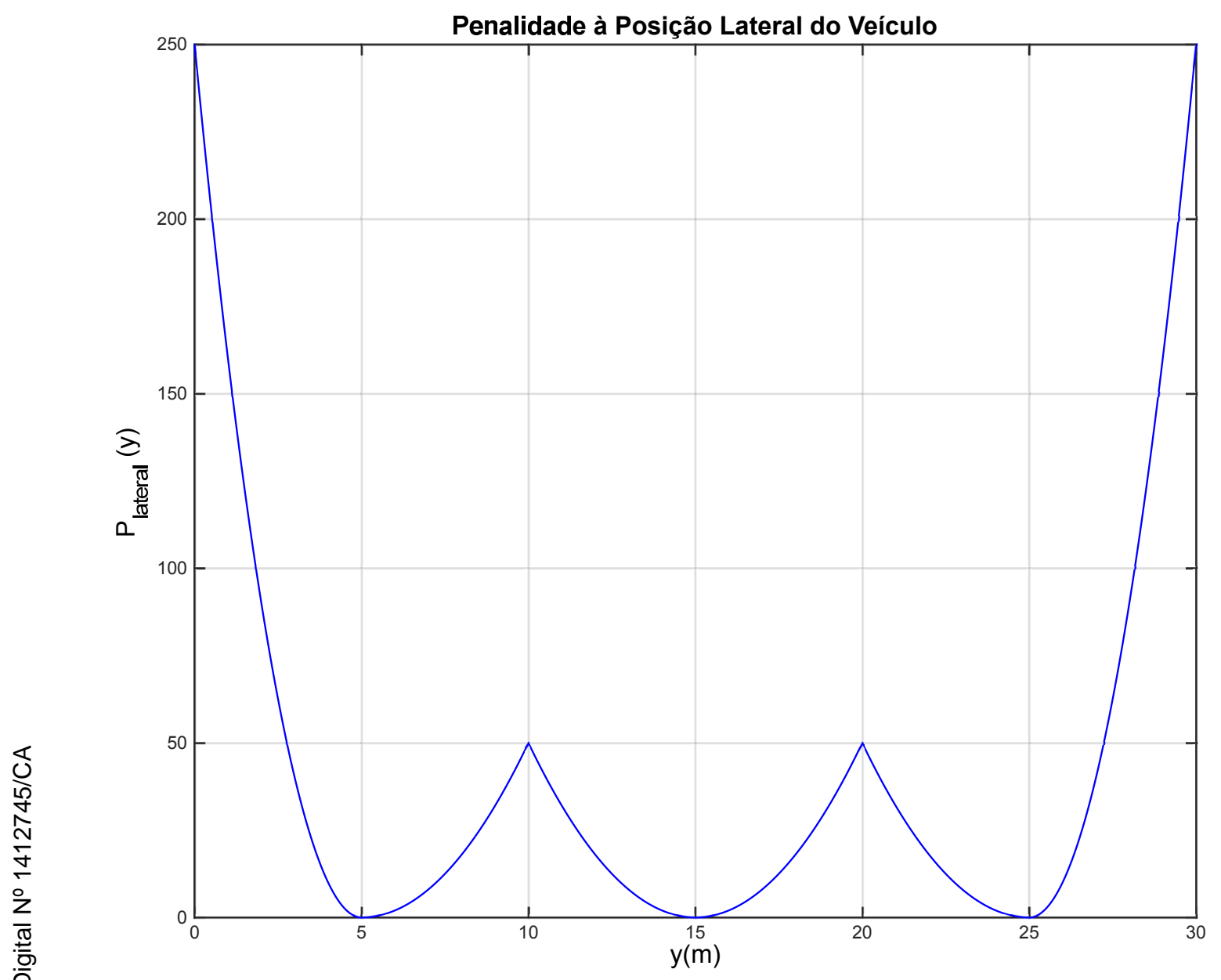

Figura 6.15: Função Penalidade à Posição Lateral utilizada no teste de navegação em rodovias com faixas estreitas.

Controle Semiautônomo foi capaz de alterar a trajetória do veículo mantendoo a uma distância segura da ameaça representada por um explosivo IED através de uma manobra de troca de pistas, fazendo com que o movimento lateral em $y$ se estabilize. A Figura 6.16 ilustra os resultados obtidos na execução deste teste, sendo a velocidade longitudinal do veículo igual a $30 \mathrm{~km} / \mathrm{h}$ e o tempo total de simulação de $40 \mathrm{~s}$. A trajetória em verde representa o movimento do veículo sob ação do controlador com a função $J(t)$ enquanto que a trajetória representada em cor-de-rosa ilustra o movimento nas mesmas condições para a função $J_{1}(t)$. Pode-se, novamente, perceber que a utilização da função $J_{1}(t)$ permite uma atenuação mais rápida das oscilações laterais, garantindo um maior grau de estabilidade relativa ao veículo. 


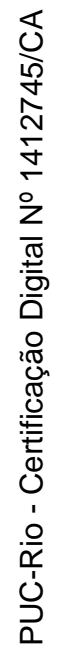

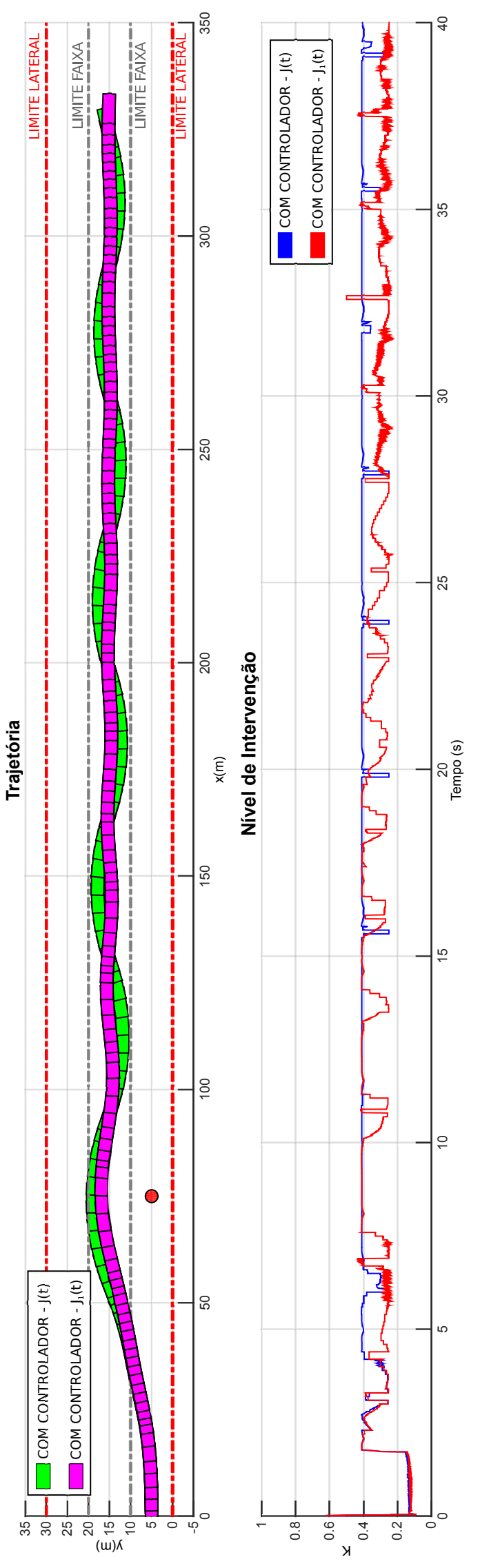

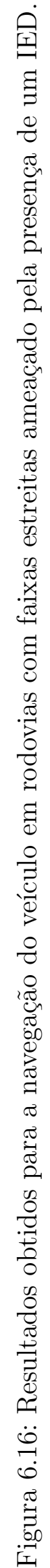




\section{7 \\ Conclusões e Sugestões para Trabalhos Futuros}

Nesta dissertação foi proposta uma nova abordagem para os projetos de Sistemas de Controle Semiautônomos aplicados a veículos militares. Um novo sistema foi desenvolvido a partir da utilização de técnicas de inteligência Artificial Fuzzy e de Controladores Preditivos Baseados em Modelos MPCs, representados pelo projeto de seus principais elementos, denominados Ponderador Fuzzy e Subcontrolador Preditivo. Testes e simulações do sistema proposto foram conduzidas com o uso de um modelo dinâmico veicular, obtido e implementado a partir de informações técnicas acerca da VBTP-MR GUARANI, disponibilizadas pelo Departamento de Ciência e Tecnologia do Exército Brasileiro. Os resultados dos testes executados demonstraram a eficácia do sistema proposto, porque a intervenção de um controlador digital se mostrou essencial para manter a segurança do veículo e de seus tripulantes quando este é empregado em um terreno ocupado por ameaças inimigas hostis, principalmente se o motorista não tiver conhecimento prévio destas ameaças.

Durante o desenvolvimento do trabalho buscou-se aplicar rigorosamente uma sistemática condizente com o método científico, a partir da observação e definição de um problema específico, da coleta de dados e referências bibliográficas sobre o assunto, da formulação e proposta de uma solução para o problema observado, e finalmente da realização de testes e obtenção de resultados capazes de atestar a eficácia da solução projetada, pelo menos em casos particulares do problema.

As contribuições mais relevantes, as dificuldades encontradas ao longo do trabalho desenvolvido e algumas sugestões para trabalhos futuros são descritas com maiores detalhes nas seções a seguir.

\section{1}

\section{Principais Contribuições desta Dissertação}

A principal contribuição resultante do desenvolvimento desta dissertação, conforme mencionado anteriormente, foi a inserção de técnicas de IA Fuzzy em um projeto de um sistema de controle semiautônomo para viaturas militares, implementado através da modelagem e simulação dinâmica dos sistemas 
envolvidos.

A partir da apresentação do problema definido no Capítulo 1 e da visão geral da solução proposta no Capítulo 2, foram desenvolvidos os elementos necessários para a implementação do sistema de controle semiautônomo.

No Capítulo 3 foram estabelecidos os conceitos teóricos básicos para o projeto do Ponderador Fuzzy, bem como foram apresentados os detalhes de seu desenvolvimento e implementação em ambiente de simulação numérica. A utilização das técnicas de IA para a mesclagem de sinais físicos necessária para o desenvolvimento do sistema proposto pode ser considerada uma aplicação original, principalmente pela escassez de referências bibliográficas que tratam especificamente do assunto.

Muito embora a utilização de controladores preditivos em sistemas veiculares não seja uma temática inovadora, a implementação do Subcontrolador Preditivo Baseado em Modelos apresentado no Capítulo 4 contém peculiaridades relevantes e pouco exploradas, relacionadas à utilização de um modelo cinemático não-linear para concepção do projeto, e ao formato da função objetivo empregada, que por sua vez leva em consideração os níveis de ameaças inimigas a que o veículo militar está sujeito, bem como busca impor limites aos esforços de controle aplicados ao veículo e a seu posicionamento no terreno.

O desenvolvimento do modelo dinâmico veicular utilizado para a realização de simulações com o sistema proposto foi exposto no Capítulo 5. Os resultados destas simulações e testes constituem o Capítulo 6, em que a eficácia da solução desenvolvida para determinados casos particulares do problema é apresentada, atestando-se, portanto, sua relevância como contribuição para a comunidade acadêmica e para a área de Ciência, Tecnologia e Inovação no âmbito do Exército, do Ministério da Defesa e do Governo Federal.

\section{2}

\section{Dificuldades Encontradas}

Dentre as maiores dificuldades encontradas para a realização deste trabalho, pode-se destacar as restrições de acesso do autor a um modelo dinâmico capaz de caracterizar, com nível suficientemente grande de precisão, os comportamentos da VBTP-MR GUARANI. Estas restrições acabaram por ensejar o desenvolvimento do modelo dinâmico apresentado no Capítulo 5, que tornou-se imprescindível para a realização dos testes simulados do sistema. No entanto, a realização dos mesmos testes com o emprego de um modelo mais confiável seria de grande valor, porque daria maior credibilidade à solução proposta.

O estabelecimento e a calibração das funções objetivo utilizadas no subcontrolador preditivo também se tornaram tarefas de maior complexidade do 
que a esperada, pelo fato de que a função pode tomar diversas formas diferentes, de acordo com o desejo do projetista. Modificar esta função objetivo pode alterar sensivelmente o comportamento dos sistemas de controle e controlado, o que favorece a busca por uma metodologia prática através da qual se possa estabelecer e calibrar estes parâmetros.

Um outro problema enfrentado diz respeito à necessidade de se tentar reduzir os Níveis de Intervenção do controlador digital $K$ médios. Idealmente esta variável deve se tornar a menor possível, evitando situações em que o motorista possa se sentir desconfortável ao dirigir o veículo devido à intervenção do controlador. Nos resultados apresentados no Capítulo 6 pode-se observar que a utilização das técnicas Fuzzy para a implementação do ponderador de sinais dificulta a redução do valor de $K$ para que este possa se tornar predominantemente nulo, tornando o sistema proposto mais intrusivo do que o desejado.

Houve ainda a dificuldade de se comparar o sistema proposto com outros sistemas disponíveis na literatura, principalmente pelas peculiaridades de se trabalhar com veículos militares e pela baixa disponibilidade e dificuldade de se reproduzir os resultados relatados em algumas publicações acadêmicas sobre sistemas semelhantes. O fato do trabalho ser direcionado para aplicações militares em si já é uma adversidade, pois muitos trabalhos nesta área tem publicação restrita, tornando as atividades de pesquisa frequentemente mais trabalhosas.

\section{3}

\section{Sugestões para Trabalhos Futuros}

Propõe-se dar continuidade a este trabalho com a busca pela maior eficiência do sistema proposto, pela modificação das configurações de seus subelementos, como o Ponderador Fuzzy ou o Subcontrolador Preditivo. A redução do caráter intrusivo do sistema proposto também é um objetivo importante, já que diminuiria o desconforto ao motorista e os riscos de acidentes relacionados ao alto grau de automação mencionados no Capítulo 1. A implementação de melhorias no sistema será mais efetiva se houver disponibilidade de um modelo dinâmico mais preciso do veículo, em vez de se utilizar o modelo simplificado para a realização de simulações preliminares.

É também necessário realizar uma implementação experimental do sistema, com a utilização de microcontroladores embarcados em um veículo e de sensores e atuadores capazes de fornecer os dados de entradas e saídas para seu total aproveitamento. No entanto, antes da realização de testes experimentais é importante que se estabeleça uma metodologia para a definição da função ob- 
jetivo utilizada no Subcontrolador Preditivo. Uma sugestão seria a utilização de outras técnicas de IA para a solução deste problema, como por exemplo os Algoritmos Genéticos.

Outra sugestão de trabalho está relacionada com a análise de viabilidade econômica para a implementação deste sistema em viaturas militares, considerando-se os custos de aquisição e instalação e o retorno que o sistema traria como benefícios para a Força Terrestre em termos de economia de recursos financeiros, humanos e operacionais. 


\section{Referências Bibliográficas}

[1] EXÉRCITO BRASILEIRO. ESTADO-MAIOR DO EXÉRCITO. IG 2012: Modelo Administrativo do Ciclo de Vida dos Materiais de Emprego Militar. 1.1

[2] WORLD HEALTH ORGANIZATION. Global status report on road safety 2013: supporting a decade of action. Technical report, World Health Organization, 2013. 1.1

[3] NATIONAL HIGHWAY TRAFFIC SAFETY ADMINISTRATION. TRAFFIC SAFETY FACTS 2012. Technical report, National Center for Statistics and Analysis, 2012. 1.1

[4] NATIONAL HIGHWAY TRAFFIC SAFETY ADMINISTRATION. Critical reasons for crashes investigated in the national motor vehicle crash causation survey. Technical report, National Center for Statistics and Analysis, 2015. 1.1

[5] HENRY, H.. Non-Hostile Casualties in These Kinds of Wars from the Korean War to Operation Iraqi Freedom. PhD thesis, Georgia Southern University, May 2008. 1.1

[6] FERREIRA, A.. Sistemas de combate do futuro: elementos para formulação conceitual. Master's thesis, Escola de Comando e EstadoMaior do Exército, 2004. 1.1

[7] LIU XIN, D. B.. The latest status and development trends of military unmanned ground vehicles. In: CHINESE Automation Congress (CAC), 2013, 2013. 1.1

[8] HAYKIN, S.. Neural Networks - A comprehensive Foundation. Prentice Hall, 1999. 1.2

[9] SHERIDAN, T. B.. Telerobotics, Automation and Human Supervisory Control. The MIT Press, Cambridge, Massachussets, 1992. 1.2.1 
[10] STRAND, N.; NILSSON, J.; KARLSSON, I. C. M. ; NILSSON, L.. Semiautomated versus highly automated driving in critical situations caused by automation failures, 2014. 1.2.1

[11] YU, H.; SPENKO, M. ; DUBOWSKY, S.. An Adaptive Shared Control System for an Intelligent Mobility Aid for the Elderly. Autonomous Robots, 15(1):53-66, July 2003. 1.2.1, 3.2

[12] LATOMBE, J. C.. Robot Motion Planning. Springer, 1991. 1.2.2, 6.3.6

[13] LAUMOND, J.-P.. Robot Motion Planning and Control. Springer, 1998. 1.2 .2

[14] ARKIN, R. C.. Behavior-based Robotics. The MIT Press, 1998. 1.2.2

[15] SIEGWART, R.; NOURBAKHSH, I.. Introduction to Autonomous Mobile Robots. The MIT Press, 2005. 1.2.2

[16] CHOSET, H.; LYNCH, K.; HUTCHINSON, S.; KANTOR, G.; BURGARD, W.; KAVRAKI, L. ; THRUN, S.. Principles of Robot Motion - Theory, Algorithms, and Implementations. The MIT Press, 2005. 1.2.2

[17] NEDJAH, N.; DOS SANTOS COELHO, L. ; DE MACEDO MOURELLE, L.. Mobile Robots - The Evolutionary Approach. Springer, 2007. 1.2.2

[18] JARADAT, M. A. K.; GARIBEH, M. H. ; FEILAT, E. A.. Autonomous mobile robot dynamic motion planning using hybrid fuzzy potential field. Soft Computing, 16(1):153-164, June 2011. 1.2.2

[19] FAJEN, B.; WARREN, W.; TERMIZER, S. ; KAEBLING, L.. A dynamical model of steering, obstacle avoidance, and route selection, 2003. 1.2 .2

[20] HUANG, W. H.; FAJEN, B. R.; FINK, J. R. ; WARREN, W. H.. Visual navigation and obstacle avoidance using a steering potential function. Robotics and Autonomous Systems, 54(4):288-299, 2006. 1.2.2

[21] IAGNEMMA, K. D.. Rough-terrain mobile robot planning and control with application to planetary exploration. Thesis, Massachusetts Institute of Technology, 2001. 1.2.2

[22] IAGNEMMA, K.; RZEPNIEWSKI, A.; DUBOWSKY, S. ; SCHENKER, P.. Control of Robotic Vehicles with Actively Articulated Suspensions in Rough Terrain. Autonomous Robots, 14(1):5-16, Jan. 2003. 1.2 .2 
[23] IAGNEMMA, K.; GOLDA, D.; SPENKO, M. ; DUBOWSKY, S.. Experimental Study of High-speed Rough-terrain Mobile Robot Models for Reactive Behaviors. In: Siciliano, P. B.; Dario, P. P., editors, EXPERIMENTAL Robotics VIII, número 5 em Springer Tracts in Advanced Robotics, p. 654-663. Springer Berlin Heidelberg, Jan. 2003. 1.2.2

[24] IAGNEMMA, K.. Traction Control of Wheeled Robotic Vehicles in Rough Terrain with Application to Planetary Rovers. I. J. Robotic Res., 23:1029-1040, 2004. 1.2.2

[25] LIMA, R. M.. Simulação Tridimensional em Tempo Real de Veículos Robóticos em Terrenos Acidentados. Thesis, PUC-Rio, Rio de Janeiro, Sept. 2010. 1.2.2

[26] DA COSTA BLOIS DE ASSIS, P. F.. Controle de Atitude de um Veículo Robótico Elétrico em Fase Balística. Thesis, PUC-Rio, Rio de Janeiro, Aug. 2013. 1.2.2

[27] ACKERMANN, J.; SIENEL, W.. Robust yaw damping of cars with front and rear wheel steering, 1993. 1.2.3

[28] ACKERMANN, J.; BÜNTE, T. ; ODENTHAL, D.. Advantages Of Active Steering For Vehicle Dynamics Control. 1999. 1.2.3

[29] GUO, L.; GE, P.-S.; YUE, M. ; ZHAO, Y.-B.. Lane Changing Trajectory Planning and Tracking Controller Design for Intelligent Vehicle Running on Curved Road. Mathematical Problems in Engineering, 2014:e478573, Jan. 2014. 1.2.3

[30] hOFFMANN, G.; TOMLIN, C.; MONTEMERLO, D. ; THRUN, S.. Autonomous Automobile Trajectory Tracking for Off-Road Driving: Controller Design, Experimental Validation and Racing. In: AMERICAN Control Conference, 2007. ACC '07, p. 2296-2301, July 2007. 1.2.3

[31] CAMACHO, E.; BORDONS, C.. Model Predictive Control. Advanced Textbooks in Control and Signal Processing. Springer, second edition edition, 2007. $1.2 .4,4.1 .2$

[32] BORRELLI, F.; FALCONE, P.; KEVICZKY, T.; ASGARI, J. ; HROVAT, D.. MPC-based approach to active steering for autonomous vehicle systems. In: INTERNATIONAL Journal ON Vehicle Autonomous Systems, volumen $3: 2 / 3 / 4$, s. 265 . International Journal on Vehicle Autonomous Systems, 2005. 1.2.4 
[33] KEVICZKY, T.; FALCONE, P.; BORRELLI, F.; ASGARI, J. ; HROVAT, D.. Predictive control approach to autonomous vehicle steering. In: AMERICAN Control Conference, 2006, p. 6 pp.-, June 2006. 1.2.4

[34] FALCONE, P.; BORRELLI, F.; ASGARI, J.; TSENG, H. ; HROVAT, D.. Predictive Active Steering Control for Autonomous Vehicle Systems. IEEE Transactions on Control Systems Technology, 15(3):566580, 2007. 1.2.4

[35] FAlCONE, P.; TUFO, M.; BORRELlI, F.; ASGARI, J. ; TSENGZ, H.. A linear time varying model predictive control approach to the integrated vehicle dynamics control problem in autonomous systems. In: 2007 46TH IEEE Conference ON Decision AND Control, p. 2980-2985, 2007. 1.2.4

[36] ANDERSON, S. J.. A unified framework for trajectory planning, threat assessment, and semi-autonomous control of passenger vehicles. Thesis, Massachusetts Institute of Technology, 2009. 1.2.5, 2.2, $3.2,5.1 .2$

[37] ANDERSON, S. J.; PETERS, S. C.; PILUTTI, T. E. ; IAGNEMMA, K.. An optimal-control-based framework for trajectory planning, threat assessment, and semi-autonomous control of passenger vehicles in hazard avoidance scenarios. International Journal of Vehicle Autonomous Systems, 8(2):190-216, Jan. 2010. 1.2.5, 3.2

[38] ANDERSON, S. J.; PETERS, S. C.; PILUTtI, T. E. ; IAGNEMMA, K.. Design and Development of an Optimal-Control-Based Framework for Trajectory Planning, Threat Assessment, and Semiautonomous Control of Passenger Vehicles in Hazard Avoidance Scenarios. In: Pradalier, C.; Siegwart, R. ; Hirzinger, G., editors, ROBOTICS Research, número 70 em Springer Tracts in Advanced Robotics, p. 39-54. Springer Berlin Heidelberg, 2011. 1.2.5, 3.2

[39] ANDERSON, S.; PETERS, S.; IAGNEMMA, K. ; OVERHOLT, J.. SemiAutonomous Stability Control and Hazard Avoidance for Manned and Unmanned Ground Vehicles. p. 1-8, 2010. 1.2.5, 3.2

[40] ANDERSON, S.; PETERS, S. C. ; IAGNEMMA, K.. Semi-autonomous avoidance of moving hazards for passenger vehicles. In: ASME 2010 Dynamic Systems AND Control Conference, 2010. 1.2.5, 3.2 
[41] ANDERSON, S.; KARUMANCHI, S. ; IAGNEMMA, K.. Constraint-based planning and control for safe, semi-autonomous operation of vehicles. In: 2012 IEEE Intelligent Vehicles Symposium (IV), p. 383-388, June 2012. 1.2.5, 3.2

[42] ANDERSON, S. J.. Constraint-based navigation for safe, shared control of ground vehicles. Thesis, Massachusetts Institute of Technology, 2013. 1.2.5, 3.2

[43] GRAY, A.; GAO, Y.; HEDRICK, J. ; BORRELLI, F.. Robust Predictive Control for semi-autonomous vehicles with an uncertain driver model. In: 2013 IEEE Intelligent Vehicles Symposium (IV), p. 208-213, June 2013. 1.2 .5

[44] STORMS, J.; TILBURY, D.. Blending of human and obstacle avoidance control for a high speed mobile robot. In: AMERICAN Control Conference (ACC), 2014, p. 3488-3493, June 2014. 1.2.5, 3.2

[45] SARIMVEIS, H.; BAFAS, G.. Fuzzy model predictive control of nonlinear processes using genetic algorithms. Fuzzy Sets and Systems, 139(1):59-80, 2003. 1.2 .6

[46] JERZY GARUS, P. S.. Application of fuzzy control to steering of semiautonomous underwater vehicle. 2008. 1.2.6

[47] NILSSON, J.. On the Interaction Between Driver Assistance Systems and Drivers in Situations of System Failure. 2011. 2

[48] CHEN, Y.; LI, L.. Advances in Intelligent Vehicles. Elsevier, first edition edition, 2014. 2

[49] KUMAR, M. V.. Design of a stability augmentation system for a helicopter using lqr control and ads 33 handling qualities specifications. Aircraft Engineering and Aerospace Technology, 80(2):111123, march 2008. 2.1

[50] CHEN, F.; M., W. ; DUAN, L.. Letting drivers know what is going on in traffic. Elsevier, 2014. 2.1

[51] PETERS, S. C.; IAGNEMMA, K.. Stability measurement of highspeed vehicles. Vehicle System Dynamics, 47(6):701-720, 2009. (document), 1, 3.3.2, 3.5

[52] ROSS, T. J.. Fuzzy Logic With Engineering Applications. John Wiley and Sons, second edition, 2004. 3.1 
[53] ZADEH, L. A.. Fuzzy sets. Information and Control, 8:338-353, 1965. 3.1 .1

[54] ZIMMERMANN, H.. Fuzzy Set Theory and Its Applications. Kluwer, Boston, MA, second edition, 1991. 3.1.2

[55] IEEE. Fuzzy Logic Systems for Engineering: A Tutorial, volumen 83, 1995. 3.1 .2

[56] TANSCHEIT, R.. SISTEMAS FUZZY. DEE-PUC-Rio, C.P. 38.063, 22452-970 Rio de Janeiro, RJ, 2014. (document), 3.2, 3.1.3

[57] AZEVEDO SÁ, H.; NETO, M. ; MEGGIOLARO, M.. Artificial Intelligence based semi-autonomous control system for military vehicle. Rio de Janeiro, June 2015. SAE BRASIL. 3.6

[58] QIN, S. J.; BADGWELL, T. A.. A survey of industrial model predictive control technology. Control Engineering Practice, 11(7):733-764, July 2003. 4.1

[59] RAJAMANI, R.. Vehicle Dynamics and Control. Springer, second edition edition, 2012. 4.2

[60] AZEVEdo SÁ, H.; FERREIRA, A.; NETO, M. ; MEGGIOLARO, M.. Fuzzy shared semi-autonomous control system for military vehicles. São Paulo, september 2015. SAE BRASIL. 4.5

[61] MULTICORPOS ENGENHARIA . Modelagem e análises da Viatura Blindada para Transporte de Pessoal (VBTP). Technical Report, 2008. 5, 5.2, 5.2.6, 5.3

[62] KAMBHAMPATI, C.; GARCES, F. ; WARWICK, K.. Approximation of non-autonomous dynamic systems by continuous time recurrent networks. In: IEEE, editor, PROCEEDINGS OF THE IEEE-INNS-ENNS INTERNATIONAL JOINT CONFERENCE ON NEURAL NETWORKS, volumen 1 , p. $64-69,2000$. 5.1.1

[63] JAZAR, R. N.. Vehicle Dynamics - Theory and Aplication. Springer, 2008. 5.2 .6

[64] AZEVEdo SÁ, H.; FERREIRA, A.; NETO, M. ; MEGGIOLARO, M.. Using fuzzy inference systems for blending human and automatic control on combat ground vehicles. In: ABCM, editor, 23RD INTERNATIONAL CONGRESS OF MECHANICAL ENGINEERING (COBEM), 2015. 6.2 